\title{
Wave Interaction With Permeable CoAstal Structures
}

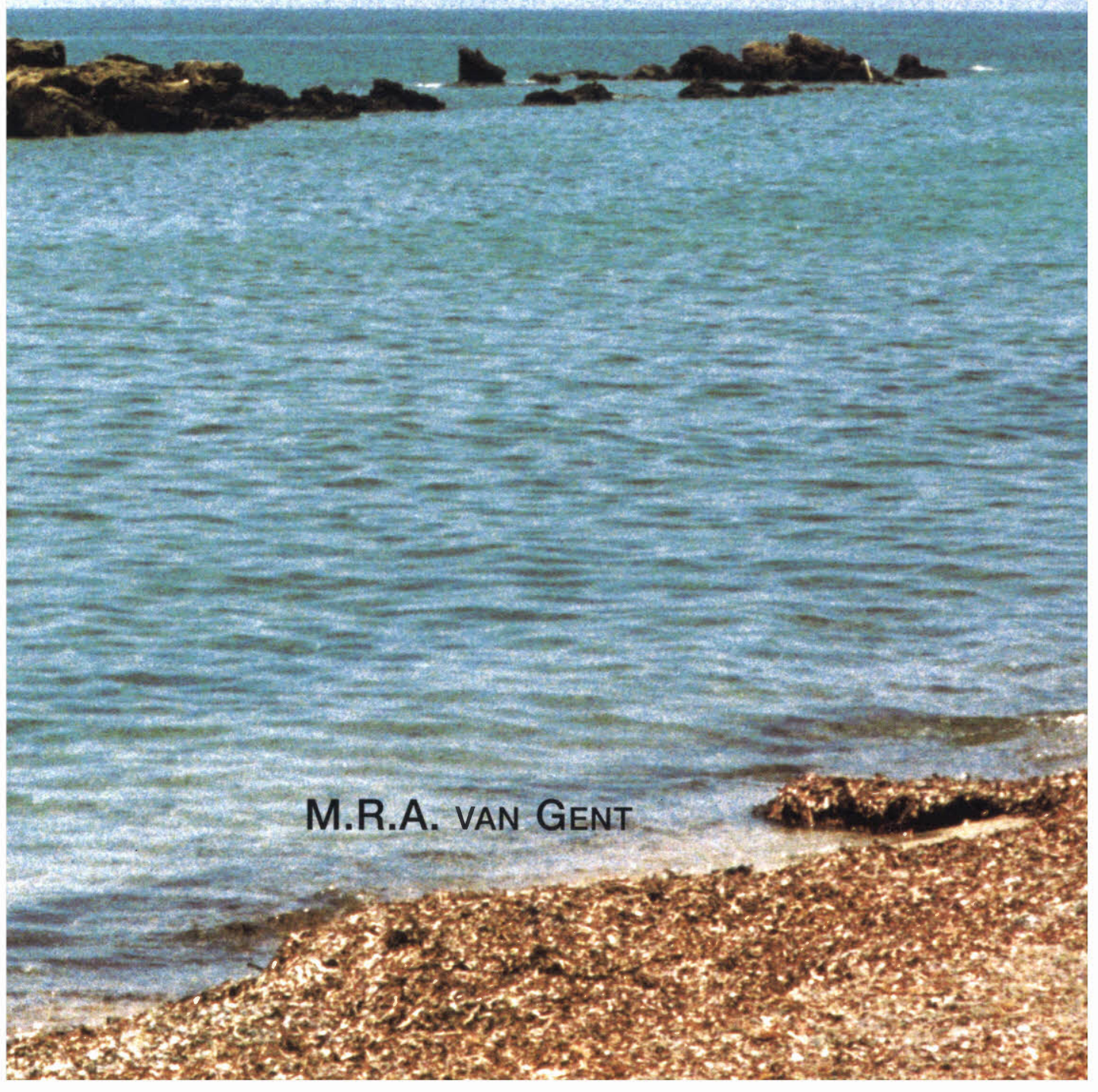


Wave Interaction with Permeable

Coastal Structures 


\section{Wave Interaction with Permeable Coastal Structures}

\section{PROEFSCHRIFT}

ter verkrijging van de graad van doctor aan de Technische Universiteit Delft, op gezag van de Rector Magnificus, Prof.ir. K.F. Wakker, in het openbaar te verdedigen ten overstaan van een commissie, door het College van Dekanen aangewezen, op dinsdag 12 december 1995 te 16.00 uur

$$
\text { door }
$$

Marcel Roland Alexander VAN GENT civiel ingenieur geboren te Ermelo

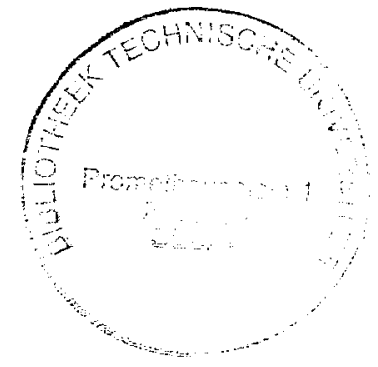


Dit proefschrift is goedgekeurd door de promotor:

Prof.ir. K. d'Angremond.

Leden van de promotiecommissie:

$\begin{array}{ll}\text { Rector } & \text { Voorzitter } \\ \text { Prof.ir. K. d'Angremond } & \text { Hoogleraar Waterbouwkunde, Technische Universiteit Delft } \\ \text { Prof.dr.ir. J.A. Battjes } & \text { Hoogleraar Vloeistofmechanica, Technische Universiteit Delft } \\ \text { Dr.ir. J.W. van der Meer } & \text { Hovens, Kusten en Offshore Sector, Waterloopkundig Laboratoritm } \\ \text { Prof.dr.ir. M.J.F. Stive } & \text { Hoogleraar Kustmorfodynamica, Technische Universiteit Delft } \\ \text { Prof.dr. J.H.J. Terwindt } & \text { Hoogleraar Fysische Geografie, Universiteit Utrecht } \\ \text { Prof.dr.ir. A. Verruijt } & \text { Hoogleraar Grondmechanica, Technische Universiteit Delft } \\ \text { Prof.dr.ir. H.J. de Vriend } & \text { Hoogleraar Modellering van Integrale Civieltechnische Systemen, Universiteit } \\ & \text { Twente }\end{array}$

\section{CIP-DATA KONINKLIJKE BIBLIOTHEEK, DEN HAAG}

Gent, Marcel Roland Alexander van

Wave Interaction with Permeable Coastal Structures /

Marcel Roland Alexander van Gent. - Delft: Delft University Press.-III.

Thesis Delft University of Technology.- With ref.- With summary in Dutch.

ISBN 90-407-1182-8

Subject headings: Wave phenomena / hydrodynamics

Cover: Ancient breakwater, Paphos, Cyprus $(\approx 300 \mathrm{BC} / \approx 200 \mathrm{AD})$

Copyright (C) by M.R.A. van Gent, 1995

All rights reserved

No part of the material protected by this copyright notice may be reproduced or utilized in any form or by any means, electronic or mechanical, including photocopying, recording or by any information storage and retrieval system, without permission from the publisher: Delft University Press, Stevinweg 1, $2628 \mathrm{CN}$ Delft, The Netherlands.

Printed in the Netherlands 


\section{Samenvatting}

De titel van dit proefschrift is "Golfinteractie met doorlatende kustwaterbouwkundige constructies". Veel kustwaterbouwkundige constructies worden gebouwd om de achterliggende gebieden zoals polders, haventerreinen, havenbassins en toegangsgeulen te beschermen tegen de invloed van golven. Golfoverslag, golfoploop, golfreflectie en golfdoordringing kunnen hinderlijke of zelfs gevaarlijke situaties veroorzaken. Om de betreffende constructies optimaal te laten functioneren en optimaal te ontwerpen moet zoveel mogelijk inzicht verkregen worden in de fysische processen die de invloed van golven op constructies, en vice versa, bepalen. Met dit inzicht kunnen vervolgens voorspellende numerieke modellen gemaakt worden die bruikbaar zijn voor ontwerp-, beheers- en onderzoeks-doeleinden.

Het onderzoek beschreven in dit proefschrift is met name geconcentreerd op golfinteractie met constructies die doorlatende delen bevatten zoals het geval is bij golfbrekers die opgebouwd zijn uit stortsteen. Een relatief nieuw type golfbreker is de zogenaamde berm-golfbreker. Deze golfbrekers vervormen als gevolg van de golfwerking; onder stormcondities verplaatsen stenen zodat de zeewaartse kant van de golfbreker vervormt totdat een nieuw evenwicht is bereikt. Het inschatten van deze vervorming is belangrijk om eventueel bezwijken van de constructie te kunnen voorspellen en om de golfinteractie met de vervormde constructie te bepalen.

Eén van de belangrijke fysische processen bij golfinteractie met golfbrekers opgebouwd met steenmateriaal is de stroming door doorlatende delen van de constructies. Laboratoriumproeven zijn uitgevoerd om inzicht te krijgen in de weerstand die stromingen door poreuze materialen ondervinden waarbij met name kenmerken van deze stromingen zijn bestudeerd die voor de kustwaterbouwkundige praktijk van belang zijn; oscillerende en stationaire turbulente stromingen door steenmaterialen. Geconcludeerd werd dat oscillerende turbulente stroming door poreuze media tot een hogere weerstand leidt dan op grond van een vergelijking met stationaire turbulente stroming verwacht kon worden. De extra weerstand hangt af van het stromingsveld waarin de parameter die de verhouding weergeeft van de mate van turbulentie t.o.v. de mate van oscillatie een belangrijke rol speelt. 
$\mathrm{Na}$ inventarisatie van modelleringen om golfbeweging te simuleren is een tweetal numerieke modellen ontwikkeld. Series van individuele golven worden gesimuleerd waarbij beide modellen beperkt zijn tot golven die loodrecht op de constructie invallen. Omdat de doorlatendheid van de constructie de waterbeweging zowel binnen als buiten de constructie bepaalt, zijn beide waterbewegingen en de interactie daartussen in beide modellen gesimuleerd.

Het eerste model is een één-dimensionaal model waarbij brekende golven op een relatief simpele manier worden gemodelleerd en drukken als hydrostatisch worden verondersteld. Uit een groot aantal vergelijkingen met laboratoriumproeven en toepassingen met veel types constructies is gebleken dat de verstrekkende aannamen die ten grondslag liggen aan het model een brede toepasbaarheid niet in de weg staan. Het model is o.a. zeer geschikt om de invloed van variaties in de hydrodynamische omstandigheden en aanpassingen in het ontwerp van kustwaterbouwkundige constructies te bestuderen. Hoewel het model nog op enige punten verbeterd en uitgebreid kan worden, laten de principes die ten grondslag liggen aan het model slechts weinig ruimte om de waterbeweging in een nog grotere mate van detail te simuleren. Daarom is een tweede numeriek model ontwikkeld dat kan leiden tot een nog grotere toepasbaarheid en grotere hoeveelheid informatie omtrent het stromingsveld.

In nauwe samenwerking met het Waterloopkundig Laboratorium is voortgebouwd op een onderzoekslijn voor het ontwikkelen van een adviesgereedschap voor complexe stromingsproblemen. Door dit twee-dimensionale model (2DV) geschikt te maken voor het simuleren van golven, inclusief brekende golven, op doorlatende kustwaterbouwkundige constructies is een model ontstaan dat zeer complexe interacties tussen golven en constructies kan simuleren. Hoewel het model nog niet gemakkelijk toepasbaar is, biedt het model zeer goede mogelijkheden om een breed toepasbaar advies- en onderzoeksmodel te worden waarbij het eerder genoemde ééndimensionaal model en dit twee-dimensionaal model elkaar goed aanvullen.

$\mathrm{Na}$ het uitvoeren van een additionele validatie voor beide modellen met bermgolfbrekers is het één-dimensionale model uitgebreid met een modellering om het vervormen van constructies zoals berm-golfbrekers, grindstranden en reef-type constructies te simuleren. Hiermee is een model ontstaan dat zowel de interactie tussen externe en interne waterbewegingen simuleert maar ook de interactie tussen waterbewegingen en de vervorming van constructies. 


\section{Abstract}

Wave interaction with permeable coastal structures is studied and discussed in this thesis. Physical processes involved in the hydraulic and structural response of coastal structures under wave attack are examined and predictive numerical models for wave interaction with permeable coastal structures are developed. Special attention is given to berm breakwaters. This relatively new type of rubble-mound structure reshapes under heavy storm conditions by redistributing the stones in the seaward profile. The reshaping of such dynamic structures is modelled numerically.

Porous media flow has been studied theoretically, experimentally and numerically. Laboratory experiments were carried out to study gaps in knowledge in this field such as the resistance of porous media to an oscillatory wave motion. Emphasis was put on flow through coarse granular material in which resistance components for laminar and turbulent flow as well as inertial resistance are significant. The tests showed that the values for the friction coefficients in a conventional description of the resistance are higher for an oscillatory wave motion than for a stationary flow. This increased friction depends on the flow field. New formulations for porous media flow were derived and implemented in two predictive numerical models.

A one-dimensional model based on shallow-water wave equations and a twodimensional (2DV) numerical model based on Reynolds-averaged Navier-Stokes equations were developed for simulating wave motion both inside and outside permeable structures. Both models simulate normally incident wave trains in the time-domain. The first model has become an engineering and research tool which has been validated and applied for many flow conditions and several types of coastal structures. The model is suitable for studying the influence of variations in the hydrodynamic properties and of variations in the lay-out of coastal structures. The second model is a research tool, mainly developed at Delft Hydraulics, for simulating complex flow patterns providing a detailed description of for instance breaking waves. Depending on the type of structure and the complexity of the wave motion, one of the two models can be used to obtain the required information on the flow field. 
Wave interaction with berm breakwaters is studied by performing physical-model tests which were used for additional validations of the two numerical models. A procedure was developed to simulate the reshaping of dynamic structures such as berm breakwaters, reef-type structures and gravel beaches and was incorporated in the one-dimensional wave model. This integrated simulation model can therefore be used to study the interaction of the internal and external wave motion of permeable structures and to study the interaction of the wave motion with the structures themselves. 


\section{Contents}

Samenvatting (Abstract in Dutch)

Abstract

1. Introduction 1

1.1 General 1

1.2 Background of the present study 3

1.3 Aim and scope of the present study 5

1.4 Outline 5

2. Theoretical background 7

2.1 Introduction 7

2.2 Modelling of wave motion on coastal structures $\quad 8$

$\begin{array}{lll}2.2 .1 & \text { Potential flow models } & 8\end{array}$

2.2.2 Finite-amplitude shallow-water equation models 9

$\begin{array}{ll}2.2 .3 \text { Boussinesq-type models } & 15\end{array}$

$\begin{array}{ll}2.2 .4 \text { Navier-Stokes-type models } & 16\end{array}$

$\begin{array}{ll}2.3 \text { Modelling of porous media flow } & 18\end{array}$

2.4 Modelling of combined external-internal wave motion 19

3. Porous media flow 23

3.1 Introduction $\quad 23$

3.2 Formulations for porous media flow 23

$\begin{array}{ll}3.3 \text { Importance of inertia } & 27\end{array}$

3.4 Permeability measurements 30

$\begin{array}{ll}3.4 .1 \text { Description of the measurements } & 30\end{array}$

$\begin{array}{ll}3.4 .2 \text { Stationary flow tests } & 34\end{array}$

$\begin{array}{ll}3.4 .3 \text { Oscillatory flow tests } & 38\end{array}$

3.4.4 Expressions for friction coefficients $\quad 42$

3.5 Scale effects 45

3.6 Conclusions $\quad 46$ 
4. Numerical simulation of wave attack by a 1D model 47

$\begin{array}{ll}4.1 \text { Introduction } & 47\end{array}$

4.2 Model composition and basic equations $\quad 47$

$\begin{array}{ll}4.2 .1 \text { General model composition } & 47\end{array}$

$\begin{array}{ll}4.2 .2 \text { Basic equations } & 49\end{array}$

4.2.3 Boundary conditions $\quad 51$

4.2.4 Infiltration and seepage $\quad 55$

$\begin{array}{ll}4.3 \text { Numerical scheme } & 57\end{array}$

$\begin{array}{ll}\text { 4.3.1 Numerical discretisation } & 57\end{array}$

$\begin{array}{ll}\text { 4.3.2 Numerical dissipation } & 60\end{array}$

$\begin{array}{ll}4.4 \text { Validation of the numerical model } & 64\end{array}$

4.4.1 Comparison with an analytical solution 64

4.4.2 Comparison with data from physical-model tests 65

$\begin{array}{ll}4.5 \text { Numerical model applications } & 71\end{array}$

4.5.1 Sensitivity to permeability of structures 71

4.5.2 Impressions of the flow field 74

$\begin{array}{ll}\text { 4.5.3 Various other applications } & 75\end{array}$

$\begin{array}{ll}4.6 \text { Conclusions } & 76\end{array}$

5. Numerical simulation of wave attack by a 2D model 79

$\begin{array}{ll}5.1 \text { Introduction } & 79\end{array}$

5.2 Model composition and basic equations $\quad 80$

$\begin{array}{ll}\text { 5.2.1 General model composition } & 80\end{array}$

$\begin{array}{ll}5.2 .2 \text { Basic equations } & 81\end{array}$

$\begin{array}{ll}\text { 5.2.3 Volume-of-Fluid method } & 83\end{array}$

$\begin{array}{ll}\text { 5.2.4 Boundary conditions } & 86\end{array}$

$\begin{array}{ll}5.3 \text { Numerical scheme } & 90\end{array}$

5.4 Validation of the numerical model 91

$\begin{array}{ll}\text { 5.4.1 Comparison with analytical solutions } & 91\end{array}$

5.4.2 Comparison with data from physical-model tests 96

$\begin{array}{ll}5.5 \text { Numerical model applications } & 101\end{array}$

5.6 Improvements and extensions of the numerical model 105

$\begin{array}{ll}5.7 \text { Conclusions } & 107\end{array}$ 
6. Berm breakwaters 109

$\begin{array}{ll}6.1 \text { Introduction } & 109\end{array}$

$\begin{array}{ll}6.2 \text { Berm breakwater features } & 109\end{array}$

$\begin{array}{ll}6.3 \text { Physical-model tests } & 113\end{array}$

6.3.1 Description of physical-model tests 113

$\begin{array}{ll}\text { 6.3.2 Discussion of test results } & 117\end{array}$

6.4 Validation and intercomparison of the numerical models 119

6.4.1 Validation of the one-dimensional wave model 119

6.4.2 Validation of the two-dimensional wave model 121

6.4.3 Evaluation of the numerical model validations 129

$\begin{array}{ll}6.5 \text { Conclusions } & 131\end{array}$

7. Wave load - response model 133

$\begin{array}{ll}7.1 \text { Introduction } & 133\end{array}$

$\begin{array}{ll}7.2 \text { Modelling of forces and profile development } & 134\end{array}$

7.2.1 Approach for simulating profile development 134

7.2.2 Modelling of forces on stones 135

$\begin{array}{ll}\text { 7.2.3 Modelling of stone displacements } & 137\end{array}$

7.3 Calibration and validation of the wave load-response model 139

$\begin{array}{ll}7.4 \text { Applications with the wave load-response model } & 146\end{array}$

7.4.1 Profile development of gravel beaches 146

7.4.2 Profile development of berm breakwaters 149

7.4.3 Profile development of reef-type structures 151

$\begin{array}{ll}7.5 \text { Conclusions } & 153\end{array}$

8. Conclusions and recommendations 155

$\begin{array}{ll}\text { Acknowledgements } & 161\end{array}$

$\begin{array}{ll}\text { References } & 163\end{array}$

$\begin{array}{ll}\text { Notation } & 171\end{array}$

$\begin{array}{ll}\text { Curriculum vitae (in Dutch) } & 177\end{array}$ 
viii 


\section{Chapter 1}

\section{Introduction}

\subsection{General}

Coastal regions are environments with several functions essential for the safety and the economy of their hinterlands. The importance of potential flooding of lowlands, of drinking water supply, of harbours, of fisheries, of environmental aspects and of recreation make coastal regions multi-functional areas in which a balance must be found between the various functions. To find the optimum solution, coastal engineering provides a link between the physical processes in coastal regions and the management of these regions. In this thesis, hydrodynamic processes are studied and modelled to provide coastal engineers with knowledge and tools to predict properties of the hydrodynamic processes and to design structures in coastal regions.

Among the most important hydrodynamic processes in coastal regions are the propagation of water waves and their effects on the coast and on coastal structures. These free surface waves may cause overtopping of dikes, in which cases these structures do not provide adequate flood protection. The down-rush of water at the rear-side of the dike may also cause unacceptable erosion thus failing to safeguard the structures' stability. Wave penetration into harbours and wave transmission through permeable structures result in ship motions which must be limited. In addition, the wave forces on coastal structures such as dikes, breakwaters and gravel beaches and on the individual elements of these structures must be predicted to protect the structure from failure and unacceptable damage. For instance, the dimensions of the elements and the lay-out of the cross-section of the structure must be designed. The above mentioned examples indicate that wave propagation in coastal regions and wave attack on coastal structures must be predicted to determine the location of the structures and to optimize the design of each structure. 
Wave propagation and wave attack on coastal structures lead to a response of the structure or if the loads exceed the strength or resistance against motion to displacements of elements of the structure. For some types of structures this response can only be acceptable if the displacements that occur are limited (dikes, conventional rubble-mound breakwaters). For other types of structures many more displacements can be allowed (gravel beaches, berm breakwaters). In the latter, to determine the new seaward slope and its influence on the wave attack the location of displaced units must be known.

To predict wave attack on coastal structures, physical modelling can be used. Often small-scale tests are performed to limit expenses, even though the tests might be influenced by scale-effects. Small-scale tests with structures with permeable parts can relatively easily be influenced by scale-effects due to the difficulty of representing both the stability of stones and the permeability correctly. Another problem with physical modelling is that accurate measurements are not always possible, for instance in breaking waves.

An alternative way to predict wave attack on coastal structures and the subsequent structural response is through mathematical description of the dominant physical processes. Analytical solutions of the governing equations which describe the dominant processes can often only be found for a limited number of applications. In many cases in coastal engineering, especially those with significant non-linear effects, no widely-applicable analytical solutions can be found and preference is given to numerical methods of solution.

In this thesis wave attack on permeable coastal structures is studied both by means of physical modelling and by numerical modelling of the dominant processes. Emphasis is put on structures like berm breakwaters, conventional rubble-mound structures and gravel beaches, where the flow through the permeable part of the structure effects the external wave motion and the resulting forces on elements of the structures. The flow inside the permeable part is studied both theoretically and through physical modelling. This physical modelling of porous media flow is necessary to describe the flow mathematically. Two numerical models have been developed to simulate wave attack on and inside permeable coastal structures. With data from new physical-model tests an additional validation of both numerical models is performed. After verification of the wave attack, as provided by the numerical models, a response model is developed to study the interaction of this 
wave attack with the displacement of stones and gravel on the seaward slope of structures like berm breakwaters and gravel beaches.

\subsection{Background of the present study}

For many years the complex phenomena arising from the breaking of waves on coastal structures and their effects on the structures have been studied, with emphasis on physical-model tests and the empirical relations arising from such tests. For instance run-up levels, overtopping discharges and the stability of stones in the seaward profile are predicted by using hydraulic parameters like the wave height in front of the structure and structural parameters like the stone diameter. These empirical relations account for the effects of the wave motion without modelling the wave motion. Through mathematical modelling of this wave motion itself, more detailed information like velocities and accelerations of water moving along the slope can be obtained. Using these properties, assessed through numerical modelling, may lead to more generally applicable solutions for hydrodynamic processes and stability parameters. In general, a mathematical solution may exclude possible scaleeffects which occur in small-scale physical modelling. In addition, an accurate mathematical description is an important complementary design tool.

The above indicates the need for a predictive mathematical model and consequently a numerical model for breaking waves on coastal structures. Such models are valuable for designing coastal structures with permeable parts consisting of granular material like rubble-mound breakwaters because a wide variety of parameters, like stone diameter, grading and roughness as well as structure lay-outs increase the possible design options. In combination with a limited number of physical-model tests, a numerical model might provide information concerning the effects of changes in the design of a breakwater.

Here, the numerical modelling of individual breaking waves consists of a two-track approach with two complementary numerical models. Although for both models the present study is restricted to normally incident waves, the assumptions do not prevent extension towards the modelling of oblique wave attack. For the first of the two models, far-reaching assumptions have been made beforehand which limit the possibility of implementing detailed descriptions of the physical processes of the wave motion. This, however, does not imply that the model cannot provide accurate 
results for a wide range of hydrodynamic properties of various types of coastal structures. For the second model less restrictive assumptions have been made beforehand which enables a long term development by continuing the implementation of more detailed descriptions of the physical processes. For instance, in the second model more detailed descriptions of air-entrapment, turbulence and structure lay-out can be implemented, while the basic assumptions of the first model do not permit such an in-depth development. Although the two models serve both practical engineers and research-based engineers, research on which the first model was based was especially intended to provide a design tool for engineers while the second model still requires additional assistance by researchers.

To model porous media flow accurately, physical-model testing was necessary in order to obtain values for friction coefficients and to study the dependency of these coefficients on several parameters. After modelling of this porous media flow, the interaction between the external wave motion and the internal wave motion can be studied and incorporated in the two numerical models.

Both numerical models need to be verified. Tests in which the interaction between external and internal wave motion is of major importance are suitable. Berm breakwaters are not the only appropriate type of structure for this goal, but because berm breakwaters are relatively new and to date have received relatively little attention, research aimed at this type of structure is even more relevant.

The natural response of berm breakwaters to hydrodynamic loads makes them economically attractive, not in the least because smaller rock material can be used than with conventional breakwaters. On the other hand, the dynamic behaviour, typical of berm breakwaters requires special attention. The seaward slope undergoes reshaping until a stable seaward profile has developed. This dynamic behaviour of the seaward slope is very much depending on the hydrodynamic loads and vice versa. This interactive character of the hydrodynamics and the reshaping process are studied here, not only with physical-model tests but also with a new wave loadresponse model implemented in one of the numerical models.

Like empirical relations to predict hydrodynamic parameters, such relations also exist for the structural response. Although the most recent relations are valid for a wide range of parameters, no detailed modelling of both the hydrodynamics and the structural response are included. Therefore, for a more accurate prediction ultimately 
more detailed information on the hydrodynamics will be needed. The earlier mentioned numerical models can provide such detailed information on the wave motion along the slope. The response of the structure to this wave attack can also be modelled and solved numerically. Coupling of such a response model to a wave model enables the simulation in the time-domain of the wave interaction with dynamic structures like berm breakwaters and gravel beaches. The simulation of profile development of the seaward slopes may be used not only to predict the dynamically stable seaward profile but also to study the influence of reflection caused by super-structures on the profile or to study the degradation of the size of stones due their movement along the slope. In addition, such wave load-response can also be used as a complementary design tool.

\subsection{Aim and scope of the present study}

The aim of the research presented in this thesis is to contribute to a better understanding of physical processes involved in the hydraulic and structural response of coastal structures under wave attack and to develop predictive models of wave interaction with permeable coastal structures with special attention to berm breakwaters.

To achieve these objectives, laboratory experiments were carried out to provide new insight into physical processes and to validate predictive models. These predictive models must be able to simulate wave interaction with permeable structures in the time-domain and include the simulation and effects of porous media flow. The numerical modelling of wave attack and the response of structures is restricted to normally incident waves.

\subsection{Outline}

The general lay-out of this thesis is as follows. In Chapter 2, formulations for models to simulate wave motion on coastal structures and models for porous media flow are discussed. Porous media flow is treated in Chapter 3 which includes a description and analysis of physical-model tests to study stationary and oscillatory porous media flow. 
The first of the two numerical models able to simulate normally incident waves on various types of coastal structures, including permeable structures, applies a onedimensional description of the wave attack. The model is presented in Chapter 4. The second numerical model is based on a two-dimensional description of this wave motion which enables a detailed simulation of the breaking process. Chapter 5 deals with this model. Physical-model tests on a berm breakwater are discussed in Chapter 6 along with an additional validation of both numerical models.

The two numerical models determine hydrodynamic properties through which the wave loads can be assessed. In Chapter 7 a model simulating the response of a structure to the wave loads is described and coupled to one of the numerical wave models. The wave load-response model is validated and used to study the profile development of the seaward slopes of gravel beaches, berm breakwaters and reeftype structures.

In Chapter 8 an overview of the main conclusions is presented with suggestions for future developments. 


\section{Chapter 2}

\section{Theoretical background}

\subsection{Introduction}

In this chapter the main assumptions and the main lines of the mathematical description for some groups of numerical wave models are discussed. Firstly, four types of model formulations to simulate free surface waves propagating on finite water depth are described briefly. Thereafter, some aspects of models for simulating porous media flow are mentioned. Finally, combined models simulating both free surface waves and porous media flow are discussed.

Most wave models have initially been developed for wave propagation over gently sloping beaches. Wave motion and, in general, the motion of an incompressible Newtonian fluid can be described accurately by the Navier-Stokes equations. However, because solving these equations is very complex it is appropriate to use approximations in order to derive equations which are easier to solve. For instance, before waves start to break the flow can be assumed inviscid and irrotational, leading to potential flow models which can be used to study wave propagation over uneven bottoms preceding wave breaking. A brief discussion of potential flow models is given in Section 2.2.1.

In shallow water the non-linear effects of wave propagation cannot always be neglected. Here, two types of shallow-water equations are discussed namely the finite-amplitude shallow-water equations (Section 2.2.2 and Chapter 4) and the Boussinesq equations (Section 2.2.3). The shallow-water equations are not valid for describing the breaking process, so in regions in the transition zone from nonbreaking to broken waves, empirical expressions, approximate models or the full Navier-Stokes equations (see Section 2.2.4 and Chapter 5) must be applied. After 
breaking, the finite-amplitude shallow-water equations can again be used to approximate the bores originating from the breaking process, up to the shoreline. Peregrine $(1967,1972)$ gives a derivation of linearised water wave equations, finiteamplitude shallow-water wave equations and the Boussinesq equations.

In principle, for wave attack on structures the same model formulations as used for wave propagation over beaches can be used. However, due to the steeper slopes of structures, for some types of the models not all approximations used to derive the applied equations are valid. Models based on such types of equations are therefore approximate models, for which verification is not only required to test the numerical model itself, but also to study the consequences of exceeding the range of validity of the equations.

For wave motion inside permeable structures, the same types of equations as for the wave motion outside the structure can be used. Models with permeable structures based on potential flow theory, finite-amplitude shallow-water equations and NavierStokes equations have been developed. The formulations for these models are discussed in the Sections 2.3 and 3.2.

Finally, some formulations and aspects for the simultaneous modelling of the wave motion inside and outside permeable structures are discussed in Section 2.4. Two of such integrated models are described in detail in the Chapters 4 and 5 .

\subsection{Modelling of wave motion on coastal structures}

\subsubsection{Potential flow models}

As long the waves are not breaking, even strongly non-linear waves can accurately be described by models based on potential flow theory. These models use the assumptions that compressibility and viscous effects can be neglected. For flow conditions in which air-entrainment or wave impacts occur, compressibility cannot be neglected. If initially no rotation occurs and if no vorticity is transported into the fluid through the boundaries, neglecting the viscosity of the fluid implies that the wave motion is free from rotation. However, for many cases rotation is transported into the fluid domain at the bottom boundary and, as in breaking waves, at the free surface boundary. 
Moreover, the computations become very complex when the fluid domain becomes multiple-connected. This is the case when an overturning wave tongue hits the free surface underneath (the backwash water layer of the previous wave). These multipleconnected free surfaces can be solved by using advanced techniques such as the Volume-of-Fluid method (VOF), see Hirt and Nichols (1981), but are not easily solved when using the most suitable and frequently applied techniques for potential flow models, i.e., the Boundary Integral Equation (BIE) or Boundary Element Methods (BEM). Because potential flow models become less accurate near breaking due to the increasing importance of viscous effects, a model based on the NavierStokes equations, that include viscous effects, is more appropriate for describing the wave breaking process itself.

Although no potential flow models are capable of simulating the complete breaking process and only limited wave-structure interactions are possible, they provide very accurate information on the generation of breaking waves. For two-dimensional models see Longuet-Higgins and Cokelet (1976), Vinje and Brevig (1981), Dold and Peregrine (1986) and Klopman (1987) and for a three-dimensional model Broeze (1993). Methods developed by Stokes (1847) and Rienecker and Fenton (1981), assuming potential flow, will be used as suppliers of incident waves for the numerical models described in respectively Chapter 4 and Chapter 5 .

\subsubsection{Finite-amplitude shallow-water equation models}

Until breaking occurs finite-amplitude shallow-water equations can be used to describe wave propagation over short distances (a few wavelengths) on gentle slopes. After breaking they can be used to approximate the bores originating from the breaking process. Although the equations are not strictly valid for steeper slopes or to describe the breaking process, several numerical models have been developed that use these equations to simulate wave motion on steep coastal structures, including breaking waves. They provide information on the wave motion which is sufficiently accurate for many applications. This indicates that for many applications the consequences of exceeding the range of the validity of the equations may be limited. Owing to the steep slopes, the number of wavelengths between the toe of a structure and the water line is small. In such cases there is insufficient time for inaccuracies in the solution due to invalid assumptions to evolve and to effect the solution to a large extent. 
In Chapter 4 a numerical model based on this type of equation is described in detail. For a detailed description of the derivation of this type of equation, see Peregrine (1972) or Dingemans (1994). Here, the assumptions behind the derivation of the finite-amplitude shallow-water wave equations will be indicated.

As a basis, the Navier-Stokes equations of motion for an incompressible Newtonian fluid with a constant fluid mass density will be used. For a derivation of the NavierStokes equations see for instance Lamb (1932) or Batchelor (1967).

$$
\frac{\partial \boldsymbol{u}}{\partial t}+(\boldsymbol{u} \cdot \nabla) \boldsymbol{u}+\nabla \frac{p}{\rho}-v \nabla^{2} \boldsymbol{u}=\boldsymbol{k}
$$

The continuity equation is equal to the following incompressibility constraint:

$$
\nabla \cdot u=0
$$

Here, normally incident gravity waves are studied. Variations in the horizontal direction perpendicular to the direction of wave propagation are neglected as well as their effects on the wave motion in the remaining two directions ( $x$ and $z$ coordinates). Neglecting viscous effects leads to the Euler equations:

$$
\begin{aligned}
& \frac{\partial u}{\partial x}+\frac{\partial w}{\partial z}=0 \\
& \frac{\partial u}{\partial t}+u \frac{\partial u}{\partial x}+w \frac{\partial u}{\partial z}+\frac{1}{\rho} \frac{\partial p}{\partial x}=0 \\
& \frac{\partial w}{\partial t}+u \frac{\partial w}{\partial z}+w \frac{\partial w}{\partial z}+\frac{1}{\rho} \frac{\partial p}{\partial z}+g=0
\end{aligned}
$$

The shallow water assumption implies that the wavelength must be much greater than the water depth. This consequently leads to the term $\partial w / \partial x$ being of a small magnitude. The condition for an irrotational flow,

$$
\frac{\partial u}{\partial z}=\frac{\partial w}{\partial x}
$$


shows that the term $\partial u / \partial z$ is also small for shallow water, which means that a uniform velocity can be assumed over the depth.

For shallow water the terms in Equation 2.5 with variations of the vertical velocity in time and space $(\partial w / \partial t, \partial w / \partial x$ and $\partial w / \partial z)$ are significantly smaller than the term with the variation of the pressure in the vertical direction $(1 / \rho \cdot \partial p / \partial z)$. Neglecting these relatively small terms and integration of this equation for vertical momentum (Eq.2.5) with respect to $z$, along with the dynamic boundary condition, shows that for shallow water the pressures are hydrostatic (the dynamic boundary condition implies that the pressure is zero at the surface after neglecting the surface tension and the stresses due to the atmosphere above the water).

The above mentioned assumptions lead to the following one-dimensional momentum equation:

$$
\frac{\partial u}{\partial t}+u \frac{\partial u}{\partial x}+g \frac{\partial \eta}{\partial x}=0
$$

where $\eta$ is the elevation of the free surface with respect to the horizontal axis. The term $\partial \eta / \partial x$ can be replaced by $\partial\left(h-z_{\eta}\right) / \partial x$ where $h$ is the instantaneous local water depth and $z_{0}$ is the slope elevation with respect to the horizontal axis.

Integration of the continuity equation (Eq.2.3) with respect to $z$ over the instantaneous local water depth (from the slope elevation $z_{0}$ to the level of the free surface $\eta$ ) gives:

$$
w_{\eta}=-\int_{z_{0}}^{\eta} \frac{\partial u}{\partial x} d z+w_{z_{0}}
$$

where $w_{\eta}$ is the vertical velocity at the free surface. With $w_{z_{0}}=-u_{z_{0}} \mathrm{~d} z_{0} / \mathrm{d} x$ this yields:

$w_{\eta}=-\frac{\partial}{\partial x} \int_{z_{0}}^{\eta} u d z+u_{\eta} \frac{\partial \eta}{\partial x}$

Using the kinematic boundary condition at the free surface, implying that fluid particles at the free surface move with the surface, 


$$
\frac{\partial \eta}{\partial t}+u_{\eta} \frac{\partial \eta}{\partial x}=w_{\eta}
$$

this yields, after replacing $\partial \eta / \partial t$ by $\partial h / \partial t$ :

$$
\frac{\partial h}{\partial t}+\frac{\partial h u}{\partial x}=0
$$

where $h$ is the instantaneous local water depth and $u$ is the mean horizontal velocity.

Using the continuity equation (Eq.2.11), the momentum equation (Eq.2.7) can be rewritten and from this the set of governing equations for finite-amplitude shallowwater wave equations are obtained (Eq.2.11 and Eq.2.12):

$$
\frac{\partial h u}{\partial t}+\frac{\partial h u^{2}}{\partial x}+g h \frac{\partial\left(h-z_{0}\right)}{\partial x}=0
$$

Peregrine (1972) derived this set of equations by using non-dimensional variables to show the relative magnitude of the terms and to justify the omission of some terms. Several authors derived this set of equations by assuming hydrostatic pressures (neglecting vertical accelerations) and initial uniform horizontal velocities like in Van Gent (1992) where a control volume is used to derive the balances of momentum and mass.

The solution of the finite-amplitude shallow-water wave equations shows that the propagation of the wave crests occurs faster than the propagation of the wave troughs. This amplitude dispersion results in a continually steepening of the wave front. Frequency dispersion (the process in which all Fourier wave components travel at their own velocity) may counteract the effects of the amplitude dispersion. For the finite-amplitude shallow-water wave equations the absence of frequency dispersion prevents adequate counteracting of amplitude dispersion, which results in overestimation of the non-linear effects. This leads to a steepening of the wave front which is too fast, see Dingemans (1994). The frequency dispersion can be improved by applying Boussinesq-like equations. As discussed by Ursell (1953), for long waves with small amplitudes, such Boussinesq-like equations are more 
fundamental than the finite-amplitude shallow-water wave equations treated here. Airy (1845) had already shown that applying the latter equations for waves in shallow water causes changing in the wave form when propagating at uniform depth, a conclusion which is valid for long waves with wave heights of the same order of magnitude as the water depth. The discussions in the above mentioned articles show that the shallow-water wave equation, as shown in Equation 2.12, can be used for long waves in shallow water with sufficiently large amplitudes but not so large that vertical accelerations become important (finite-amplitudes).

The steepening of the wave front leads to the formation of bores. Since steepening of the wave front also precedes the breaking of waves, bores are supposed to represent the forming of breaking waves and even the bore can be seen as a representation of the propagation of the wave front. However, the equations forming this bore are not strictly valid in this region and can therefore only be used as an approximative representation.

Analytical solutions of the shallow-water wave equations are reviewed by Meyer and Taylor (1972). Methods based on characteristics are used to find analytical solutions for waves on a constant depth. For slopes, solutions of the non-dissipative shallow-water wave equations are found for waves with limited amplitudes, that do not form bores, resulting in waves which are fully reflected. Such fully reflecting conditions are usually not valid, especially for beaches. For higher waves, solutions with bores can be found by using jump conditions at the position of the (moving) bore. Methods based on characteristics can also be used to find solutions with bores by using numerical models, however, the bores need to be detected and require separate treatment. Finite-difference methods do not require such separate treatment and numerical models based on this method have been successfully applied.

Based on the shallow-water equations (Eq.2.11 and Eq.2.12) Hibberd and Peregrine (1979) developed a numerical model with an explicit dissipative finite-difference scheme based on Lax-Wendroff (1960) and discussed by Richtmyer and Morton (1967). This finite-difference scheme causes a difference between the phase velocities of the wave components, as prescribed by the equations, and those computed by using the discretised equations. For each wave component these differences depend on the time and space-steps used in the discretised equations. Fortunately, the smaller these time and space-steps are made the smaller these differences become. In the scheme an additional term can be included to minimize 
numerical oscillations due to non-linear dispersive effects introduced by the discretisation. In most cases these parasitic waves which appear near the bore are unacceptable and therefore this additional term must be included. An additional difficulty is the treatment of the boundary at the shoreline. Most methods designed to determine the motion of the shoreline make use of extrapolations of the velocities and surface elevations near this wave front. The accuracy of these properties near the shoreline is relatively low due to the numerical oscillations which minimize the merit of accurate extrapolation procedures. Nevertheless, for many of these shoreline procedures the time-steps in the discretised equations are often limited by such shore-line procedures, rather than by the discretisation of the basic equations.

Bottom friction can be included in the non-dissipative shallow-water wave equation (Eq.2.12) as follows:

$$
\frac{\partial h u}{\partial t}+\frac{\partial h u^{2}}{\partial x}+g h \frac{\partial\left(h-z_{0}\right)}{\partial x}=-\frac{\tau_{b}}{\rho}
$$

The bottom shear stress $\tau_{b}$ can be expressed as:

$$
\tau_{b}=\frac{1}{2} \rho f|u| u
$$

where $f$ is the friction factor which needs to be determined empirically.

The finite-amplitude shallow-water wave equations that include bottom friction have not been solved analytically. Based on these equations and by using concepts of Hibberd and Peregrine (1979), several numerical models have been developed and used for many practical cases. For applications with steep impermeable coastal structures where wave reflection and run-up on impermeable rough slopes have been studied see for instance Kobayashi et al. (1987). Chapter 4 provides a description of a numerical model to simulate wave motion on impermeable coastal structures and also the wave motion on and inside permeable structures. Figure 2.1 shows an example of a simulation of the wave motion on an impermeable structure obtained from this one-dimensional model where breaking waves are represented as bores. 


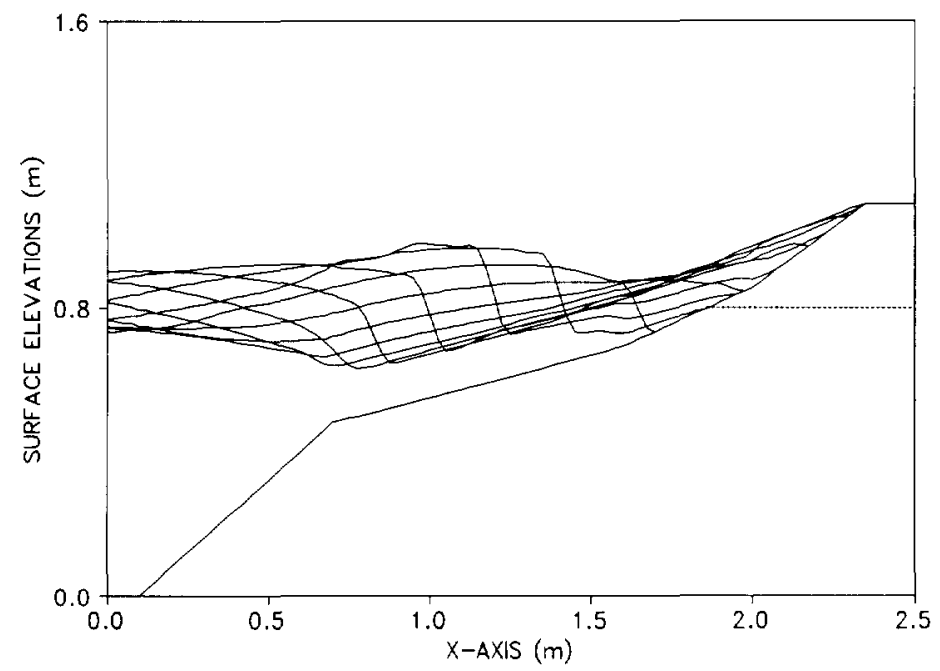

Fig.2.1 Simulation of the wave motion on an impermeable structure with a model based on finite-amplitude shallow-water equations.

\subsubsection{Boussinesq-type models}

As mentioned in the previous sub-section, the finite-amplitude shallow-water wave equations give a relatively quick steepening of the wave front because non-linear effects are overestimated. This is related to the omission of the effect of vertical flow accelerations on the pressure, resulting in the absence of frequency dispersion. Boussinesq-like equations contain additional terms to improve these characteristics. For waves with small amplitudes in relation to the water depth and travelling over long distances, for instance on beaches and mildly sloping structures, this effect cannot be neglected. Therefore, weakly non-linear equations like the Boussinesq equation (1872) are preferable to describe waves before they start to break. However, their applicability is limited since for most applications these models are less accurate than finite-amplitude shallow-water wave models for slopes steeper than about 1:10. So, although their applicability may be wide for spilling breakers on beaches, their field of application is smaller for wave motion on structures. Furthermore, the one-dimensional Boussinesq-type models are, like the models based on the equations in the previous sub-section, not capable of simulating the 
overturning wave tongue and, consequently, not capable of simulating the breaking process of overturning/ plunging waves.

Boussinesq-type models for the surf-zone have been developed by Abbott et al. (1983) and Schäffer et al. (1993), the latter including spilling breakers in an empirical, geometrical approach.

\subsubsection{Navier-Stokes-type models}

The motion of an incompressible Newtonian fluid can be described accurately by the Navier-Stokes equations. For flow conditions in which air-entrainment or wave impacts occur, compressibility has to be taken into account, although, in most wave motions the effects of compressibility can be neglected.

The second term in the Navier-Stokes equation (Eq.2.1) is the non-linear convective term. For conditions in which this term is of importance, e.g., for relatively high waves in coastal areas, no analytical solutions exist and discrete solutions are required. Such solutions are also required because of non-linearity caused by freesurface boundary conditions. For flow conditions in which this convective term is relatively large compared to the shear stresses specified in the fourth term, the flow field can become turbulent which means that infinitesimally small deviations in the initial and boundary conditions cause large deviations in the solution. Often one is not interested in such a co-incidental solution but in the average of the possibly occurring properties, i.e., the motion of the mean flow and not the coincidental deviation from it. Averaging the possible solutions of the Navier-Stokes equation leads to the Reynolds-equation describing the mean flow:

$$
\frac{\partial \bar{u}}{\partial t}+(\bar{u} \cdot \nabla) \bar{u}+\nabla \frac{\bar{p}}{\rho}+\nabla \cdot\left(\overline{u^{\prime} u^{\prime}}\right)-v \nabla^{2} \bar{u}=k
$$

where the fourth term specifies the Reynolds-stresses. These contain Reynolds pressures and shear-stresses. The gradients of the Reynolds pressures can usually be neglected since they are much smaller than the gradients of the normal pressures in the third term of the Reynolds-equation. For most applications the Reynolds shearstresses, i.e., turbulence shear-stresses, are much larger than the viscous shear stresses described by the fifth term, permitting neglecting of the latter. Omitting the 
Reynolds pressure component, the Reynolds stresses can be approximated by a gradient-type of transport:

$\nabla \cdot \overline{\left(u^{\prime} u^{\prime}\right)} \approx-\nabla \cdot\left(v_{t} A\right)$

where $\nu_{t}$ is the eddy-viscosity, i.e., turbulence viscosity and the components of $A$ are $A_{i j}=\left(\partial u_{i} / \partial x_{j}+\partial u_{j} / \partial x_{i}\right)$.

Models based on potential flow theory fail to model the breaking process while models based on the finite-amplitude shallow-water wave equations or Boussinesqlike equations cannot model the wave front in detail. This can be overcome by solving the two-dimensional (2DV) Navier-Stokes/Reynolds-equations. This requires a powerful method, able to deal with multiple-connected free surfaces. The 'Marker And Cell' method (MAC), see Welch et al. (1966), and the 'Volume-of-Fluid' method (VOF), see Hirt and Nichols (1981), are such advanced techniques. For instance the first method is used by Sakai et al. (1986) for simulations of breaking waves. For the second method, the treatment at the surface can be improved by using the adapted flux-method known as 'FLAIR', see Ashgriz and Poo (1991). Because the governing equations and the procedure for solving these equations do not require a specific definition of the free surface, very complex shapes of this surface can be dealt with including air-entrapment where air is modelled as vacuum. The pressure-gradients in the Navier-Stokes/Reynolds equation can be computed from given velocities by applying the pressure Poisson equation:

$$
\frac{1}{\rho} \nabla^{2} p=\nabla \cdot\left(-(\boldsymbol{u} \cdot \nabla) \boldsymbol{u}+\nabla \cdot\left(v_{t} A\right)+\boldsymbol{k}\right)
$$

where the vector $\boldsymbol{k}$ represents the gravitational accelerations. By solving this equation conservation of mass is satisfied.

The VOF-method, as initiated by Hirt and Nichols (1981), is used by Lemos (1992) who combined the model with a $k-\epsilon$ turbulence model, by Van der Meer et al. (1992) where smooth impermeable slopes are implemented based on Petit and Van den Bosch (1992), and by Wu (1994) for breaking waves against a vertical wall. In principle the models are not only capable of simulating free surfaces which become multiple-connected but also capable of modelling air-entrapment, see Figure 2.2. Both are essential for the simulation of overturning waves. Because the models are 
two-dimensional, they can accommodate a wider range of types of structures then the models based on the one-dimensional descriptions, as mentioned in the previous two sub-sections.

In Chapter 5 a numerical model based on the Reynolds-averaged Navier-Stokes and the VOF-method is described. The model, into which smooth impermeable slopes are implemented by Petit and Van den Bosch (1992), has been extended and verified, enabling simulations of wave motion on and inside permeable structures.
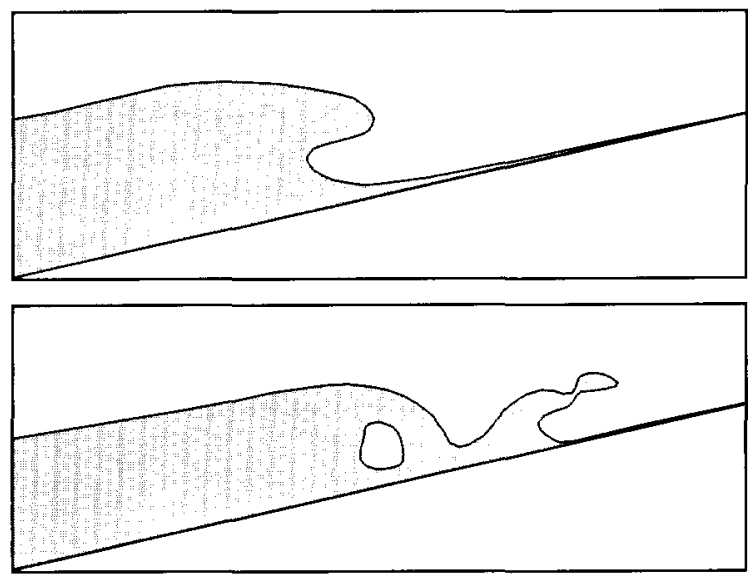

Fig.2.2 Simulation of a breaking wave on an impermeable slope by a numerical model based on the NavierStokes-equations solved by using the VOF-method.

\subsection{Modelling of porous media flow}

Wave attack on permeable coastal structures with a high permeability such as those consisting of coarse granular material or large artificial blocks, cannot be modelled accurately without modelling porous media flow. The energy dissipation inside the permeable parts, the infiltration and seepage in the swash and backwash area, and the interactive flow between the external wave motion and the internal wave motion often cause the wave attack to be quite different from the flow on impermeable structures. 
For the numerical simulation of wave motion inside permeable structures, in principle the same types of equations can be used as for the external wave motion as discussed in the previous sub-sections. However, the equations must be adapted because the porosity and different friction terms need to be implemented. Because the flow through the permeable parts of coastal structures is often turbulent, the porous media flow is different from the well-known groundwater flow which is a laminar flow. Furthermore, the wave attack on coastal structures and their relatively coarse material make the porous media flow highly time-dependent. Therefore, not only must the differences between laminar and turbulent porous media flow be studied but also the influence of the oscillatory flow on the friction. In Chapter 3 porous media flow will be discussed in detail and experimental tests to study porous media flow will be described.

After implementing the permeability of the porous medium in the formulations, numerical models were developed for porous media flow, while some are connected to models for the external wave motions. These are formulations based on potential flow theory (Koutitas, 1982), finite-amplitude shallow-water wave equations (Hannoura, 1978; Van Gent, 1992/1994-a; Wurjanto and Kobayashi, 1993; Engering et al., 1993) and Navier-Stokes equations (Van Gent et al., 1994-a/c). The latter two types of equations will be described in Chapter 3 and applied in Chapters 4 and 5 .

\subsection{Modelling of combined external-internal wave motion}

In the previous sections numerical models for the external wave motion and models for porous media flow have been mentioned. Some of them contain descriptions of both the internal and external wave motion which permits computation of both wave motions simultaneously. The coupling of both parts, however, is different in all of the numerical models mentioned.

Koutitas (1982) gave a description of a numerical model where the external wave motion was modelled with finite-amplitude shallow-water wave equations and the internal wave motion with a model based on potential flow theory. The model described in Chapter 4 (Van Gent, 1992/1994-a) and those by Wurjanto and Kobayashi (1993) and Engering et al. (1993) all use equations of the shallow-water type (long-wave equations) for both the external wave motion and the internal wave motion. In the model treated in Chapter 5 the wave motion described is based on 
Navier-Stokes equations in both the external and the internal region. Except for the latter numerical model the models use a one-dimensional description of both the free and phreatic surface. Neither gives a detailed description of the un-saturated zone between the free and phreatic surface, see Figure 2.3.

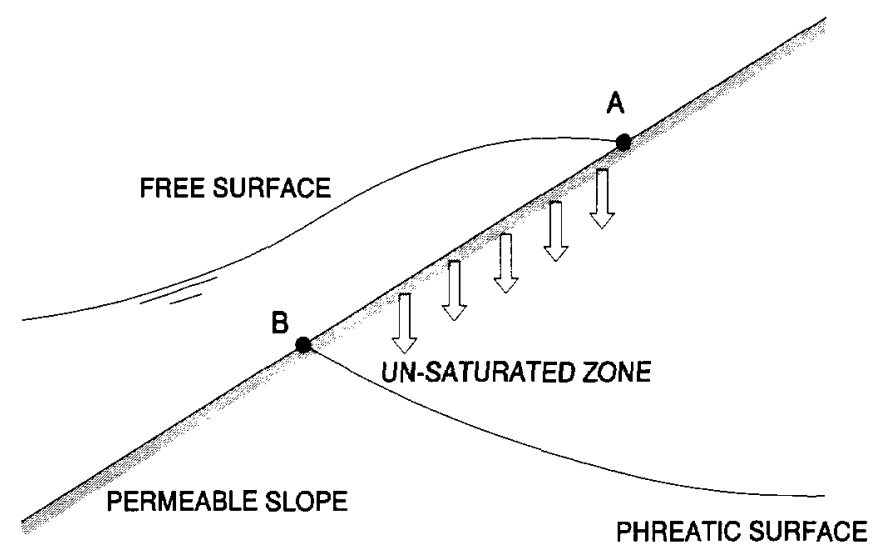

Fig.2.3 Un-saturated zone between the free and phreatic surface.

The models by Koutitas (1982) and Wurjanto and Kobayashi (1993) neglect this phenomenon completely because the free surface and the phreatic surface are forced to stay connected ( $A$ and $B$ in Figure 2.3 are then at the same point). For the situation in Figure 2.3 this causes the run-up point $(A)$ to be pulled downward and the phreatic surface to be pushed upward. This causes severe inaccuracies in the calculation of both the external and internal wave motion for cases in which, due to the relatively high internal friction, the phreatic surface is unable to keep up with quick motion of the swash and backwash. In the model by Engering et al. (1993) and the model described in Chapter 4, the free and phreatic surfaces do not have to remain connected (points $A$ and $B$ in Figure 2.3 are treated separately). A separate treatment for the movement of point $B$ is included in both models by prescribing a maximum velocity for the phreatic surface in the vertical direction. Engering et al. (1993) force the phreatic surface to move in the direction of the run-up point $(B$ moves towards $A$ ) while the treatment by the model described in Chapter 4 does not require this. Furthermore, this model takes the infiltration through the un-saturated zone into account. The model described in Chapter 5 does not need such separate 
treatment since it can give a two-dimensional description of the surface and is, in principle, able to deal with un-saturated zones.

The different treatment of aspects like the one mentioned above easily cause relatively large differences between the respective numerical models even though they might use the same basic equations and similar numerical schemes. Other aspects of the coupling between the two parts of the model will be discussed in Chapter 4. 


\section{Chapter 3}

\section{Porous media flow}

\subsection{Introduction}

The need for studying porous media flow for modelling wave motion on and inside coastal structures has been discussed in the previous chapters. In Section 3.2 formulations to describe porous media flow will be given. The importance of nonstationary porous media flow in coastal engineering applications is shown in Section 3.3. Measurements to study both stationary and non-stationary porous media flow are described in Section 3.4. Parts of the research treated in this chapter are more specifically described in Van Gent (1991, 93-a, 94-c or 95-a). A valuable discussion of dynamics of fluids in porous media is given by Bear (1972).

\subsection{Formulations for porous media flow}

The well-examined groundwater flow and flow through other small-size material is mostly laminar. Laminar stationary flow of an incompressible fluid through a homogeneous porous medium can be described by using the Law of Darcy (1856):

$$
u=-\frac{K}{\rho g}(\nabla p+\rho g)
$$

where $\boldsymbol{u}$ denotes the vector of the filter velocities, also called bulk velocity or specific discharge velocity. For the permeability coefficient $K$, hereafter $K=1 / a$, many relations exist, see Bear (1972). The following expression, after Kozeny (1927), is supported here, since it can be derived theoretically:

$$
a=\alpha \frac{(1-n)^{2}}{n^{3}} \frac{v}{g D^{2}}
$$


where $a=1 / K, \nu$ is the kinematic viscosity, $D$ is a characteristic length-scale, $n$ is the porosity of the porous medium and $\alpha$ is a non-dimensional coefficient to be determined empirically.

For many applications for civil engineering purposes the vertical accelerations can be neglected. For such applications often a one-dimensional description of the flow, including the assumption of hydrostatic pressures, will do. For laminar porous media flow this reduces Equation 3.1 to the one-dimensional equation $I=a \cdot u$ where $I$ is the pressure gradient $(I=-1 / \rho g \cdot \partial p / \partial x), a$ the dimensional friction coefficient $(s / m)$ and $u$ the depth-averaged filter velocity. For flow through a porous medium of coarse granular material the resistance can be reasonably well expressed by a term that is linear with the flow velocity $(a \cdot u)$ and a term that is quadratic with the flow velocity $(b \cdot u|u|)$. Such a relation was proposed by Forchheimer (1901):

$$
I=a u+b u|u|
$$

where $a$ and $b$ are both dimensional coefficients. The first term can be seen as the laminar contribution and the second term can be seen as the contribution of turbulence, although the influence of large-scale convective transport is also included in this second term (small-scale convective transport occurs on the scale of the pores). For turbulent porous media flow, and in the transition between laminar and turbulent flow, this equation can be used. The friction coefficients $a$ $(s / m)$ and $b\left(s^{2} / m^{2}\right)$ are dimensional and contain several parameters. Many empirical and semi-empirical formulae have been derived from measurements. For a literature survey see Bear (1972). Here, for the friction coefficient $a$, expression 3.2 is used again. The coefficient $\alpha$ is not assumed constant at first since it might still depend on the flow properties or the geometry of the porous medium. For the friction coefficient $b$ an expression proposed by Ergun (1952) and others is used, since it can also be derived by using the Navier-Stokes equations (see e.g., Van Gent, 1991):

$$
b=\beta \frac{1-n}{n^{3}} \frac{1}{g D}
$$

The Forchheimer equation (Eq.3.3) is valid for stationary flow. Polubarinova Kochina (1952) added a time-dependent term. This type of formula for unsteady porous flow is referred to as the extended Forchheimer equation: 
$I=a u+b u|u|+c \frac{\partial u}{\partial t}$

where $c$ is a dimensional coefficient $\left(s^{2} / m\right)$. This formula can also be derived from the Navier-Stokes equation, using concepts like averaging techniques (e.g., Irmay, 1958; Van Gent, 1991). Irmay (1958) did not take the phenomenon added mass into account and therefore derived for $c$ the expression $c=1 / n g$.

To accelerate a given volume of water, momentum is needed. More momentum is needed to accelerate the same volume of water in a porous medium. This is called added mass because the extra momentum needed suggests that a larger volume of water has to be accelerated. Including the phenomenon added mass in the expression for the coefficient $c, \mathrm{Gu}$ and Wang (1991) and Van Gent (1991) derived the same type of expression theoretically:

$c=\frac{1+c_{A}}{n g}=\frac{1+\gamma \frac{1-n}{n}}{n g}$

where $\gamma$ is a non-dimensional coefficient that takes the phenomenon added mass into account.

The extended Forchheimer equations (Eq.3.5) cannot directly be used for flow through porous media with considerable large-scale convective transport. This can be included by an additional term:

$I=a u+b u|u|+c \frac{\partial u}{\partial t}+d u \frac{\partial u}{\partial x}$

where $d=1 / n^{2} g$. For porous media flow with a phreatic surface and a sloping impermeable bottom (with elevation $z_{c}$ ), the pressure gradient in the horizontal direction can be rewritten as (assuming hydrostatic pressures in the vertical direction):

$$
I=-\frac{1}{\rho g} \frac{\partial p}{\partial x}=-\frac{\partial\left(h-z_{c}\right)}{\partial x}
$$


Now, Equation 3.7 can be rewritten as:

$$
\frac{1+c_{A}}{n g} \frac{\partial u}{\partial t}+\frac{1}{n^{2} g} u \frac{\partial u}{\partial x}+\frac{\partial\left(h-z_{c}\right)}{\partial x}=-a u-b u|u|
$$

Using the continuity equation for the porous medium,

$$
\frac{\partial h}{\partial t}+\frac{1}{n} \frac{\partial h u}{\partial x}=0
$$

this Equation 3.9 can be rewritten as:

$$
\begin{aligned}
\left(1+c_{A}\right) \frac{\partial h u}{\partial t}-c_{A} u \frac{\partial h}{\partial t}+\frac{1}{n} \frac{\partial h u^{2}}{\partial x} & +n g h \frac{\partial\left(h-z_{c}\right)}{\partial x} \\
& =-n g h(a u+b u|u|)
\end{aligned}
$$

Equations 3.10 and 3.11 resemble the continuity equation and the finite-amplitude shallow-water wave equation (long-wave equation) for free surface wave motion as written in Equations 2.11 and 2.12. The numerical model discussed in Chapter 4 uses formulations of the type denoted in Equations 3.10 and 3.11 . Equation 3.11 can be derived directly from the Navier-Stokes equations with the same approach as discussed in Section 2.2.2. The Navier-Stokes equations can be adapted for direct use for porous media flow, see also Van Gent (1991). The equations for twodimensional incompressible flow with a constant fluid mass density through a homogeneous isotropic porous medium read:

$$
\begin{aligned}
\frac{1+c_{A}}{n g} \frac{\partial u}{\partial t}+\frac{1}{n^{2} g}\left(\frac{\partial u^{2}}{\partial x}+\frac{\partial u w}{\partial z}\right) & +\frac{1}{\rho g} \frac{\partial p}{\partial x}= \\
& -a u-b u \sqrt{\left(u^{2}+w^{2}\right)} \\
\frac{1+c_{A}}{n g} \frac{\partial w}{\partial t}+\frac{1}{n^{2} g}\left(\frac{\partial u w}{\partial x}+\frac{\partial w^{2}}{\partial z}\right) & +\frac{1}{\rho g} \frac{\partial p}{\partial z}= \\
& -a w-b w \sqrt{\left(u^{2}+w^{2}\right)}-g
\end{aligned}
$$


For the coefficients $a$ and $b$ the expressions denoted in Equations 3.2 and 3.4 can be used. However, the coefficients $\alpha$ and $\beta$ in the expressions for $a$ and $b$ respectively must be determined empirically from tests with sufficiently small convective terms. Otherwise the coefficients in the Forchheimer equation (Eq.3.3) and the adapted Navier-Stokes equations ( $E q .3 .12$ and $E q .3 .13)$ are not the same. The presence of a large convective term results in a higher value for the coefficient $b$ in the Forchheimer equation since the momentum needed to give the water this acceleration ends up in this quadratic term. A possible additional resistance, similar to the added mass resistance due to local acceleration, might occur due to convective acceleration. Such a phenomenon can easily be included in the Equations 3.12 and 3.13. However, in the measurements described in this chapter no convective term was present and therefore no conclusions can be drawn concerning this matter.

The expressions for $a$ and $b$ (Eq.3.2 and Eq.3.4) contain representative length-scales $D$. For granular material a characteristic stone diameter seems to be the most appropriate. It can be argued whether $D_{n I 5}, D_{n 50}$ or $D_{E Q}$ is the most appropriate characteristic length-scale for the porous medium. The equivalent sphere diameter $D_{E Q}$ is defined as $D_{E Q}=\left(6 M_{50} / \pi \rho_{a}\right)^{1 / 3}$ where $M_{50}$ is the average mass of a rock grading. The diameter $D_{n 15}$, can be seen as a representative scale for the size of the pores. On the other hand, $D_{E Q}$ can be used as a characteristic length-scale while the influence of grading (affecting the size of the pores) can be included separately in the expressions for $\alpha$ and $\beta$ (see Eq.3.2 and Eq.3.4). The diameter $D_{n s 0}$ is also a very common characteristic length-scale. In the measurements which will be described here, the values $\alpha$ and $\beta$, calculated with $D_{n / 5}, D_{n 50}$ and $D_{E Q}$ respectively will all be presented.

\subsection{Importance of inertia}

The extended Forchheimer equation (Eq.3.5) contains three contributions to the total resistance for flow through a porous medium, namely the resistance due to laminar and turbulent flow and the inertial resistance. Gu and Wang (1991) discussed the importance of these three components for a wide range of practical coastal wave conditions. A discussion using a similar approach is given below. 
The relative importance of resistance forces can be estimated by using two nondimensional parameters. The magnitude of the resistance due to turbulence relative to the laminar resistance is linear with the Reynolds-number, $R e$, defined as $U D / \nu$ where $\nu$ is the kinematic viscosity and $U$ is a characteristic velocity (for which the maximum pore velocity is taken). The magnitude of the resistance due to turbulence relative to the inertial resistance is linear with the Keulegan-Carpenter number, $K C$, defined as $U T / D$ where $T$ is the wave/oscillation period. The magnitude of the inertial resistance relative to the laminar resistance is linear with $\operatorname{Re} / K C=D^{2} / T \nu$.

Table 3.1 Dominant resistance components under coastal wave conditions.

\begin{tabular}{|c|c|c|c|c|c|}
\hline $\begin{array}{l}\text { Material } \\
\text { description }\end{array}$ & $D(m)$ & $U(\mathrm{~m} / \mathrm{s})$ & $\begin{array}{l}\text { Re } \\
(U D / \nu)\end{array}$ & $\begin{array}{l}R e / K C \\
\left(D^{2} / T \nu\right)\end{array}$ & $\begin{array}{l}\text { Dominant } \\
\text { resistance }\end{array}$ \\
\hline Sand & $O\left(10^{-3}\right)$ & $<O\left(10^{-3}\right)$ & $<O\left(10^{\circ}\right)$ & $<O\left(10^{\circ}\right)$ & Laminar \\
\hline $\begin{array}{l}\text { Pebbles } \\
\text { Fine gravel }\end{array}$ & $O\left(10^{-2}\right)$ & $O\left(10^{-2}\right)$ & $O\left(10^{2}\right)$ & $O\left(10^{2}\right)$ & $\begin{array}{l}\text { Laminar } \\
\text { Turbulence } \\
\text { Inertial }\end{array}$ \\
\hline $\begin{array}{l}\text { Coarse gravel } \\
\text { Crushed stone }\end{array}$ & $O\left(10^{-1}\right)$ & $O\left(10^{-1}\right)$ & $O\left(10^{4}\right)$ & $O\left(10^{4}\right)$ & $\begin{array}{l}\text { Turbulence } \\
\text { Inertial }\end{array}$ \\
\hline $\begin{array}{l}\text { Boulders } \\
\text { Crushed stone }\end{array}$ & $O\left(10^{\circ}\right)$ & $O\left(10^{\circ}\right)$ & $O\left(10^{\circ}\right)$ & $O\left(10^{\circ}\right)$ & $\begin{array}{l}\text { Turbulence } \\
\text { Inertial }\end{array}$ \\
\hline $\begin{array}{l}\text { Artificial blocks } \\
\text { Large rock }\end{array}$ & $O\left(10^{\circ}\right)$ & $>O\left(10^{\circ}\right)$ & $>O\left(10^{6}\right)$ & $>O\left(10^{6}\right)$ & $\begin{array}{l}\text { Turbulence } \\
\text { Inertial }\end{array}$ \\
\hline
\end{tabular}

* classification by Gu and Wang (1991), for standard classification of stones see PIANC (1972).

With the estimates $\alpha \sim O(1000), \beta \sim O(I)$ and $\gamma \sim O(1)$, where $\alpha, \beta$ and $\gamma$ are the coefficients in Equations 3.2, 3.4 and 3.6, the relative magnitude of the resistance forces can be estimated:

$$
\begin{aligned}
& \left|\frac{f_{I}}{f_{L}}\right|=\frac{\text { inertial resistance }}{\text { laminar resistance }} \sim 10^{-2} \frac{R e}{K C} \\
& \left|\frac{f_{T}}{f_{L}}\right|=\frac{\text { turbulence resistance }}{\text { laminar resistance }} \sim 10^{-2} R e \\
& \left|\frac{f_{T}}{f_{I}}\right|=\frac{\text { turbulence resistance }}{\text { inertial resistance }} \sim K C
\end{aligned}
$$


Table 3.1 and Figure 3.1, both derived from $\mathrm{Gu}$ and Wang (1991), give an illustration of the dominant resistance components under coastal wave conditions. Figure 3.1 shows regions with different dominant resistance components in relation to the above mentioned dimensionless parameters $K C$ and $R e$. Under coastal wave conditions porous flow through sand is dominated by laminar resistance (denoted with $f_{L}$ ). Inertial resistance $\left(f_{l}\right)$ and resistance due to turbulence $\left(f_{T}\right)$ are of minor importance $\left(f_{L} \gg f_{i} ; f_{L} \gg f_{T}\right)$. For porous flow inside gravel beaches and rubble-mound structures, however, inertial resistance and resistance due to turbulence cannot be neglected. In small-scale physical-model tests, none of the three resistance components can be neglected.

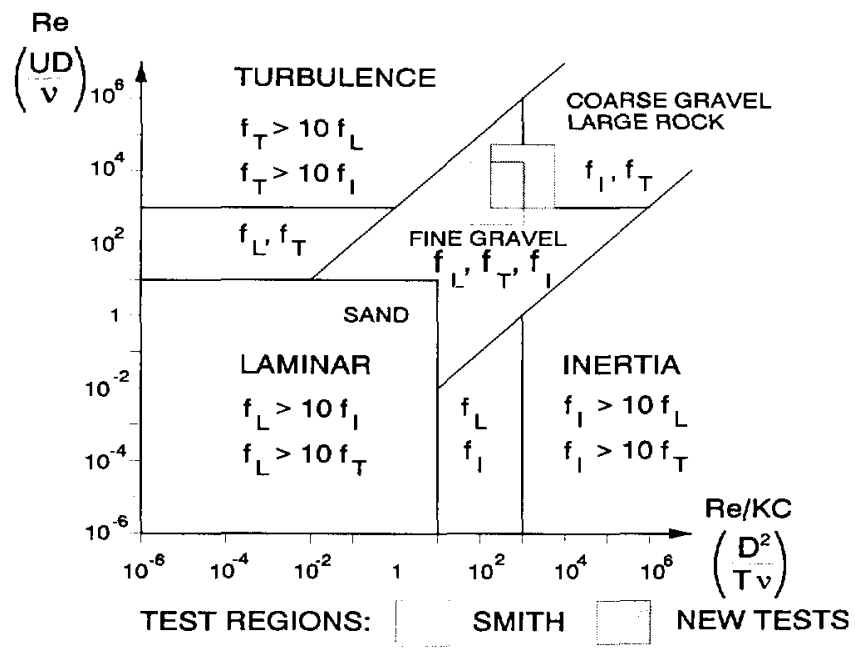

Fig.3.I Regions with different dominant resistances (laminar, turbulence and inertia) and the region where new oscillatory flow tests have been performed.

The friction coefficients in the linear (laminar) term $(a)$ and in the quadratic (turbulence) term $(b)$ from the Forchheimer equations were measured before in tests with stationary flow. A very limited number of measurements with oscillatory flow has been performed and reported. Available data were insufficient, however, to determine inertia coefficients systematically. Therefore, the coefficient in the inertia term $(c)$ needs to be studied. Furthermore, it must be verified whether a possible 
dependency of the coefficients $a$ and $b$ on parameters like the Re-number and the $K C$-number exists, see a discussion in Van Gent (1991).

Smith (1991) did experiments in an oscillating water tunnel through different arrangements of packing of spheres. Two sizes of spheres and two arrangements of the packing were tested with different amplitudes of the velocity and different oscillation periods. One sample of rock material was tested. Although his data-set was not sufficient to improve or extend existing porous media flow formulations, his experiments provided valuable experience which contributed a lot to the design of the set-up for new experiments to study both stationary and oscillatory flow through rubble-mound material.

New measurements were carried out, mainly to study the differences between stationary and non-stationary flow rather than to improve or extend the formulations for stationary porous media flow. It was supposed that relatively large differences between stationary and oscillatory flow could occur in a flow regime where inertia is relatively important compared to the contribution of turbulence. The experiments described here were done in the regime where the ratio of the contribution of inertia compared to the contribution of turbulence is larger than in the measurements by Smith (1991). The new tests were done with higher $R e$-numbers and with lower $K C$ numbers.

The magnitude of the dominant resistance components in the new tests, described in the following section, has been illustrated in Figure 3.1. The figure shows that none of the three resistance components can be neglected in the tested region. The figure shows the relevant areas for sand, fine gravel, coarse gravel and large rock under coastal wave conditions. It illustrates that the tested region is of importance for applications with coastal wave conditions.

\subsection{Permeability measurements}

\subsubsection{Description of the measurements}

In Van Gent (1993-a) the measurements, the test results and the analysis used to derive new expressions for porous media flow coefficients have been described in detail. In the following, a summary of these activities is given. The measurements 
were performed in the oscillating water tunnel of Delft Hydraulics within the framework of the European MAST-G6s research project.

\section{Experimental set-up}

The tests were performed in an oscillating water tunnel having the shape of a Utube. In the horizontal section of the U-tube, $15 \mathrm{~m}$ long and $0.30 \mathrm{~m}$ wide, a box $(l=0.75 \mathrm{~m} ; h=0.50 \mathrm{~m} ; b=0.30 \mathrm{~m})$ containing porous material was placed, see Figure 3.2. To obtain a sufficiently large flow rate through the samples, the cross-section of the horizontal section of the U-tube was reduced. To obtain this, an additional bottom was placed $0.30 \mathrm{~m}$ above the permanent bottom of the tunnel and a slope was created on both sides of the test section.

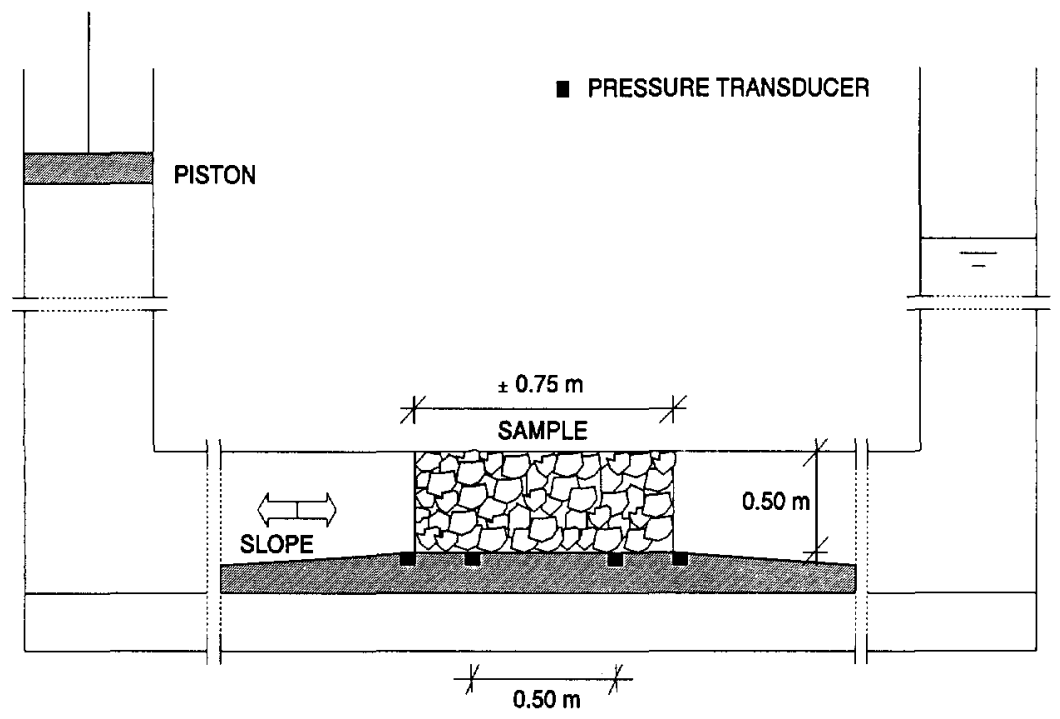

Fig.3.2 Experimental set-up.

A piston positioned at one of the shafts produced oscillating water movements. Various combinations of amplitudes and oscillation periods could be generated. The piston movement was recorded (both the control signal and the actual signal). This made possible the assessment of the filter velocities through the sample. These 
velocities were checked with a Laser-Doppler Velocity meter (LDV) positioned above the slope and outside the range of the water particles moving through the sample. Although the control signal that was used for the oscillatory flow tests was sinusoidal, it appeared that the actual displacement was not exactly the same. For each oscillation period the stroke of the piston was increased in steps of about $1 \%$ of the maximum stroke of the piston $(\approx 1.50 \mathrm{~m})$. The step-wise increase in stroke was continued till the moment the maximum pressure of the tunnel was reached. The average maximum piston movement was about $10 \%$ of the maximum stroke of the piston which corresponded to a maximum velocity of about $0.5 \mathrm{~m} / \mathrm{s}$ near the sample. This indicates that the tests were carried out in the lower range of the possible piston displacement which led to relatively large deviations from a sinusoidal motion of the piston at the points where the piston changes direction.

A stationary flow can be produced in the tunnel with a flow rate up to $0.10 \mathrm{~m}^{3} / \mathrm{s}$. After positioning of the sample in the tunnel a large flow discharge was imposed on the sample such that air bubbles were removed. The actual test-runs started with a constant flow of $0.01 \mathrm{~m}^{3} / \mathrm{s}$. The flow rate was increased in steps of $0.01 \mathrm{~m}^{3} / \mathrm{s}$ up to a maximum $0.10 \mathrm{~m}^{3} / \mathrm{s}$.

At the bottom of the box pressure transducers and differential pressure transducers were installed, both inside the box and just outside. The distance between the transducers inside the box was $0.50 \mathrm{~m}$. The distance between the transducers installed outside the box was $0.8 \mathrm{~m}$. For the stationary flow tests the flow rate generated by the pump was measured (both the control and the actual flow rate) and checked with the LDV-equipment. All signals were recorded during one minute with a sampling frequency of $100 \mathrm{~Hz}$.

To reduce wall effects halves of spheres of roughly the same size as the tested rock material were glued to the vertical sides of the box containing the samples of rock material, see Figure 3.3. Although wall effects were reduced, the filter velocities were multiplied by a factor, for which 0.95 was assumed to be a realistic value, to account for the remaining wall effects. The velocities measured from the piston and the measured velocities near the sample differed slightly due to leakage below the additional bottom. This has been taken into account by using an estimate of the leakage. This estimate was based on measurements with the LDV-equipment in the cross-section both above and below the additional bottom, see for details Van Gent (1993-a). 


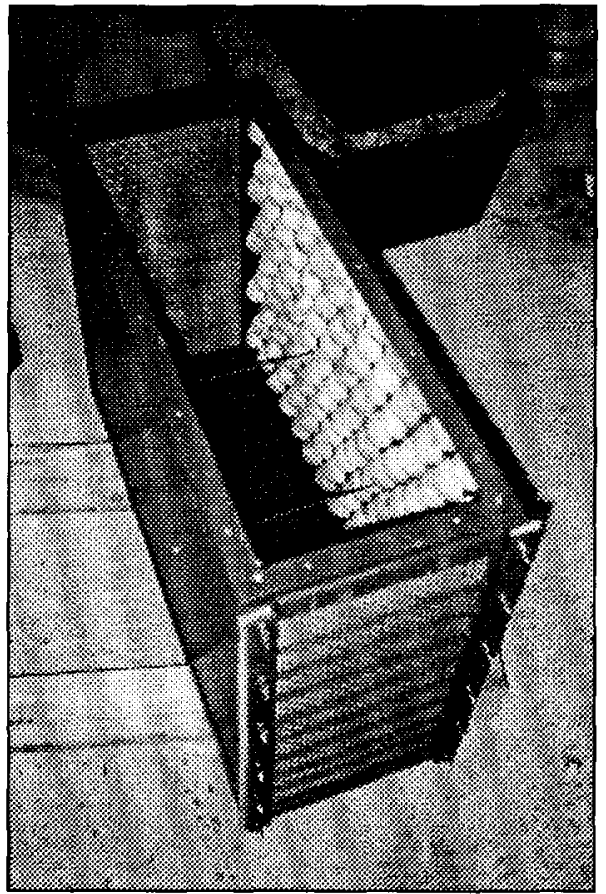

Fig.3.3 Reduction of wall effects.

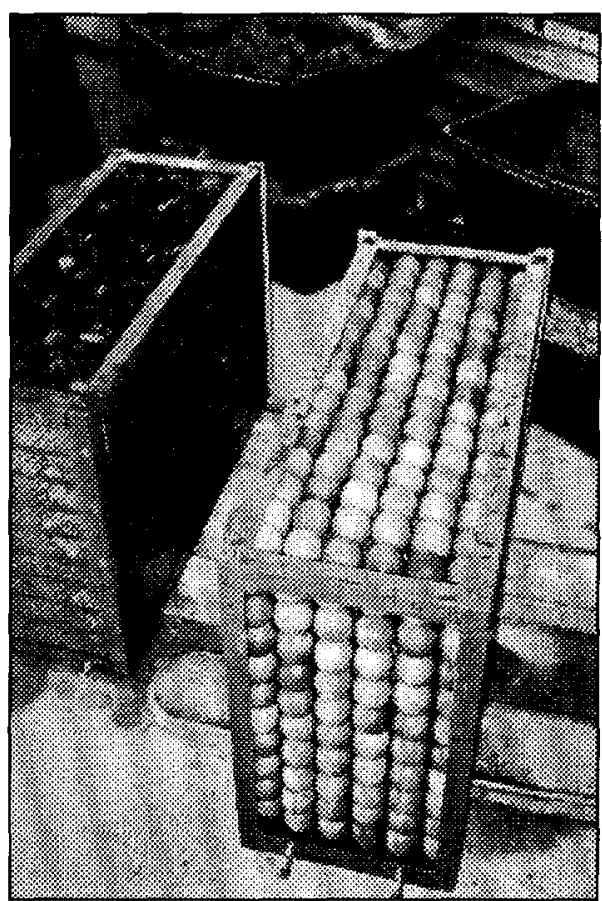

Fig.3.4 Sample with spheres.

\section{Tested material}

Five samples of various types of stones were tested. Their relevant properties are given in Table 3.2. Test materials denoted with $R I, R 3$ and $R 4$ were provided by Hydraulic Research, Wallingford (U.K.). Test material $R 3$ was obtained from material $R l$ which was rounded by abrasion in a cement mixer to get a 5 to $10 \%$ weight loss. $R 4$ was obtained from material $R I$ and rounded to get a 20 to $25 \%$ weight loss. A full description is given by Bradbury et al. (1988). Material $R 8$ was used as core material in tests at Hannover, see Ouméraci (1991). Apart from the five samples of stones, a sample of wooden spheres in a cubic packing arrangement was tested, see Figure 3.4.

The porosity $n$ was assessed by weighing the stone sample in a box with a volume equal to the box placed in the oscillating water tunnel. The volume of the stones 
was found by division by the stone density. The porosity of the sample of spheres was derived theoretically. Because the wooden spheres expand in water, the actual porosity could have been slightly lower. The aspect ratio $l / t$ is defined as the average length of the longest axis of the stones $(l)$ divided by the minimum length perpendicular to this axis $(t)$. The rock samples were compacted before testing so that no compaction could take place during execution of the tests.

Table 3.2 Description of tested material

\begin{tabular}{llcccccc}
\hline Code & Material & $D_{n I 5}(m)$ & $D_{n 50}(m)$ & $D_{E Q}(m)$ & $D_{n 85} / D_{n 15}$ & $l / t$ & $n$ \\
\hline$R 1$ & Irregular rock & 0.0525 & 0.0610 & 0.0760 & 1.27 & 1.9 & 0.442 \\
$R 3$ & Semi round rock & 0.0419 & 0.0487 & 0.0607 & 1.27 & 2.0 & 0.454 \\
$R 4$ & Very round rock & 0.0425 & 0.0488 & 0.0606 & 1.26 & 2.2 & 0.393 \\
$R 5$ & Irregular rock & 0.0170 & 0.0202 & 0.0251 & 1.03 & 2.3 & 0.449 \\
$R 8$ & Irregular rock & 0.0230 & 0.0310 & 0.0385 & 1.74 & 2.0 & 0.388 \\
$S 1$ & Spheres & 0.0460 & 0.0460 & 0.0460 & 1.0 & 1.0 & 0.476 \\
\hline
\end{tabular}

The number of samples is not sufficient for a full parameter study. Parameters such as porosity, diameter, grading, aspect ratio and shape (gross shape, roughness and surface texture) are varied. Since the number of samples is rather limited and many parameters are varied, formulations for the friction coefficients (Eq.3.2 and Eq.3.4) cannot be extended to include parameters like grading and aspect ratio. However, the results can be compared with existing formulae.

\subsubsection{Stationary flow tests}

The coefficients $a$ and $b$ from the Forchheimer equation (Eq.3.3) could be derived by using the measured pressure gradients and measured filter velocities and applying linear regression analysis. Assuming that the coefficients are constant for the tested range, a plot $I / u$ versus $u$ would give a straight line. $I$ is the measured hydraulic gradient and $u$ is the calculated filter velocity derived from the piston displacement. Extrapolation of the lines in Figure 3.5 gives the $a$-values at the vertical axis. The $b$-values can be derived from the slopes of the lines. 


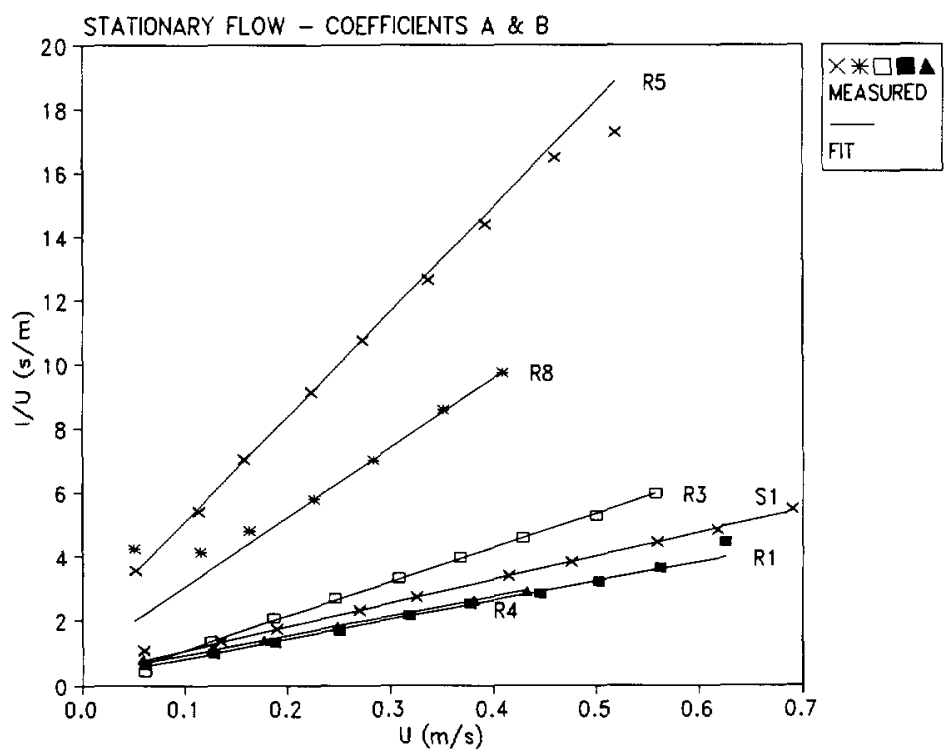

Fig.3.5 Data points from stationary flow tests and fits to the Forchheimer equation (eq.3.3).

It appears that the assumption that the $a$ and $b$ values for a particular sample are constant within the tested range, is correct since the measured data correspond fairly well with the fitted line except for the two lowest measuring points with sample $R 8$ and the highest point from sample $R 5$ (excluded from further analysis). One data point from sample $R 4$ has also been excluded since it was assumed that this point was caused by an error in the data-acquisition or by failure of the equipment. All other data points, resulting in rather straight lines, do not indicate that the validity of the Forchheimer equation (prescribing straight lines in Figure 3.5) should be questioned. Therefore, the divergent points from the samples $R 4, R 5$ and $R 8$ have not been included in the further analysis.

Table 3.3 shows results of the stationary flow tests. The coefficients $a$ and $b$ from the Forchheimer equation (Eq.3.3) are given as well as their standard deviation (std). The values of $\alpha$ and $\beta$ from Equation 3.2 and 3.4 were calculated, using three characteristic length scales for $D: D_{n 15}, D_{n 50}$ and the equivalent sphere diameter $D_{E Q}$. 
Table 3.3 Results stationary flow tests ${ }^{l}$.

\begin{tabular}{lllrrrrrrrr}
\hline Sample & $a$ & std $a$ & $\alpha-D_{n i s}$ & $\alpha-D_{n 50}$ & $\alpha-D_{E Q}$ & $b$ & std $b$ & $\beta-D_{n j s}$ & $\beta-D_{n s 0}$ & $\beta-D_{E Q}$ \\
\hline$R 1$ & 0.23 & 0.037 & 1327 & 1791 & 2780 & 6.0 & 0.076 & 0.48 & 0.55 & 0.69 \\
$R 3$ & 0.00 & 0.016 & 0 & 0 & 0 & 10.7 & 0.05 & 0.75 & 0.88 & 1.09 \\
$R 4$ & 0.34 & 0.015 & 808 & 1066 & 1644 & 6.0 & 0.06 & 0.25 & 0.29 & 0.36 \\
$R 5$ & 1.81 & 0.093 & 1204 & 1662 & 2566 & 32.8 & 0.75 & 0.91 & 1.07 & 1.33 \\
$R 8$ & 0.89 & 0.055 & 554 & 1007 & 1552 & 21.7 & 0.4 & 0.47 & 0.63 & 0.78 \\
$S 1$ & 0.33 & 0.023 & 2070 & 2070 & 2070 & 7.4 & 0.16 & 0.69 & 0.69 & 0.69 \\
\hline
\end{tabular}

Table 3.4 Ranges in oscillatory flow tests.

\begin{tabular}{lccccc}
\hline Sample & $\hat{U}(\mathrm{~m} / \mathrm{s})$ & $T(\mathrm{~s})$ & $R e$ & $K C$ & $A c$ \\
\hline$R I$ & $0.13-0.50$ & $2-4$ & $15000-66000$ & $8-60$ & $0.007-0.049$ \\
$R 3$ & $0.12-0.45$ & $2-4$ & $12000-46000$ & $8-65$ & $0.007-0.033$ \\
$R 4$ & $0.12-0.49$ & $2-4$ & $16000-58000$ & $11-82$ & $0.007-0.058$ \\
$R 5$ & $0.05-0.25$ & $2-4$ & $2000-10000$ & $9-88$ & $0.003-0.022$ \\
$R 8$ & $0.09-0.34$ & $2-4$ & $6000-25000$ & $13-91$ & $0.007-0.036$ \\
$S 1$ & $0.07-0.51$ & $2-4$ & $5000-38000$ & $6-93$ & $0.007-0.052$ \\
\hline
\end{tabular}

Table 3.5 Results oscillatory flow tests ${ }^{l}$.

\begin{tabular}{lrrrrrrrrrr}
\hline Sample & $b($ stat $)$ & $b$ & std $b$ & $b$ (range) & $c$ & std $c$ & $c($ range $)$ & $\gamma$ & std $\gamma$ & $\gamma($ range $)$ \\
\hline$R 1$ & 6.0 & 8.5 & 1.23 & $7.2-11.5$ & 0.21 & 0.14 & $0-0.40$ & 0.41 & 0.13 & $0.24-0.58$ \\
$R 3$ & 10.7 & 13.6 & 2.02 & $12-17$ & 0.27 & 0.14 & $0-0.45$ & 0.42 & 0.21 & $0.09-0.83$ \\
$R 4$ & 6.0 & 9.2 & 0.84 & $8.1-12$ & 0.30 & 0.14 & $0-0.45$ & 0.32 & 0.13 & $0.10-0.48$ \\
$R 5$ & 32.8 & 35 & 5.23 & $31-50$ & 0.12 & 0.16 & $0-0.40$ & 0.33 & 0.24 & $0.08-0.62$ \\
$R 8$ & 21.7 & 23 & 1.80 & $21-28$ & 0.31 & 0.14 & $0-0.45$ & 0.30 & 0.12 & $0.09-0.45$ \\
$S 1$ & 7.4 & 9.3 & 3.34 & $6-21$ & 0.15 & 0.13 & $0-0.30$ & 0.27 & 0.10 & $0.15-0.36$ \\
\hline
\end{tabular}

${ }_{1} a$ in $\mathrm{s} / \mathrm{m} ; b$ in $\mathrm{s}^{2} / \mathrm{m}^{2} ; c$ in $\mathrm{s}^{2} / m ; \alpha-D_{n / S}$ denotes the $\alpha$-value calculated with $D_{n / 5}$ for $D ; b($ stat $)$ is the $b$-coefficient from the stationary flow tests; std denotes the standard deviation. 
Smith (1991) found values for $\alpha$ and $\beta$, with $D_{E Q}$ as characteristic length-scales, between 437-3752 and 0.36-1.06 respectively. In the present tests, these ranges were $0-2780$ and $0.36-1.33$ respectively. The comparison of these results shows that neither of these ranges is substantially divergent. Both test series also clearly indicate that the coefficients $\alpha$ and $\beta$ (Eq.3.2 and Eq.3.4) are not constant for all samples. Other expressions for $a$ and $b$ than those used in Equations 3.2 and 3.4 exist. For instance Engelund (1953), Koenders (1985) and Den Adel (1987) gave expressions with different powers for the porosity. They also prescribe constant values for $\alpha$ and $\beta$. This consequently leads to considerable differences between the values predicted by these equations and the values actually measured for $a$ and $b$ for each sample. These expressions, however, also considerably overestimate the average $b$-values of all samples, see van Gent (1993-a).

The coefficients $\alpha$ and $\beta$ are not constant for all samples. This implies that the expressions for $a$ and $b$ (Eq.3.2 and Eq.3.4) are over-simplified. Probably parameters such as grading, aspect ratio and shape (gross shape, roughness and surface texture) still have to be implemented in the expressions. Furthermore, the orientation of stones with respect to the mean flow direction may play a role. For a free-falling stone, the longest axis is more likely to orientate horizontally while the smallest axis of the stone is more likely to orientate in the vertical direction, see Figure 3.6, as a result of which the porous medium is not isotropic. This can, however, be implemented in two-dimensional porous media flow equations ( $E q .3 .12$ and Eq.3.13) by prescribing different coefficient $a$ and $b$ in the two directions.

Based on comparisons between measurements by several authors, in Van Gent (1993-a) a simple implementation of the influence of the orientation of stones with respect to the mean-flow direction is proposed: $\beta$ in Equation 3.4 can be replaced by $\beta_{0}(l / t)^{0.5 \cdot \tan \left(\psi^{-4}-4^{\circ}\right)}$ where $l / t$ is the aspect ration and $\psi$ the minimum angle between the direction of the mean flow and the direction of the longest axis of the stones. Although the third dimension must be regarded as well, in Figure 3.6 the situation with a horizontal mean-flow direction $\left(A, \psi=0^{\circ}\right)$ is supposed to give less resistance than for a situation where this flow is vertical $\left(B, \psi=90^{\circ}\right)$. The proposed formula, however, cannot be verified with the present measurements. For flow conditions in which the direction of the mean flow is not known beforehand, based on the measurements the use of 1.1 as an average value for $\beta_{\theta}$ (assuming an average of $\psi=45^{\circ}$ and using $D_{n 50}$ for $D$ in Eq.3.4) can be advised. 


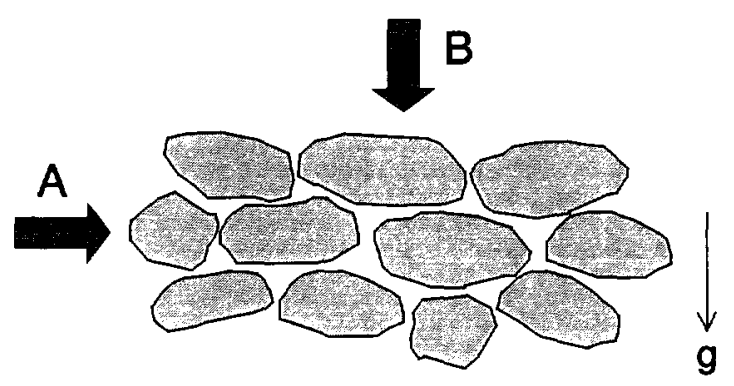

Fig.3.6 Orientation of stones in relation to the direction of the mean flow.

\subsubsection{Oscillatory flow tests}

The oscillatory flow tests were performed for relatively high Reynolds-numbers and for low Keulegan-Carpenter numbers. The ranges of some relevant parameters for the oscillatory flow tests are listed in Table 3.4. Note that in both the Re-number and in the $K C$-number the maximum pore velocity $(\hat{U} / n)$ is taken as the representative velocity. As a measure for the accelerations in the porous medium the non-dimensional $A c$-number is introduced here and defined as $A c=\hat{U} /(n T g)$. Three oscillation periods were used: 2,3 and $4 \mathrm{~s}$. Maximum filter velocities $\hat{U}$ up to 0.50 $\mathrm{m} / \mathrm{s}$ were used.

Deviations near the zero-crossings of the velocity signal occurred due to testing in the lower range of the capacity of the piston displacement. The $c$-term amplifies deviations from a smooth velocity signal. This made it impossible to separate the contributions of the $a$ and $b$-terms to the complete signal of the pressure gradient for each test run individually. Therefore, the assumption was made that the values for the coefficients $a$ are equal to those measured in the stationary flow tests. As will be shown later, the results of the oscillatory tests indicate that the term $a \cdot u+b \cdot u \cdot|u|$ for oscillatory flow conditions is larger than for stationary flow. The difference is assumed to be caused by a higher $b$-value (contribution of turbulence) rather than by a higher $a$-value (laminar contribution). It can be expected that unlike a stationary flow, an oscillatory movement of the fluid causes extra turbulence rather than extra laminar flow. This indicates that it is more likely that for 
oscillatory flow the $b$-values are higher than that the $a$-values are higher. It might also be that the $a$-value becomes lower and that the $b$-value increases for oscillatory flow. The term $a \cdot u+b \cdot u \cdot|u|$ also increased in oscillatory flow tests with one of the samples where the $a$-value was zero in the stationary flow tests. Since it is supposed that $a$-values do not become negative, it is assumed that $a$-values do not become lower in an oscillatory wave motion.

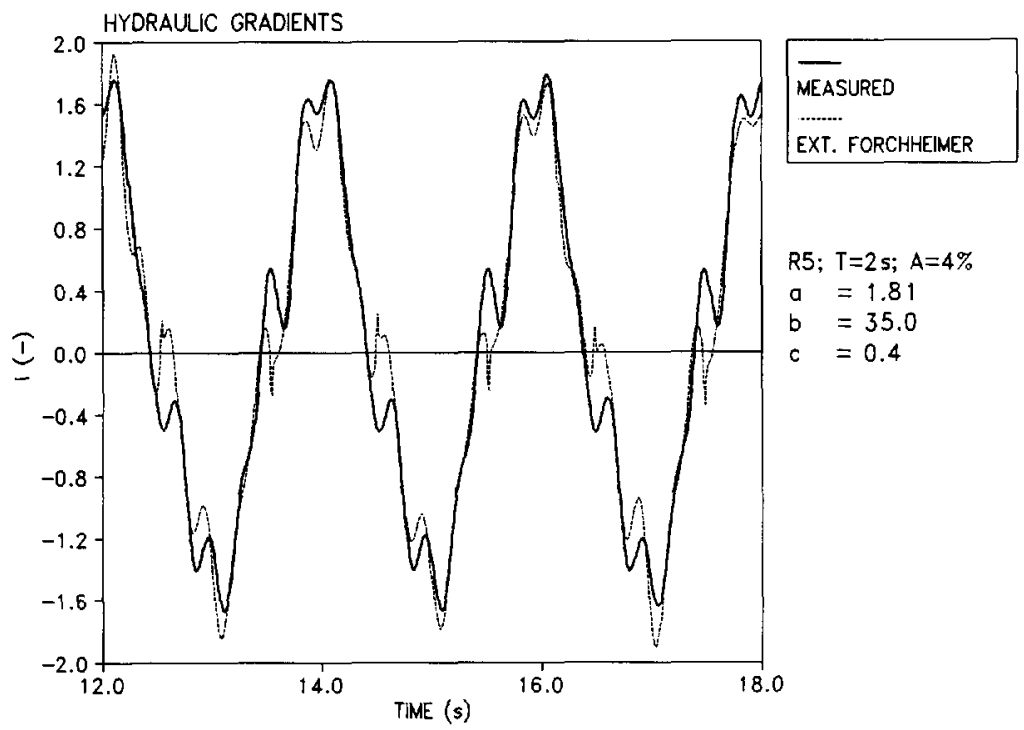

Fig.3.7 Measured hydraulic gradient (I) and fit to the extended Forchheimer equation (eq.3.5).

The $b$ and $c$ coefficients were determined by using a graphical approach; comparisons were made between the signal from the measured pressure gradient $I$ and the calculated signal obtained by using the extended Forchheimer equation (Eq.3.5). The term $c \cdot \partial u / \partial t$ is supposed to be zero at the peak of the velocity signal $(u=\hat{U})$. Therefore, the term $a \cdot u+b \cdot u \cdot|u|$ could be determined from these maximum velocities. The $c$-term is relatively important around the zero-crossings of the velocity signals $(u \ll \hat{U}$ ); the $c$-coefficients could be determined by fitting the extended Forchheimer equation to the measured signal near the zero-crossings. Despite the complicated way used to derive the $c$-coefficients it is estimated that, 
based on the observed influence of variations of these values, this approach does not give errors larger than roughly $10 \%$.

Figure 3.7 shows an example of measured pressure gradients from a test with rock sample $R 5$ with an oscillation period of $2 s$ and a maximum filter velocity of $\hat{U}=0.20 \mathrm{~m} / \mathrm{s}$. The fit to the extended Forchheimer equation is shown as well.

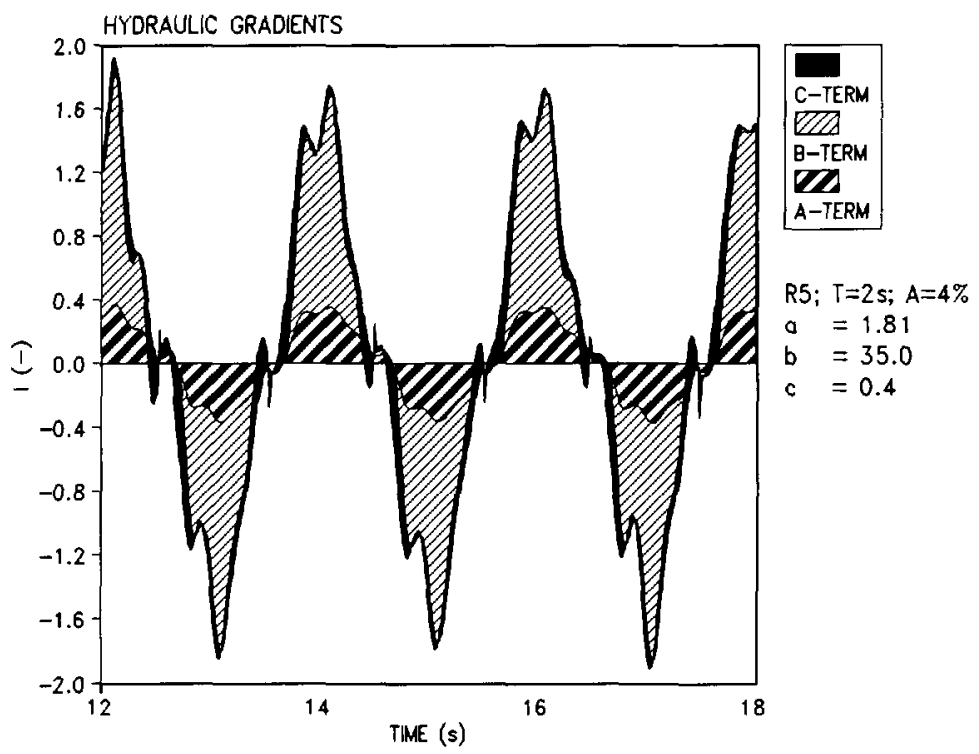

Fig.3.8 Contribution of each term to a signal from the extended Forchheimer equation (eq.3.5).

In Table 3.5, the results of the oscillatory flow tests have been summarised. For comparison, the $b$-values from the stationary flow tests have also been listed ( $b$ stat). The $b$-values from the oscillatory flow tests are higher. The $b$ and $c$-values show large standard deviations. However, as will be shown in the following subsection, these deviations are systematic rather than random. For the tests with small amplitudes of the velocities (small $\hat{U}$ ), the term with the $c$-coefficients (Eq.3.5) did not contribute to a distinctly better representation of the measured hydraulic gradient. Therefore, the corresponding $c$-values were set at zero. These values, of which the accuracy is very low, have not been used to determine the corresponding 
added mass coefficients $\gamma$, see Table 3.5 and Equation 3.6 (they would lead to negative added mass coefficients).

Smith (1991) found $c$-values in the range $0.13-1.3$ with an average of 0.36 . Here, $c$-values were found between 0 and 0.45 , with an average of 0.23 . His corresponding $\gamma$-values, neglecting the negative values, were between 0 and 1.10 with an average of 0.29 and a standard deviation of 0.24 . Here, values for $\gamma$ between 0.08 and 0.83 were found, with an average of 0.34 and a standard deviation of 0.17 .

In Figure 3.8, the contributions of the $a, b$ and $c$-terms to the complete signal from the test shown in Figure 3.7 are illustrated. The figure shows that the contribution of the $c$-term is rather limited. Even for a test with a relatively high $c$-value $(c=0.4)$, the contribution of the $c$-term is only of relative importance in a small part of the oscillation period, i.e., near the zero-crossings.

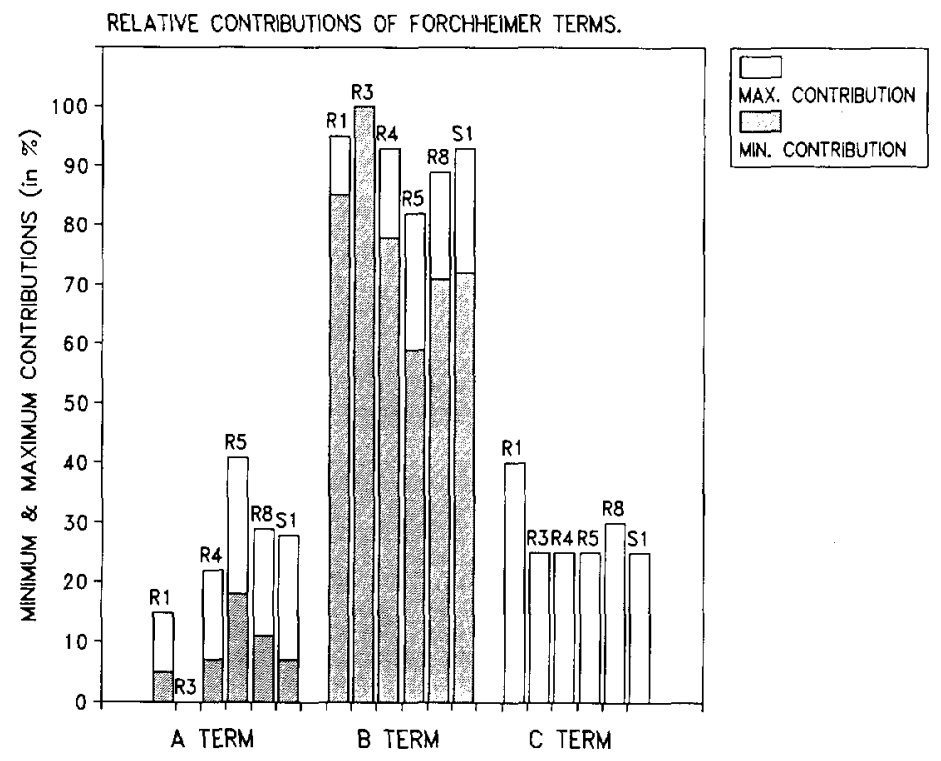

Fig.3.9 Contributions of each term from the extended Forchheimer equation (eq.3.5). 
For each sample the contributions of the three terms from the extended Forchheimer equation (Eq.3.5) are calculated with respect to the maximum hydraulic gradient $\left(I_{M a x}\right)$, see Figure 3.9. The ratio of $a \cdot \hat{U}$ and $I_{\text {Max }}$ varied between 0 and 0.41 . The term with coefficient $b$ is the largest for all samples; the ratio of $b \cdot \hat{U} \cdot|\hat{U}|$ and $I_{M a x}$ varied between 0.59 and 1.00 . The contribution of the term with coefficient $c$ reached its maximum just after the zero-crossings. At that point, the contribution of $(c \cdot d u d t)_{M a x}$ reached its maximum of $40 \%$ of $I_{M a x}$ for some tests with sample $R l$. It may look as if the influence of the $a$-term is of the same order of magnitude as the contribution of the $c$-term. However, the part of signal in which the contribution of the $c$-term is relatively large, is small.

\subsubsection{Expressions for friction coefficients}

The measurements showed that oscillatory flow conditions lead to higher values for the friction coefficients $b$ than under stationary flow conditions, especially for the relatively low $K C$-numbers. Figure 3.10 shows this dependency for the tests with the rock samples. The expression for the friction coefficient $b$ contains the nondimensional coefficient $\beta$, see Equation 3.4. Here, this coefficient is divided into the stationary flow contribution $\beta_{c}$ and an extra resistance $\beta^{\prime}$ in the case of an oscillatory wave motion. In Figure 3.11 this extra resistance is shown as function of the Keulegan-Carpenter number defined as $K C=\hat{U} T /\left(n D_{n 50}\right)$.

A dependency of the friction coefficients on the $K C$-number was found for the resistance of a single cylinder in an oscillatory flow by Keulegan and Carpenter (1958). They found that the drag coefficient increases with lower $K C$-numbers while the inertia coefficient increases with higher $K C$-numbers. Here, the same conclusion was found for the drag (quadratic) coefficient but the inertia coefficient seems to increase with the $A c$-parameter rather than with the $K C$-number. Boundary layers, and possibly small eddies, will be destroyed if the flow direction changes. This destruction of the boundary layers requires extra momentum. The destruction of these boundary layers will be greater if the inertia term, relative to the turbulence term, is larger. This is inversely proportional to the $K C$-number, since the $K C$ number can be seen as the ratio between the influence of the turbulence term and the influence of inertia. Boundary layers are not developed instantaneously. This causes a kind of history effect in the friction term; the friction at a specific point of time is not directly dependent on the momentary velocity at that time. To account 
for this phenomenon, a characteristic velocity of the flow field is more useful than the momentary velocity. Therefore, this phenomenon can be implemented by taking the maximum bulk/filter velocity $\hat{U}$ for the characteristic velocity in the $K C$-number. The dependency of the Forchheimer friction coefficient $b$ on the $K C$-number has been incorporated in the expression:

$$
b=\beta_{\varepsilon}\left(1+\frac{7.5}{K C}\right) \frac{1-n}{n^{3}} \frac{1}{g D_{n 50}} \quad \text { where } \quad K C=\frac{\hat{U} T}{n D_{n 50}}
$$

Smith (1991) did a relatively small number of tests in a range with low $K C$ numbers. This might explain why he did not find a dependency on this parameter although it might also be that for smooth spheres this dependency on the $K C$ number is weaker than for flow through stone samples. This could not been verified by using the present tests because only one sample of spheres was tested.

The inertia term from the extended Forchheimer equation has also been analysed. Again a dependency on the flow field was found although much weaker than the dependency of the $b$-values on the $K C$-number. The $c$-values seem to depend on the acceleration parameter $A c=\hat{U} / n T g$. It has been incorporated in the expression for the added mass coefficient $\gamma$, see Equations 3.16. Because the importance of the whole inertia term is small, see Figures 3.8 and 3.9, this dependency on the $A c$-number is not as important as the dependency of the coefficient $b$ on the $K C$-number. For reasons of simplicity, one may decide to neglect the complex dependency of the coefficient $c$ on the flow field and use a constant value for $\gamma$ of 0.34 , a value which is rather close to the value found by Smith (1991), i.e., 0.29.

$$
\begin{aligned}
& a=\alpha \frac{(1-n)^{2}}{n^{3}} \frac{v}{g D_{n 50}^{2}} \\
& b=\beta_{c}\left(1+\frac{7.5}{K C}\right) \frac{1-n}{n^{3}} \frac{1}{g D_{n 50}} \text { where } K C=\frac{\hat{U} T}{n D_{n 50}} \\
& c=\frac{1+\gamma \frac{1-n}{n}}{n g} \text { where } \gamma=0.85-\frac{0.015}{A c} \text { and } A c=\frac{\hat{U}}{n g T}>\frac{0.015}{\frac{n}{1-n}+0.85}
\end{aligned}
$$




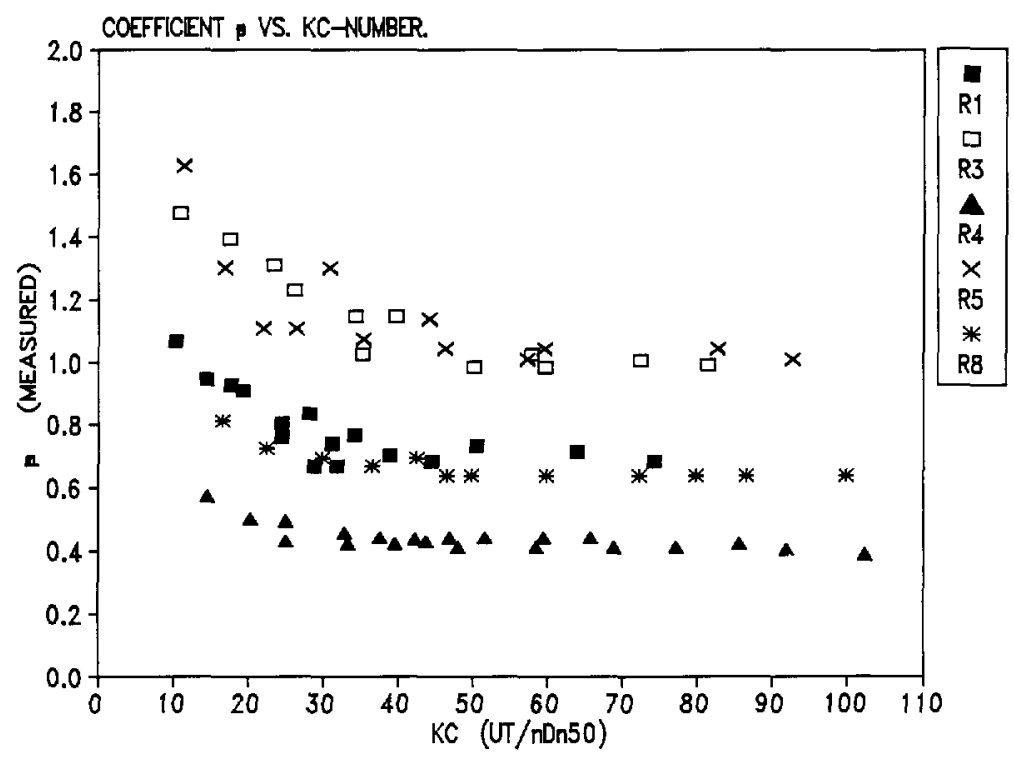

Fig.3.10 Friction coefficient $\beta$ as a function of the KC-number.

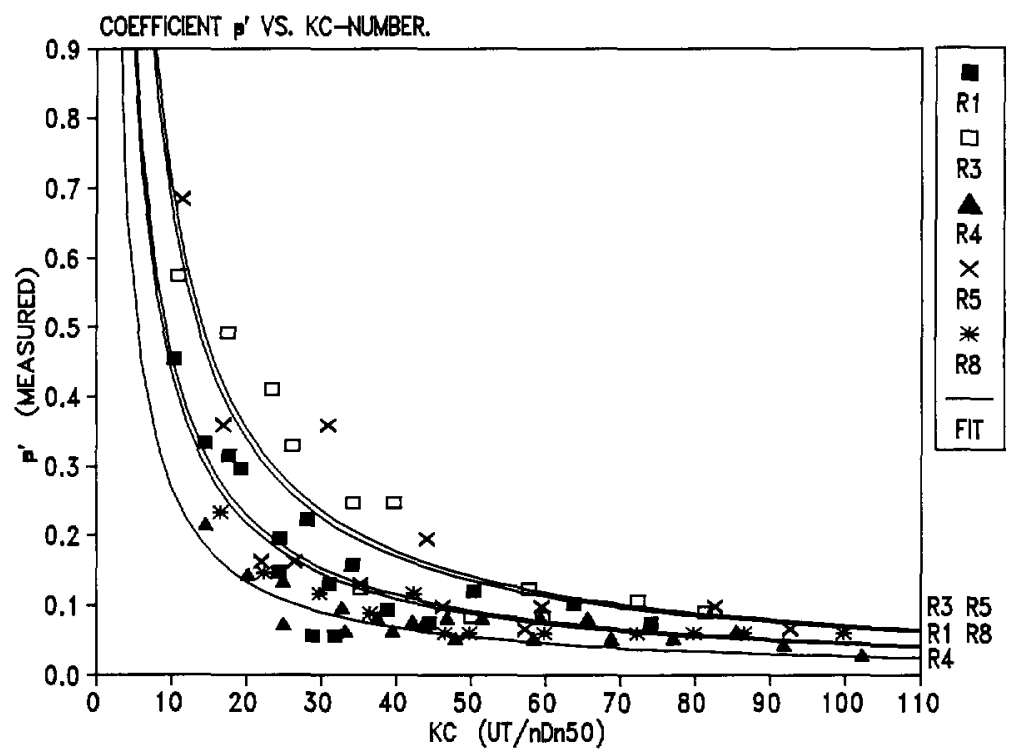

Fig.3.11 Friction coefficient $\beta^{\prime}$ as a function of the KC-number (with fits to eq.3.15). 
Equation 3.16 shows the expressions for the coefficients $a, b$ and $c$. Although the coefficients $\alpha$ and $\beta_{c}$ may still depend on parameters like grading, shape, aspect ratio or the orientation of the stones, the values 1000 and 1.1 can be used for $\alpha$ and $\beta_{c}$ respectively if for the characteristic length-scale the $D_{n 50}$ is used. Replacing the $D_{n 50}$ by the $D_{E Q}$ gives for these values 1500 and 1.4 respectively while the coefficient 7.5 in Equations 3.15 and 3.16 must be replaced by 5.9. The expressions for $a, b$ and $\gamma$ in Equation 3.16 (with $c_{A}=\gamma \cdot(1-n) / n$ ) can also be used in the Equations 3.113.13 .

\subsection{Scale effects}

Many small-scale physical models are used to study wave motion on coastal structures containing permeable parts, e.g., rubble-mound structures. The schematisation of the permeable part easily introduces scale effects, see for a discussion for instance Cohen de Lara (1955) or Le Méhauté $(1957,1958)$. The stones in the cover layer are usually scaled with the model factor, the length-scale factor $\lambda_{s}$ between the prototype structure and the small-scale model, to represent the stability of the stones correctly. Applying this scale factor for the stones results in an acceptable representation of the non-linear friction for porous media flow ( $E q .3 .4$ or $E q .3 .15)$. However, this scale factor is not applicable to scale the linear friction (Eq.3.2). Applying the same scale factor leads to a too high friction in the smallscale model. This aspect is of minor importance if the linear contribution can be neglected with respect to the quadratic friction term $(a \cdot u \ll b \cdot u \cdot|u|)$. However, this is usually not the case in small-scale model tests. This discrepancy can be partially solved by scaling the core material by a different factor, leading to larger corematerial although this introduces other scale effects on the friction between the cover and core material and the behaviour of granular filters. If both the linear and the quadratic friction are significant, one can use a different scale factor to represent the total resistance $(a \cdot u+b \cdot u \cdot|u|)$ optimally. However, the relative contributions of the linear and quadratic terms depend on the flow field which varies not only in the structure itself, but also for each wave condition. To assess characteristic velocities inside the permeable structure for the complete test series, one can apply numerical models able to model this internal flow field. 


\subsection{Conclusions}

Formulations for porous media flow have been derived for implementation in the numerical models described in the subsequent two chapters. To contribute to the study of porous media flow unconventional measurements were performed, described and analysed. The measurements, performed in a U-tube tunnel showed differences between stationary and oscillatory flow conditions. For flow regimes where inertia is important (low Keulegan-Carpenter numbers), the friction is greater than under stationary flow conditions. The differences between stationary and oscillatory flow depend on the Keulegan-Carpenter number which means that the resistance depends on the flow-field. Inertia coefficients have also been determined. The contribution of the inertial resistance is smaller than the two other resistance components, namely the laminar friction and the friction due to turbulence. The analysis of the test results has led to new expressions for porous media flow friction-coefficients where effects of non-stationary flow have been incorporated. 


\section{Chapter 4}

\section{Numerical simulation of wave attack by a 1D model}

\subsection{Introduction}

In Chapter 2 formulations for numerical simulation of normally incident waves on coastal structures are discussed. Numerous numerical models have been developed based on the finite-amplitude shallow-water wave equations of which those by Hibberd and Peregrine (1979) and the subsequent model by Kobayashi et al. (1987) can be seen as a basis for further developments. In this chapter a numerical model that can be seen as an extension of those two models will be presented. It is not only applicable to a wider range of impermeable structures but also for permeable structures. The derivation of the formulations for the external wave motion is discussed in Section 2.2.2 and those for the porous media flow in Section 3.2. Parts of the research treated in this chapter are more specifically described in Van Gent (1992, 1994-a). Here, typical aspects of the numerical model will be treated with special emphasis on the coupling of the external wave motion and the internal porous media flow. The validation of the numerical model is also discussed. In Chapter 6 additional verification tests are presented. Furthermore, some applications of the numerical model, named odifLOCS (One DImensional FLOw on and in Coastal Structures), are presented.

\subsection{Model composition and basic equations}

\subsubsection{General model composition}

A combined model with interaction between the external and internal wave motion will be discussed here. The model is composed in such a way that an external layer 
of water partially overlaps a layer of water governed by the equations for porous media flow. The basic equations will be discussed in the next sub-section. Figure 4.1 shows a sketch of the general composition of the model.

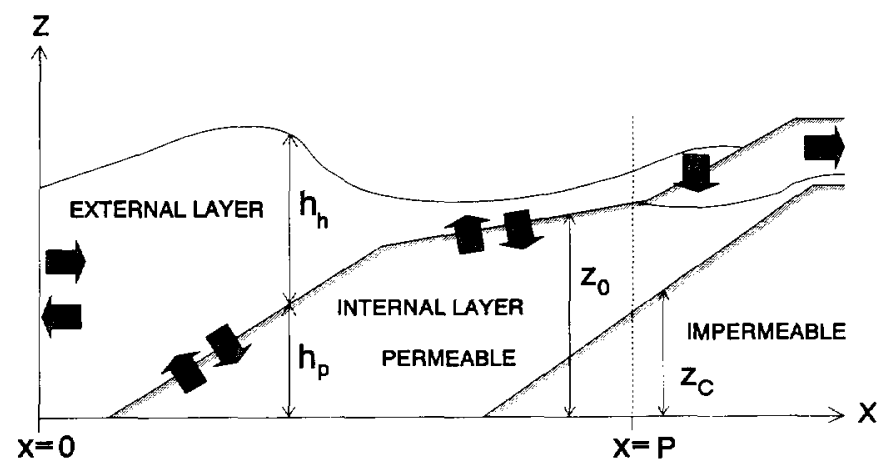

Fig.4.1 Model composition.

The slope of the structure is divided into a number of slope sections, each of which has a constant angle of the slope and a constant bottom friction coefficient. The slope can be modelled as impermeable or permeable. Permeable structures can be modelled as homogeneous or with an impermeable core, again divided into a number of core sections with a constant angle of the slope for each section. The permeable region is modelled as homogeneous which means that a constant porosity and a constant stone diameter are used.

At the seaward boundary, either regular waves or irregular incident waves can be prescribed. The landward boundaries, both for the free surface flow and for the internal boundary of the porous media flow, can be modelled as open or closed (non-reflecting or fully reflecting respectively). Other specific boundaries are the interface between the external and internal wave motion, the position of the run-up point ('shoreline' at the outer slope) and the boundaries for the phreatic surface. These will be treated in detail in the following sub-sections.

As discussed in Section 2.4, in this model the free surface and the phreatic surface can be disconnected as shown in the Figures 2.3 and 4.1. This requires the modelling of the infiltration and seepage phenomena. These will be discussed briefly in the following sub-sections. 


\subsubsection{Basic equations}

In the derivation and the accompanying assumptions for the finite-amplitude shallow-water wave equations as discussed in Chapter 2, no source terms are included, see Equations 2.11 and 2.13. This is also the case for the corresponding equations for porous media flow modelling, Equations 3.10 and 3.11. As can be seen in Figure 4.1, the region with free surface flow partially overlaps the permeable region. In this section with overlapping regions, the external wave motion causes pressure differences resulting in a flow between the external volume of water and the volume in the permeable part. Both the volume-flux of this exchange and the momentum of this flow must be incorporated in the basic equations as source terms.

For the external wave motion the basic equations become:

$$
\begin{aligned}
\frac{\partial h u}{\partial t}+\frac{\partial h u^{2}}{\partial x} & =-g h \frac{\partial h}{\partial x}-g h \tan \theta_{s}-\frac{1}{2} f u|u|+q q_{x} \\
\frac{\partial h}{\partial t}+\frac{\partial h u}{\partial x} & =q
\end{aligned}
$$

where $h$ is the thickness of the water layer in the external part, $u$ is the depthaveraged velocity in this layer, $\theta_{s}$ is the angle of the outer slope, $f$ is the bottom friction coefficient, $q$ is the volume-flux of the flow between both layers and $q_{x}$ is the horizontal component of the velocity of this flow which is obtained by assuming that this flow is perpendicular to the slope.

For the internal wave motion the governing equations read:

$$
\begin{aligned}
& \left(1+c_{A}\right) \frac{\partial h u}{\partial t}-c_{A} u \frac{\partial h}{\partial t}+\frac{1}{n} \frac{\partial h u^{2}}{\partial x}=-n g \frac{\partial \frac{1}{2} h^{2}}{\partial x}-n g h \tan \theta_{c} \\
& \frac{\partial h}{\partial t}+\frac{1}{n} \frac{\partial h u}{\partial x}=-\frac{q}{n}
\end{aligned}
$$


where $h$ is the thickness of the water layer in the permeable part, $u$ is the depthaveraged filter/discharge velocity in this layer, $\theta_{c}$ is the angle of the slope of the core, $a, b$ and $c_{A}$ are coefficients for the permeability and flow resistance of the porous medium and $n$ is the porosity.

The friction coefficient $f$, arising from the simplification of the bottom shear stress (Eq.2.14), has to be determined empirically. For slopes consisting of stones, the friction coefficient $f$ can be estimated by using the empirical formula from Madsen and White (1975):

$f=0.29\left(\frac{h_{0}}{D}\right)^{0.5}\left(\frac{D \tan \theta_{s}}{R}\right)^{0.7}$

where $h_{0}$ is the depth at the toe of the structure and $R$ is the run-up level which can be estimated by using the wave height (for instance $R=H$ or $R=1.5 \cdot H$ ). The formula was assessed for fully turbulent flow on a uniform slope.

Kamphuis (1975) and others also derived relations for the friction coefficient $f$ experimentally. The simple expression $f=0.4\left(a_{\delta} / k_{s}\right)^{-0.75}$ for $a_{\delta} / k_{s}<100$ where $k_{s}=2 \cdot D_{90}$ was found for rough turbulent flow for which the friction factor is independent of the Reynolds-number. Although these experiments were performed in an oscillating water tunnel with a horizontal bottom and at depths greater than a few times the particle diameters, on the basis of physical-model tests Cornett and Mansard (1994) concluded that the formula is accurate for rubble slopes as well. Friction factors varied roughly between 0.12 and 0.6 corresponding to relative roughness factors $a_{\delta} / k_{s}$ between approximately 3.7 and 0.8 (Slopes $1: 1.75$ and $1: 3$, $D_{n s 0}=0.042 \mathrm{~m}, H=0.10-0.22 \mathrm{~m}, T=1.5-3.0 \mathrm{~s}$ ). Cornett and Mansard (1994) also found higher friction coefficients during backwash than during swash.

As an indication, for smooth slopes for $f$ the value 0.02 can be used while for rough slopes the value for $f$ is higher, roughly between 0.10 and 0.60 . For very rough slopes it is expected that the bottom friction cannot be taken simply as a constant times the squared velocity. It is likely that inertia effects such as those observed for the coefficient $b$ in Equation 3.15 for porous media flow, cause additional friction. This, however, has not been quantified and therefore is not included here. 
In the permeable part above which no phreatic surface exists (between $x=0$ and $x=P$ in Figure 4.1), the pressure is assumed to be hydrostatic and determined by the position of the free surface. This assumption will be verified by using the physicalmodel tests discussed in Chapter 6 . In this section with overlapping regions, the pressure gradient for the permeable part is determined by the slope of the free surface and not by the slope of the permeable layer. Therefore, in this section the term $-n g \partial\left(1 / 2 h^{2}\right) / \partial x$ in Equation 4.2 must be replaced by $-n g h_{p} \partial\left(h_{h}+h_{p}\right) / \partial x$ where $h_{h}$ is the thickness of the external layer and $h_{p}$ is the thickness of the permeable layer. The thickness of this layer $\left(h_{p}\right)$ in this region is time-independent $\left(h_{p}=z_{0}-z_{c}\right)$. In the region with a phreatic surface $(x>P$ in Figure 4.1$)$, the pressure is determined by the phreatic surface.

By assuming hydrostatic pressures in the derivation of the one-dimensional equation for porous media flow, the friction in the vertical direction is not accounted for directly. It is assumed that applying values for the friction coefficients $\alpha$ and $\beta$ which are about a factor 1.5 higher than those obtained in Chapter 3, this shortcoming can be compensated for slightly. For the porous media flow coefficients $a, b$ and $c_{A}$ the expressions shown in Equations 3.2, 3.4 and 3.6 can be used. In addition, the dependency of the coefficients $b$ and $c_{A}\left(c_{A}=\gamma \cdot(1-n) / n\right)$ on the flow field can be taken into account, see Equation 3.16. The maximum velocities $\hat{U}$ are assessed by recording the maximum velocities which occurred during the preceding wave period. For computations with irregular waves the peak-period $T_{p}$ has been used as the characteristic wave period.

\subsubsection{Boundary conditions}

\section{Incident waves}

At the inflow boundary incident waves must be defined. Regular or irregular wave trains can be used. Regular wave trains are computed with the Stokes second-order wave theory (Stokes, 1847) or the Cnoidal wave theory (in conformance with Roy, 1986), depending on the Ursell-number, $U$ (Ursell, 1953) $(U<26$ : Stokes, $U>26$ : Cnoidal). Irregular wave trains can be applied by using existing time-series or by generating time-series based on the TMA-spectrum defined with the wave height $H_{r m s}$ and the peak period $T_{p}$. This spectrum is based on the JONSWAP-spectrum but adapted to finite water depth, see Bouws et al. (1985). 
The seaward boundary allows a reflected wave to leave the computational domain. This can be done by applying the conventional method of characteristics with the Riemann-invariants $\alpha_{R}$ and $\beta_{R}\left(\alpha_{R}=u+2 c\right.$ and $\beta_{R}=-u+2 c$ with $\left.c=\sqrt{ }(g h)\right)$. Therefore, Equation 4.1 is rewritten for a horizontal bottom in the following form:

$$
\begin{aligned}
& \frac{\partial \alpha_{R}}{\partial t}+(u+c) \frac{\partial \alpha_{R}}{\partial x}=-\frac{\frac{1}{2} f u|u|}{h} \text { along } \frac{d x}{d t}=u+c \\
& \frac{\partial \beta_{R}}{\partial t}+(u-c) \frac{\partial \beta_{R}}{\partial x}=+\frac{\frac{1}{2} f u|u|}{h} \text { along } \frac{d x}{d t}=u-c
\end{aligned}
$$

Assuming linear long waves at the inflow boundary implies $(x=0): h=h_{0}+\eta_{i}+\eta_{r}$ and $u=u_{i}+u_{r}$ where $u_{i}=\eta_{i} \sqrt{ }\left(g / h_{0}\right)$ and $u_{r}=-\eta_{r} \sqrt{ }\left(g / h_{0}\right)\left(h_{0}\right.$ is the still-water level at $\left.x=0\right)$. For $h_{0} \gg \eta$ this yields $\eta_{r}=1 / 2 \beta_{R} V\left(h_{0} / g\right)-h_{0}$ at $x=0$ where the seaward advancing characteristic $\beta_{R}$ can be assessed from information from the computational domain through Equation 4.5. This yields both the position of the free surface $(h)$ and the velocity $(u)$ at $x=0$.

\section{Landward boundaries}

At the landward boundary for the external wave motion an open or a closed boundary can be used. An open boundary, obtained by using a non-reflecting boundary based on the method of characteristics, has been implemented to enable computations with overtopping where the crest is the end of the computational domain or for submerged structures. A closed boundary can be used to model a fully reflecting boundary necessary for computations with a vertical wall (e.g., at the crest of a structure). The one-dimensional model is less accurate if large changes in the angle of the slope occur or for computations with wave motions where the assumption that the pressures are hydrostatic does not hold. Therefore, the assumptions for the model require that the wave action near such a vertical part is relatively calm. This excludes many applications with overtopped vertical structures.

Boundaries similar to the landward boundary for external wave motion must also be described for the porous media flow. Again a non-reflecting boundary, for 
overtopping of an impermeable core (phreatic level higher than the top of the core) or a fully reflecting boundary for very steep core sections can be used.

\section{Free surface at the slope}

The treatment of the boundary at the intersection with the slope is similar to those described by Hibberd and Peregrine (1979) and Kobayashi et al. (1987). At the last wet point, the 'shoreline' ( $A$ in Fig.4.2), an extrapolation procedure is performed to determine the depth at the computational point upward from the shoreline ( $B$ in Fig. 4.2). If after the following time-step, the depth at this last point becomes greater than a minimum water depth $\Delta$, the shore-line in the computation moves upward. If, on the other hand, after the new time-step the depth at the position of the shoreline ( $A$ in Fig.4.2) becomes smaller than the minimum water depth $\Delta$, the shoreline is moved downward.

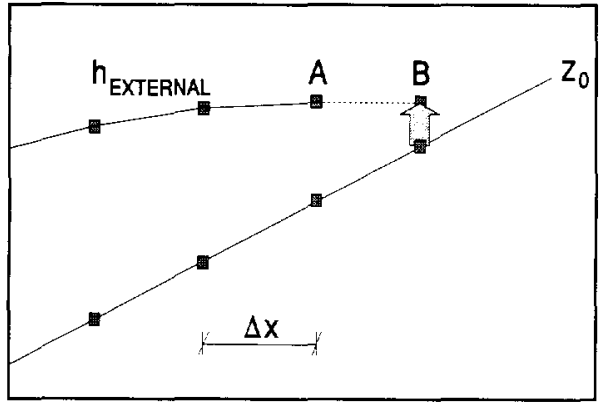

Fig.4.2 Treatment of the free surface at the structure interface.

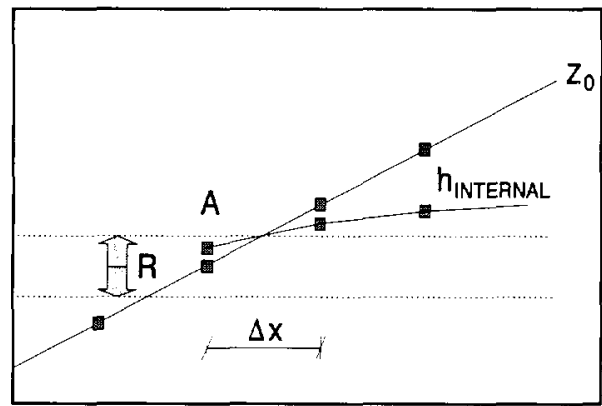

Fig.4.3 Treatment of phreatic surface at the structure interface.

This concept has been used in many models but the extrapolation procedures often differ. In the extrapolation procedures information is used from positions in the computational domain at which the accuracy of the properties is relatively low. Therefore, very accurate extrapolation procedures yield very limited profit. As long as the exact treatment of this boundary at the slope has negligible effect on the accuracy of the computation, preference should be given to a treatment which does not lead to instabilities at this landward boundary. 


\section{Phreatic surface}

Several boundaries for the porous media flow need to be dealt with. For computations with an impermeable core, the treatment of the last wet-point on the impermeable core is treated in the same way as the free surface at the outer slope. The point where the phreatic surface meets the outer slope needs a separate treatment. In the model, the phreatic surface at this internal boundary point can fluctuate between two levels ( $R$ in Figure 4.3). These levels are exactly between the slope elevation of the boundary grid point and the slope elevation of the neighbouring grid points. This means that the phreatic level can fluctuate between the lower limit and the upper limit. If the phreatic level becomes lower than the lower limit, the internal boundary point is moved downward. If the level becomes higher than the upper limit the boundary point is moved upward.

Because the model is one-dimensional, no vertical velocities are computed. However, the downward vertical velocity of the phreatic surface has a maximum. This is the result of the equilibrium of gravity and friction. If this maximum should be exceeded, the gradient in the pressures $(I=-I / \rho g \cdot \partial p / \partial z)$ would be greater than one. This means that the water would flow quicker than the free seepage velocity which is assumed not to occur at the phreatic surface. The upward velocity also has a maximum which is in the same order of magnitude as the maximum downward velocity. This aspect is discussed in Hölscher et al. (1988). The maximum upward velocity taken can be different from the maximum downward velocity, however, here the maximum vertical velocity is taken the same in both directions. In formula:

$I=a w+b w|w| \leq 1$

where $I$ stands for the pressure gradient in the vertical direction (with one as the maximum value), $w$ for the vertical velocity and $a$ and $b$ for the Forchheimer friction coefficients (Equations 3.2 and 3.4). For $w, n\left(\partial h_{p} / \partial t\right.$ ) is taken. The maximum vertical velocity of the phreatic surface can be solved from this equation. The true maximum differs from this value because the flow does not have to be completely vertical at the phreatic surface. 
Like the vertical velocity at the phreatic surface, the flow $q$ between the external flow and the internal flow (see Equations 4.1 and 4.2) is also limited. The velocity of this flow can, however, be higher than the free seepage velocity calculated from Equation 4.6 because the pressure gradient $(I)$ can be greater than one. The exact pressure gradient in the vertical direction is unknown in this one-dimensional model, where the pressures are assumed to be hydrostatic. The assumption that the pressure gradient is smaller than one is made here to determine the maximum velocity for the flow $q$.

To facilitate computations with submerged and low-crested structures, some additional boundaries are needed. For structures that become dry at the crest for some period, the wave motion can be modelled both in front of and behind the structure by using only one layer describing the external wave motion. In the dry region at the crest a very thin layer of water is modelled instead of a dry slope. For the minimum thickness of this layer of water, a very low value for $\Delta$ can been used. The external wave motion has direct influence on the internal wave motion in the region where the layer describing the external wave motion overlaps the layer describing porous media flow (through hydrostatic pressures). For structures that become dry at the crest for some period, two of these regions of overlapping layers are modelled with a phreatic surface in the region in between. This implies that two regions with an interactive flow, $q$, are modelled and that the procedure used to handle the phreatic surface reaching the slope is also applied at the rear of the structure. Infiltration is modelled in the region of the 'dry' crest for those cases in which the layer of water at the crest is greater than $\Delta$.

\subsubsection{Infiltration and seepage}

The disconnection of the free surface and the phreatic surface leads to infiltration or seepage as shown in Figure 2.3. The implementation of phenomena like infiltration and seepage is required to uncouple the free surface and the phreatic surface (discontinuous surface). Those phenomena are modelled in a rather simple way. However, modelling of the motion of water on and inside a structure with a continuous surface, would give an unrealistic coupling, see Section 2.4. Forcing the movement of the phreatic level so that it stays connected with the external free surface, causes disturbance of both the external and the internal motion. Therefore the application of the chosen model seems justified. 
An area with infiltration occurs if the free surface appears above the phreatic surface with a 'dry' area or un-saturated area in between (see Figure 4.4). In the unsaturated zone the water can be spread in the horizontal direction due to the influence of the stones and due to the initial horizontal momentum of this water. A rather simple procedure to handle infiltration is used here; the direction of the water in this un-saturated area is assumed to be vertical. Furthermore, in the model this water reaches the phreatic surface instantaneously with a vertical velocity equal to the free seepage velocity ( $w$ in Eq.4.6). For fine material, more detailed modelling of infiltration can be obtained by applying concepts based on Green and Ampt (1911) and Richards (1931) for vertical infiltration in un-saturated bottoms. Although rapidly varying water motion can be accounted for, these concepts are derived and verified (see Reeder et al., 1980) only for flow through fine grained material where laminar flow occurs in the zone of saturation. Under such flow conditions different phenomena may be dominant than for turbulent porous flow through coarse rubble mound material. Because the model is intended to describe wave motion under these turbulent flow conditions, a simple procedure based on the free seepage velocity is used.

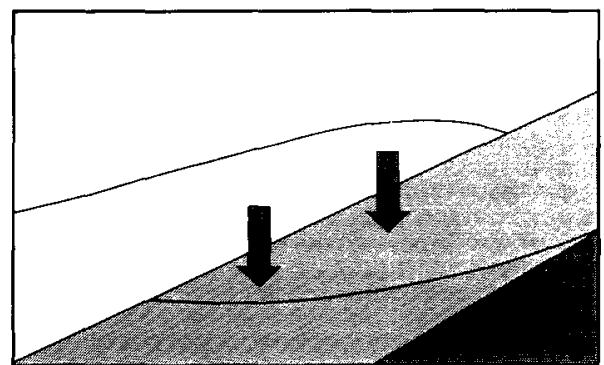

Fig.4.4 Situation with infiltration.

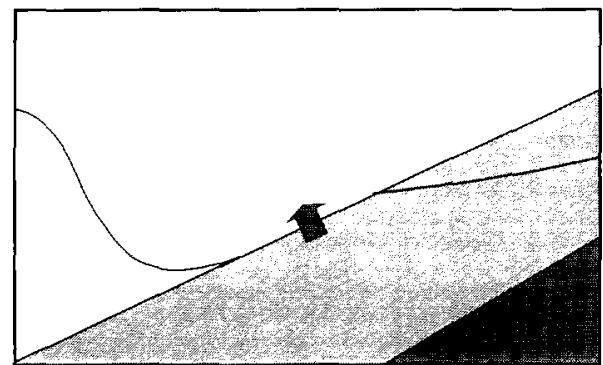

Fig.4.5 Situation with seepage.

Another phenomenon, seepage, can occur if the phreatic surface reaches a 'dry' slope (see Figure 4.5). A new phreatic surface is computed without the restriction that this surface has to stay inside the structure; if the new phreatic surface appears to be above the slope of the structure, the volume above this boundary (outside the structure) is assumed to be the flow out of the structure. The restriction concerning the maximum value of the velocity of the phreatic level, as discussed in the previous sub-section, results in a maximum velocity of this outflow. 


\subsection{Numerical scheme}

\subsubsection{Numerical discretisation}

The shallow-water wave equations and the corresponding equations for porous media flow are solved with an explicit finite difference scheme. The second-order scheme by Lax-Wendroff (1960), analysed by Richtmyer and Morton (1967), conserves the quantities mass and momentum well. The equations are written in conservation form (with $m=h \cdot u$ ). Before discretising the equations, the variables are made dimensionless (in conformance with Kobayashi et al., 1987): $t=t^{\prime} / T^{\prime}$; $x=x^{\prime} /\left(T^{\prime} \sqrt{ }\left(g \cdot H^{\prime}\right) ; \quad u=u^{\prime} / \sqrt{ }\left(g \cdot H^{\prime}\right) ; \quad h=h^{\prime} / H^{\prime} ; \quad z_{0}=z_{0}{ }^{\prime} / H^{\prime} ; \quad \theta=T^{\prime} \sqrt{ }(g / H) \cdot \tan \theta_{s} ;\right.$ $f=1 / 2 \cdot T^{\prime} \sqrt{ }(g / H) \cdot f^{\prime} ; q_{x}=q_{x} / \sqrt{ }\left(g \cdot H^{\prime}\right)$ and $q=q^{\prime} \cdot T^{\prime} / H^{\prime}$ where the notation with primes, denoting dimensional variables and those without non-dimensional properties, is only applicable in this sub-section. Suitable dimensionless variables could, however, also have been obtained by replacing $T^{\prime}$ by $\sqrt{ }\left(H^{\prime} / g\right)$ as a characteristic quantity to reduce time to non-dimensional time (in conformance with Hibberd and Peregrine, 1979) which is preferable if the relative magnitude of several terms in the equations is studied.

The equations are rewritten in vector form. For the external wave motion this yields:

$$
\frac{\partial \tilde{u}}{\partial t}+\frac{\partial \tilde{F}}{\partial x}+\tilde{G}=0
$$

where

$\tilde{u}=\left[\begin{array}{l}m \\ h\end{array}\right], \quad \tilde{F}=\left[\begin{array}{c}\frac{m^{2}}{h}+\frac{h^{2}}{2} \\ m\end{array}\right], \quad \tilde{G}=\left[\begin{array}{c}h \theta+f u|u|-q q_{x} \\ q\end{array}\right]$

Applying the Lax-Wendroff scheme with space-step $\Delta x$, time-step $\Delta t$ and $\tilde{u}_{j, n}=\tilde{u}(j \Delta x, n \Delta t)$ yields:

$$
\begin{gathered}
\tilde{u}_{j, n+1}=\tilde{u}_{j, n}-\lambda\left(\frac{1}{2}\left(\tilde{F}_{j+1, n}-\tilde{F}_{j-1, n}\right)+\Delta x \tilde{G}_{j, n}\right) \\
+\frac{1}{2} \lambda^{2}\left(\tilde{g}_{j, n}-\tilde{g}_{j-1, n}-\Delta x \tilde{S}_{j, n}\right)
\end{gathered}
$$


where $\lambda=\Delta t / \Delta x$ and

$$
\begin{aligned}
& \tilde{g}_{j, n}=\frac{1}{2}\left(\tilde{A}_{j+1, n}+\tilde{A}_{j, n}\right)\left(\tilde{F}_{j+1, n}-\tilde{F}_{j, n}+\frac{1}{2} \Delta x\left(\tilde{G}_{j+1, n}+\tilde{G}_{j, n}\right)\right) \\
& \tilde{A}=\frac{\partial \tilde{F}}{\partial \tilde{u}}=\left[\begin{array}{cc}
\frac{2 m}{h} & h-\frac{m^{2}}{h^{2}} \\
1 & 0
\end{array}\right] \\
& \tilde{S}_{j, n}=\Delta x \frac{\partial \tilde{G}_{j, n}}{\partial t}=\left[\begin{array}{c}
-\frac{1}{2} \theta_{j}\left(m_{j+1, n}-m_{j-1, n}\right)+\theta_{j} q_{j, n}+\Delta x k_{j, n}+\Delta x l_{j, n} \\
r_{j, n}
\end{array}\right] \\
& k_{j, n}=2 f_{j} \frac{\left|u_{j, n}\right|}{h_{j, n}}\left[\begin{array}{c}
\left(u_{j, n}^{2}-h_{j, n}\right) \frac{h_{j+1, n}-h_{j-1, n}}{2 \Delta x}-u_{j, n} \frac{m_{j+1, n}-m_{j-1, n}}{2 \Delta x} \\
-h_{j, n} \theta_{j}-f_{j} u_{j, n}\left|u_{j, n}\right|+q_{j, n}\left(q_{x j, n}-u_{j, n}\right)
\end{array}\right]
\end{aligned}
$$

The term $r_{j, n}=\partial q_{j, n} / \partial t$ can be discretised by using $\partial q / \partial t=-\partial / \partial x\left[\partial h_{p} u_{p} / \partial t\right]$ where this term can be obtained from the discretisation of the porous media flow equations (where $h_{p}$ is the thickness of the porous layer and $u_{p}$ is the filter velocity) or by discretising $r_{j, n}=\partial q_{j, n} / \partial t$ backwards in time. The latter has been used here. The term $l_{j, n}=\partial\left(q_{j, n} \cdot q_{x j, n}\right) / \partial t$ is also discretised backwards in time. Because these terms are not rewritten as terms without time-derivatives, the scheme is not strictly a LaxWendroff scheme, but these alternative discretisations of the terms, which in many cases are relatively small, reduce the complexity and computational time considerably.

The discretisation of the corresponding equations for describing the porous media flow (Eq.4.2) can be discretised very similar to those for the external wave motion. The expression for the bottom friction is, in fact, replaced by the Forchheimer porous flow friction terms and in some terms the porosity is included, but those adaptations do not effect the discretisation method. 
The Lax-Wendroff scheme allows the possibility to include an additional term to minimize numerical oscillations, appearing as parasite waves near the wave front, see for instance Hibberd (1977). These parasite waves, due to non-linear dispersive effects introduced by the discretisation, appeared to be unacceptable for computations with bores. For the external wave motion this additional term is included, but for the internal wave motion physical damping is sufficient to minimize these numerical oscillations. This additional term is included in the right side of Equation 4.9:

$$
\tilde{D}_{j, n}=\frac{1}{2} \lambda\left(\tilde{Q}_{j+\frac{1}{2}, n}\left(\tilde{u}_{j+1, n}-\tilde{u}_{j, n}\right)-\tilde{Q}_{j-\frac{1}{2}, n}\left(\tilde{u}_{j, n}+\tilde{u}_{j-1, n}\right)\right)
$$

where

$$
\tilde{Q}_{j+\frac{1}{2}, n}=e_{1_{j+\frac{1}{2}, n}} \tilde{I}+\frac{1}{2} e_{2_{j+\frac{1}{2}, n}}\left(\tilde{A}_{j, n}+\tilde{A}_{j+1, n}\right)
$$

in which $\tilde{I}$ is the unit matrix and the coefficients $e_{1}$ and $e_{2}$ are written by using the eigenvalues of $\tilde{A}, v_{1}=u+c$ and $v_{2}=u-c$ :

$$
\begin{aligned}
& e_{1_{j+\frac{1}{2}, n}}=\frac{\epsilon_{2}\left|v_{2_{j+1, n}}-v_{2_{j, n}}\right|\left(v_{1_{j, n}}+v_{1_{j+1, n}}\right)-\epsilon_{1}\left|v_{1_{j+1, n}}-v_{1_{j, n}}\right|\left(v_{2_{j, n}}+v_{2_{j+1, n}}\right)}{2\left(c_{j, n}+c_{j+1, n}\right)} \\
& e_{2_{j+\frac{1}{2}, n}}=\frac{\epsilon_{1}\left|v_{1_{j+1, n}}-v_{1_{j, n}}\right|-\epsilon_{2}\left|v_{2_{j+1, n}}-v_{2_{j, n}}\right|}{\left(c_{j, n}+c_{j+1, n}\right)}
\end{aligned}
$$

Damping increases for higher values of $\epsilon_{1}$ and $\epsilon_{2}$. For both constants the value 1.1 was used in all computations with this additional damping.

Figure 4.6 shows surface elevations derived from computations with and without additional damping. The computation with regular waves $(H=0.20 \mathrm{~m} ; T=1.5 \mathrm{~s})$ on an impermeable slope with a friction factor $f=0.15$ was performed with a space-step of $\Delta x=0.025 \mathrm{~m}$, a time-step of $\Delta t=0.006 \mathrm{~s}$ and a minimum water depth at the shoreline of $\Delta=0.005 \mathrm{~m}$. The comparison clearly indicates that computations without additional damping show parasite waves near the wave front. The additional damping term diminishes these numerical oscillations effectively without affecting the run-up level. 


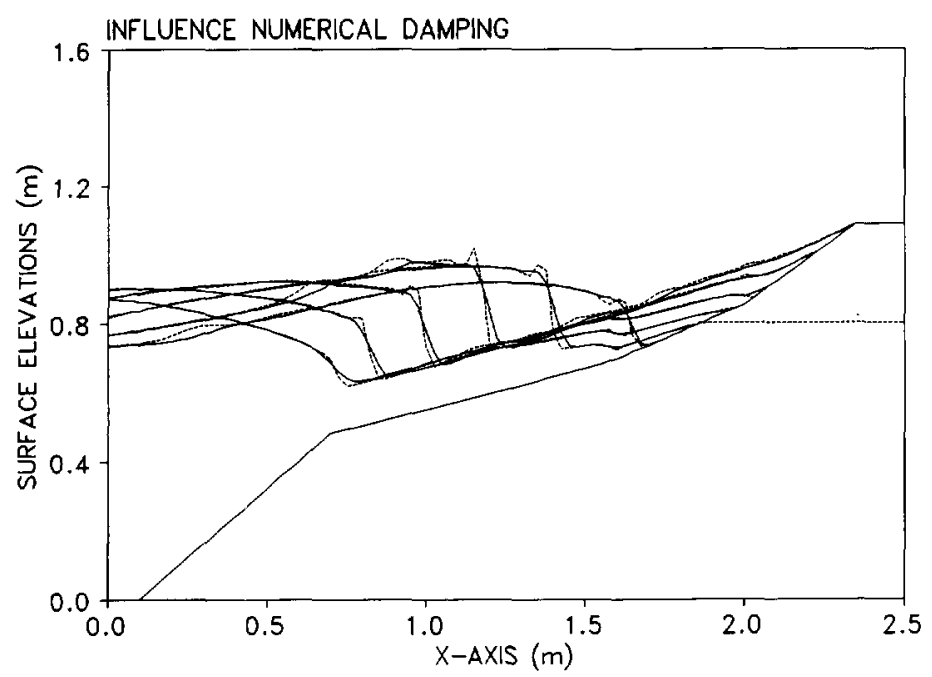

Fig.4.6 Influence of damping term on surface elevations; with (lines) and without (dashed) additional damping.

\subsubsection{Numerical dissipation}

The wave profile at a specific moment can be divided into a large number of (Fourier-) components of different height and different length. Wave propagation can be seen as a combination of the propagation of each of these components. The behaviour of each of these components with respect to the amplitudes and the frequencies of these components (amplitude and frequency dispersion), is implicitly described by the applied equations. However, since the shallow-water equations only give an approximation of the actual wave propagation, differences occur between the actual behaviour of these components and that described by the equations (modelling error). In addition, the discretisation of the equations also causes differences between the propagation of the components in the equations and those in the discretised equations (discretisation error).

As an indication, differences between the simple-wave equation $(\partial u / \partial t+c \cdot \partial u / \partial x=0)$ and the discretisation of this equation using the Lax-Wendroff numerical scheme will be shown. Due to non-linearity such an analysis cannot be performed for the 
shallow-water wave equations. Here, results of an analysis of the Lax-Wendroff numerical scheme similar to those by Petit (1994) for a large number of numerical schemes will be shown.

Each of the wave components, characterised by a wave number $(k=2 \pi / L)$ and angular celerity $\left(\omega_{e q}=2 \pi / T\right)$, is subjected to different dissipation and dispersion characteristics, since the discretisation has different effects on all of these components. Substituting a Fourier-component $u_{j, n}=\hat{u} D_{\Delta t}{ }^{n} e^{-i \omega n \Delta t} e^{i k j \Delta x}$ (at the point $j \Delta x$ and time $n \Delta t$ ) in the discretised equation, yields the growth-rate per time-step, $D_{\Delta t}$ (dissipation), of the amplitudes $\hat{u}$ of the components in the discretised equation compared to those in the equation itself: $D_{\Delta t}=\sqrt{ }\left[\left(1-\mu^{2}(1-\cos \alpha)\right)^{2}+\mu^{2} \sin ^{2} \alpha\right]$ for a given Courant-Friedrichs-Lewy (CFL)-number $\mu=c \cdot \Delta t / \Delta x$ and component $\alpha=k \cdot \Delta x=$ $2 \pi / L \cdot \Delta x$. The above substitution also yields the celerity of components in the discretised equation, $c_{\text {num }}=\omega_{\text {num }} / k$, compared to those in the equations, $c_{e q}$, the following relative dispersion: $c_{n u m} / c_{e q}=1 /(\mu \alpha) \cdot \arccos \left[\left(1-\mu^{2}(1-\cos \alpha)\right) / D_{\Delta t}\right]$.
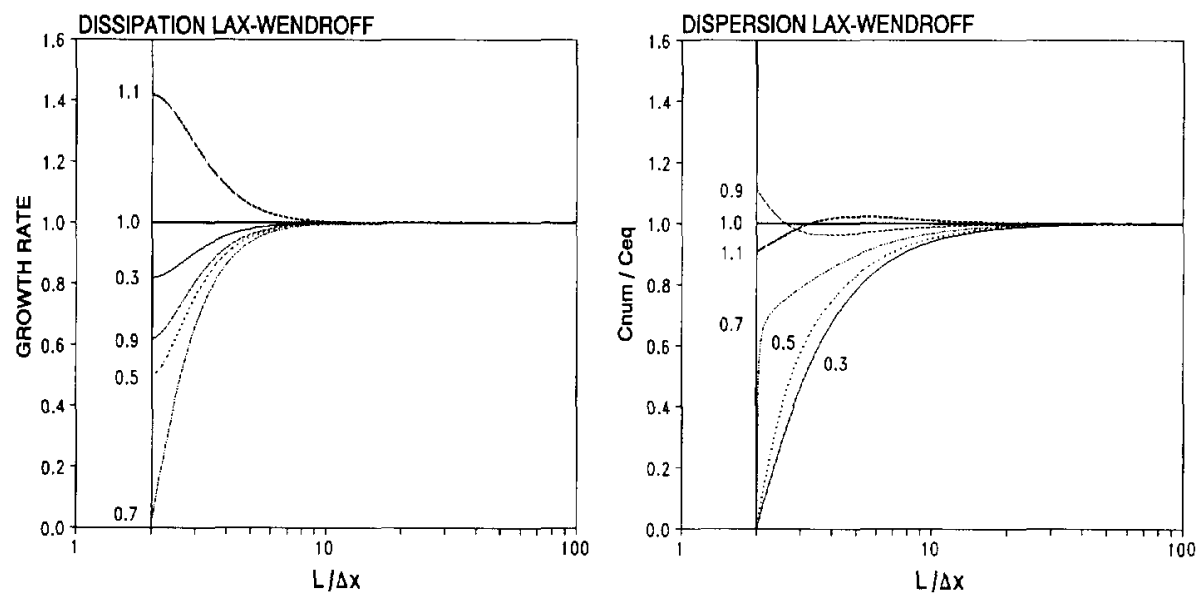

Fig.4.7 Dissipation and dispersion by the numerical scheme (labels denote the CFL-number $\mu$ ).

The left graph of Figure 4.7 shows the growth-rate and the right graph shows the dispersion for components with a given number of computational points $(\Delta x)$ per wavelength $(L)$. Because the shortest possible wavelengths in the numerical model 
are only $2 \cdot \Delta x$ in length, the lower limit of the number of grid-points per wavelength is 2 . Both the growth rate and the dispersion depend on the CFL-number. The growth-rate for a CFL-number $\mu=1.1$ shows that this yields an unstable computation since the growth-rate is greater than one ('negative dissipation'). The ideal situation is for a CFL-number $\mu=1.0$ for which both the dissipation and dispersion in the discretised equations are the same as in the equations itself. The celerity of the components in the discretised equations, compared to those described by the equations, for instance, for a CFL-number $\mu=0.7$ are better than those for lower CFL-numbers. The dissipation of the shortest components (close to $2 \cdot \Delta x$ ) is large for this CFL-number which means that the shortest components which are inaccurately described (dispersion) dissipate relatively quickly. Although this analysis is performed for the simple-wave equation, it is assumed that for the shallow-water wave equations similar trends will occur. Therefore, this analysis will be used to find appropriate values for $\Delta t$ and $\Delta x$.

The numerical model described here uses a constant grid spacing and a constant time-step. Therefore, the celerity in the shallow-water equations $(c=u \pm \sqrt{ }(g \cdot h))$ varies in time and space which means that the choice of constant CFL-number $\mu=1.0$ is not possible. This implies that computations with accurate simulation of the short wave components is impossible. In the applied numerical model, the short components are of relative importance near the wave front. In this position numerical dissipation of these components is relatively large (left side of the left graph). Since these wave fronts (bores) are supposed to represent breaking waves, an area where energy is dissipated, the numerical dissipation at this position might not be completely inappropriate but this numerical dissipation instead of physical dissipation introduces a dependency of the results on the CFL-number ( $\Delta t$ and $\Delta x$ ). To minimize this dependency due to numerical dissipation, one can apply the model with specific values of $\Delta t$ and $\Delta x$ yielding the same 'average' CFL-number, or by using a large number of computational points per wavelength.

For flow conditions where the average velocity is close to zero, the average of the celerity $c_{\text {avg }}$ is about $\sqrt{ }\left(g \cdot h_{0}\right)$. The choice of a specific number of computational points per wavelength, $n_{\Delta x}$, to achieve a sufficient accuracy yields a condition for the space-step $\left(\Delta x=L / n_{\Delta x}=\sqrt{ }\left(g \cdot h_{0}\right) \cdot T / n_{\Delta x}\right)$. The choice of a specific 'average' CFLnumber, for instance $\mu_{\text {avg }}=0.7$, yields the condition for the time-step ( $\Delta t=$ $\left.\mu_{\text {avg }} \cdot \Delta x / c_{\text {avg }}=\mu_{\text {avg }} \cdot T / n_{\Delta x}\right)$. 
The maximum value of the celerity, $c_{\max }$, must be limited to satisfy the stability criterium throughout the computation (for computations without additional damping $\mu=c \cdot \Delta t / \Delta x \leq l$ where $c=|u \pm V(g \cdot h)|)$. In practice, the choice of an 'average' CFLnumber $\mu_{\text {avg }} \leq 0.7$ yields a stable computation if the treatment of the boundary at the slope does not require a stricter limitation.

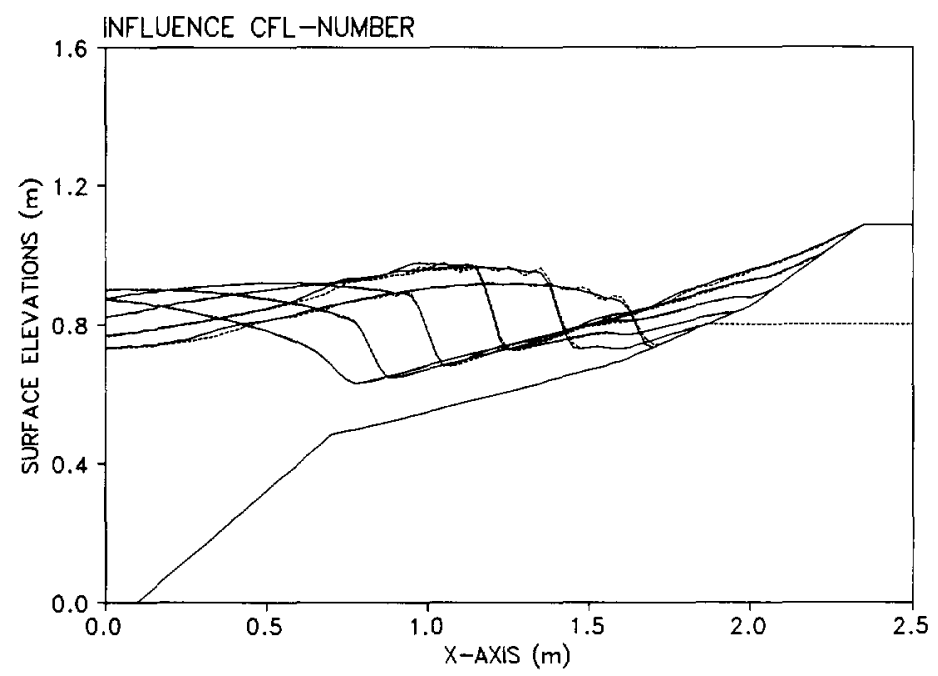

Fig.4.8 Influence of CFL-number on surface elevations; $\mu=0.7$ (lines) and $\mu=0.07$ (dashed).

Figure 4.8 shows that the influence of the CFL-number on computed surface elevations is relatively small, except for the region near the wave front $(H=0.20 \mathrm{~m}$, $T=1.5 \mathrm{~s}, \Delta x=0.025 \mathrm{~m}$ ). In this region parasite waves are not only damped by the additional term to diminish these numerical oscillations (see previous sub-section) but also by the numerical scheme itself (Fig.4.7). The dissipation of short wave components is relatively small for the low CFL-number $\mu_{\text {avg }}=0.07$ but reaches a maximum for $\mu_{\text {avg }}=0.7$ (see left graph is Figure 4.7). Although the influence of variation in CFL-numbers can be low, due to the large number of computational points and a low ratio of wavelength to computational domain length, parasite waves are effectively removed for computations with $\mu_{\text {avg }}=0.7$ without changing the global appearance of the solution. 


\subsection{Validation of the numerical model}

\subsubsection{Comparison with an analytical solution}

Numerical model results have been compared with analytical solutions of standing waves on a slope as given by Carrier and Greenspan (1958). These exact solutions of the shallow-water wave equations are derived for waves on a slope without friction. From the analytical solution a relation between the amplitude of sinusoidal incident waves $\left(\eta_{i n}\right)$ and the (vertical) amplitude at the shoreline $\left(A_{s}\right)$ can be derived: $A_{s}=\eta_{i n} \pi / \sqrt{ }\left(s T / 8 \cdot\left(g / h_{0}\right)\right)$ where $s$ is the slope $\left(s=\tan \theta_{s}\right), T$ is the wave period and $h_{0}$ is the depth at the toe of the slope. Breaking at the slope does not occur if $A_{s} \leq 1 /\left(4 \pi^{2}\right) \cdot g \cdot T^{2} \cdot s^{2}$.

For comparison with numerical model results incident waves with an amplitude equal to the maximum amplitude without occurrence of breaking waves are taken: $\eta_{\text {in }}=1 /(8 \sqrt{ } 2) \cdot 1 / \pi^{3} \cdot s^{2.5} \cdot T^{2.5} \cdot g^{1.25} \cdot h_{0}^{-0.25}$. For a slope $1: 4$, a wave period of $5.0 \mathrm{~s}$ and a still-water level $h_{0}=2.0 \mathrm{~m}$ at the toe of the slope this gives an incident wave height of $0.15 \mathrm{~m}$.

The numerical computation was done with a minimum water depth of $\Delta=0.005 \mathrm{~m}$ at the slope. To obtain a stable computation with the above mentioned wave conditions, the treatment of the boundary at the frictionless slope determines the maximum possible CFL-value for a specific value of the friction coefficient for which the very low value $f=0.001$ was used. For the space-step and the time-step, $\Delta x=0.045 \mathrm{~m}$ and $\Delta t=0.003 \mathrm{~s}$ were used respectively giving $\mu=0.30$. The computation was done without the numerical damping term as analysed in the previous section, since no parasite waves occurred in the computation of this standing wave.

Figure 4.9 shows comparisons for both surface elevations and velocities. The comparison of the six surface profiles during up-rush show good agreement, although the run-up is slightly underestimated. The velocities during up-rush and down-rush show good agreement as well, except for the high velocities in the relatively thin water layers near the run-up point. 

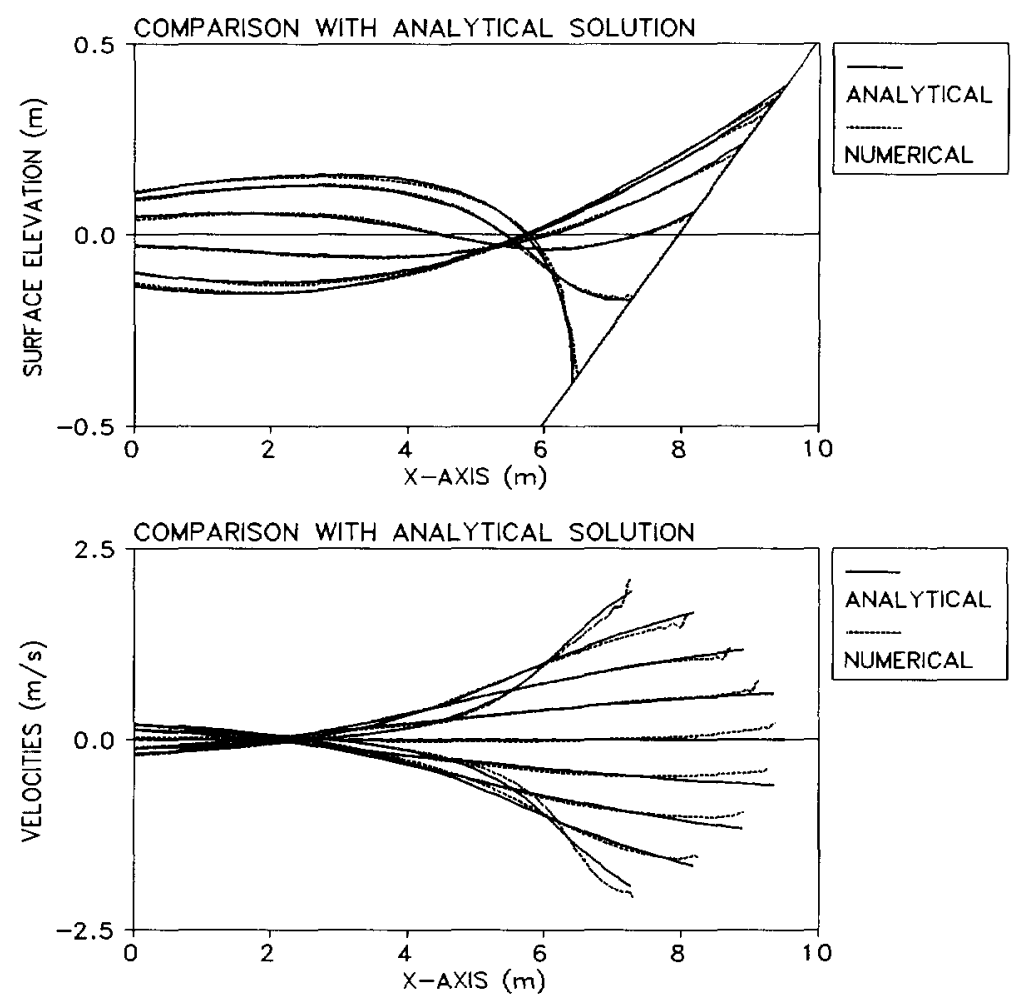

Fig.4.9 Comparison of analytical and numerical solutions of a standing wave; surface elevations (upper graph) and velocities (lower graph).

\subsubsection{Comparison with data from physical-model tests}

Further validation of the hydraulic model was performed with data from physicalmodel tests. Surface elevations and velocities above a berm breakwater slope have been compared in Torum and Van Gent (1992). In Chapter 6, an additional validation of computed surface elevations and run-up levels on a berm breakwater slope is described. Here, comparisons will be shown for run-up and run-down levels on impermeable and permeable slopes, as well as coefficients for wave transmission over submerged and low-crested structures. 
A verification of run-up and run-down levels on an impermeable structure has been performed. With respect to the treatment of the run-up point ('shoreline procedure') run-up on smooth slopes is relatively difficult to describe in a numerical model because of the relatively large fluctuations of the run-up point. Measurements performed by Burger and Van der Meer (1983) in a large-scale flume have been used to verify run-up and run-down levels. The run-up and run-down levels were measured visually. Regular waves were generated on a slope $1: 3$. Wave heights varied roughly between $H=0.2 \mathrm{~m}$ and $H=1.1 \mathrm{~m}$. In the computations a low value for the friction coefficient was used; $f=0.005$ (lower values lead to unstable computations).

Figure 4.10 shows the comparisons of run-up levels on impermeable slopes. The non-dimensional run-up $\left(R_{u} / H\right)$ and run-down levels $\left(R_{d} / H\right)$ are shown as a function of the surf-similarity parameter $\xi_{0}$ (Battjes, 1974). The tests were done with plunging, collapsing and surging waves. For these tests a local maximum near the transition from plunging waves to collapsing waves was found in both the physicalmodel tests and in the computational results. The agreement between the measured and computed run-up levels is rather good. Although the model gives increasing run-down levels (absolute values) for higher values of the surf-similarity parameter, the trend is not correctly reproduced quantitatively.

Run-up levels on a permeable slope have been verified against 49 tests with regular waves on uniform sloping structures performed by Ahrens (1975). Tests with three slope angles were used: $1: 2.5,1: 3.5$ and $1: 5$. The stone diameters $\left(D_{E Q}\right)$ varied between $0.20 \mathrm{~m}$ and $0.34 \mathrm{~m}$. Wave heights and wave periods varied between $H=0.55-1.15 \mathrm{~m}$ and $T=2.8-11.3 \mathrm{~s}$ respectively. The surf-similarity parameters varied between $\xi_{0}=0.7$ and $\xi_{0}=6.3$. The depth in front of the structure was $h_{0}=4.58 \mathrm{~m}$.

For the friction coefficient the empirical formula by Madsen and White (1975), Equation 4.3 , in which $R=1.5 \cdot H$ was used for the run-up level, has been applied. The structure had a core of sand. This was implemented in the computations as an impermeable core. The porosity of the filter layer was estimated to be $n=0.40$. For the friction coefficients 2120 and 2.0 were used for $\alpha_{D-E Q}$ and $\beta_{D-E Q}$ respectively. Added mass was not modelled.

The results are presented in Figure 4.11. The non-dimensional run-up levels $\left(R_{u} / H\right)$ are shown as a function of the surf-similarity parameter. The agreement is rather 


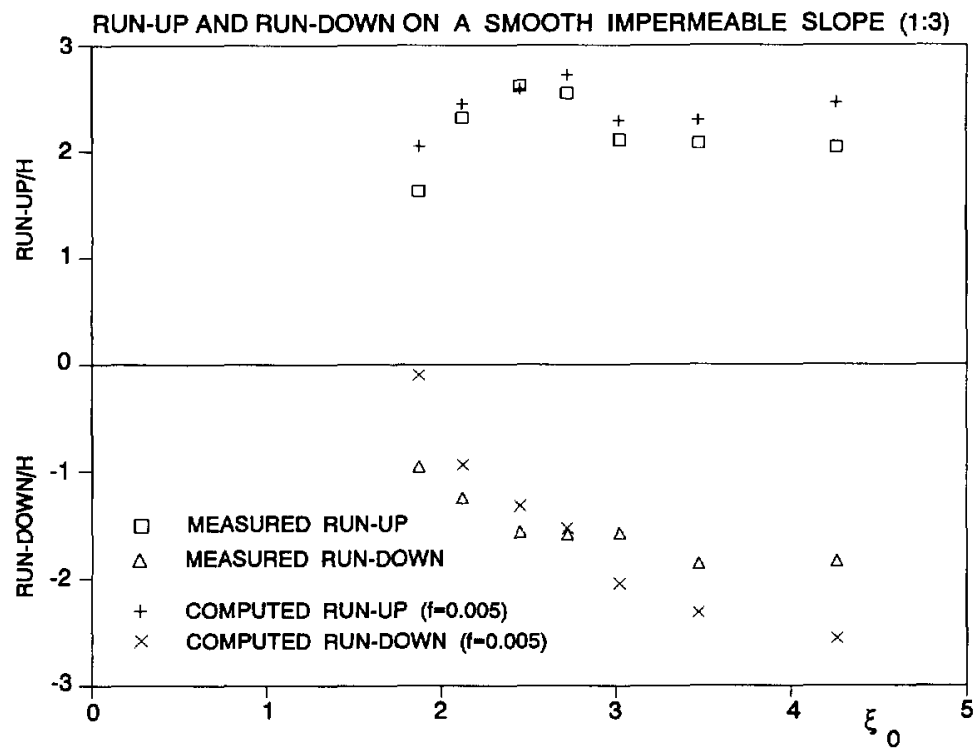

Fig.4.10 Comparison of run-up and run-down levels for regular waves on a smooth impermeable slope.

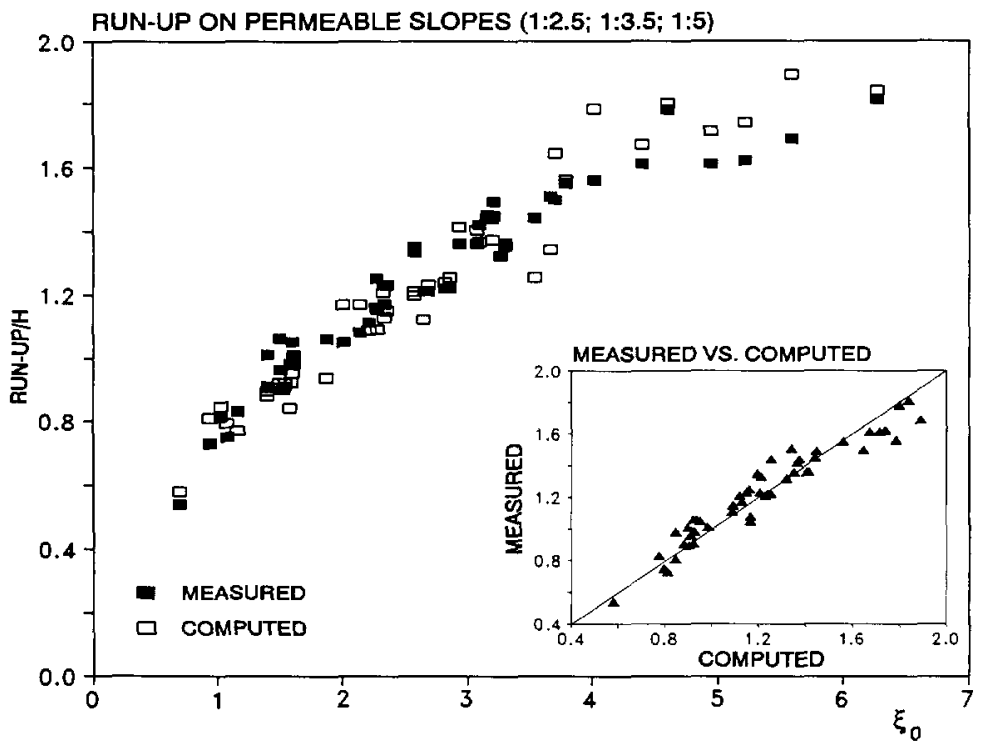

Fig.4.11 Comparison of run-up levels for regular waves on permeable slopes. 
good. For the highest values of the surf-similarity parameter $\left(\xi_{0}>5\right)$ the deviations increase. From the comparisons it can be concluded that the model predicts run-up levels on permeable slopes sufficiently accurately.

Lisev (1993) measured overtopping discharges over reshaped berm breakwaters. The crest of the structure was positioned at a level of $1.07 \mathrm{~m}$ while the depth at the toe was $h_{0}=0.80 \mathrm{~m}$. Stone sizes in the cover layer and core were $D_{n 50}=0.034 \mathrm{~m}$ and $D_{n 50}=0.011 \mathrm{~m}$ respectively. Eleven series of irregular wave trains were tested with wave heights varying between $H_{s}=0.146 \mathrm{~m}$ to $H_{s}=0.295 \mathrm{~m}$ and wave periods between $T_{p}=2.0 \mathrm{~s}$ and $T_{p}=2.8 \mathrm{~s}$.

In the numerical model the structure was homogenous with a stone size of $D_{n s 0}=0.034 \mathrm{~m}$. The influence of the flow field on the values of the friction coefficients $\beta$ and $\gamma$ have again been implemented as described in Equations 3.16 and Section 4.2.2. In these computations the following values have not been varied: $f=0.15$ (estimated by using Equation 4.3 with $h_{0}=0.80 \mathrm{~m}$, the most gentle sloping part in the reshaped profile, $1: 4.3$ and $R=H_{s}$ for which $H_{s}=0.20 \mathrm{~m}$ was taken); $n=0.40 ; \alpha_{D n 50}=1500 ; \beta_{c D n 50}=1.65 ; \Delta x=0.05 \mathrm{~m} ; \Delta t=0.01 \mathrm{~s} ; \Delta=0.005 \mathrm{~m}$. For each wave condition five series of about 500 waves were generated, based on a TMAspectrum.

Figure 4.12 shows the measured and computed overtopping discharges as a function of the relative freeboard defined as $F^{\prime}=F /\left(H_{s}^{2} g T_{p}^{2} / 2 \pi\right)^{1 / 3}$. The five computed overtopping discharges per wave condition were averaged while the vertical lines in Figure 4.12 denote the corresponding standard deviations. Overtopping discharge is one of the most difficult properties to predict because of the relatively large influence of the irregularity of wave trains and the low percentage of overtopping causing waves (between zero and about 40 waves for the conditions with a high and low relative freeboard respectively). Nevertheless, the numerical model seems to be able to provide a useful estimate of overtopping discharges. However, the computed overtopping discharges may easily deviate a factor two from the measured discharges for wave conditions with relatively large overtopping discharges.

To study the accuracy of predictions of wave transmission, two series of computations have been performed with low-crested and submerged structures. For all computations the structure modelled was based on the small-scale tests by 


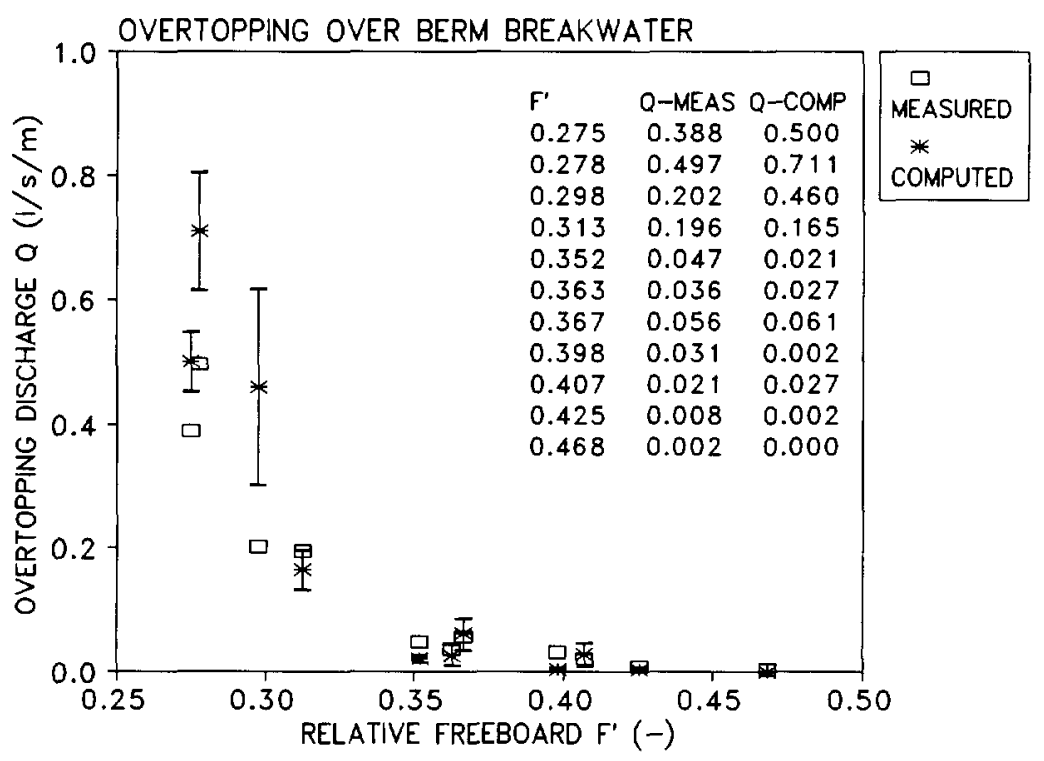

Fig.4.12 Wave overtopping over a berm breakwater.

Daemen (1991). Both the front slope and rear slope were 1:1.5. The crest of the structure was positioned at a level of $0.50 \mathrm{~m}$ while the depth at the toe varied between $h_{0}=0.25 \mathrm{~m}$ and $h_{0}=0.75 \mathrm{~m}$. The width at the crest was $0.12 \mathrm{~m}$. Stone sizes in the cover layer and core were $D_{n 50}=0.040 \mathrm{~m}$ and $D_{n 50}=0.028 \mathrm{~m}$ respectively.

Two series of eleven computations with a wave train of 200 to 250 waves (TMAspectrum) were performed. The first series of eleven computations had waves with $H_{s}=0.132 \mathrm{~m}\left(H_{\mathrm{rms}}=0.100 \mathrm{~m}\right)$ and $T_{p}=2.10 \mathrm{~s}$ (wave steepness $s_{o p}=0.02$ ), those in the second series had waves with a wave steepness of $s_{o p}=0.04$ characterised by $H_{s}=0.132 \mathrm{~m}\left(H_{r m s}=0.100 \mathrm{~m}\right)$ and $T_{p}=1.45 \mathrm{~s}$. This led to dimensionless crest heights between $R_{c} / H_{s}=-1.9$ for submerged structures and $R_{c} / H_{s}=+1.9$ for non-overtopped structures.

In the numerical model the structure was modelled as homogenous with a stone size of $D_{n 50}=0.030 \mathrm{~m}$. The influence of the flow field on the values of the friction coefficients $\beta$ and $\gamma$ have been implemented as described in Equations 3.16 and Section 4.2.2. In these computations the following values have not been varied: 


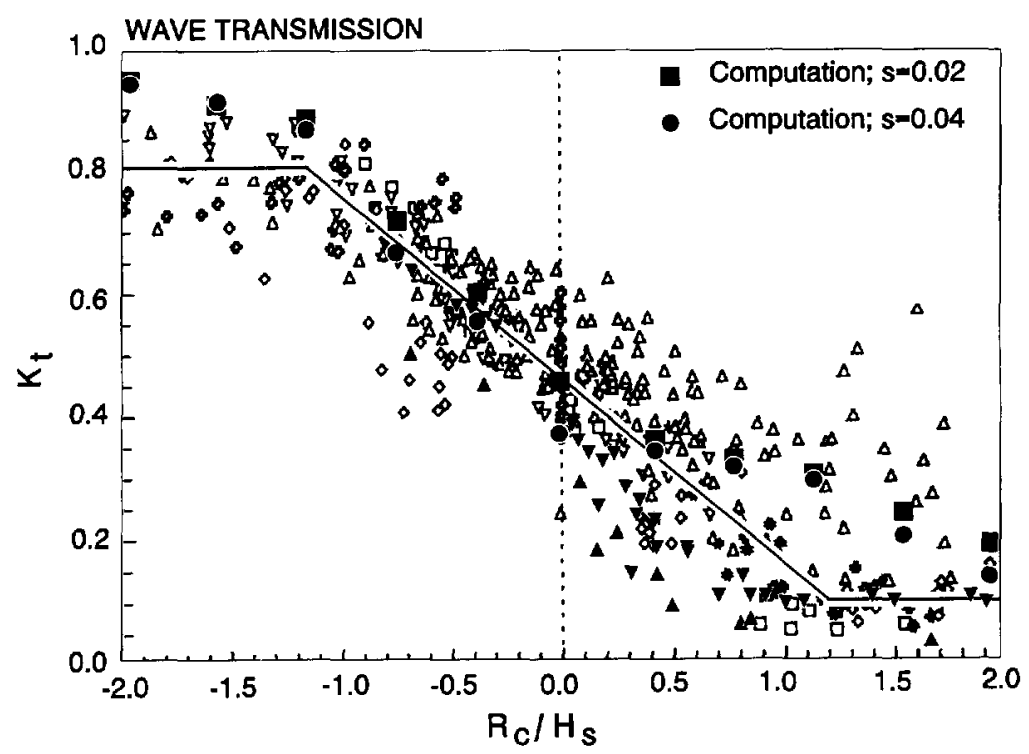

Fig.4.13 Wave transmission at low-crested and submerged structures.

$f=0.15$ (estimated by using Equation 4.3 with $h_{0}=0.25 \mathrm{~m}$, a representative slope of $1: 3.24$ and $\left.R=H_{s}\right) ; n=0.40 ; \alpha_{D n 50}=1500 ; \beta_{c D n 50}=1.65 ; \Delta x=0.025 \mathrm{~m} ; \Delta t=0.005 \mathrm{~s}$; $\Delta=0 \mathrm{~m}$.

Figure 4.13 shows the computed transmission coefficients $\left(K_{t}=H_{t} / H_{i}\right)$ as function of the relative crest height in a diagram (from Van der Meer and d'Angremond, 1991), with data from physical-model tests by several authors. The use of different stone diameters in these tests is the main cause of the large spread around 'average' values. Data by Daemen (1991) is added ( $\left.\checkmark: s_{o p}=0.02 ; \wedge: s_{o p}=0.04\right)$. For structures with a relatively high crest, wave transmission is largely determined by the permeability of the core, while for structures with a crest near the still-water level the permeability of the cover layer is more important. Variations in stone diameter therefore contribute to a large variation in wave transmission coefficients for higher values of the relative crest height.

In the region with higher crests, the numerical model gives higher wave transmission coefficients than those obtained from the physical-model tests, probably 
due to an overestimation of the permeability. For the computations with submerged structures $\left(R_{c} / H_{s}<0\right)$ wave transmission coefficients are close to the 'average' measured values but still somewhat higher than the corresponding data by Daemen (1991). These data also show lower values for the transmission coefficients for tests with a wave steepness of $s_{o p}=0.04$ than those with $s_{o p}=0.02$. Although weaker, this trend can also be observed in the numerical model results. Unlike data from measurements, the numerical model gives transmission coefficients up to $K_{l}=l$ for structures of which the level of the crest is a few times the wave height below stillwater level, which is a logical result. In general, the numerical model shows explicable trends in variations of the transmission coefficients as a result of varying parameters. The computed values of the transmission coefficients can be used as rough approximations.

\subsection{Numerical model applications}

\subsubsection{Sensitivity to permeability of structures}

In the previous section some model results for run-up and wave transmission are shown. Here, some results obtained with three types of structures are described to show the influence of the permeability of these structures. For this purpose, an impermeable structure, a permeable structure with an impermeable core and a homogeneous permeable structure are used. Regular waves with a wave height $H=0.20 \mathrm{~m}$ and a wave period $T=1.5 \mathrm{~s}$ on a seaward slope corresponding to a reshaped profile of a berm breakwater were computed. For the permeable structures, the porous media flow friction-coefficients as given in Equation 3.16 were used $\left(\alpha_{D n 50}=1500 ; \beta_{c \text { Dn50 }}=1.65\right)$. The applied numerical parameters are $\Delta x=0.025 \mathrm{~m}$, $\Delta t=0.006 \mathrm{~s}$ and $\Delta=0.005 \mathrm{~m}$.

Figure 4.14 shows the envelope of surface elevations for the three structures. As expected, the run-up level and the fluctuations in surface elevations are the largest for the impermeable structure. Figure 4.15 shows the maximum depth-averaged velocities that occur during one wave cycle for each position above the slope (positive is towards the crest of the structure). These velocities reach an absolute maximum just below the still-water 'shoreline'. In both directions, the absolute maxima reach the highest values for the case with an impermeable structure. For the maximum velocity in the direction away from the crest of the structure, this 


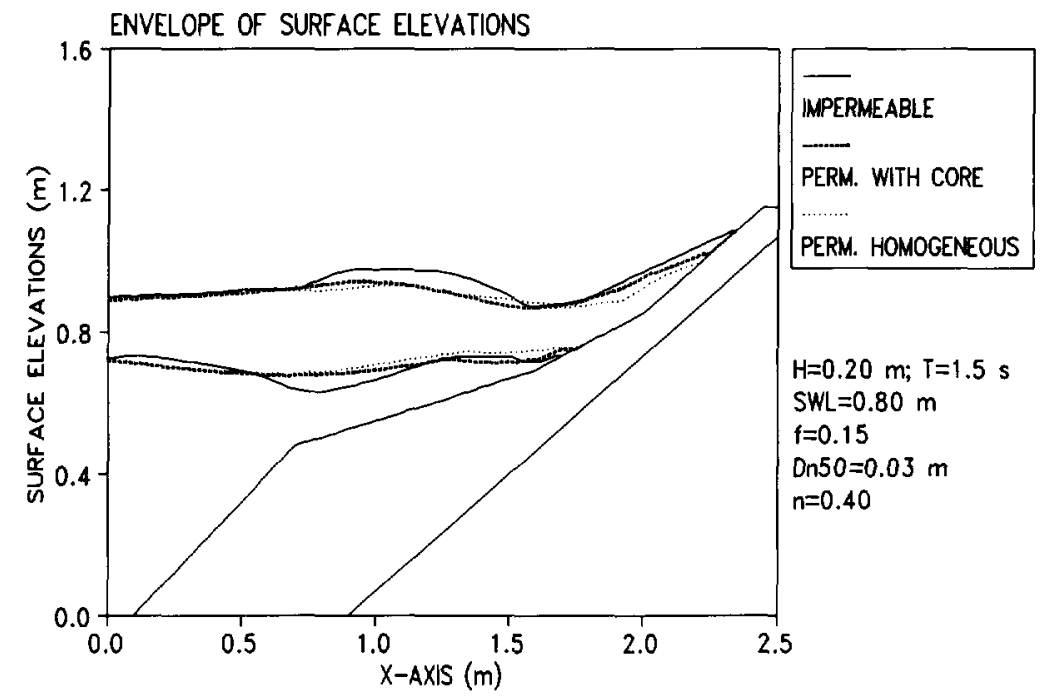

Fig.4.14 Envelope of surface elevations for three types of structures with the same seaward slope.

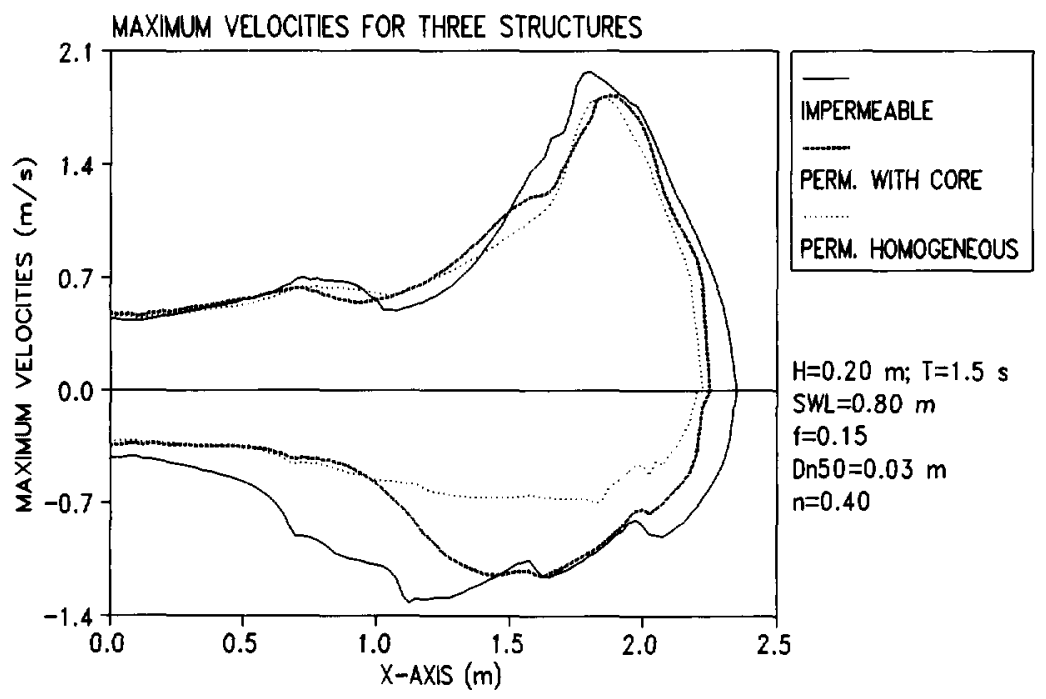

Fig.4.15 Maximum depth-averaged velocities in both directions for three types of structures with the same seaward slope. 


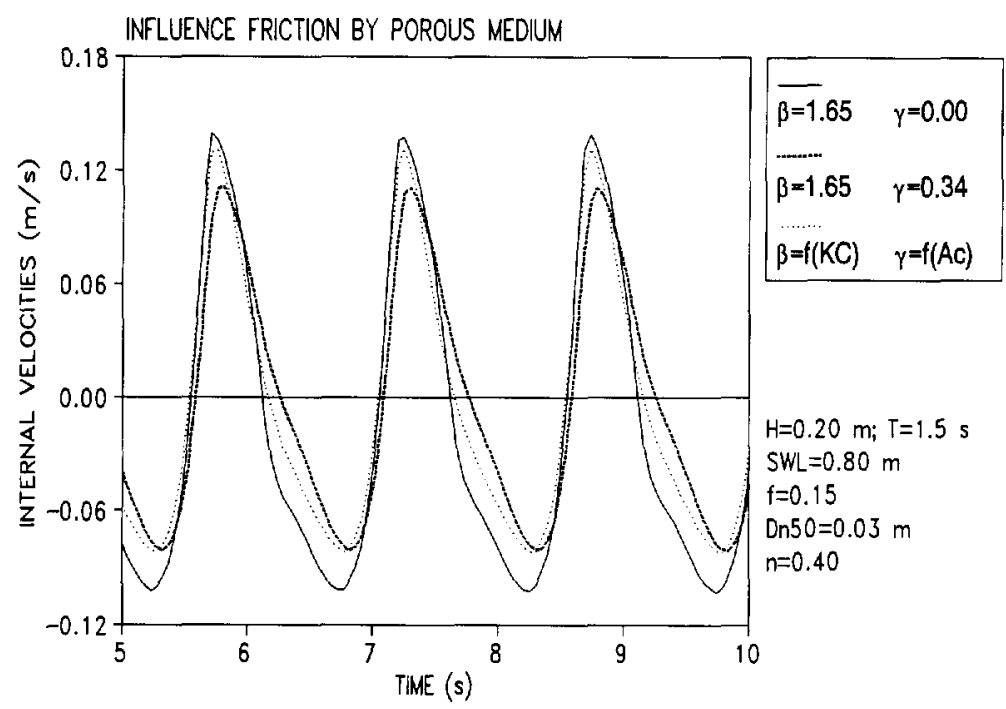

Fig.4.16 Influence of added mass and flow-dependent frictioncoefficients on the velocities inside a berm breakwater.

maximum occurs more seaward, namely near the flattest part of the seaward slope. The influence of the impermeable core is relatively small compared to the computation with a homogeneous structure, except for the maximum velocities in the seaward direction. The homogeneous structure gives less reflection $\left(K_{r}=0.16\right.$ with $\left.K_{r}=H_{r} / H_{i}\right)$ than the one with an impermeable core $\left(K_{r}=0.2 I\right)$. The impermeable structure gave a reflection coefficient $K_{r}=0.22$. Reflection of these regular waves causes local maxima in the curve for maximum velocities in the seaward direction.

To show the influence of added mass and the implementation of flow-dependent friction coefficients, a comparison is made between signals of computed filtervelocities. Figure 4.16 shows signals at a position inside the berm of the structure with an impermeable core as shown in Figure $4.14(x=0.80 \mathrm{~m})$. The first computation is done without added mass and with a constant value for the friction coefficient $\beta$. The second computation is performed with a constant value for the added mass coefficient $\gamma$. The dependency of these two coefficients on the flow field (Eq.3.10) is taken into account in the third computation (equal to the one used in the Figures 4.14 and 4.15). At this position, the filter-velocities reach the highest value in the computation without added mass but at some other positions, for 
instance more towards the crest, those obtained with the other two computations show higher maxima. Figure 4.16 also shows that inertia effects found when including added mass lead to a small phase shift, i.e., a time-lag, compared to the situation without added mass. Increasing the porous flow friction coefficients shows explicable trends in parameters like run-up, reflection and internal set-up, but the influence of taking added mass and flow-dependent friction coefficients into account is more difficult to predict. However, in most cases computations including added mass or flow-dependent friction coefficients show similar results to those obtained with a constant and slightly higher value for the friction coefficient $\beta$, namely somewhat higher run-up levels and somewhat higher reflection coefficients.

\subsubsection{Impressions of the flow field}

Because the numerical model is a one-dimensional model, which implies that no equation for the momentum in the vertical direction is solved, the model does not provide vertical velocities directly. This does not mean that no estimate of these vertical velocities can be given. Van Gent (1992) describes a simple approach used to derive vertical components of velocities leading to vector plots which give some additional information concerning the computed flow field. The approach, which does not affect the computation of the wave motion itself, is discussed briefly and some examples are given.

In principle, the horizontal components of velocities at specific elevations are not all equal to the depth-averaged velocity since the velocity profile is not uniform over the depth. However, the model does not provide sufficient information from which to obtain the deviations from these depth-averaged velocities. Vertical components have been estimated, however, by assuming a uniform profile for the horizontal velocities. To obtain vertical components, the kinematic boundary is used at the free surface ( $E q .2 .10)$. At the slope, the velocity is supposed to be parallel to the slope except for structures with a permeable slope. For such structures the interactive flow $(q)$, assumed to be perpendicular to the slope, also contributes to the velocity components. This affects both the horizontal and vertical components. The approach described here provides velocity vectors at the surface and along the slope. Velocity vectors between the free surface and the slope are obtained through linear interpolation. The velocity vectors inside the permeable layer are computed by using the same approach. After solving the differential equations, the vertical 
components of velocity vectors in the region of the external wave motion can be obtained through: $w=[\Delta h / \Delta t+u \cdot \Delta h / \Delta x] \cdot\left(z-z_{0}\right) / h+\left[u \cdot \Delta z_{0} / \Delta x+q \cdot(\cos \theta)^{2}\right] \cdot\left(1-\left(z-z_{0}\right) / h\right)$ where $z$ is the vertical position. For the horizontal component of the velocity above the slope the approach yields: $u=u_{d a}-\cos \theta \cdot \sin \theta \cdot\left(1-\left(z-z_{0}\right) / h\right) \cdot q$ where $u_{d a}$ is the depth-averaged velocity.

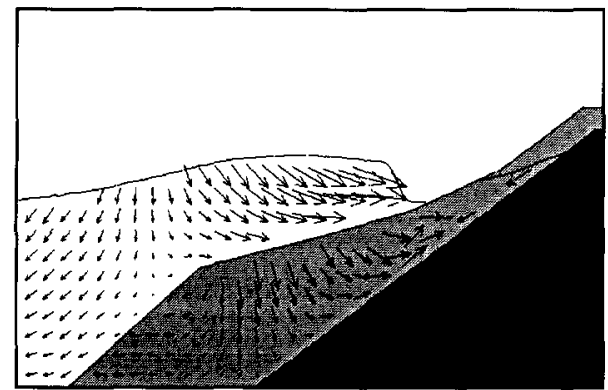

Fig.4.17 Impression of the flow field on and inside a berm breakwater with an impermeable core.

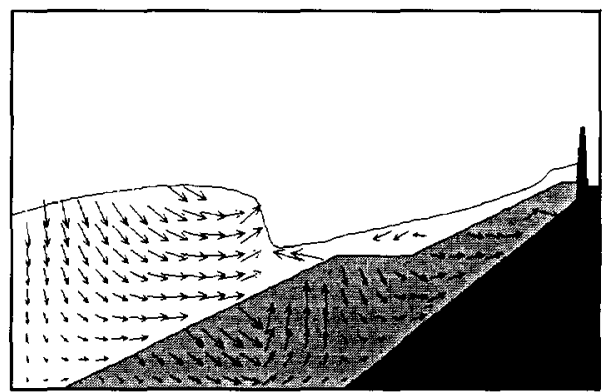

Fig.4.18 Impression of the flow field on and inside a permeable structure with a crown-wall.

Some applications of the approach are shown in Figures 4.17 and 4.18. The scale for the vectors inside the breakwaters is about three times larger than for those outside. The first figure shows the computed flow field for a wave on a slope of a berm breakwater with an impermeable core. The second figure shows a similar impression of the flow field for a rubble-mound structure with a crown-wall at the crest, modelled with a fully reflecting boundary. Reflection caused by this crownwall can be seen in this figure.

\subsubsection{Various other applications}

Reference will be made to some applications using the numerical model described without discussing them in detail. A sensitivity analysis as well as applications involving the estimate of the permeability coefficient as applied by Van der Meer (1988) and the prediction of the magnitude of the internal set-up for a practical case, are given in Van Gent (1994-a). Lisev (1993) investigated the influence of the layout of the core of berm breakwaters. Based on physical-model tests and the use of 
the numerical model it was concluded that the core can be extended into the berm without essentially affecting the performance of the structure. Julien (1993-a/b) studied the effects of the position and the magnitude of friction on properties like run-up levels and energy dissipation. The effects of berms on run-up levels were also studied. Kwik (1994) studied the influence of wave spectra on overtopping discharges, including a comparison of numerical model results with prototype measurements with double peaked wave-spectra. Hamilton and Hall (1994) verified applications with rubble-mound structures with crown-walls and De Groot et al. (1995) carried out an additional validation. The model was used to study wave transmission over an impermeable submerged structure with a fully reflecting wall behind this structure, to clarify trends observed in a limited data-set from physicalmodel tests, see Klopman and Klein Breteler (1994). In Van Gent (1994-e) the model has been extended for wave interaction with vegetation on embankments by simulating the motion of reed.

\subsection{Conclusions}

A numerical model for simulation of normally incident waves on various types of structures was made, based on shallow-water wave equations. The wave motion outside structures and the flow inside the permeable regions are modelled simultaneously, which enables applications with permeable structures. The method used to connect the external wave motion and the internal wave motion allows the free surface and the phreatic surface to move independently, i.e., in the onedimensional model the free surface can be disconnected from the phreatic surface. This enables implementation of phenomena like infiltration and seepage.

Analysis of the numerical scheme and an additional damping term shows the effects of numerical aspects on the computations. Comparison of the numerical model results with an analytical solution of the shallow-water wave equations shows that the numerical scheme and the boundary conditions only cause small inaccuracies. Comparison with data from physical-model tests show that for some parameters, e.g., run-up levels, the model provides accurate results. For parameters which do not show sufficient correspondence with physical-model tests, e.g., wave transmission coefficients, variations of such parameters as a result of variations in hydraulic and structural properties show the same trends as observed in such physical-model tests. 
The model allows for the studying of variations of hydraulic parameters as results of variations in structural lay-out, e.g., the permeability of structures.

Since the model solves one-dimensional equations, implying also that the free surface is described as a function of the horizontal coordinate, the field of application is limited. Although the model is easy to use in many practical situations, eventually a more sophisticated description of the flow field will be required to obtain more accurate results, a more detailed description of the flow field and a wider field of application. 
78

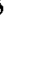

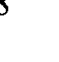
7 


\section{Chapter 5}

\section{Numerical simulation of wave attack by a 2D model}

\subsection{Introduction}

In Chapter 4 a numerical model for simulation of normally incident waves on coastal structures is discussed with emphasis on the implementation and validation of wave motion on and inside permeable structures. In this chapter a similar procedure is applied but now for a model based on a different type of equation, namely the Navier-Stokes equations. The advantages of the relatively simple model applied in the previous chapter, such as computational speed, accessibility and a good accuracy of some of the predicted hydraulic properties, may be sufficient for many applications. However, in many cases a wider range of applicability, a higher accuracy and a more detailed description of the flow field are desired. Therefore, a numerical model has been developed which is intended to provide more accurate and detailed descriptions of the flow field for a wider range of structures including permeable structures.

The model treated in this chapter, named SKYLLA, is based on the Navier-Stokes equations which are solved by using the Volume-of-Fluid (VOF) method. The model by Hirt and Nichols (1981) is used as a basis for further developments. Petit and Van den Bosch (1992) modified aspects of the original model such as the treatment of the free surface, the procedure to satisfy the equation for continuity and the implementation of smooth impermeable upward slopes. Activities described in this chapter were carried out in close cooperation with H.A.H. Petit and P. van den Bosch, both of Delft Hydraulics. The joint research is described in detail in Petit et al. (1994-a/b/c), Van Gent et al. (1994-a/b/c), Van Gent and Petit $(1994,1995)$ and Van Gent and Vis (1994). The analytical solutions for testing the numerical model for cases with porous media flow were provided by H.A.H. Petit. Both his 
cooperation and his permission to present those analytical solutions in Section 5.4.1 are gratefully acknowledged.

\subsection{Model composition and basic equations}

\subsubsection{General model composition}

The two-dimensional numerical model with a combined modelling of free surface wave motion and porous media flow will be discussed here. The model is twodimensional which allows for simulations with large variations in the vertical direction in both the flow field and in the lay-out of structures. The basic equations will be discussed in the next sub-section. The subsequent sub-section deals with the method used to solve these equations. This method uses cells for which a nonequidistant rectangular grid is used. Figure 5.1 shows a sketch of the general composition of the model.

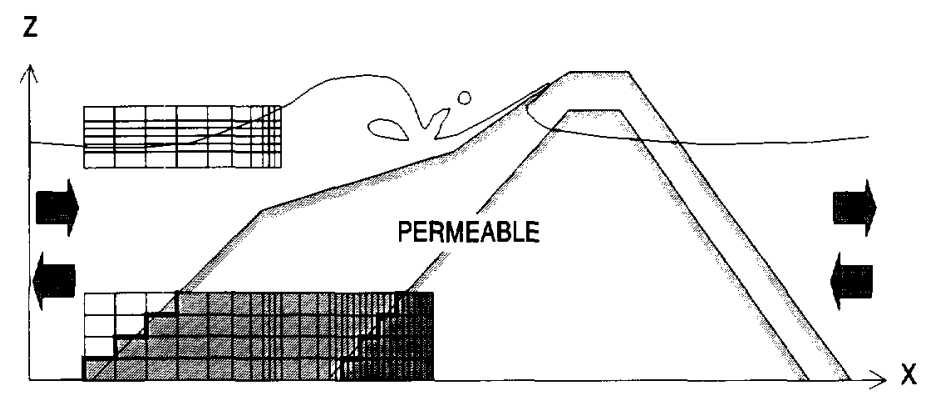

Fig.5.1 Model composition.

Smaller cells can be used in regions where the flow field is expected to become relatively complex, for instance in regions where overturning waves occur. Cells are assigned a specific porosity which is $n=1.0$ in the region of the external wave motion and a different porosity in regions where porous media flow will be simulated. Because the numerical model uses velocities at the four boundaries of each cell, porosities are redefined at the cell boundaries. This is done by interpolation between porosities of two neighbouring cells. This implies that the transition between regions of a different porosity is described by a poly-line 
consisting of line segments along cell boundaries with a porosity in between those of the surrounding regions. A number of regions with a different stone diameter and porosity can be specified. In each of these regions, the porous medium is homogeneous and isotrope. At the boundaries between regions with different properties, no friction other than those for the description of porous media flow are implemented. Impermeable slopes as well as combinations of impermeable parts with permeable parts can be modelled.

The left and right boundaries of the computational domain can be open, in which case these boundaries act as weakly reflecting boundaries. Regular waves can be generated at these boundaries while reflected waves can leave the computational domain here.

\subsubsection{Basic equations}

In Section 2.2.4 the Navier-Stokes equations are discussed briefly. For normally incident waves the wave motion is described by momentum equations in twodimensions. The governing equations for the external flow read:

$$
\begin{aligned}
& \frac{\partial u}{\partial t}+\frac{\partial u^{2}}{\partial x}+\frac{\partial u w}{\partial z}+\frac{1}{\rho} \frac{\partial p}{\partial x}-v_{t}\left(\frac{\partial^{2} u}{\partial x^{2}}+\frac{\partial^{2} u}{\partial z^{2}}\right)+g_{x}=0 \\
& \frac{\partial w}{\partial t}+\frac{\partial u w}{\partial x}+\frac{\partial w^{2}}{\partial z}+\frac{1}{\rho} \frac{\partial p}{\partial z}-v_{t}\left(\frac{\partial^{2} w}{\partial x^{2}}+\frac{\partial^{2} w}{\partial z^{2}}\right)+g_{z}=0
\end{aligned}
$$

where $u$ and $w$ are the velocities in the $x$ and $z$ direction respectively and $\nu_{t}$ the turbulence viscosity. By applying a constant viscosity, these equations only deviate slightly from the original Navier-Stokes equations (Eq.2.l) because for the kinematic viscosity $(\nu)$ a value is taken of the magnitude as the turbulence viscosity $\left(\nu_{t}\right)$. The grid is too coarse to simulate turbulence directly. This implies that the equations describe the mean flow and do not include turbulence components. In fact, the Reynolds-equations (Eq.2.15) are solved by neglecting Reynolds-pressures and the laminar shear-stresses and by using the formulation for the Reynolds shearstresses as written in Equation 2.16 with a constant turbulence viscosity. 
For the internal wave motion adapted Navier-Stokes equations for porous media flow were derived, see Equations 3.12 and 3.13. To simplify the solution of this set of equations and to avoid separate procedures for each of the regions with different properties, this set of equations (Eq.5.1-5.2 and Eq.3.12-3.13) is reduced to a set of equations that can be applied throughout the entire computational domain:

$$
\begin{aligned}
\frac{1+c_{A}}{n} \frac{\partial u}{\partial t}+\frac{\partial}{\partial x}\left(\frac{u}{n}\right)^{2}+\frac{\partial}{\partial z}\left(\frac{u}{n} \frac{w}{n}\right) & +\frac{1}{\rho} \frac{\partial p}{\partial x}+g a u+g b u \sqrt{\left(u^{2}+w^{2}\right)} \\
& -n^{m} v_{t}\left(\frac{\partial^{2} u}{\partial x^{2}}+\frac{\partial^{2} u}{\partial z^{2}}\right)+g_{x}=0 \\
\frac{1+c_{A}}{n} \frac{\partial w}{\partial t}+\frac{\partial}{\partial x}\left(\frac{u}{n} \frac{w}{n}\right)+\frac{\partial}{\partial z}\left(\frac{w}{n}\right)^{2} & +\frac{1}{\rho} \frac{\partial p}{\partial z}+g a w+g b w \sqrt{\left(u^{2}+w^{2}\right)} \\
& -n^{m} v_{t}\left(\frac{\partial^{2} w}{\partial x^{2}}+\frac{\partial^{2} w}{\partial z^{2}}\right)+g_{z}=0
\end{aligned}
$$

where $u$ and $w$ represent filter/discharge-velocities in permeable regions. The integer $m$ is high enough to assure that the corresponding terms are sufficiently small to be negligible in permeable regions (where these term have no physical meaning). The coefficients for the porosity $n$, the dimensional friction coefficients $a$ and $b$, and the added mass coefficient $c_{A}$, can be varied per cell. For the coefficients $a, b$ and $\gamma$ $\left(c_{A}=\gamma \cdot(1-n) / n\right)$, the expressions given in Equation 3.16 are used. By specifying a stone diameter for each cell and a characteristic filter/discharge velocity $\hat{U}$ for the entire permeable region in advance, these porous media flow friction-coefficients are assigned a specific constant value for each cell. These coefficients are zero in the non-permeable region.

Conservation of mass, $\partial w / \partial x+\partial w / \partial z=0$, is satisfied in both the region with free surface flow and the permeable regions by solving the pressure Poisson equation (similar to Eq.2.17). This equation is obtained by taking the time derivative of the equation for conservation of mass and by replacing the time-derivatives $\partial u / \partial t$ and $\partial w / \partial t$ in this equation by there equivalents obtained from the Equations 5.3 and 5.4. This yields the pressure field from a given velocity field at a specific moment of time. 


\subsubsection{Volume-of-Fluid method}

Solving the Navier-Stokes equations yields a velocity field at a specific moment. When applied to wave propagation, new velocities result in changes of the free surface. In complex flow patterns such as occur in overturning waves, methods that describe the free surface evolution directly by solving differential equations for the free surface position (surface tracking methods) are very difficult to handle. However, in the VOF-method of Hirt and Nichols (1981) the fluid domain can be changed without using a description of the free surface position (surface capturing method). In principle, this enables the simulation of complex flow patterns with, for instance, multiple-connected free surfaces that occur in an overturning wave tongue hitting the water layer underneath. The principle of this method will be discussed briefly below.

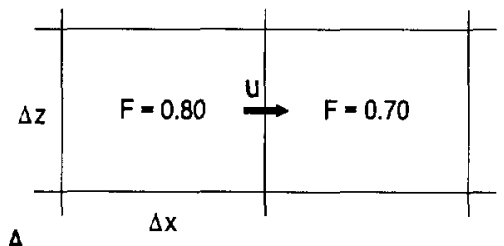

A
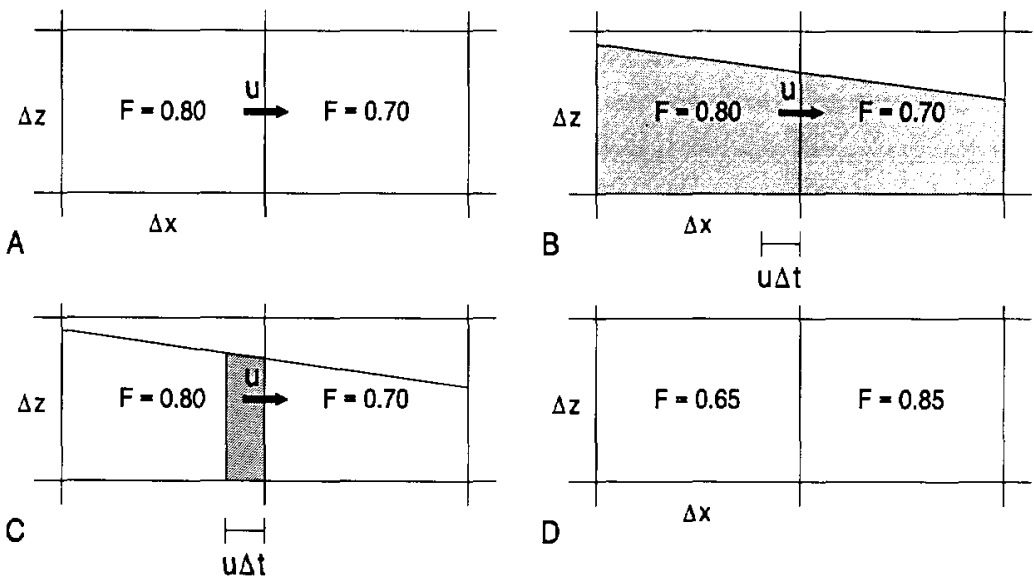

Fig.5.2 Transport of fluid based on the VOF-method.

The VOF-method makes use of fluid fractions, i.e., a percentage of each cell in the computational domain is filled with fluid. This fluid fraction $(F)$ can vary between zero (empty) and one (full). Based on the computed velocity field, a fraction of the fluid in a cell is transported to the surrounding cells. For cells which are not completely filled, this can be done in several ways. Figure 5.2 shows the principle 
of the method. Based on the two fluid fractions of two neighbouring cells (Fig.5.2$A$ ), a 'local surface', schematised by a straight line intersecting the two cells, can be constructed $(B)$. A part of the fluid is transported between these two cells $(C)$ by using the instantaneous time-step $\Delta t$ and the velocity obtained from solving the Navier-Stokes equations. This yields new fluid fractions in both cells $(D)$. At each time-step this procedure to transport fluid between two cells is carried out at all cell boundaries.
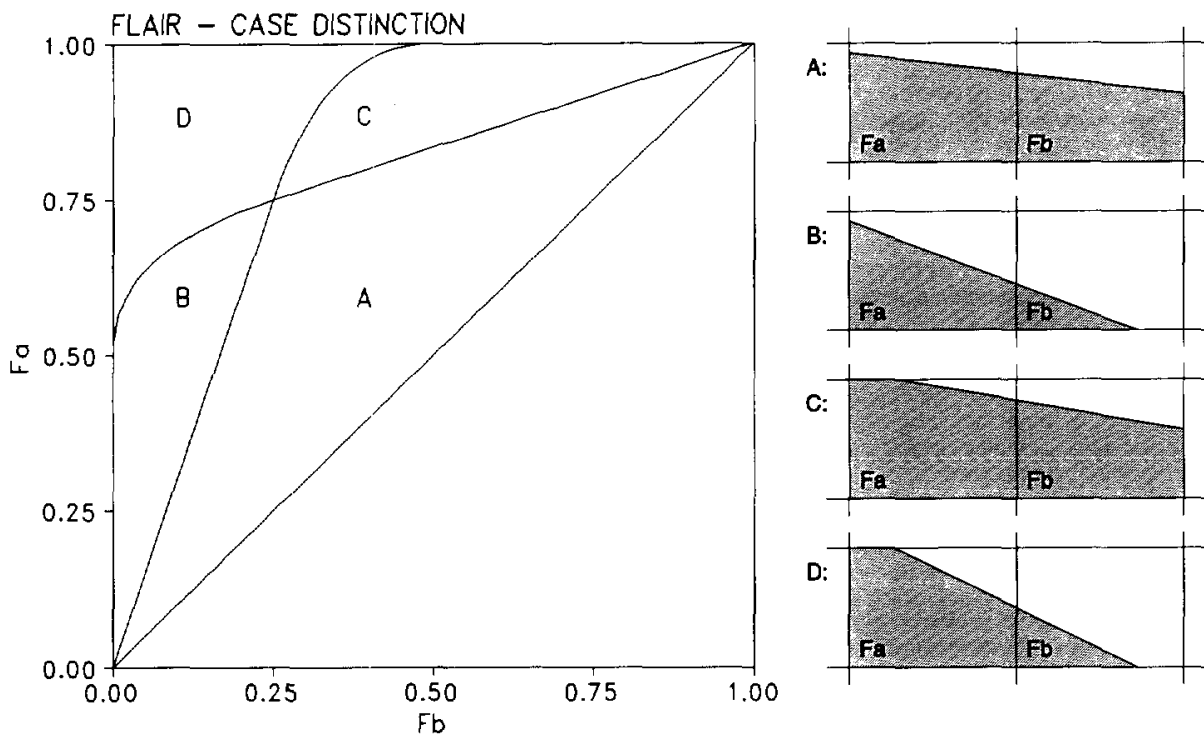

B:

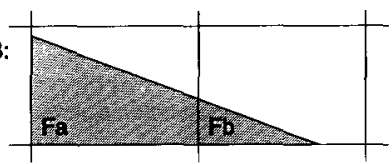

c:

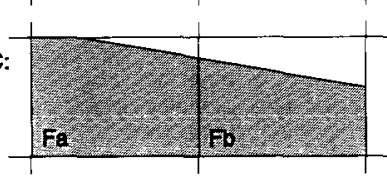

D:

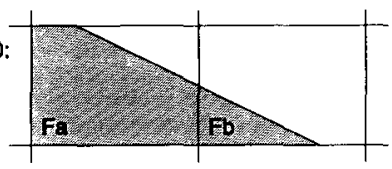

Fig.5.3 Distinction of 'local surface' for transport of fluid between two partially filled cells.

The volume to be transported between two cells depends considerably on the procedure used to construct a 'local surface' as shown in Figure 5.2- $B$. This definition of the 'local surface' can be done in several ways. The original VOFmethod of Hirt and Nichols (1981) defines a 'local surface' as being either horizontal or vertical. Several authors provided alternative definitions for these 'local surfaces'. The one of Ashgriz and Poo (1991), called FLAIR, was found to be the most accurate of the concepts considered. Figure 5.3 shows four cases of how to construct a 'local surface' between two neighbouring cells where neither is 
completely filled or completely empty. Based on the fluid fractions, the FLAIRmethod defines which of the four cases is to be used (left diagram). All combinations of two cells can be orientated such that the fluid fraction in the left cell is greater than the one on the right side $\left(F_{a}>F_{b}\right)$.

For transporting fluid between two cells of one which is partially filled and the other one is completely empty or completely filled, a 'local surface' needs to be defined within this partially filled cell. Figure 5.4 shows the four possible types of 'local surface' slopes for a partially filled cell with an empty neighbouring cell. The procedure, as described in Figure 5.3, can provide the 'local surface' slope between the partially filled cell (Fig.5.4) and its upper neighbouring cell, and also between this cell and its lower neighbouring cell. The average of these two 'local surface' slopes is taken as the slope of the surface inside the partially filled cell. Based on this slope, $\beta$, and the fluid fraction, $F_{a}$, a distinction can be made between the four possible cases, see the left diagram in Figure 5.4.
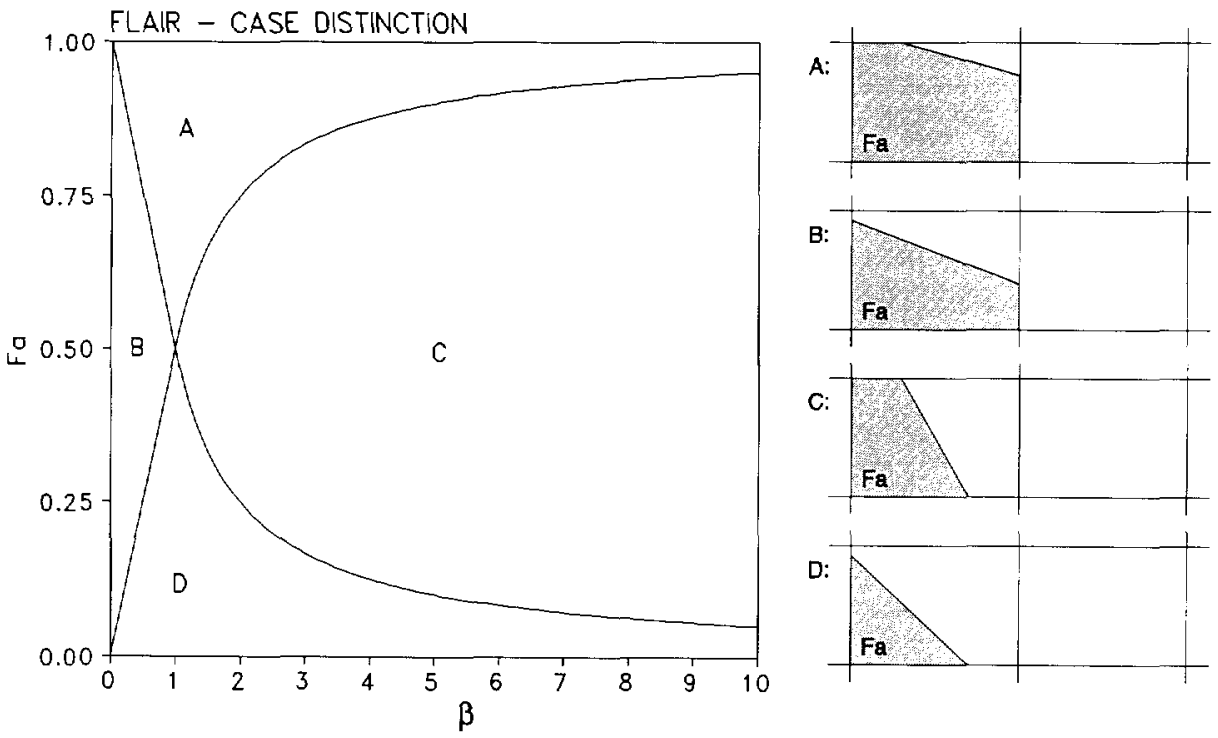

Fig.5.4 Distinciion of 'local surface' inside a partially filled cell for transport of fluid to an empty neighbouring cell. 
For cases in which the neighbouring cell is completely filled, the same procedure as the one in Figure 5.4 can be applied. For all combinations of completely filled cells and completely empty cells the 'local surface' orientation is known. The procedure described determines the 'local surfaces' without any other information than the fluid fractions in the cells. For transporting fluid between two cells the fluid fractions of these two cells provide sufficient information for most of the cases. To obtain more accurate procedures more information on the fluid fractions and the velocity field in the surrounding cells can be used. However, this complicates the procedure considerably. This has not been done so far, except for cases in which the procedure described by Ashgriz and Poo (1991) was found to give unacceptable inaccuracies. Petit and Van den Bosch (1992) concluded that this was the case for situations like those shown in Figure 5.3 where the neighbouring cell on the left side of these two cells is empty. Their procedure to handle these situations has been implemented in the model and was found to considerably increase the accuracy of the treatment near empty cells.

Because filter/discharge velocities are used in the numerical model, the procedures to transport mass between the cells (VOF-method and FLAIR-method), do not require any adaptation for transport inside permeable regions.

\subsubsection{Boundary conditions}

\section{Free surface}

At the free surface and close to impermeable slopes not all velocities necessary to discretise the equations are within the fluid domain. Figure 5.5 shows the velocities which are required for the discretisation to obtain a horizontal velocity inside the fluid (Fig.5.5-A) and near the free surface (Fig.5.5-B). Boundary conditions are required to solve the lack of information at the free surface. Several conditions can be applied. For instance, a method in which the velocities outside the fluid domain are obtained by copying velocities from the fluid domain to the positions outside the fluid (no gradients in velocities near the free surface) has been investigated. Methods where these velocities are obtained by extrapolation from velocities inside the fluid domain and a method where the flow is assumed to be irrotational at the free surface were also studied. The assumption of irrotational flow is not valid in regions with breaking waves. Based on comparisons with analytical solutions, it was 
found that applying the method using the assumption of irrotational flow near the inflow boundary in combination with the method of copying velocities from the fluid domain proved to be the most appropriate method of those investigated (Petit et al., 1994-a).
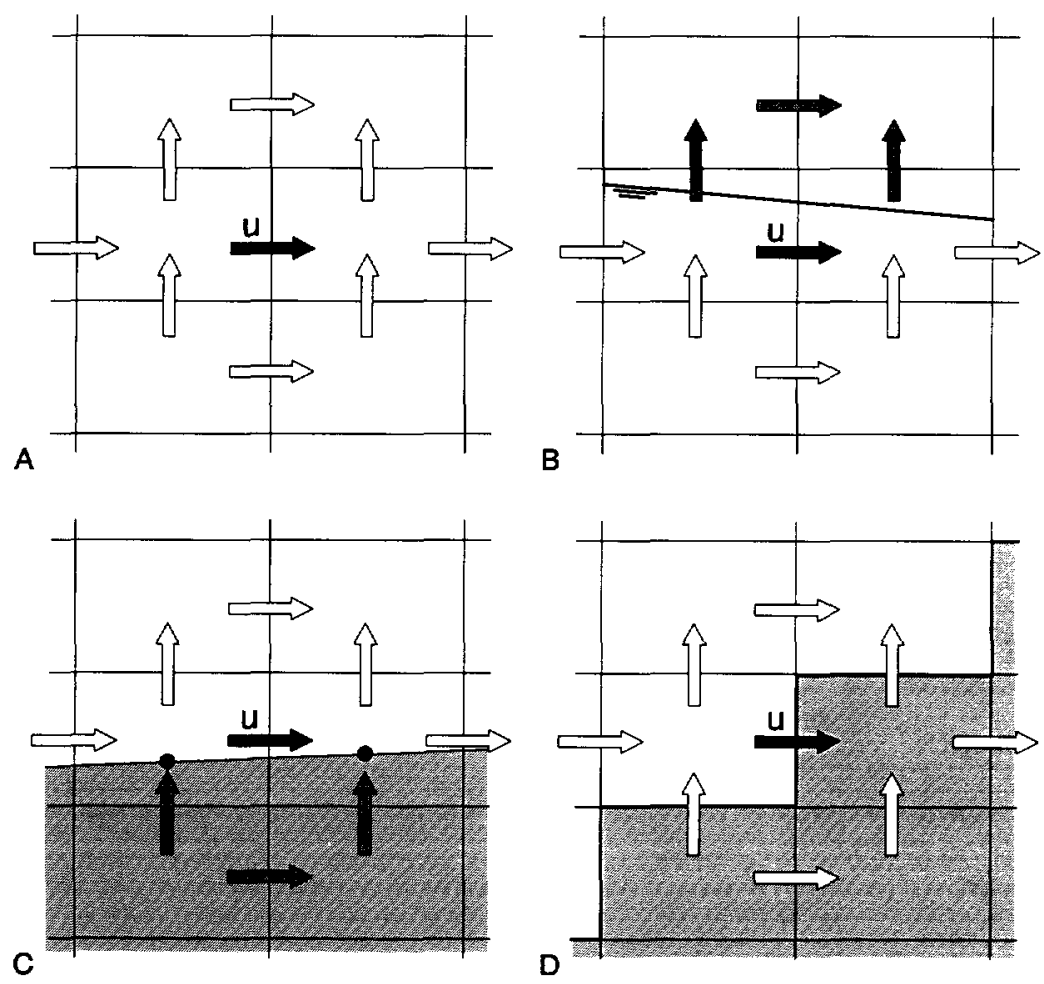

Fig.5.5 Required velocities in discretisation for horizontal velocities; A) in the fluid, $B)$ at the free surface, C) at impermeable slopes,

D) at permeable boundaries.

\section{Impermeable slopes}

The boundaries for impermeable slopes are defined on sub-grid level which means that the slope can intersect cells (no 'stair-case' slope). Figure 5.5-C shows that for 
the discretisation of some velocities in the fluid, virtual velocities at positions which are actually inside the impermeable structure are also required. To solve this, at these positions velocities are defined in such a way that at the position of the impermeable slope specified boundary conditions are satisfied. Both the procedures to satisfy no-slip or free-slip boundary conditions have been implemented. A large number of types of intersections of impermeable slopes with cells can be distinguished. In Petit et al. (1994-c) several of these types of intersections are treated. This enables description of climbing and falling impermeable slopes where these slopes are described by straight lines inside each cell. Not all types of intersections with cells have been described and implemented but already a large number of possible structural lay-outs have been made possible. Simulations with realistic representations of surface roughness are not yet possible for structures with a limited roughness since no variation of bottom friction is possible other than $a$ ) completely smooth by applying the free-slip boundary condition or $b$ ) a specific, but not variable, friction by applying a no-slip boundary condition.

For permeable slopes no additional boundary conditions are required since permeable slopes are described along cell boundaries and therefore do not intersect cell boundaries (Fig.5.5-D). No formulation for additional bottom friction is implemented for permeable slopes.

\section{In- and outflow boundaries}

The left and right boundaries of the computational domain can either be closed or open. If open boundaries are required, waves must be allowed to leave the computational domain without causing reflections back into the computational domain. Therefore, at both sides weakly reflecting boundaries are implemented while at the same time waves can be generated at these boundaries. For computations with open boundaries on both sides of the computational domain, the numerical flow is hard to control. Often an uncontrollable and unrealistic average discharge through the computational domain occurred. Therefore, weakly-reflecting boundary conditions have been implemented which allow for the prescription of average values of both the velocities and the surface elevations. This allows for computations where the average discharge can be prescribed as zero in limit, or for instance given a value in such a way that the mass-transport associated with a specific wave train is allowed to enter and leave the computational domain. As will 
be discussed in the following sub-section, incident waves $\left(\eta_{i}\right)$ are obtained by using a program by Klopman (1989) who also proposed the following type of expression for obtaining an average-prescribing weakly reflecting boundary:

$$
\frac{\partial}{\partial t}\left(\eta-\eta_{i}\right)-c \frac{\partial}{\partial x}\left(\eta-\eta_{i}\right)+r_{\eta}(\eta-\bar{\eta})=0
$$

where the value of $r_{\eta}$ determines how fast the surface at the boundary is forced towards the prescribed average value of the surface elevation $(\bar{\eta})$. By applying zero as the value for $r_{\eta}$ the conventional expression for a weakly reflecting boundary appears. The same expression is used for the horizontal velocity $(u)$, so both the parameters $r_{\eta}$ and $r_{u}$ need to be prescribed in advance. Appropriate values have to be determined based on experience with similar flow conditions. For computations with only one open boundary the values zero for both $r_{\eta}$ and $r_{u}$ will do.

\section{Incident waves}

Regular wave trains can be generated at the weakly reflecting boundaries. These incoming non-linear waves are based on the theory by Rienecker and Fenton (1981). Use is made of the program RFWAVE by Klopman (1989). The theory is based on potential flow theory for gravity waves over a horizontal bottom. Since this theory is applied here for waves which are partially reflected by the presence of structures, not only incident waves but also reflected waves are present at the open inflow boundary. The reflected waves cause a difference between the actual free surface at the boundary and the contribution of the incident waves to this free surface. The incident waves and reflected waves can be distinguished but the problem remains that horizontal and vertical velocities have to be prescribed for the incident waves up to the level of the actual free surface and not to the level of the free surface belonging to the incident waves only. Therefore, a method of stretching the velocity-profiles from the level of the free surface of the incident waves to the actual free surface is applied to solve this problem. This 'stretching' cannot satisfy both the balance of momentum and of mass. Based on comparisons of numerical test results with an analytical solution, it was decided to satisfy the balance of momentum and allow small deviations of the balance of mass. More detailed information concerning the treatment and verification of these incident waves and 
the treatment of empty or partially filled cells near open boundaries, can be found in Petit et al. (1994-a) and Van Gent et al. (1994-a).

For an adequate representation of an irregular wave climate a relatively long wave train must be computed. See Section 5.6 for a discussion of the involved problems concerning the computing time.

\subsection{Numerical scheme}

For the numerical discretisation of the basic equations ( $E q .5 .3-5.4)$, a partial-upwind numerical scheme was applied. The discretisation itself and an analysis to obtain stability criteria are given in Van Gent et al. (1994-b). Here, only a brief analysis of the dissipation and dispersion characteristics of the partial-upwind scheme, similar to the one performed in Section 4.3.2, will be discussed.

To give an indication of the differences between the behaviour of wave components as described by the equations and those by the discretised equations, again a comparison is made by using the simple-wave equation $(\partial w / \partial t+c \cdot \partial w / \partial x=0)$ instead of the (adapted) Navier-Stokes equations ( $E q$.5.3-5.4). The partial-upwind scheme with the upwind fraction $\beta_{u p}$ (where $0<\beta_{u p} \leq 1$ ), space-step $\Delta x$, time-step $\Delta t$, CFLnumber $\mu=c \cdot \Delta t / \Delta x$ and $u_{j, n}=u(j \Delta x, n \Delta t)$ yields:

$u_{j, n+1}=u_{j, n}-\mu\left[\beta_{u p}\left(u_{j, n}-u_{j-1, n}\right)+\frac{1}{2}\left(1-\beta_{u p}\right)\left(u_{j+1, n}-u_{j-1, n}\right)\right]$

Substituting again the Fourier-component $u_{j, n}=\hat{u} D_{\Delta l}{ }^{n} e^{-i \omega n \Delta t} e^{i k j \Delta x}$ (at the point $j \Delta x$ and time $n \Delta t$ ) in the discretised equation, yields the growth-rate per time-step, $D_{\Delta t}$, of the amplitudes of the components $(\hat{u})$ in the discretised equation compared to those in the equation itself: $D_{\Delta u}=\sqrt{ }\left[1+\mu \cdot(1-\cos \alpha) \cdot\left(\mu \cdot\left(1+\beta_{u p}{ }^{2}+\left(1-\beta_{u p}{ }^{2}\right) \cdot \cos \alpha\right)-2 \beta_{u p}\right)\right]$ per component with $\alpha=k \cdot \Delta x=2 \pi / L \cdot \Delta x$. The above substitution also yields the celerity of components in the discretised equation, $c_{\text {num }}=\omega_{\text {num }} / k$, compared to those in the equations, $c_{e q}: c_{n u m} / c_{e q}=1 /(\mu \alpha) \cdot \arccos \left[\left(1-\mu \cdot \beta_{u p} \cdot(1-\cos \alpha)\right) / D_{\Delta t}\right]$.

Figure 5.6 shows the growth-rate per time-step and the dispersion by the scheme relative to those of the equations itself. For the upwind fraction $\beta_{u p}$, the value 0.5 was used. Lower upwind fractions yield higher growth-rates and lower values for 
the relative dispersion which consequently means that lower upwind fractions lead to less accurate results. The left graph in Figure 5.6 indicates that for higher values of the CFL-number, the growth-rate per time-step is greater than one which leads to instable computations. The stability condition for this scheme is $\mu \leq \beta_{u p}$ for the simple-wave equation. This restriction is more complex for the two-dimensional Navier-Stokes equations containing diffusion terms (see Van Gent et al. 1994-b).
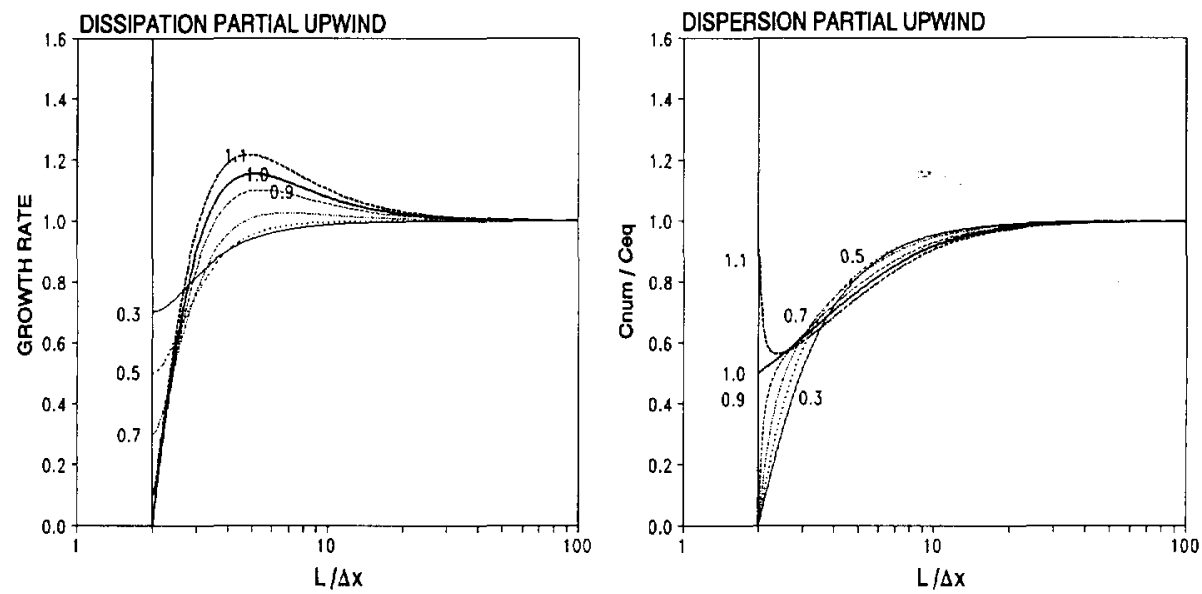

Fig.5.6 Dissipation and dispersion by the numerical scheme (labels denote the CFL-number $\mu ; \beta_{u p}=0.5$ ).

\subsection{Validation of the numerical model}

\subsubsection{Comparison with analytical solutions}

\section{Waves over a horizontal bottom}

For the validation of the numerical model, and especially for the validation of the implementation of weakly reflecting boundaries, a comparison was made for wave propagation over a horizontal bottom. At one side regular waves with a height of $0.20 \mathrm{~m}$ and a period of $3.0 \mathrm{~s}$ on a still-water depth of $1.0 \mathrm{~m}$ were generated, based on the analytical solution by Rienecker and Fenton (1981). An open outflow 
boundary was positioned at exactly two wavelengths $(\lambda=8.835)$ behind the inflow boundary. A free-slip boundary was applied at the bottom. At the free surface the condition that the flow is free from rotation is applied. In the discretisation an upwind fraction of $\beta_{u p}=0.30$ was applied. In the $x$ and $z$-direction, 295 and 40 cells were used respectively $(\Delta x=0.06 \mathrm{~m}$, equidistant, and $\Delta z=0.02 \mathrm{~m}$ at the still-water level). For the time-step $\Delta t=0.005 \mathrm{~s}$ was used $\left(\mu_{x}=0.26\right)$. For the viscosity a constant value of $\nu_{t}=0.025 \mathrm{~m}^{2} / \mathrm{s}$ was specified. The coefficients $r_{\eta}$ and $r_{u}$ were both taken zero here which means that the weakly reflecting boundaries do not prescribe a given average.

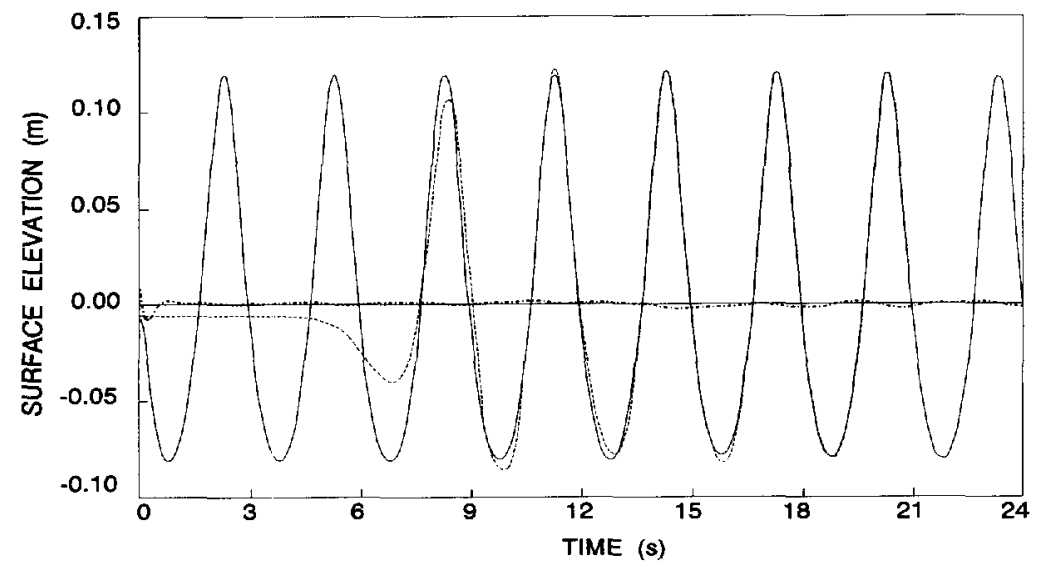

Fig.5.7 Surface elevations at in-and outflow boundaries (lines and dashed lines resp.) and differences between those by the analytical solution and at the inflow boundary (center line).

Figure 5.7 shows the free surface as computed by the numerical model at both sides of the computational domain. Since the computational domain is exactly two wavelengths long, the graph shows that the differences between the surface elevations at both boundaries are small, both with respect to magnitude and to phase. The third signal shows the difference between the surface elevations as prescribed by the analytical solution and the computed surface elevations at the inflow boundary. These differences are less than $4 \mathrm{~mm}$ (less than $2 \%$ of the wave height). This indicates that the numerical model can simulate wave propagation over a horizontal bottom rather accurately. 


\section{Flow through porous media}

Several verifications of the implementation of porous media flow have been performed. Before the wave motion on and inside a permeable structure is verified by using physical-model tests, three comparisons with analytical solutions are carried out. The first case concerns a layer of water with a thickness $L_{w}$ that is initially positioned above a dry permeable part, see Figure 5.8. At $t=0$, the layer of water starts entering the permeable part. For this simplified case of uniform flow entering a permeable part $\left(-L_{w}<x_{0}<0\right)$, the Navier-Stokes equations are reduced to a set of one-dimensional differential equations (Van Gent et al., 1994-b) where $u$ is the filter-velocity, $n$ the porosity and $x_{0}$ the position of the free surface, at $t=0$, $x_{0}=-L_{w}$ :

$$
\frac{d u}{d t}=\frac{-\frac{g}{n}\left(L_{w}+x_{0}\right)\left(a u+b u^{2}-1\right)-\left(\frac{1}{n^{2}}-1\right) u^{2}-g x_{0}}{\frac{L_{w}+x_{0}}{n^{2}}-x_{0}}
$$

With $d x_{0} / d t=u$, this set of differential equations was solved by using a fourth-order Runge-Kutta method with $\Delta t=0.005 \mathrm{~s}$ while for the constants $L_{w}, n, g, a, b$ the values $0.5 \mathrm{~m}, 0.5,4 \mathrm{~m} / \mathrm{s}^{2}, 0 \mathrm{~s} / \mathrm{m}$ and $16.9 \mathrm{~s}^{2} / \mathrm{m}^{2}$ were used respectively (for $g, 4 \mathrm{~m} / \mathrm{s}^{2}$ is taken instead of $9.81 \mathrm{~m} / \mathrm{s}^{2}$ to exaggerate the local maximum and the local minimum in Figure 5.8). After the layer has entered the permeable part, the differential equation reduces to: $d u / d t=n g\left(1-a u-b u^{2}\right)$ for which an analytical solution was found:

$$
u(t)=\left(u_{1}-u_{2} \frac{u\left(t_{0}\right)-u_{1}}{u\left(t_{0}\right)-u_{2}} e^{-b n g\left(u_{1}-u_{2}\right)\left(t-t_{0}\right)}\right) /\left(1-\frac{u\left(t_{0}\right)-u_{1}}{u\left(t_{0}\right)-u_{2}} e^{-b n g\left(u_{1}-u_{2}\right)\left(t-t_{0}\right)}\right)
$$

where $u_{1}=-a / 2 b+\sqrt{ }\left(a^{2}+4 b\right) / 2 b, u_{2}=-a / 2 b-\sqrt{ }\left(a^{2}+4 b\right) / 2 b$ and $u\left(t_{0}\right)$ is the initial velocity at $t=t_{0}$ where $t_{0}$ is the moment at which the whole layer of water has entered the permeable part. Figure 5.8 shows the comparison of the numerical results $(\Delta x=0.05 \mathrm{~m})$ and these solutions. At $t=0$, the velocity is zero, at $t=0.435 \mathrm{~s}$ a local maximum of $u=0.6848 \mathrm{~m} / \mathrm{s}$ occurs and at $t=0.850 \mathrm{~s}\left(t_{0}\right)$ the layer has entered the permeable part, after which the velocity converges to the velocity $0.75 \mathrm{~m} / \mathrm{s}$. 

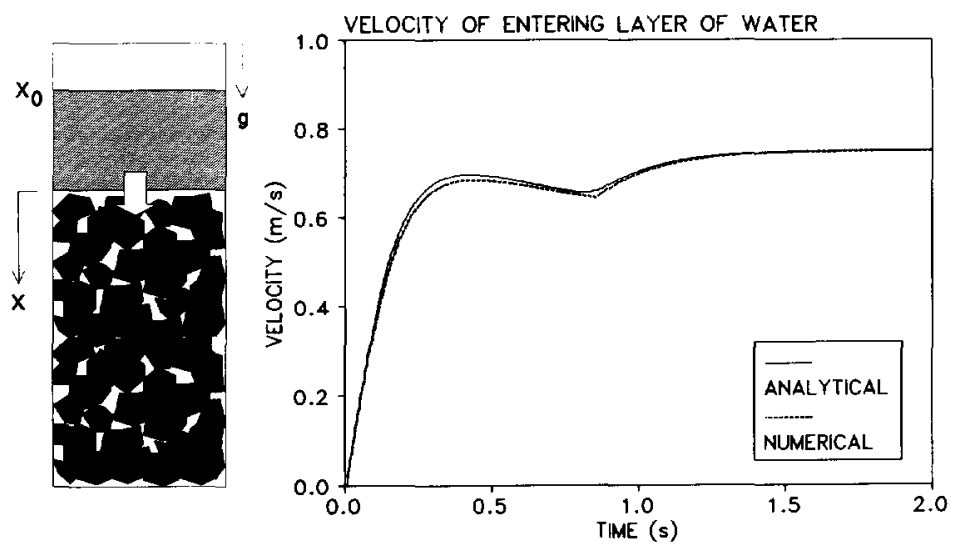

Fig.5.8 Comparison of numerical results with an analytical solution for the velocity of a layer of water entering a porous block.
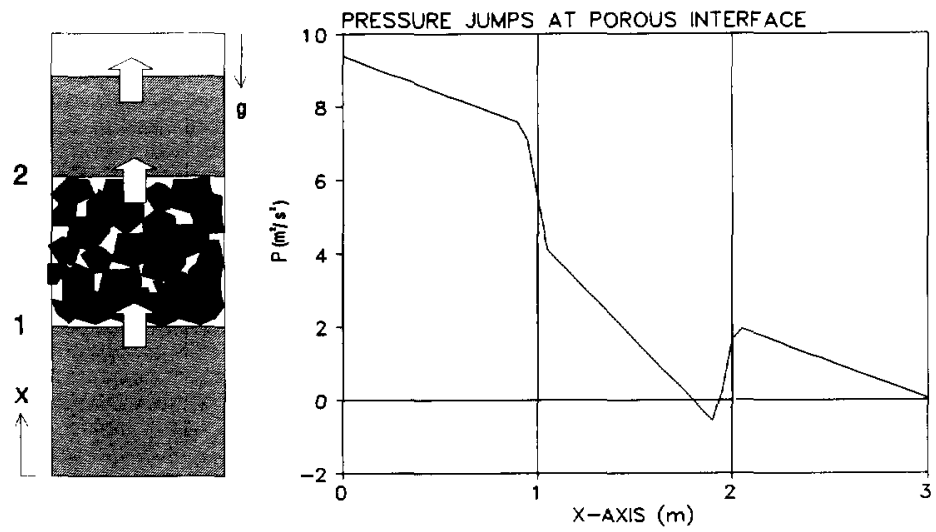

Fig.5.9 Calculated pressure jumps at the interfaces of a porous block with a steady flow.

The difference between the numerical model results and the solutions of the set of simplified differential equations reaches a maximum of $0.0129 \mathrm{~m} / \mathrm{s}$ at $t=0.4 \mathrm{~s}$. As shown in Figure 5.8, the phenomenon is well reproduced. 
A second verification concerns the flow through a saturated permeable block, see Figure 5.9. At $x=0$ a constant inflow with a velocity of $1 \mathrm{~m} / \mathrm{s}$ is produced while between $x=1 m$ and $x=2 m$ a saturated permeable block is positioned. The pressure jumps at the interfaces $(x=1 \quad m$ and $x=2 m$ ) can be determined analytically. Integrating the momentum equation for a uniform flow in the $x$-direction yields:

$$
\begin{aligned}
P\left(x_{2}+\delta x\right) & -P\left(x_{2}-\delta x\right)= \\
& \left(\frac{1}{n^{2}}-1\right) u^{2}-\delta x\left(g\left(a u+b u^{2}+2\right)+\left(1+\frac{1+c_{A}}{n}\right) \frac{\partial u}{\partial t}\right)
\end{aligned}
$$

where $x_{2}$ is the position of the outflow boundary $(x=2 \mathrm{~m})$. The same procedure can be used at the inflow boundary $(x=1 \mathrm{~m})$. The pressure jump is then equal to the one at the inflow boundary, except for the sign. Outside the permeable block the pressure is determined by $\partial P / \partial x=-g$ while inside the permeable block the pressure gradient can be assessed through $\partial P / \partial x=-g\left(a u+b u^{2}+1\right)$.

In Figure 5.9 the numerical results are shown. Some arbitrary values for the constants $n, a, b$ and $g$ were used $\left(0.5,1 \mathrm{~s} / \mathrm{m}, 0.75 \mathrm{~s}^{2} / \mathrm{m}^{2}\right.$ and $2 \mathrm{~m} / \mathrm{s}^{2}$ respectively). Because in the numerical model the pressure jumps are spread over $3 \cdot \Delta x$, $\delta x=3 / 2 \cdot \Delta x$ is used in Equation 5.9 for comparison of analytical solution with the numerical model results. The pressure jumps of the analytical solution and the numerical model results were $2.4375 \mathrm{~m}^{2} / \mathrm{s}^{2}$ and $2.5065 \mathrm{~m}^{2} / \mathrm{s}^{2}$ respectively. This comparison is again rather good. For $\delta x \downarrow 0$, the analytical solution gives $3 \mathrm{~m}^{2} / \mathrm{s}^{2}$ to which the numerical model results will come close for lower values of $\Delta x$.

A third analytical solution has been compared with numerical model results. Now, a stationary flow through a rectangular block with only linear porous friction $(b=0)$ has been examined. Neglecting convection and assuming hydrostatic pressures, the solution for the phreatic surface is determined by $h\left(x^{\prime}\right)=\sqrt{ }\left(h_{l}{ }^{2}-x x^{\prime} / L_{b} \cdot\left(h_{l}{ }^{2}-h_{2}{ }^{2}\right)\right)$ where $h_{l}$ is the free surface level at the inflow boundary (left in Fig.5.10), $h_{2}$ is the free surface level at the outflow boundary and $L_{b}$ the length of the permeable block (for Fig. 5.10: $x^{\prime}=x-2$ ). Some arbitrary values for the constants $n, a, L_{b}$ and $g$ were used $\left(0.2,4.0 \mathrm{~s} / \mathrm{m}, 6.0 \mathrm{~m}\right.$ and $10 \mathrm{~m} / \mathrm{s}^{2}$ respectively). The levels $h_{1}$ and $h_{2}$ were $2.0 \mathrm{~m}$ and $1.0 \mathrm{~m}$ respectively. In the numerical computation for $\Delta x=0.1 \mathrm{~m}$ has been used. The phreatic level was defined as the level at which, in the computation, $50 \%$ 


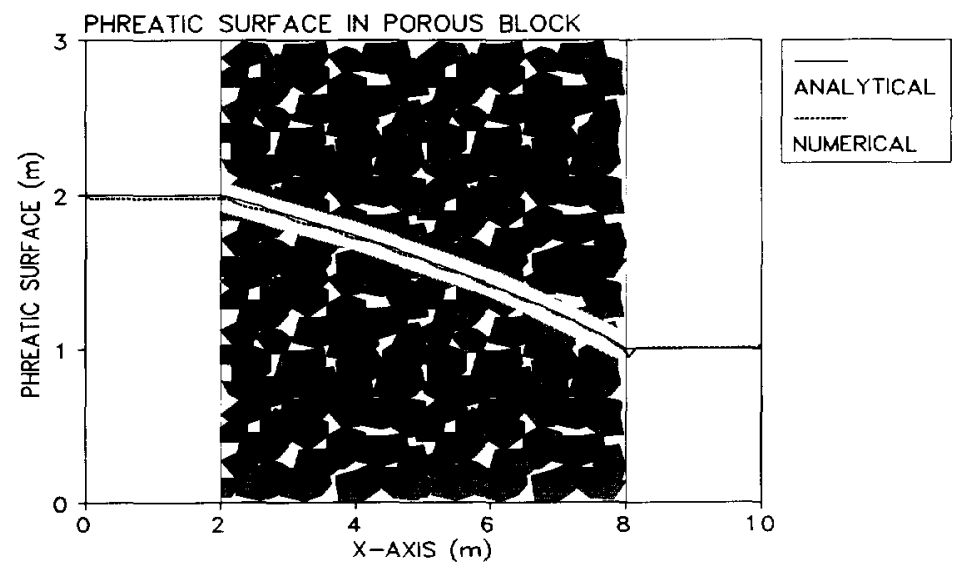

Fig.5.10 Comparison of numerically computed phreatic surface and an analytical solution.

of the cell was filled with water $(F=0.5)$. Figure 5.10 shows the comparison between both phreatic surfaces. Differences at $x=2,4,6$ and $8 m$ were 0.0233 , $0.0206,0.0105$ and $0.0234 \mathrm{~m}$, respectively.

\subsubsection{Comparison with data from physical-model tests}

A validation of the numerical model against physical-model results for permeable structures will be described in Chapter 6 as well as a comparison with the onedimensional model discussed in the previous chapter. Here, a validation of numerical model simulating breaking waves in front of a submerged bar will be discussed. More detailed information concerning this validation, including computed velocities and a sensitivity analysis, can be found in Van Gent et al. (1994-a).

The physical-model tests were performed in a flume with a length of $45 \mathrm{~m}$, a width of $1.0 \mathrm{~m}$ and a depth of $1.2 \mathrm{~m}$, see Luth et al. (1994). An offshore bar was modelled with a $12 \mathrm{~m}$ long impermeable upward slope of $1: 20$ followed by a horizontal section of $4.0 \mathrm{~m}$ and a $6.0 \mathrm{~m}$ long downward slope of $1: 10$. The still-water depth at the toe of the bar was $0.80 \mathrm{~m}$, so the still-water depth on the top of the bar was $0.20 \mathrm{~m}$. The wave generator was equipped with reflection compensation. At the backward end an active wave absorber was used to prevent wave reflection. Figure 
5.11 shows a sketch of the experimental set-up. In addition to the test series to study wave kinematics over this submerged bar, additional measurements were carried out, using the same experimental set-up to be able to verify numerical model results.

Regular waves with a height of $0.29 \mathrm{~m}$ and a wave period of $1.8 \mathrm{~s}$ were used here. The wave reflection in front of the bar was $2 \%$ or less and may be considered negligible. Surface elevations were measured with wave gauges at several crosssections. Because surface elevations at all cross-sections on the upward slope were required for the validation, these surface elevations were recorded on film. Surface elevations above the downward slope were not recorded on film. The surface elevations and the area with much entrapped air were recorded after analysis of the film. Velocities were also measured and verified but these will not be presented here.

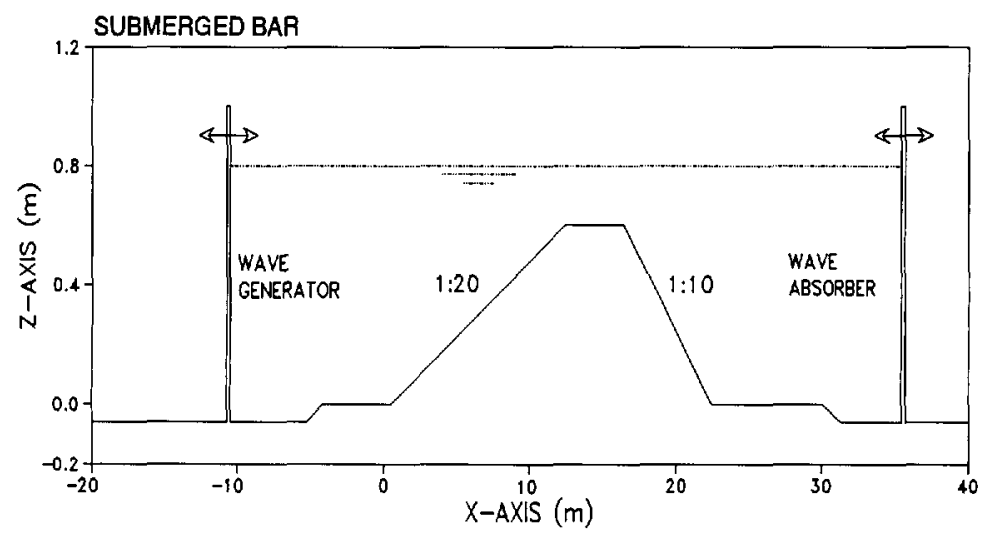

Fig.5.11 Experimental set-up for validation with waves over a submerged bar.

In the computation only the sections with the upward and horizontal slopes were modelled, while for both sections the free-slip boundary condition was applied. The incident wave boundary was positioned $0.5 \mathrm{~m}$ in front of the upward slope $(1: 20)$, the outflow boundary was positioned at the end of the horizontal section at the crest of the bar. At the boundaries, for which no average-prescribing technique was developed at the time of this validation, a net transport over the bar of about 0.05 $\mathrm{m} / \mathrm{s}$ occurred. This net mass-transport did not occur in the physical-model tests, 

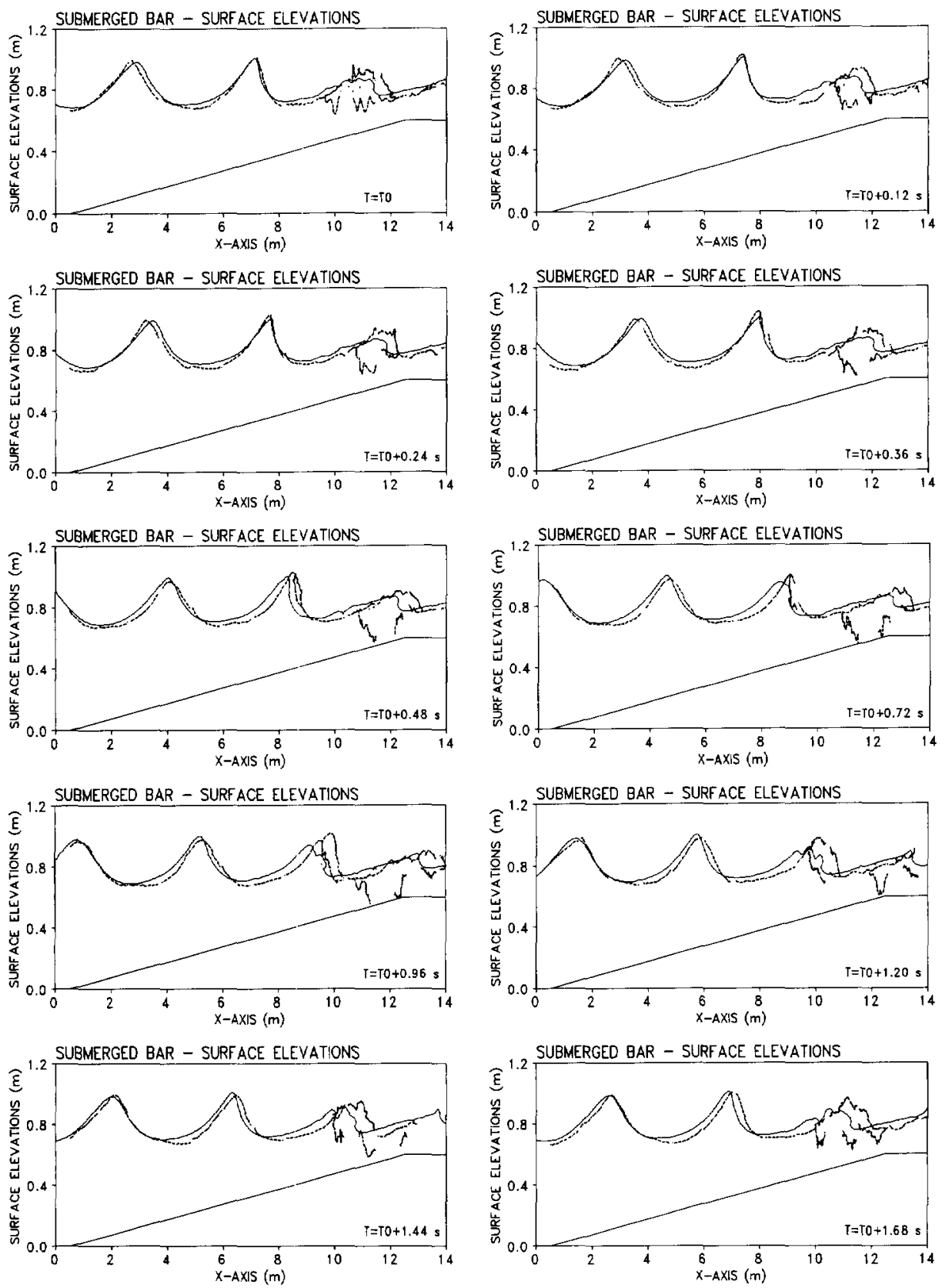

Fig.5.12 Measured (dashed) and computed (lines) surface elevations. 
since no re-circulation of water from behind the bar towards the front of the bar was included. Incident waves were generated by applying the stream-function method of Rienecker and Fenton (1981) with 16 Fourier components. In $x$ and $z$-direction 480 and 50 cells were used respectively. The time-step was flexible but not larger than $0.01 \mathrm{~s}$. For the viscosity the constant value $0.001 \mathrm{~m}^{2} / \mathrm{s}$ was taken although at the moment that the validation was carried out, at the surface a higher viscosity was required to lead to a stable computation $\left(0.008 \mathrm{~m}^{2} / \mathrm{s}\right)$. Lower values of the viscosity resulted in numerical instabilities. The upwind fraction $\beta_{u p}$ in the discretisation was 0.20 . The computed free surface elevations were defined as the levels at which cells were $50 \%$ filled with water $(F=0.5)$.
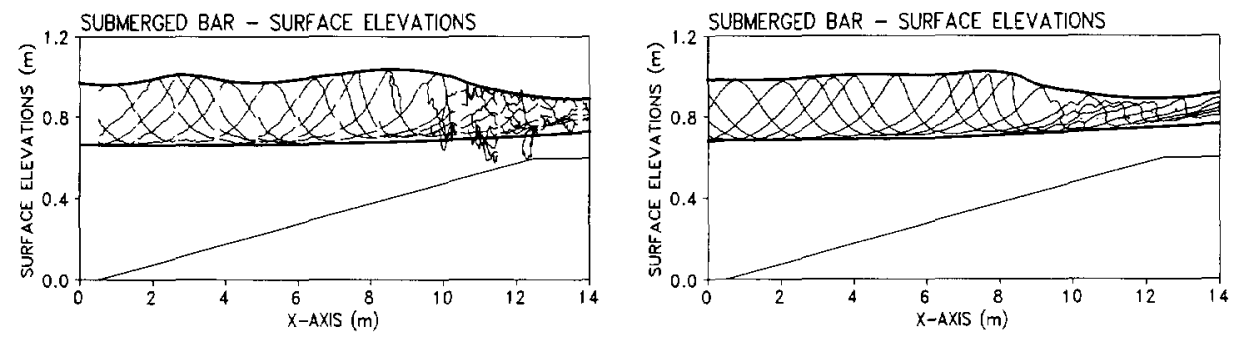

Fig.5.13 Measured (left) and computed (right) envelope of surface elevations.

Figure 5.12 shows comparisons between measured and computed surface elevations for 10 points of time within one wave-cycle. The periodicity per wave cycle was found to be satisfactory for both the computed and the measured surface elevations. These comparisons and the analysis of the envelope of the surface elevations (Fig.5.13) show that, unlike in the measurements, computational results give no increase in wave height in the first part above the $1: 20$ slope $(x=2-4 \mathrm{~m})$ and give no decrease in wave height $(x=4-6 \mathrm{~m})$ before the breaking process $(x=8-11 \mathrm{~m})$ starts. The increase in wave height above the first part of the slope cannot simply be explained by shoaling due to a limited water depth. In the model tests the wave board generated second-order waves, which means that free third-order (or higher) waves are generated in the flume. Due to the breaking process second-order and higher-order waves are also generated and can affect the wave motion near to the analysed cross-sections. The amplitude of the third-order wave generated near the wave board is much smaller than the first and second-order waves and therefore, the differences in local wave heights due to these third-order waves can only be rather 
small. However, still the phenomenon of higher-order waves is supposed to contribute to observed asymmetry and variation of the wave height in the first part above the slope $(x=2-4 \mathrm{~m})$ in the flume.

The wave height in the region of the evolution towards a breaking wave $(x=6-8 \mathrm{~m})$ is predicted rather accurately. However, the increase in wave height just before breaking $(x=7-8 \mathrm{~m})$ causes a somewhat larger wave height before breaking. The breaking process itself occurs in the same area $(x=8-11 \mathrm{~m})$. The computed transmitted wave height is accurate although the decrease in wave height occurs faster in the numerical model than in reality.

The wave celerity in the computations is lower (smaller wavelength) but this is not a problem for most applications. Although the discretisation of the time-dependent terms causes the wave celerity in the numerical model to be somewhat lower than in reality, this is not the main cause of the differences in wave celerity (variation of the time-step has little influence). Small deviations in the wave height or in the velocities of the incident waves probably cause a slightly lower wave celerity in the numerical model.

In the region where much air is entrapped (area between two dashed lines), the computations show a free surface which is positioned roughly in this area with entrapped air (taking the phase shift into account). Although the modelling of air is poor, these comparisons do not indicate that this inadequate modelling significantly influences the simulation of the flow field obtained.

Differences between measured and computed velocities were for a large part attributed to too low inflow velocities at the incident wave boundary. In most cases observed differences in wave heights can be related to the differences in velocities (underestimated wave height corresponds to underestimated velocities).

The comparison between data from these physical-model tests and the numerical model results are hindered by both unwanted phenomena in the physical-model test and by discrepancies between the observed wave conditions at the position of the inflow boundary and the incident waves used in the numerical model. Nevertheless, the validations gives a useful indication of the accuracy of the model for simulations with breaking waves. 


\subsection{Numerical model applications}

Results of practical applications with berm breakwaters will be presented in the following chapter. Here, computed flow fields near several types of structures will be shown, without a validation or discussion of quantitative results.
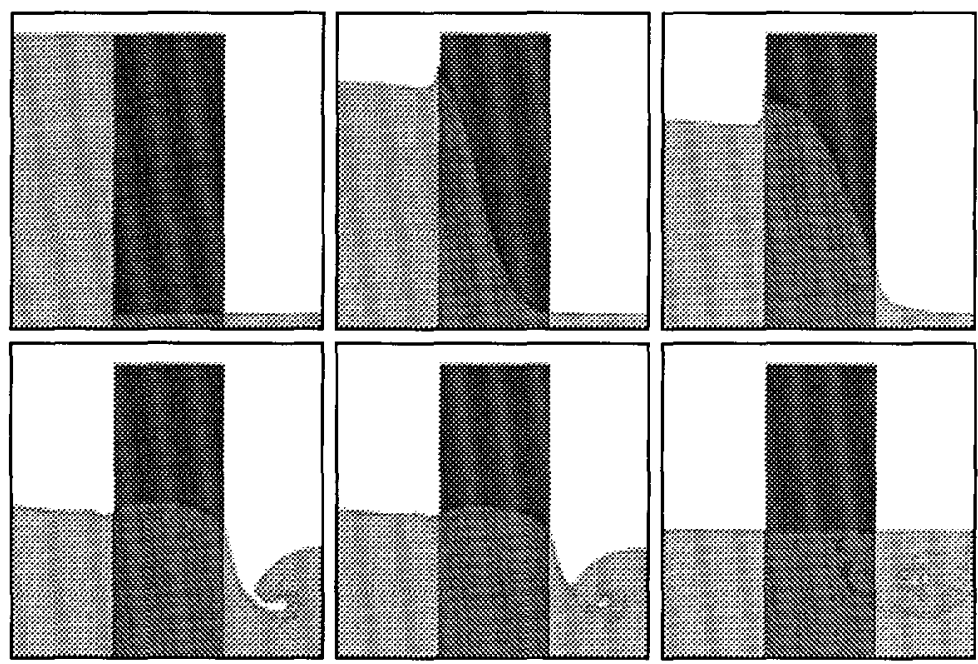

Fig.5.14 Flow through a permeable block in a closed box.

Results obtained from a simulation of a flow through a porous block are shown first. All boundaries of the computational domain are closed. Figure 5.14 shows six graphs of the computation, of which the first is the initial condition in which the water level at the left side is initially much higher than at the right side. The porous block was given a friction equal to those for stones with a porosity of $n=0.5$ and a diameter of $D=0.2 \mathrm{~m}$. The porous section and the non-porous sections on both sides are $1.0 \mathrm{~m}$ wide. The second and third figures show that the free surface at the left side decreases so quickly that, owing to friction, the phreatic surface cannot follow these rapid changes. The last figure shows the final stage in which the fluid is at rest. Entrapped-air is still in the fluid, since physical processes which cause this air to move upwards are not modelled. Nevertheless, the process seems to be simulated rather realistically. 

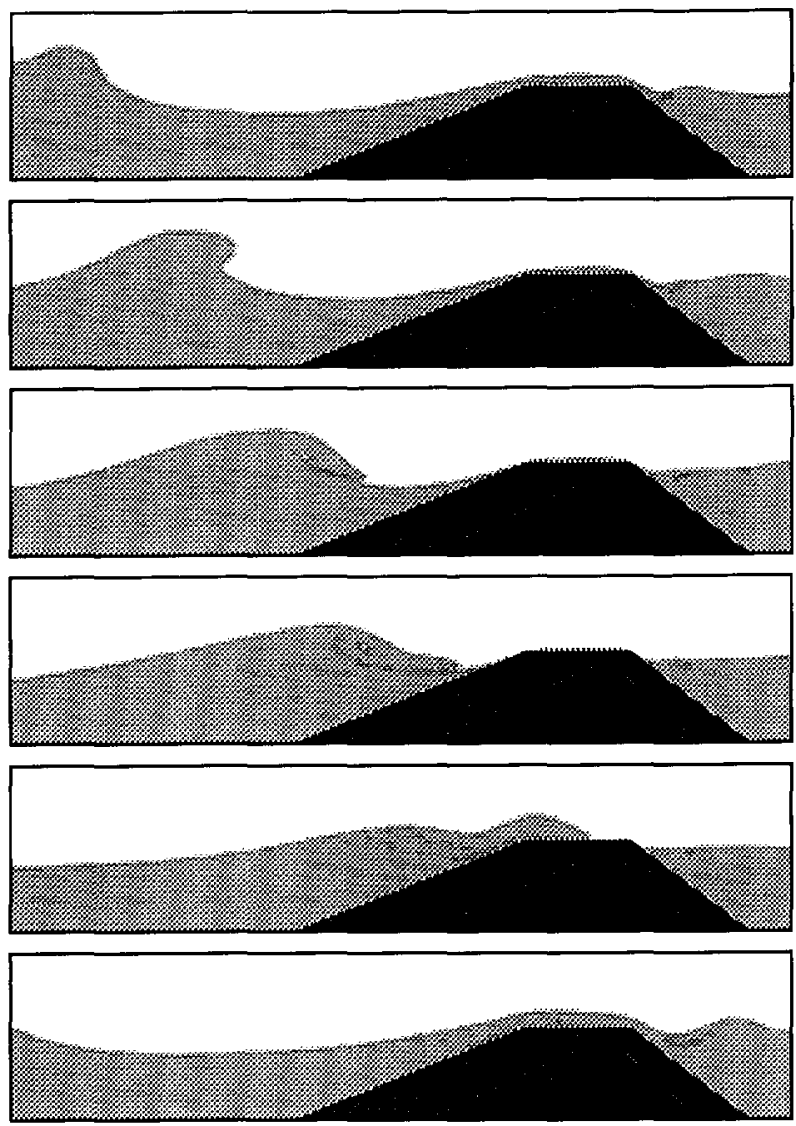

Fig.5.15 Breaking wave in front of a permeable low-crested structure.

Figure 5.15 shows a simulation of a breaking wave on and over a permeable lowcrested structure with a permeable cover layer and a permeable core. Both the left and right side of the computational domain are open. At the left side regular waves with a wave height of $H=0.45 \mathrm{~m}$ and wave period of $T=2.0 \mathrm{~s}$ were generated on a water depth of $0.80 \mathrm{~m}$. The crest of the structure was at a level of $0.90 \mathrm{~m}$ and the width of the crest was $1.25 \mathrm{~m}$. The seaward slope was $1: 2$, the rear side slope was 1:1. The computation shows how a transmitted wave is being generated by overtopping of the structure. Wave motion over submerged and low-crested 
structures, such as shown here, still needs to be studied in detail to obtain a better insight into the dependency on several parameters of phenomena like wave transmission and wave overtopping.

Figure 5.16 shows a simulation of wave motion on an impermeable slope with a horizontal berm on which a permeable part is positioned. This type of embankment
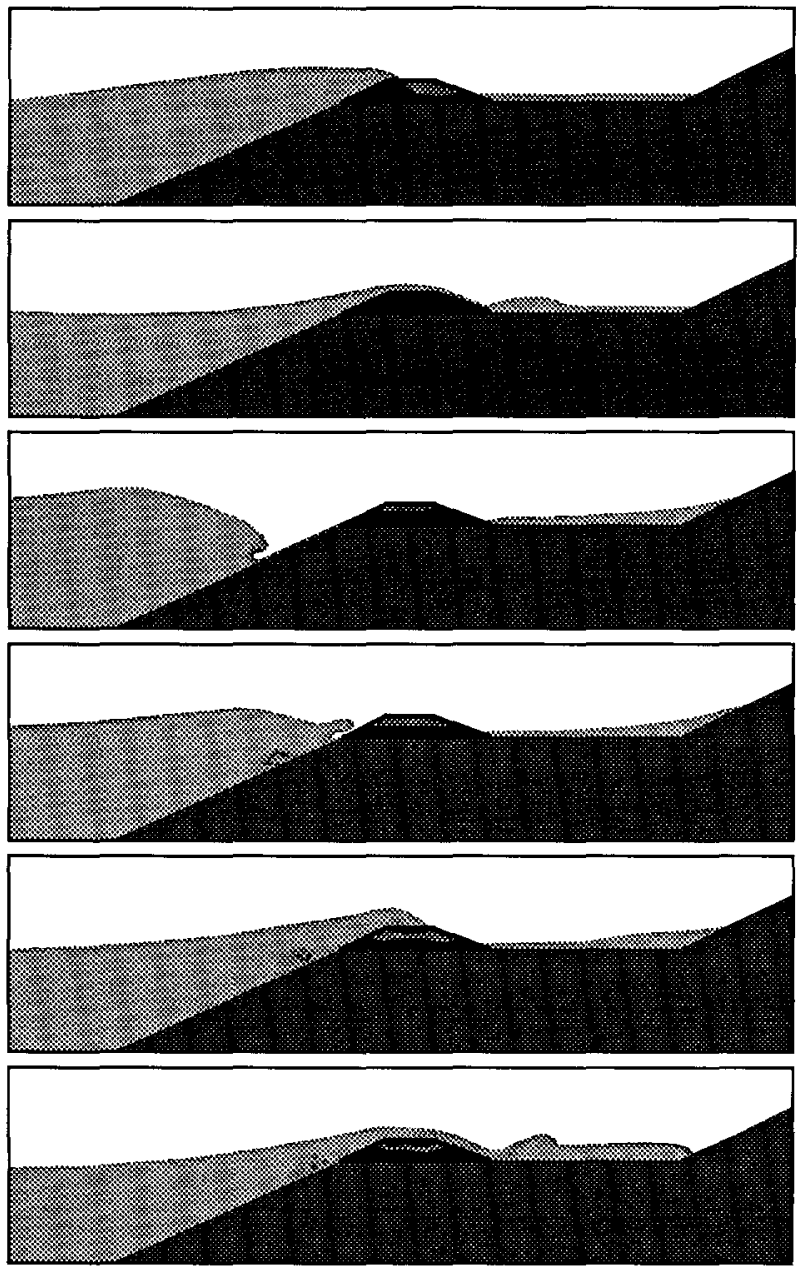

Fig.5.16 Wave motion on an impermeable slope with permeable mini-dam. 

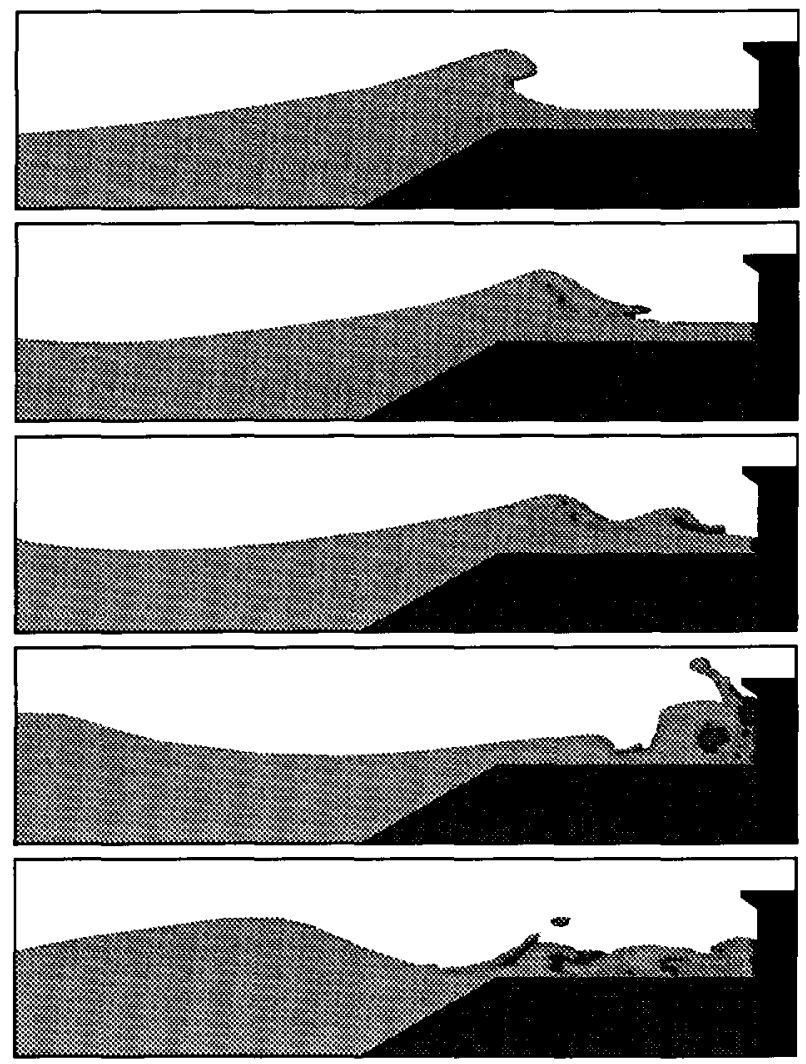

Fig.5.17 Breaking wave on a permeable slope in front of caisson with protruding parapet.

is often constructed along channels to stimulate the growth of various kinds of vegetation which also effects the wave motion and consequently the stability of revetments. In Van Gent (1994-e) reed and its effect on the wave motion have been modelled numerically on the basis of shallow-water wave equations. As shown, in principle, this can also be done by applying this two-dimensional model.

Figure 5.17 shows an example of a simulation of a breaking wave on a permeable berm in front of an impermeable caisson. Small adjustments in the lay-out of a structure may have a considerable effect on several parameters. For instance the 
addition of a small protruding element at the crest of a vertical wall may cause a considerable decrease in overtopping discharges. For such applications the numerical model can be used in combination with physical-model tests. After studying the main phenomena for estimating overtopping discharges by performing physicalmodel tests for a specific structure, the relative importance of small deviations, such as adding a protruding element to the structure, can be studied numerically. Such a numerical investigation may replace or partially replace additional model tests. However, for studying aspects such as impact forces the present numerical model is not suitable. Because it is supposed that air-entrapment and compressibility dominate the magnitude of impact forces, these aspects must be improved. Some improvements and extensions to enlarge the field of applications are proposed in the following section.

\subsection{Improvements and extensions of the numerical model}

In contrast with the one-dimensional model presented in the previous chapter where far-reaching assumptions have been made in advance, in principle the twodimensional model allows for more-detailed modelling of many relevant phenomena. For instance it may be possible to improve procedures to model turbulence or the performance of air entrapment due to complex flow patterns in order to obtain more accurate results. This gradual optimization is a basic aspect of this numerical model. It allows for the use for applications for which a sufficiently high accuracy is obtained and a simultaneous further development to extend the field of application and accuracy.

One of the main shortcomings of the model as presented here is that irregular waves cannot be computed within manageable computing time. Since simulations with irregular wave fields are required for most applications, this will be one of the first aspects to be optimised. To achieve a reduction in computing time the model uses a non-equidistant grid (Fig.5.1). This enables specification of larger grid sizes in regions with only large-scale flow structures and small grid sizes in regions where more complex small-scale flow patterns are to be expected. The time-step is also variable. If the criterium for stability is not satisfied at a specific location, the computation from the previous point of time to the new point of time is repeated with a time-step which is sufficiently small to achieve a stable computation. If the stability criterium allows, the time-step is increased again. Both the non-equidistant 
grid size and the variable time-step have resulted in a considerable reduction in computing time. However, the computing time can be diminished even further by applying a simple form of a space-varying time-step.

Figure 5.18 shows the concept of this space-varying time-step. At a specific location and a specific point of time, the stability criterium is not satisfied (denoted with the thick dot in Fig. 5.18). Then, an inner region is specified in which the computation will be repeated with a smaller time-step. The surrounding region in which the stability criterium does not require a smaller time-step, the computation towards the new point of time does not have to be repeated with smaller time-steps. By using the computational results at the boundaries of the inner region at both the old point of time and the new point of time, the computation in this inner region can be repeated with smaller time-steps to satisfy the stability criterium. Because the largest part of the computational domain does not have to be computed with the smaller time-step, which quite often can be ten times smaller than the previous time-step, this procedure can yield a considerable reduction in computing time. This enables practical use of the model for computations over many wave periods as required in the study of irregular wave fields.

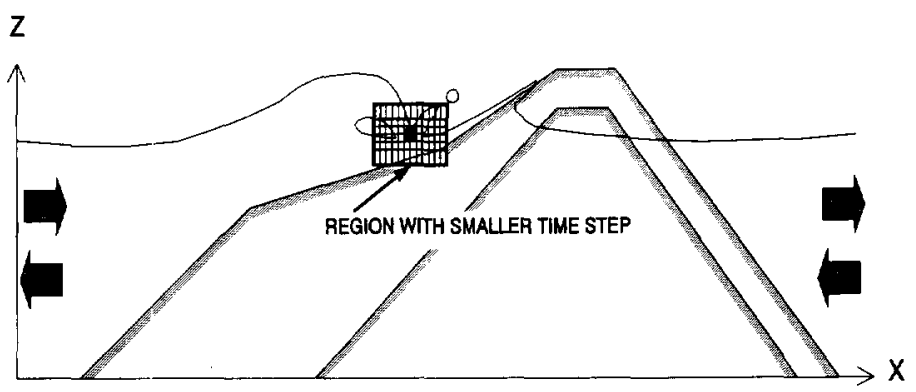

Fig.5.18 Local variable time-step in regions which, at a certain point of time, require a smaller time-step for stability reasons.

Another aspect of the model which can be improved is the implementation of a more sophisticated turbulence model. For the applications treated here, a constant turbulence viscosity is used. However, a more realistic turbulence viscosity is not a constant but depends on both space and time. Many models for implementing these dependencies have been developed although none of them has general validity 
and most of them have not initially been developed with turbulence generation under breaking waves in mind. Even sophisticated turbulence models like the $k-\epsilon$ model are not appropriate for all flow conditions. Moreover, such sophisticated turbulence models can dominate the computational effort to such an extent that they prevent the practical use of the numerical model. Whether this is the case still has to be verified. Because even without sophisticated turbulence model the model requires a considerable computing time, the contribution of such a turbulence model might be relatively small. More simple formulations such as based on mixing-length theory may be more suitable at this time but the difficult problem of prescribing a characteristic length-scale remains.

Other improvements leading to a wider applicability and higher accuracy are the implementation of surface roughness on impermeable slopes, a more sophisticated treatment of air-entrapment, improvements of the VOF/FLAIR method near the free surface and the implementation of more phenomena related to porous media flow such as infiltration and anisotropy.

\subsection{Conclusions}

By means of the two-dimensional model presented in this chapter, normally incident breaking waves on coastal structures, including permeable structures, can be simulated numerically. The methods to solve the Navier-Stokes equations, which have been adapted to describe porous media flow also, allows for detailed modelling of many physical phenomena. More sophisticated modelling of turbulence and the free surface may improve the accuracy of the model. However, as it is the model already provides rather accurate simulations of the wave motion on coastal structures. Validations against analytical solutions, a validation against breaking waves in front of a submerged bar and the realistic impressions of the flow field that the model provides confirm that the model can be rather accurate and widely applicable. Present disadvantages, such as the restriction to regular waves, can be overcome without affecting the model descriptions extensively. The wide range of applicability, however, also requires validations on a wide range of flow conditions. In the following chapter, a validation with berm breakwaters will be given. 


\section{Chapter 6}

\section{Berm breakwaters}

\subsection{Introduction}

Berm breakwaters are a relatively new type of structure. Their natural response to hydrodynamic loads makes them economically attractive, not in the least because smaller rock material can be used than with conventional breakwaters. On the other hand, the dynamic behaviour, typical of berm breakwaters requires special attention. The seaward slope undergoes reshaping until a stable seaward profile has developed. This dynamic behaviour of the seaward slope depends very much on the hydrodynamic loads and vice versa. This interactive character of the hydrodynamics and the reshaping process are studied here, as well as in the subsequent chapter.

Physical-model tests were carried out to study wave interaction with a berm breakwater. These small-scale tests were used to verify the one-dimensional model described in Chapter 4 and the two-dimensional model presented in the previous chapter. The two numerical models are also compared mutually. Here, a summary will be given of research concerning the measurements and the comparisons with the numerical models described in Van Gent (1993-c, 1994-d, 1995-b) and Van Gent et al. (1994-b).

\subsection{Berm breakwater features}

Before the physical-model tests and the additional validation of the numerical models are described, a general introduction to berm breakwaters will be given as well as a short overview of research topics related to this type of structure. 


\section{Berm breakwater concept}

Conventional breakwaters consist of armour layers with heavy artificial units or natural rock. In most cases these structures have a uniform sloping cross-section. For these conventional breakwaters only little damage (displacements) is allowed under severe storm conditions (design conditions). Wave motion causes loading on the structure which the structure has to withstand. In some cases it can be desirable to construct a breakwater which works more in harmony with the flow field in such a way that the hydrodynamic loads are reduced.

To achieve a reduction in the hydrodynamic loads, the breakwater can be constructed with a geometry such that the resistance of the structure at a specific position along the slope corresponds with the local hydrodynamic loads. In this way the resistance can be lower at positions where the hydrodynamic loads are relatively small. At positions along the slope where these loads are more severe, this resistance must be greater.

The local angle of the slope and the weight of the stones or units determine the resistance to a large extent. If uniform material is used, the angle of the slope can be steeper at positions where the loads are relatively small. At positions where these loads are larger the slope angle must be smaller. Since the hydrodynamic loads depend on the complete profile of the structure, the optimum local slope angle for a specific type of material (as steep as possible to save material) is not known in advance.

When the stones are free to move under wave attack, a profile will be formed in which the resistance to hydrodynamic loads is minimized at all positions along the profile; elements will be moved to positions where they are just stable. This means that, for instance, at positions where waves break, resulting in relatively large hydrodynamic loads, the local slope angle becomes small. At positions where the loads are less, for instance before the breaking process starts, the angle can be larger. At higher positions along the slope, the loads may be smaller and the stones have a relatively large resistance since they are not submerged. This gives steeper slopes near the run-up point. The profile gets an S-shape; steep near the seabed, gentle where the waves break and steep near the run-up point. The forming of a seaward profile that minimizes the hydrodynamic loads allows the construction with 
smaller material than is used for conventional breakwaters. This also results in designs with fewer categories of stones.

Breakwaters with an S-shaped cross-section that are constructed with units that are stable, are called S-shaped breakwaters. With the S-shape the loads are reduced, whereas the slope is steeper at positions where the loads are relatively small.

Allowing displacement of stones gives the opportunity to construct a seaward profile that is different from the expected equilibrium profile. As discussed before, nature forms a profile for which the local angle of the slope is in harmony with the local hydrodynamic loads. A breakwater which is designed to undergo such a natural profile adjustment is called a berm breakwater. Therefore, a berm breakwater can be described as a mound of rock which, as a result of wave-structure interaction, undergoes reshaping until a equilibrium seaward profile is formed.

In contrast with S-shaped breakwaters, the initial profile of a berm breakwater is not near the expected equilibrium profile. A berm breakwater is often constructed with a horizontal berm just above still-water level. In this way the berm can be used to position equipment during further construction of the breakwater.

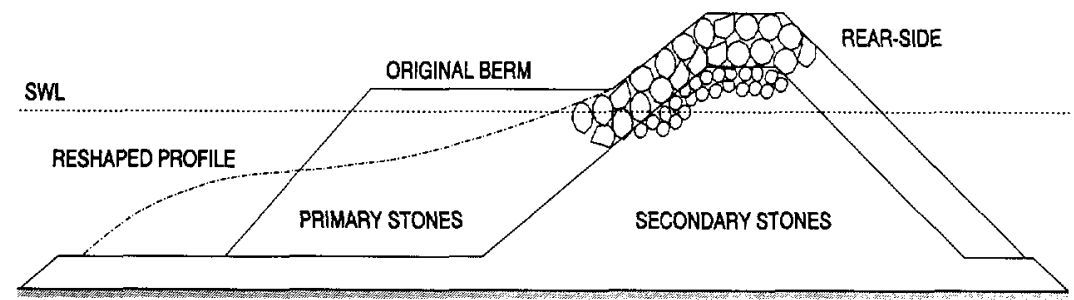

Fig.6.1 Berm breakwater lay-out.

The reshaped profile of a berm breakwater is to a large extent determined by the most severe storm that occurred during the existence of the structure. The stones in the reshaped profile are stable under mild wave conditions, but under relatively severe conditions the stones can move slightly while the (average) profile stays the same. A storm exceeding the largest storm that occurred in the existence of the structure may cause a further development of the profile until a new stable crosssection is formed. 
Often two classes of stones are used. The larger stones form the primary class and are used for the top-layer. The smaller stones form the secondary class and are positioned in the core. Unlike the core, the top-layer is allowed to reshape on the seaward side of the structure. The amount of stones from the primary class has to be sufficient to form a new equilibrium profile in such a way that the core is not affected by waves. This is the case if, after reshaping of the profile, the core is covered by stones from the primary class in a layer of at least two to three stone diameters thick.

The armour stones required for berm breakwaters are much smaller than those required for conventional breakwaters; the weight can be two to ten times smaller. A much wider gradation can be used which allows the design to be based on the actual quarry output. Because the stone sizes are smaller, the construction equipment can be lighter than that used for conventional breakwaters. Since slopes are mainly constructed under the angle of internal friction, less rehandling of stones is necessary. At some locations berm breakwaters are the only realistic type of structure; the wave conditions can be so extreme that conventional breakwaters would require unrealistically large stones, whereas at some other locations the stone sizes for conventional breakwaters are not available.

Some practical experience with berm breakwaters is described by Montgomery et al. (1988) and Juhl and Jensen (1993).

\section{Points of concern for berm breakwaters}

For the design of berm breakwaters several features need to be studied. The width and the height of the berm in the initial profile determines the amount of primary stone which can take part in the reshaping process. This amount has to be sufficient for the core material to be adequately covered after reshaping of the structure. Therefore, the reshaped profile needs to be known in advance. This reshaped profile can be predicted rather accurately on the basis of assumed design conditions, see Van der Meer (1988).

Movements of stones on a berm breakwater slope imply that rock degradation is more significant than for conventional breakwaters. Rock degradation following emplacement results in changes in stone sizes and the roughness of the stones. This 
causes a decreasing resistance to wave forces resulting, to a certain extent, in a different equilibrium profile (flatter). For some design implications concerning this aspect see Allsop and Latham (1987) and Latham et al. (1988).

Another consequence of the use of smaller stones for berm breakwaters is an increased effect on the rear-side of the structure. Damage to the rear-side of the structure is not usually allowed. This damage can be prevented by increasing the crest height, increasing the crest width, increasing the stone diameter at the rear-side or decreasing the rear slope.

Another point of concern, typical of berm breakwaters, is the so called longshore transport of the armour stones. The stones from a berm breakwater can be displaced not only to another place in the same cross-section, but also in the direction parallel to the structure. The cross-section of a dynamically stable structure can reach an equilibrium profile for a specific wave climate (no net cross-shore transport). However, under these conditions a net longshore transport can still take place. This longshore transport is caused by waves that attack the breakwater under an angle. This transport of stones has to be prevented unless the net amount of displaced stones has to be sufficiently small.

Breakwater round heads are usually more exposed to wave attack than other parts of the breakwater. A measure to deal with this problem for berm breakwaters is to increase the amount of stones in the profile at the round heads. This can be done by constructing a higher or wider berm. The equilibrium slope will be more gentle at the location of the round heads as a result of the more severe wave attack. For design aspects at singular points of berm breakwaters and for longshore transport on berm breakwaters reference is made to Burcharth and Frigaard (1988) and Van der Meer and Veldman (1992).

\subsection{Physical-model tests}

\subsubsection{Description of physical-model tests}

A small-scale physical model of a berm breakwater was tested in a flume $42 \mathrm{~m}$ long, $0.80 \mathrm{~m}$ wide and $1.05 \mathrm{~m}$ high. The wave generator was equipped with reflection-compensation to prevent re-reflection of reflected waves against the wave 
generator. The structure was positioned at $28 \mathrm{~m}$ from the wave generator. The structure was constructed in two steps. First a core consisting of coarse granular material was placed $\left(D_{n 50}=0.0175 \mathrm{~m}\right)$. The section of the wave flume with the core was sealed. This sealed section was filled with a known volume of water. This procedure provided the in situ porosity. After construction of the cover layer, composed of larger granular material $\left(D_{n 50}=0.0266 \mathrm{~m}\right)$, this procedure was repeated. Assuming that the porosity of the core before and after the construction of the cover layer was the same, the porosity of the cover layer could be determined. Both porosities appeared to be nearly the same, namely 0.418 and 0.417 , which could be expected since both categories were obtained by sieving from the same initial sample.

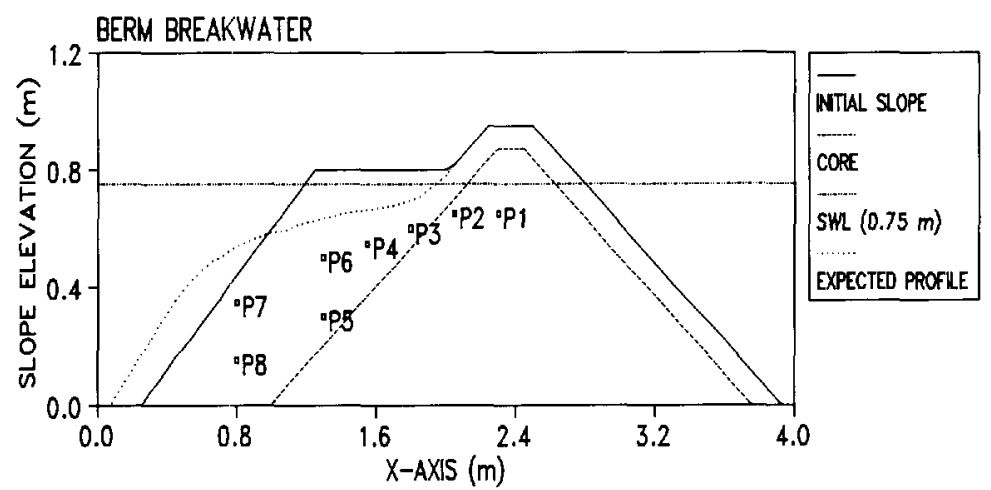

Fig.6.2 Cross-section of the berm breakwater in the experimental setup with pressure transducers indicated by P1-P8.

Figure 6.2 shows a sketch of the experimental set-up with the initially horizontal berm at a level of $0.80 \mathrm{~m}$, the still-water level being $0.75 \mathrm{~m}$. All slopes were $1: 1.5$ except for the submerged seaward slope which was 1:1.25.

Pressure transducers were positioned in the seaward slope and in the core of the structure. These transducers were fixed to thin steel bars attached to the bottom of the flume. Because the steel bars were rather thin, they were free to move slightly in the horizontal direction which may have occurred owing to settling of the structure. Therefore, the vertical positions of these transducers were known accurately whereas the horizontal positions may have changed a little in the 
direction towards the wave generator. This horizontal displacement was estimated to be less than $0.03 \mathrm{~m}$. The positions of the transducers are indicated in Figure 6.2. The pressure transducers were protected by small caps with a diameter of $0.02 \mathrm{~m}$, which is still smaller than the surrounding stones. The signals were recorded at a sampling frequency of $50 \mathrm{~Hz}$ after second-order low-pass filtering at $25 \mathrm{~Hz}$.

Velocities were measured with an electro-magnetic flow meter (EMF075) simultaneously in the vertical and horizontal direction. A velocity range of $1.0 \mathrm{~m} / \mathrm{s}$ was used. The maximum error band was $0.6 \%$ in both directions. The transducers reacted to air by giving their maximum voltage (maximum velocity) within a period of $0.20 \mathrm{~s}$. Velocities were measured every $0.10 \mathrm{~m}$ in the $x$-direction, between the toe of the structure and the area where air was enclosed owing to breaking waves. Velocities were measured at the levels of $0.35 \mathrm{~m}, 0.45 \mathrm{~m}, 0.55 \mathrm{~m}$ and $0.65 \mathrm{~m}$ above the bottom of the flume. The sampling frequency was $50 \mathrm{~Hz}$.

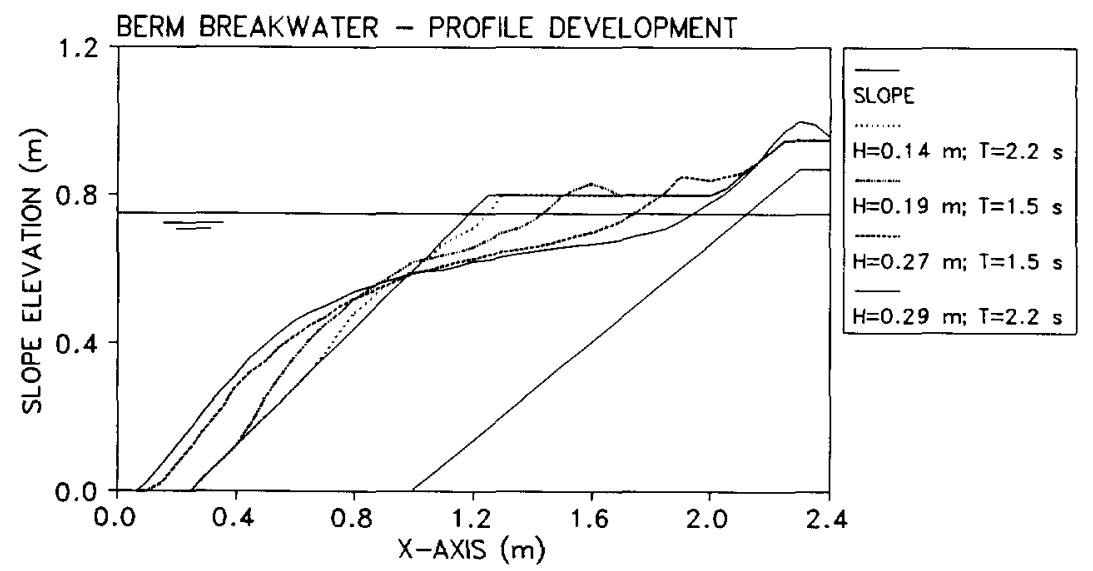

Fig.6.3 Seaward slope after four series of regular waves.

Surface elevations were recorded by three resistance-type wave gauges, two in front of the structure and one behind the structure (one $4.0 \mathrm{~m}$ in front of the crest of the structure, one $3.2 \mathrm{~m}$ behind the crest and one mobile). This permitted the study of reflections, wave transmission and the internal set-up. The maximum error band of these wave gauges is $0.5 \%$ of an operating range of $0.75 \mathrm{~m}$. Video recordings were made of the surface elevations at a rate of 25 pictures each second. The region 
above the seaward slope was divided into three partially overlapping sections. In front of each section the video camera was positioned for some time. Since regular waves were studied, the observed surface elevations in each section could be connected to those from the other two sections afterwards. The run-up levels were measured visually through the glass side-walls of the flume and were checked by using the video film. Because the water layers during run-up are smaller than the size of the stones and because the water line was specified without reference to the percentage of entrapped air, differences might have occurred between run-up and run-down levels obtained and those that would have been recorded if a run-up gauge had been used.

Reshaping the seaward profile was achieved by four series of 1000 regular waves where each series had an increased impact on the dynamic seaward slope compared to the previous series. After each series, the reshaped profile was measured visually but not restored. Figure 6.3 shows the seaward profile after each of these series of regular waves. During the last series, with the highest waves, the crest was raised from $0.95 \mathrm{~m}$ to $1.00 \mathrm{~m}$. After this reshaping process the actual tests were started. No reshaping took place during these tests.

Table 6.1 Measured properties of regular waves.

\begin{tabular}{ccccccc}
\hline$H(m)$ & $T(s)$ & $R$-up $(\mathrm{m})$ & $R$-down $(\mathrm{m})$ & $K_{r}$ & $K_{t}$ & Int.set-up $(\mathrm{m})$ \\
\hline 0.119 & 1.5 & 0.10 & -0.02 & 0.11 & 0.036 & 0.00 \\
0.162 & 1.5 & 0.15 & -0.01 & 0.25 & 0.028 & 0.02 \\
0.230 & 1.5 & 0.21 & 0.00 & 0.13 & 0.019 & 0.04 \\
0.284 & 1.5 & 0.25 & 0.02 & 0.13 & 0.017 & 0.06 \\
0.112 & 2.1 & 0.11 & -0.03 & 0.18 & 0.060 & 0.01 \\
0.166 & 2.1 & 0.20 & -0.01 & 0.19 & 0.051 & 0.03 \\
0.217 & 2.1 & 0.27 & 0.01 & 0.20 & 0.092 & 0.06 \\
0.261 & 2.1 & $>0.27$ & 0.01 & 0.21 & 0.123 & 0.07 \\
\hline
\end{tabular}

Regular waves were studied, with wave periods of $1.5 \mathrm{~s}$ and $2.1 \mathrm{~s}$. For each wave period, four wave heights were tested, varying between approximately $0.11 \mathrm{~m}$ and $0.28 \mathrm{~m}$. For those eight waves, several parameters are shown in Table 6.1. In all 
tests, the still-water level was $0.75 \mathrm{~m}$. Due to set-up behind the breakwater (internal set-up), an average water level reduction occurred at the front. The set-up behind the breakwater was measured and used to determine the average water level at the front during the tests. The run-up and run-down levels presented in Table 6.1 are related to this water level at the front. The internal set-up levels presented are the summation of the measured set-up behind the structure and the resulting water level reduction at the front (respectively $2 / 3$ and $l / 3$ of the presented values). The incident waves and reflected waves were extracted from the measured signals from two wave gauges in front of the structure. The reflection coefficients are obtained by dividing the extracted reflected wave height by the incident wave height, while the transmission coefficients were obtained by dividing the transmitted wave height by the incident wave height.

\subsubsection{Discussion of test results}

The run-up levels show an increase that is roughly linear with increased wave heights. Severe overtopping occurred for one wave series, but the damage at the rear was still limited. The run-down levels vary around the average water level in front of the structure. Reflection coefficients do not show a clear trend, although it seems as if the reflections increase for longer wave periods. The second wave series in Table 6.1 shows a very high reflection coefficient compared to other waves of the same wave period. The reasons for this high reflection are not understood. The transmission coefficients are very low and tend to increase for longer wave periods. The last two wave series show an increase in transmission due to overtopping. The waves with severe overtopping show the highest values for the transmission coefficients. The internal set-up is larger for higher waves and for longer periods.

The analysis of the video images has resulted in graphs with surface elevations in the area above the seaward slope. The surface elevations have been measured at ten points of time, with a constant time-interval, within one wave period (Fig.6.6-6.9). The surface points were determined at positions in the $x$-direction at every $0.05 \mathrm{~m}$ or $0.10 \mathrm{~m}$ (depending on the fluctuations). In the case of air entrapment (Fig.6.7 and Fig.6.9), two surface points are plotted at one $x$-position for a single moment of time; the upper shows the free surface and the area between both lines indicates where air was situated. Because a wave gauge was positioned in the region where the video images were made, the video images could be synchronised with the other 
signals. Comparisons with numerical results will be discussed in the subsequent sections.

Analysis of the signals from the pressure transducers (Fig.6.11, where zero-pressures correspond to still water) showed that the pressures inside the berm do follow the fluctuations of the free surface closely; the maxima of the measured pore-pressures occur at nearly the same moments of time at which the free surface above the transducers have maxima. Figure 6.4 shows pressure fluctuations as function of the vertical position, derived from the free surface fluctuation (upper symbols) and two pressure transducers in the same cross-section (lower symbols). At such a crosssection, the maximum minus the minimum free surface is used as the pressure fluctuation at the average free surface (zero-pressure at the free surface). This has been done for the cross-sections $x=0.8 \mathrm{~m}$ (transducers $P 7$ and $P 8$, with the slope at $z=0.54 \mathrm{~m}$ ) and $x=1.3 \mathrm{~m}$ (transducers $P 5$ and $P 6$, with the slope at $z=0.63 \mathrm{~m}$ ). Figure 6.4 shows that pressure differences caused by fluctuations of the free surface do not fully penetrate into the permeable part; the pressure differences decrease in the downward direction.
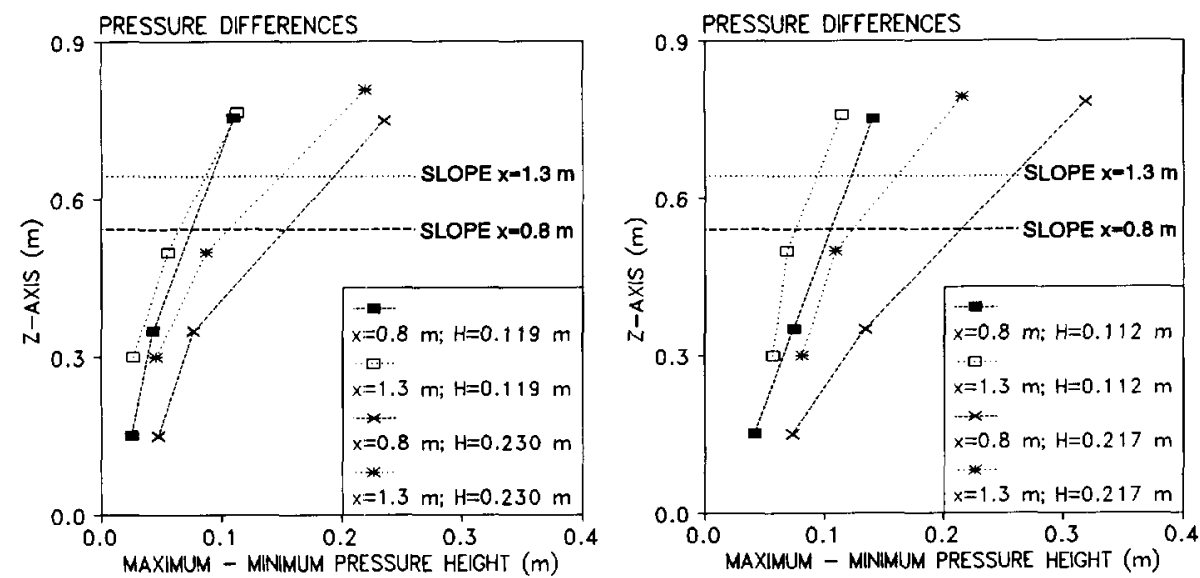

Fig.6.4 Pressure fluctuations in vertical direction; regular waves with wave periods of $T=1.5 \mathrm{~s}$ (left) and $T=2.1 \mathrm{~s}$ (right). 


\subsection{Validation and intercomparison of the numerical models}

\subsubsection{Validation of the one-dimensional wave model}

Several properties calculated by the one-dimensional numerical model described in Chapter 4 have been verified by using the physical-model tests. Velocities and surface elevations have been verified against measurements above the most gently sloping part of a berm breakwater, see for instance Tørum and Van Gent (1992). In the present tests, velocities were measured lower down the slope. Before the comparison between measured and computed surface elevations is treated, some data on run-up and run-down levels and reflections will be compared.

The test series presented in Table 6.1 have been used for comparison. In the computations the still-water level was set at the measured average water level in the section between the wave generator and the structure. The inflow and outflow boundaries were positioned at $0.20 \mathrm{~m}$ before the toe of the structure and just behind the crest of the structure respectively. In the numerical model the reshaped seaward slope of the berm breakwater was represented by five straight sections. The crest level was $1.00 \mathrm{~m}$, while the structure was modelled as a homogeneous structure with a porosity of 0.417 and a stone diameter $D_{n 50}$ of $0.0266 \mathrm{~m}$. This means that the permeable core $\left(n=0.418, D_{n 50}=0.0175 \mathrm{~m}\right)$ is represented by the same material as the cover layer. The dependency of the porous media flow friction-coefficients on the flow field has been implemented as described in Section 4.2.2. For the friction coefficient $f, 0.10$ has been used in all simulations $\left(E q .4 .3\right.$ with $\tan \theta_{s}=0.2$ and $R=0.25 \mathrm{~m}$ ). The incident waves were computed with the Stokes second-order theory.

Run-up values are compared in Figure 6.5. For calculating the surf-similarity parameter $\xi_{0}$, a 1:4 slope was taken as a representative slope. The computations represent the measured run-up values rather well. For the run-down levels, the computations with wave periods of $1.5 \mathrm{~s}$ (lower values of $\xi_{0}$ ) were rather accurate. The computations with a wave period of $2.1 \mathrm{~s}$ (higher values of $\xi_{0}$ ) do show the correct trend, but absolute differences of $0.04 \mathrm{~m}$ occur. Computations with uniform slopes also indicated that the run-up levels were represented rather accurately (Section 4.4.2). This was not the case for the run-down levels. The same conclusions can be drawn for the tests described here. 


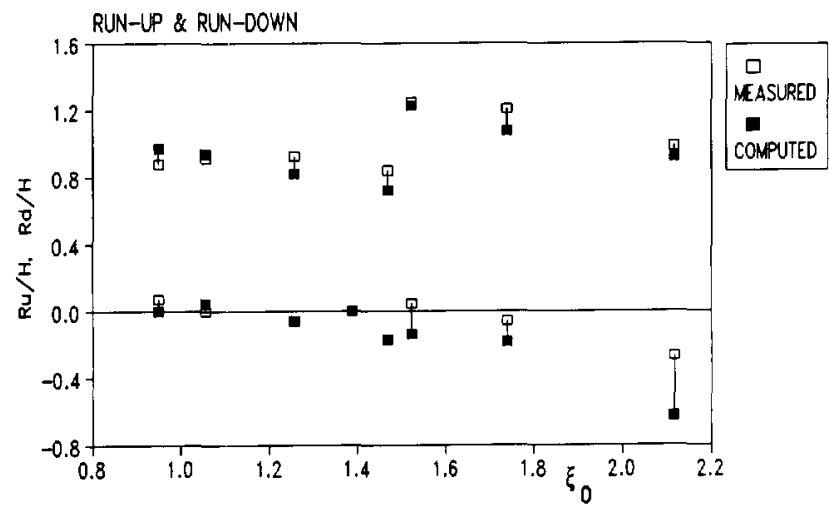

Fig.6.5 Measured and computed run-up and run-down levels on a berm breakwater.

Reflection coefficients for the eight series of waves as shown in Table 6.1 were in the measurements and the computations respectively: 0.11 vs. $0.06 ; 0.25 \mathrm{vs} .0 .06$; 0.13 vs. $0.10 ; 0.13$ vs. $0.15 ; 0.18$ vs. $0.48 ; 0.19$ vs. $0.28 ; 0.20$ vs. 0.29 and 0.21 vs. 0.27 . The agreement between these reflection coefficients is poor. However, the observed trend, that the values for the reflection coefficients are higher for longer wave periods, is reproduced.

Surface elevations obtained from the video images have been compared with numerical results for four of the wave series mentioned in Table 6.1. The upper graphs in Figures 6.6-6.9 show the measured surface elevations while those in the middle are the computed surface elevations at the same moments of time. The comparison between measured and computed surface elevations shows that the numerical results give a rather good impression of the wave action until the position where air is captured. As expected, behind this point with entrapped air the resemblance is much weaker.

Velocities measured in a single point cannot properly be compared to depthaveraged velocities produced by the numerical model since depth-averaged velocities may deviate substantially from velocities in a single point. Nevertheless, in Van Gent (1993-c), comparisons between measured velocities and calculated depthaveraged velocities are shown for four waves. Differences up to $30 \%$ occur between the measured velocities and the depth-averaged velocities. However, it is impossible 
to contribute the differences totally to inaccuracies of the model, since the variations in the velocity profile may easily cause such differences. Therefore, no firm conclusions can be made based on such a comparison.

\subsubsection{Validation of the two-dimensional wave model}

For the same wave conditions as those used in the previous sub-section, measured run-up levels, surface elevations, velocities and pressures have been compared with results from the two-dimensional numerical model described in Chapter 5.

The computational domain in the numerical model started at $4 \mathrm{~m}$ in front of the toe of the reshaped structure where the waves were generated by applying the stream function method by Rienecker and Fenton (1981) using 16 Fourier-components. The outflow boundary was positioned at the landward side at $1.5 \mathrm{~m}$ behind the crest of the structure. At both boundaries the average-prescribing weakly reflecting boundary conditions were applied. For the average water levels at these boundaries the measured values were prescribed. No net mass transport was allowed through the boundaries. The structure was modelled with the measured slope and the measured properties of both the cover layer and the core. The dependency of the porous media flow friction-coefficient $\beta$ on the flow field has been accounted for by including the dependency on the $K C$-number; $\beta=\beta_{c}(1+7.5 / K C)$ where $K C=\hat{U} T / n D_{n 50}$ and $\beta_{c}=1.1$. For the representative filter-velocity $\hat{U}$ an estimated value was applied and for $T$ the wave period was used. Added mass was not modelled. In $x$ and $z$-direction, 270 and 80 computational cells were used respectively. The computations were performed with a constant viscosity $\nu_{i}=0.005 \mathrm{~m}^{2} / \mathrm{s}$ (lower values lead to instabilities). In the discretisation of the equations an upwind fraction of $\beta_{u p}=0.2$ was used. Surface elevations were defined at positions of cells which were filled with fluid for $50 \%$. After a start-up time of six to eight waves to obtain periodic results, data was used for comparison with the measured properties.

Snapshots of the surface elevation for ten phases within one wave-cycle are shown in the Figures 6.6-6.9 for two wave conditions with a wave period of $1.5 s$ and two wave conditions with a wave period of $2.1 \mathrm{~s}$. The comparisons for the five profiles in the first half of each wave cycle show good agreement (upper graphs). In the second half of each wave cycle (lower graphs) considerable air-entrapment occurs for the two wave series with largest wave heights (Fig.6.7 and Fig.6.9). The 
First half of wave cycle:

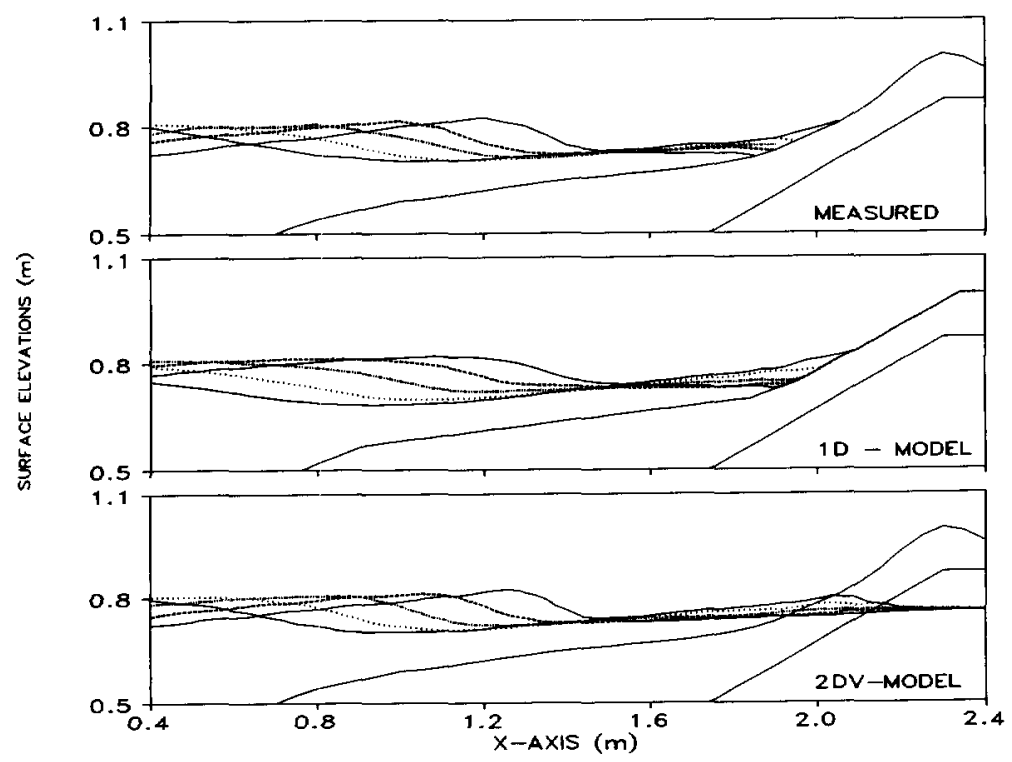

Second half of wave cycle:

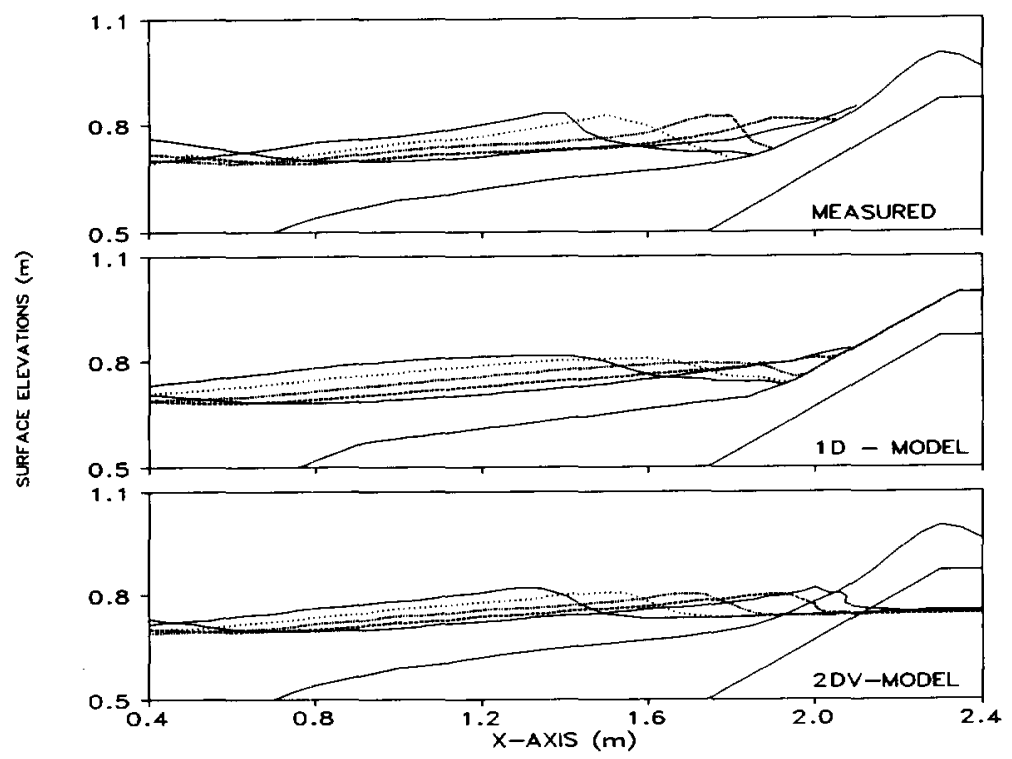

Fig.6.6 Comparison of surface elevations; measured, $1 D$-model and $2 \mathrm{DV}$-model; $H=0.119 \mathrm{~m}, T=1.5 \mathrm{~s}$. 
First half of wave cycle:

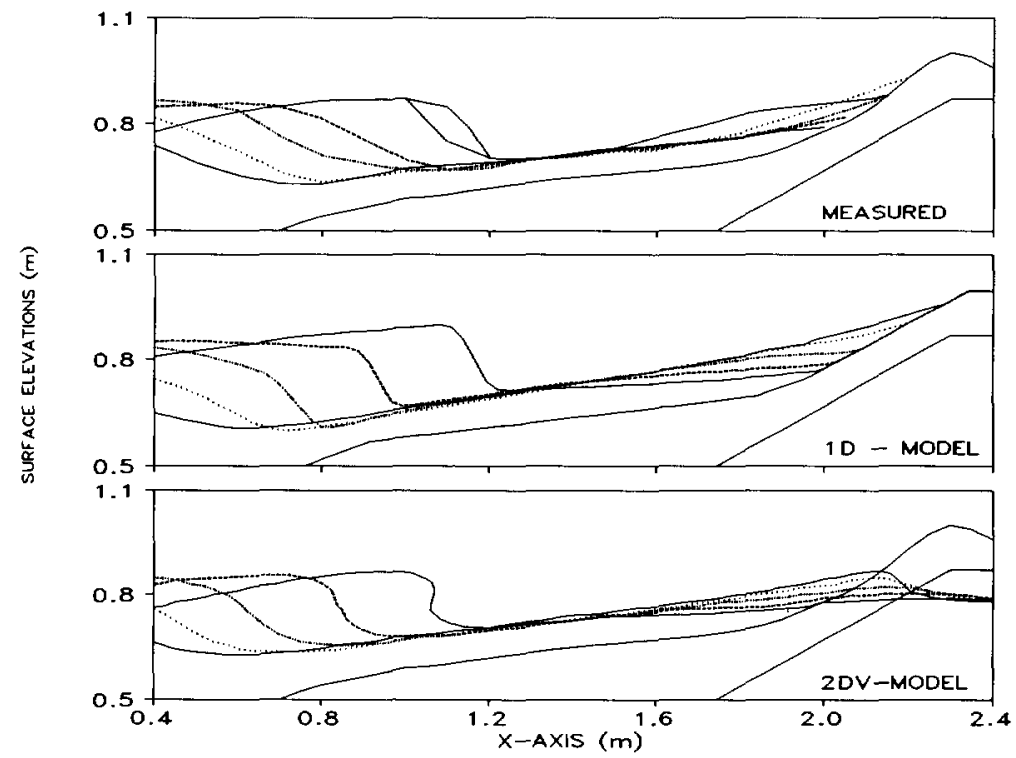

Second half of wave cycle:

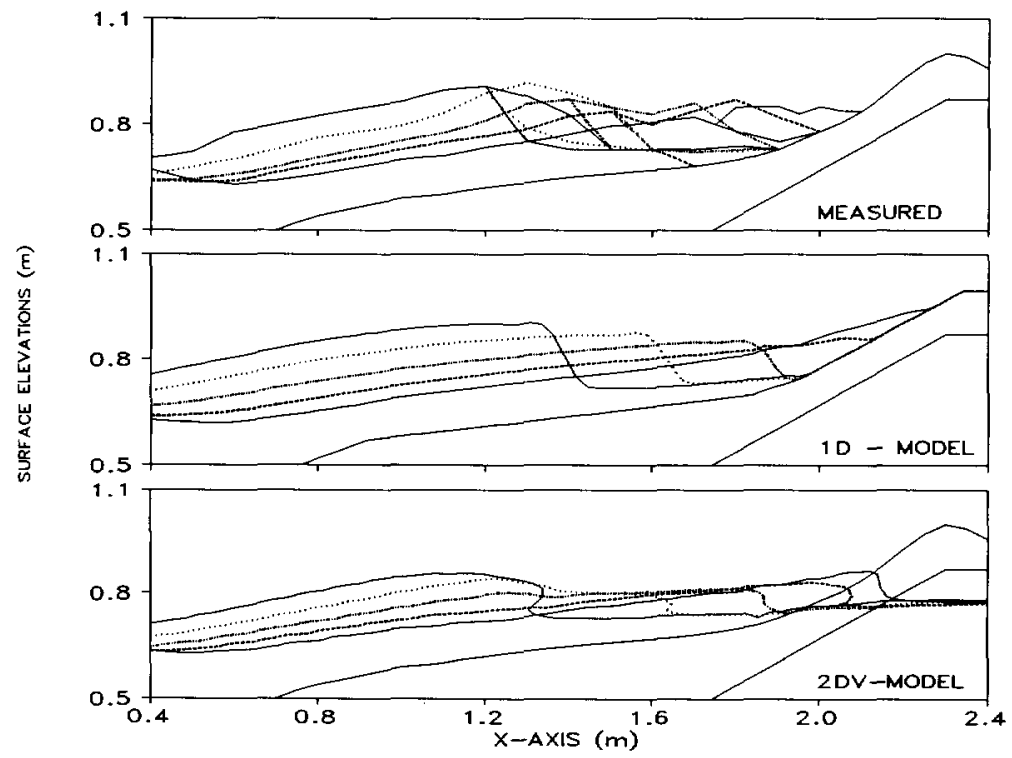

Fig.6.7 Comparison of surface elevations; measured, ID-model and $2 \mathrm{DV}$-model; $H=0.230 \mathrm{~m}, T=1.5 \mathrm{~s}$. 
First half of wave cycle:

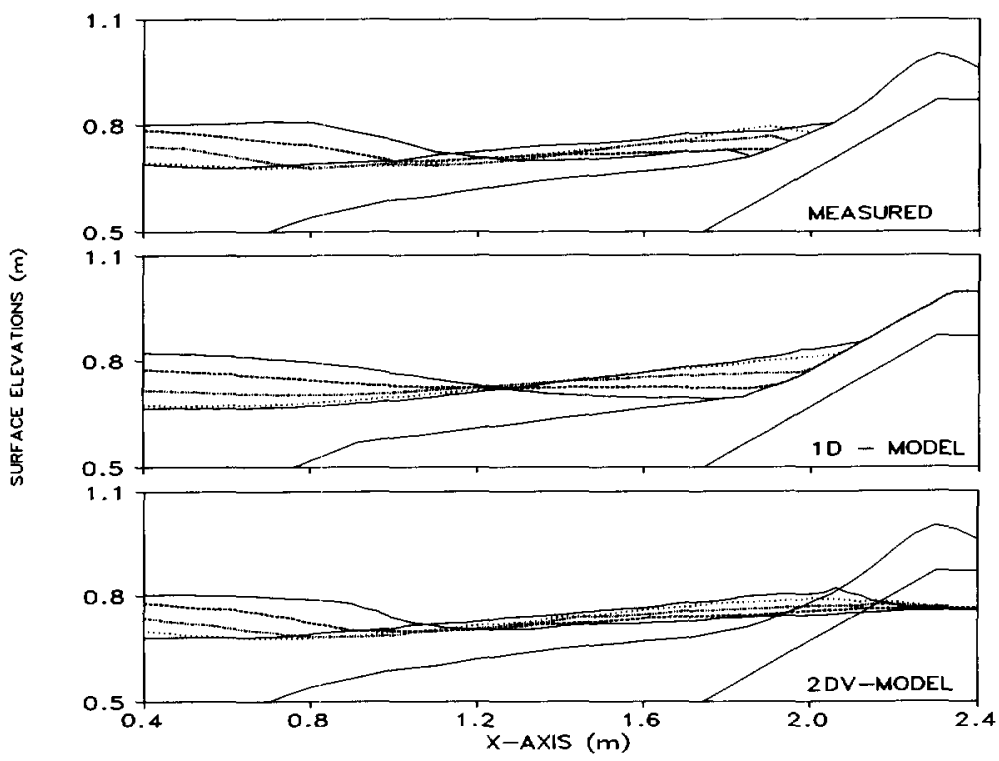

Second half of wave cycle:

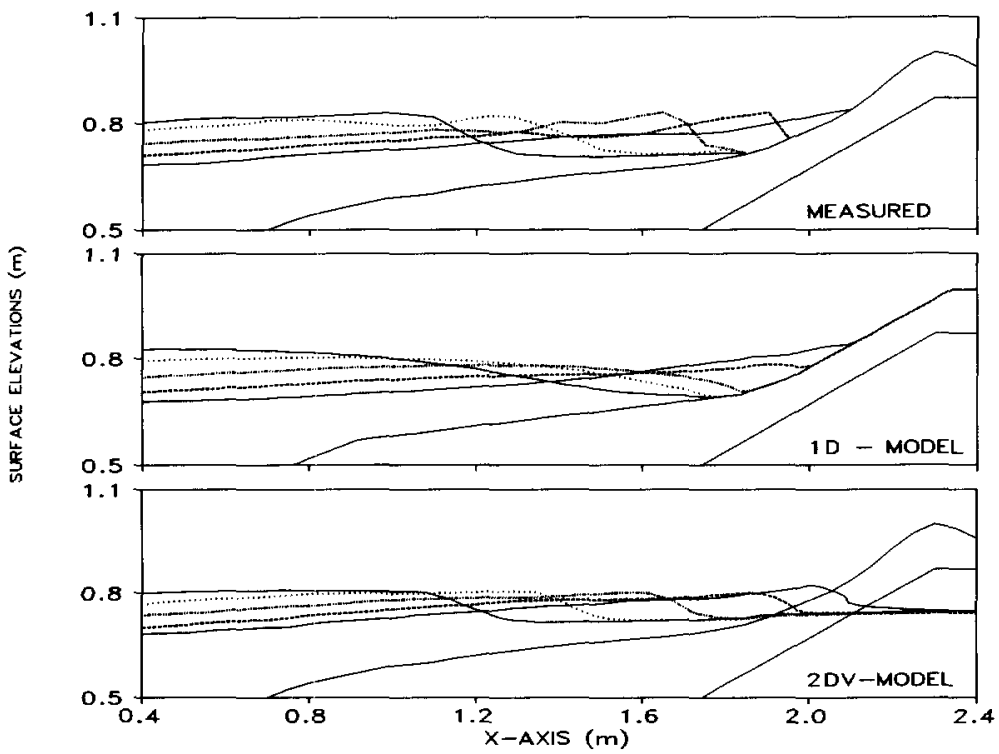

Fig.6.8 Comparison of surface elevations; measured, $1 D$-model and $2 \mathrm{DV}$-model; $H=0.112 \mathrm{~m}, T=2.1 \mathrm{~s}$. 
First half of wave cycle:

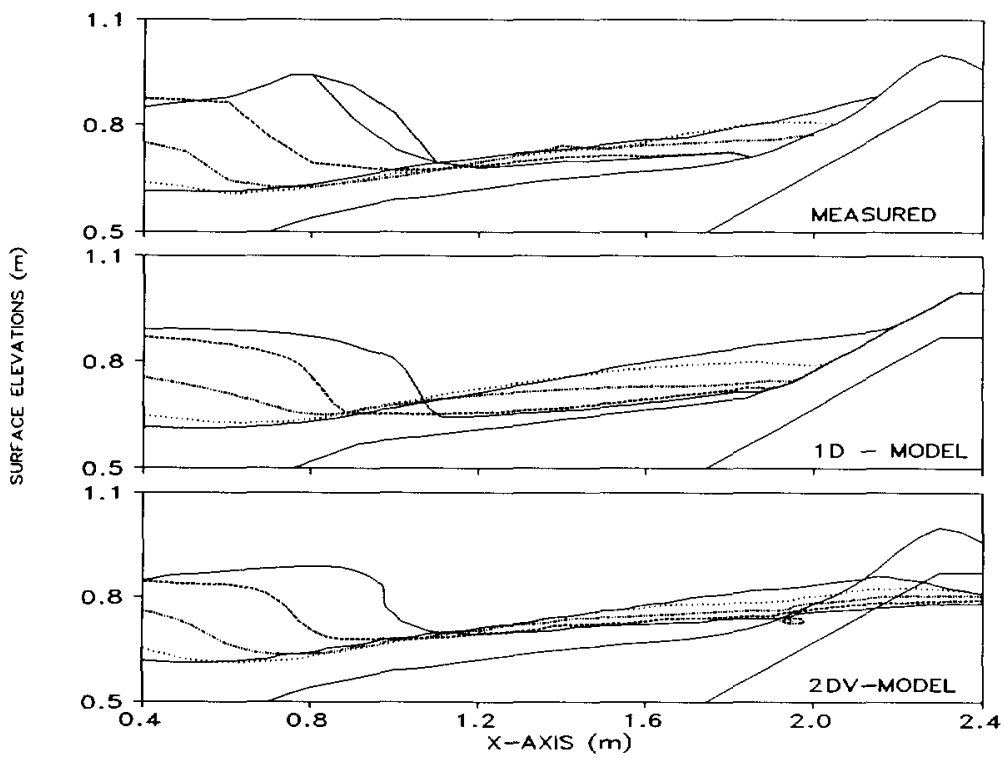

Second half of wave cycle:

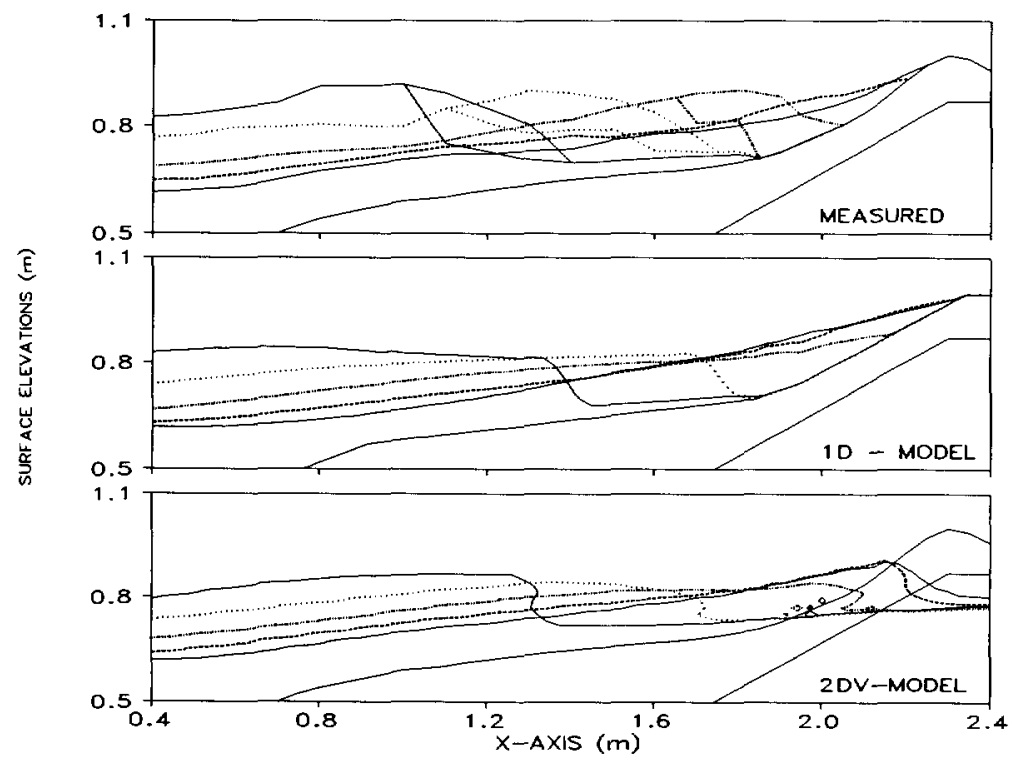

Fig.6.9 Comparison of surface elevations; measured, $1 D$-model and $2 \mathrm{DV}$-model; $H=0.217 \mathrm{~m}, T=2.1 \mathrm{~s}$. 
comparisons with the computed results become rather complex in the second part of the wave cycle since the exact position of the free surface is not clear. However, the comparisons indicate that the decrease in wave height above the berm occurs faster in the computation than observed from the measurements. It seems as if this overestimated reduction in wave height leads to an underestimation of the run-up levels. For the two wave conditions with lower waves (Fig.6.6 and Fig.6.8), the comparisons are also rather good in the second half of the wave cycle.

Run-up values obtained from the numerical model are too low for all four wave conditions 0.07 vs. $0.10 ; 0.14$ vs. $0.21 ; 0.08 v s$. 0.11 and $0.18 v s .0 .27 \mathrm{~m}$, for the measured and computed levels with the wave conditions $H=0.119 \mathrm{~m}, T=1.5 \mathrm{~s}$; $H=0.230 \mathrm{~m}, T=1.5 \mathrm{~s} ; H=0.112 \mathrm{~m}, T=2.1 \mathrm{~s} ; H=0.217 \mathrm{~m}, T=2.1 \mathrm{~s}$, respectively. All these values are relative to the average water levels in front of the structure during testing. The definition of the surface elevations at the positions of cells that are $50 \%$ full of water instead of another percentage, might influence the computed run-up levels slightly. If, for this definition, positions of cells that are $10 \%$ full of water are regarded as surface elevations, the computed run-up levels may increase but not so much that they would fit to the measured run-up levels. The error in the dissipation of energy recorded in the computed breaking process, which may result from inadequate description of the physical processes or from numerical dissipation, is assumed to cause these underestimated run-up levels.

Velocities from the measurements and the numerical model are compared. For each of the four wave conditions Figure 6.10 shows three examples of comparisons of both horizontal and vertical velocities. For the higher waves could comparisons be made only in the region before breaking because the other measurements were disturbed by air-entrainment. Most of the comparisons show that the both the horizontal and vertical velocities are represented rather well in this region. As can be expected, the differences increase for positions closer to the crest of the structure. The numerical model underestimates the surface fluctuations in this region which accompanies an underestimation of the velocities. In the region where breaking and air-entrapment occurs no velocities could be compared, but since the surface elevations are represented relatively inaccurately, the comparisons would probably yield velocities that are too low. Nevertheless, it can be concluded that in the region just before breaking, both the surface elevations and the velocities are rather well represented. 

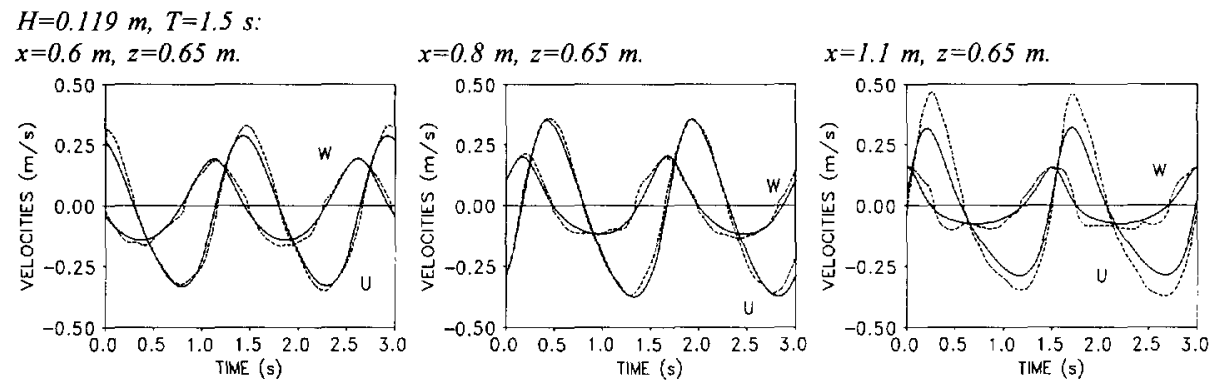

$H=0.230 \mathrm{~m}, T=1.5 \mathrm{~s}$ :

$x=0.4 \mathrm{~m}, z=0.45 \mathrm{~m}$.

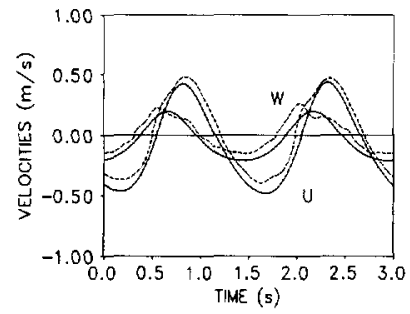

$x=0.6 \mathrm{~m}, z=0.55 \mathrm{~m}$.

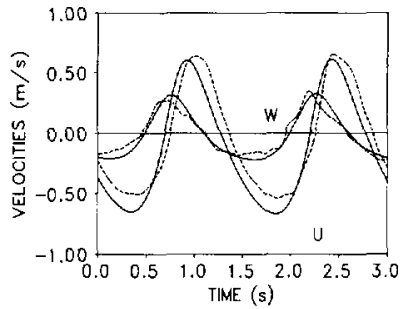

$x=0.8 \mathrm{~m}, z=0.65 \mathrm{~m}$.

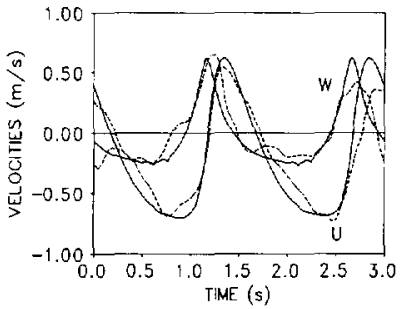

$H=0.112 \mathrm{~m}, T=2.1 \mathrm{~s}$.

$x=0.6 \mathrm{~m}, z=0.65 \mathrm{~m}$.
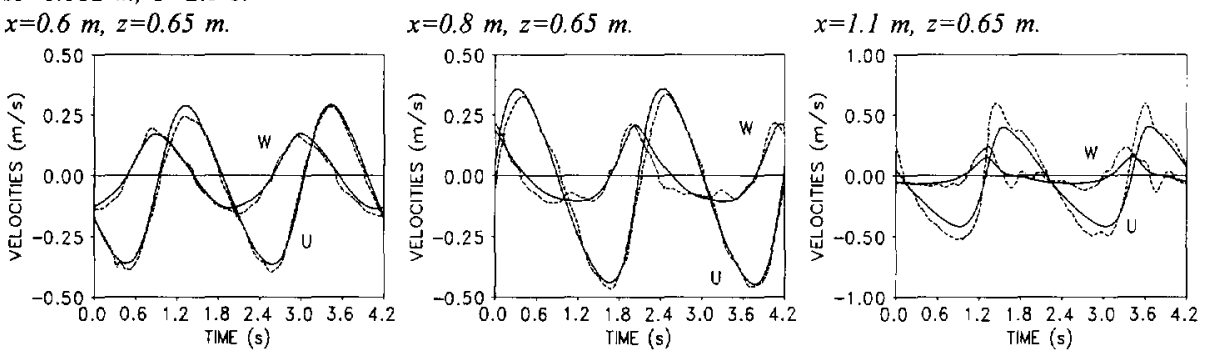

$H=0.217 \mathrm{~m}, T=2.1 \mathrm{~s}:$
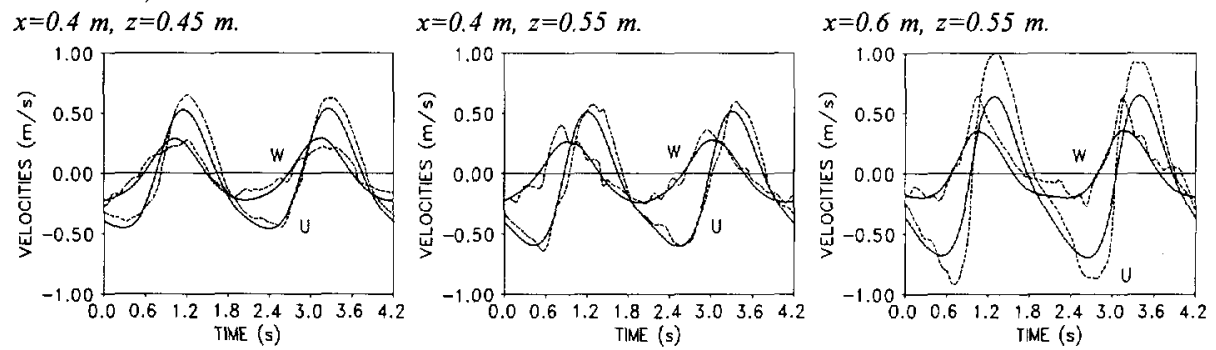

Fig.6.10 Comparison of velocities; measured (dashed) and computed by the 2DV-model (lines). 

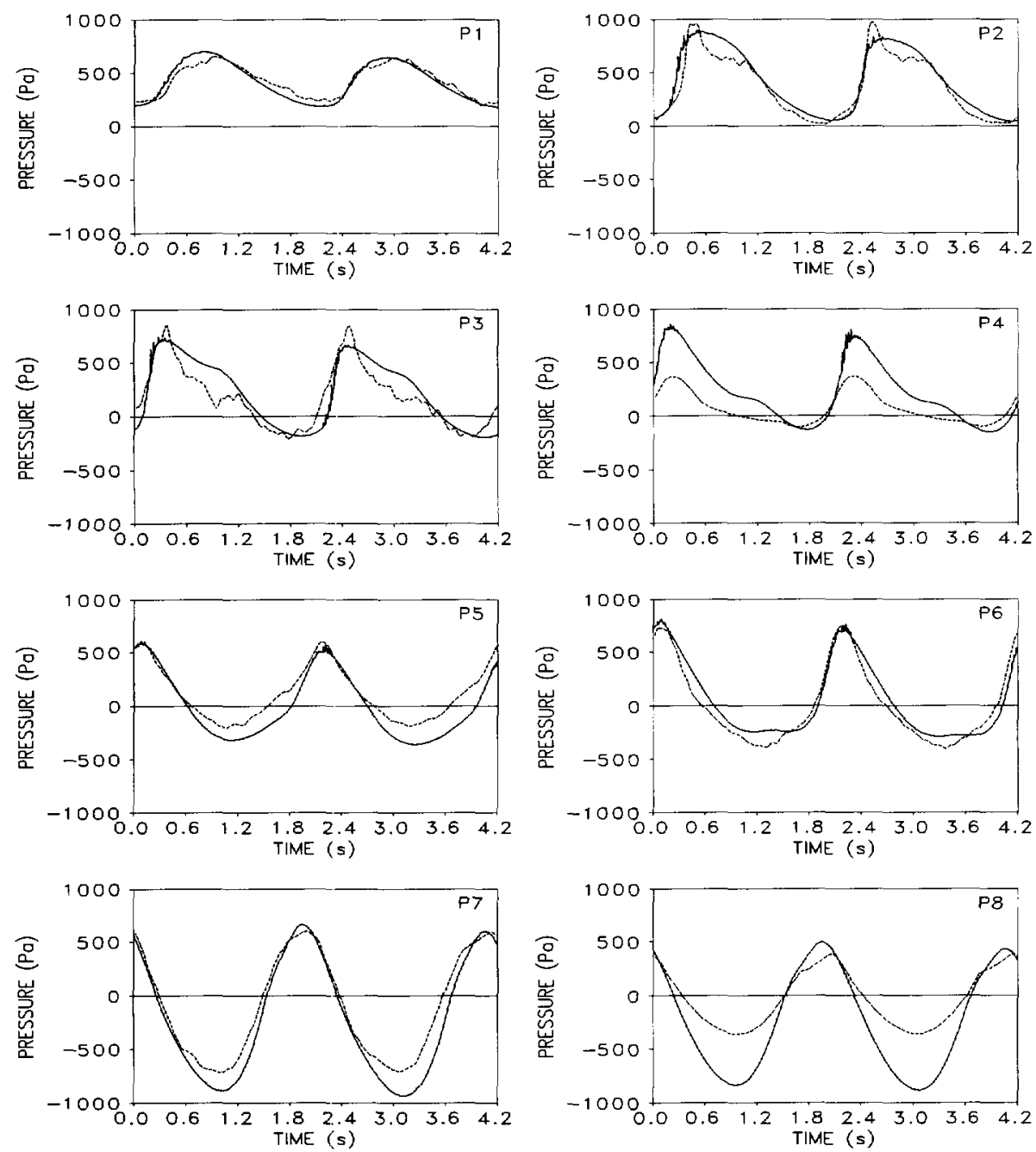

Fig.6.11 Comparison of pressures; measured (dashed) and computed (lines) by the 2DV-model; $H=0.217 \mathrm{~m}, T=2.1 \mathrm{~s}$.

Pressures obtained from the eight transducers and the computed pressures at the same positions are compared as well. The positions of these transducers are shown in Figure 6.2. Figure 6.11 shows the comparison for one of the wave conditions 
$(H=0.217 \mathrm{~m}, T=2.1 \mathrm{~s}$ ). Transducer $P 4$ is positioned between the transducers $P 3$ and $P 6$. The recorded pressures by transducer $P 4$, however, clearly deviate from those recorded by $P 3$ and $P 6$. The signals of transducer $P 4$ are roughly $50 \%$ of the expected pressures for all analysed wave conditions. Because no convincing physical explanation can be given for these low pressures the signals of transducer $P 4$ are highly questionable. The comparisons with the other transducers are fairly accurate except for those with transducer $P 8$. For this transducer the measured signal is not unrealistic compared to the signals from $P 5-P 7$. Therefore, the difference at the position of transducer $P 8$ was assumed to have been caused by a slightly different simulation of the internal flow field in this region. Both the internal set-up as recorded by transducer $P I$ (average level), and the internal wave height are reproduced with a high accuracy. The computed signals at positions just below the breaking waves (transducers $P 2, P 3$ and $P O$ ) also show good correspondence with the measured signals, although these measured signals show more high-frequency fluctuations.

\subsubsection{Evaluation of the numerical model validations}

The validations described in the previous two chapters indicate that both models can be used with good result for many applications. Here, the results from the two models with respect to the berm breakwater tests will be compared.

Surface elevations were compared for four series of waves. The first comparison, shown in Figure 6.6, indicated that both numerical models provide a rather good simulation of the wave motion. For the other comparison with relatively low waves, shown in Figure 6.8, the same conclusion can be drawn but the one-dimensional model tends to resemble a standing wave while the measurement and the twodimensional model show steeper wave fronts. The comparisons with the two series with higher waves are shown in Figures 6.7 and 6.9. In the first half of the wave cycle the steepening of the wave front is somewhat quicker in the numerical models than in the measurements, although the differences in this region are still small for both models. In the second half of the wave cycle, air-entrapment in the region of breaking makes comparisons more difficult. The resemblance of results from both numerical models to the measurements is weak. The one-dimensional model forms a steep bore but apparently the total momentum is still reproduced satisfactorily since the run-up levels are accurately reproduced. The two-dimensional model shows 
overturning waves where too much dissipation occurs, since run-up levels are not reproduced accurately. However, this is not caused solely by inaccurate modelling of the overturning wave, since this run-up levels were also inaccurate for the two series with non-overturning waves.

Run-up values are significantly better represented by the one-dimensional model. Although the use of a specific value for the empirical friction coefficient $f$ in the one-dimensional model influences the run-up levels slightly, the model provides accurate run-up values. Those obtained by using the two-dimensional model however are much less accurate. The reduction in wave height during breaking is too large in this two-dimensional model which results in too low run-up levels. The treatment of the free surface is supposed to cause the greater part of the inaccuracies. These inaccuracies are to a large extent originated from the modelling of the breaking process. Improvements of this treatment are, however, not easy to obtain.

Velocities could only be compared in the region before actual breaking occurred. However, in the region before breaking the wave deformation is simulated rather accurately by the two-dimensional model. The one-dimensional model which computes depth-averaged velocities can only provide a rough estimate of velocities in a specific position. Even for the four series of waves investigated, where the twodimensional model does not provide a substantially better simulation of the wave motion than the one-dimensional model, this two-dimensional model still provides much more detailed information on the flow field.

Pore-pressures measured in the berm of the berm breakwater appeared not to be hydrostatic, since the fluctuations of the free surface do not fully penetrate the permeable layer (Fig.6.4). In particular for cases in which the vertical components of pore-velocities are not small compared to the horizontal pore-velocities, neglecting the friction in the vertical direction might especially lead to inaccurate results. This effect was somewhat accounted for in the one-dimensional model by using a higher friction in the horizontal direction (see Section 4.4.2). Reducing the pressure gradient for porous media flow in the region where a layer of water overlaps a saturated permeable layer might be a good alternative. This reduction cannot be constant since it is likely that this reduction decreases for longer wave periods and for a higher permeability and increases for thicker permeable layers. The two-dimensional model reproduces the pore-pressures accurately which indicates 
that the internal flow field is simulated realistically and that the applied porous media flow friction-coefficients are sufficiently accurate.

In general, it can be concluded that considering the relatively large simplifications of the wave motion, the one-dimensional model simulates the flow field rather well. This indicates that the applied assumptions are justified for this application. The two-dimensional model, for which less far reaching assumptions have been made, provides a detailed description of the flow field, but the accuracy of predicted runup levels and consequently also overtopping discharges is too low. The present version is therefore not suitable for practical use on steep permeable structures with respect to these important parameters. Unlike the one-dimensional model, the twodimensional model permits more detailed modelling of many phenomena by extending the present version without large modifications of the model structure. The two-dimensional model with its capability to simulate multiple-connected free surfaces and to simulate wave motion in conditions with a large influence of twodimensional aspects however has a much larger potential for practical application than the one-dimensional model. Improvements of the model in relation to a better modelling of turbulence, air-extrusion and free surface treatment are expected to increase the accuracy and applicability of the model.

\subsection{Conclusions}

Analysis of the physical-model tests with a small-scale berm breakwater showed that the pressure differences caused by fluctuations of the free surface do not fully penetrate into the permeable part underneath. This is logical since the friction in the permeable layer affects the vertical pore-velocities and therefore also the pressure fluctuations in the vertical direction. In the one-dimensional numerical model this decrease of pressure fluctuations in the downward direction has not been taken into account. It, however, might be incorporated by reducing the magnitude of the applied pressure gradient in the horizontal direction. Although this reduction is not easy to determine because it depends on several properties including the flow field, this might lead to more accurate numerical results. Pore-pressures were rather accurately predicted by the two-dimensional numerical model.

Like the tests with impermeable and permeable uniform slopes described in Section 4.4.2, measured run-up values on a berm breakwater slope are also accurately 
predicted by the one-dimensional model. The reduction in wave height during breaking in the two-dimensional model is overestimated, which results in too low run-up levels. The present version of the two-dimensional model is therefore not suitable to predict accurate run-up levels.

Comparisons between the measured and simulated surface elevations indicate that both numerical models give a rather good impression of the wave action until breaking. The resemblance is much weaker in the area where air is captured.

The one-dimensional model does provide depth-averaged velocities. Comparisons of velocities measured at specific points therefore, do not give a good indication of the accuracy of the model. Velocities in the area just before breaking are reproduced with good accuracy by the two-dimensional model. 


\section{Chapter 7}

\section{Wave load - response model}

\subsection{Introduction}

For dynamic structures such as berm breakwaters and gravel beaches, the response to wave attack can be described by using parameters like the wave height, wave period, stone size and storm duration. The use of more detailed information on the flow field such as velocities, accelerations, pressures and forces on stones may lead to a more generally applicable description of the dynamic behaviour of structures. This can be done by simulating both the wave motion and the response of the structure numerically.

Validation of the two numerical models described in the previous chapters indicated that both models can provide accurate results for wave motion on for instance berm breakwaters. Therefore, a step towards the simulation of the movement of stones along the slope can be made. Such a numerical simulation of the reshaping process by simulating both individual waves and the motion of individual stones, requires relatively long computing times. Therefore, the one-dimensional numerical model described in Chapter 4 (ODIFLOCS) is used for this purpose rather than the timeconsuming two-dimensional model described in Chapter 5 (SKYLLA). The procedure used to simulate reshaping which will be described in this chapter can, however, also be applied in combination with other numerical models simulating individual waves such as the model described in Chapter 5 . Although only structures under normally incident waves and cross-structure transport of material are studied here, a similar procedure can also be used to model transport of stones along the structure as a result of oblique wave attack. This, however, requires a two-dimensional horizontal (2DH) or a three-dimensional (3D) numerical wave model, including porous media flow which is not yet available. 


\subsection{Modelling of forces and profile development}

\subsubsection{Approach for simulating profile development}

The stability of the stones is strongly dependent on the hydrodynamic conditions. Several expressions for this stability have been developed. Iribarren (1938) and Hudson (1953) derived widely used expressions where the hydrodynamic properties are represented by the wave height. Van der Meer (1988) performed many laboratory tests to study the influence of other hydrodynamic properties as well. The results were summarised in empirical relations that also contain hydraulic parameters like the wave period and number of waves. Although these design recommendations are sufficiently accurate for many applications, more generally applicable results can be obtained by simulating the wave motion first and then using flow properties like the velocities and accelerations to predict the forces on stones. This can be done numerically.

Results obtained from such a numerical approach may be less hampered by scale effects than those from physical-model tests on a small-scale. In addition, sensitivity of the reshaping process to parameter variations like for instance the permeability of structures, can be studied more easily with a numerical model than with physicalmodel tests. Such a numerical model can also be applied to cases for which no empirical relations exist, like for instance structures or beaches which contain large immovable components such as gravel beaches fronting seawalls or rubble mound slopes in front of rigid crest elements.

In the approach towards a numerical wave load-response model several model formulations are required. Firstly, the hydrodynamic flow, both outside and inside the structure, need to be known and modelled numerically. The one-dimensional model (Chapter 4) can be used as a first approximation. Secondly, information concerning the magnitude of forces on stones is necessary. Attempts to measure forces on idealised stones have been made by Sigurdsson (1962) and Sandstrøm (1974). Tørum (1992) measured forces on a single stone in the cover layer of a berm breakwater. Thirdly, relations between the forces on stones and the hydrodynamic behaviour are necessary. As mentioned before, the hydrodynamics can be represented by local velocities and local accelerations. As a first approximation, a Morison-type of expression (Morison et al., 1950) can be used, see 
for instance Kobayashi and Otta (1987) or Tørum (1992). Fourthly, information concerning failure mechanisms and forces causing damage is needed. Often failure mechanisms referred to as rolling, sliding or lifting are distinguished. These mechanisms or other failure mechanisms need to be modelled. Finally, the new positions of unstable stones need to be known if the complete reshaping process is to be simulated. For most breakwaters severe damage is not acceptable, so for those cases it is not of primary interest to study the new positions of the stones. However, for berm breakwaters and gravel beaches these new positions are of primary concern.

Norton and Holmes (1992) described a simulation model for the reshaping process of berm breakwaters under normally incident, monochromatic wave attack, by modelling individual stone displacements. This was based on a Morison-type of equation. In the present model, initiation of the movement of stones is also based on a Morison-type of equation, including drag, inertial and lift forces. However, unlike that of Norton and Holmes (1992), the present model can also be used with irregular waves, since it simulates the reshaping process in the time-domain. Furthermore, in the model described here, the new positions of unstable stones are determined from the hydrodynamic conditions.

\subsubsection{Modelling of forces on stones}

The hydrodynamic loads on a single stone can be modelled by using a number of forces representing different phenomena. For the relation between the hydrodynamics and the forces, local velocities and local accelerations are required. The numerical model provides these local properties although averaged over the depth. Differences between these properties at the position of the particles and the depth-averaged velocities naturally cause inaccuracies.

Three forces resulting from the hydrodynamic loads have been distinguished; the drag force acting parallel to the slope in the direction of the velocity, the inertial force acting parallel to the slope and the lift force acting perpendicular to the slope. For the drag force and the inertial force expressions similar to those in the Morison equation can be used. The lift force is the most difficult one to determine. Often, the assumption that the lift force is proportional to the squared velocity and the squared diameter of the stone is used. 
$F_{D}=\frac{1}{2} \rho c_{D} k_{2} D^{2} u|u|$

$F_{I}=\rho c_{M} k_{1} D^{3} \frac{D u}{D t}$

$F_{L}=\frac{1}{2} \rho c_{L} k_{2} D^{2} u^{2}$

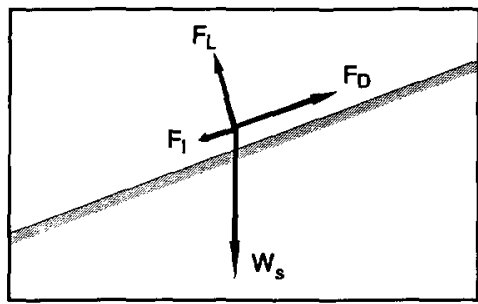

Fig. 7.1 Forces on particle.

where the acceleration $D u / D t$ is approximated by $\partial u / \partial t ; c_{D}, c_{M}, c_{L}$ are the drag coefficient, the inertia coefficient and the lift coefficient respectively; $k_{1}$ and $k_{2}$ are the volume shape factor and the area shape factor respectively. With the area shape factor $k_{2}$ the actual projected area in the flow direction can be incorporated. Since a cover particle is partially sheltered by other particles, the actual projected area is smaller than for a single particle in a flow. The sheltering effect has not been incorporated separately and therefore affects the values of the coefficients which will be derived through calibration. For spheres, the value for $k_{2}$ is $\pi / 4$ since the projected area, neglecting the sheltering effect, is $\pi / 4 D^{2}$. The volume shape factor $k_{1}$ is $\pi / 6$ for spheres since its volume is equal to $\pi / 6 D^{3}$. For stones slightly higher values must be used: $k_{1}=0.66$ and $k_{2}=0.9$ were used in all computations. A constant stone diameter is taken, while the equivalent sphere diameter $D_{E Q}$ is used as the characteristic stone size $\left(D_{E Q} \approx 1.24 \cdot D_{n 50}\right)$.

The submerged weight is often taken as the counter-acting force, although occasionally other counteracting forces have been proposed, see for instance Brandtzaeg and Tørum (1966). The submerged weight acts vertically and can be written as ( $\rho_{s}$ represents the density of the stone material):

$W_{s}=\left(\rho_{s}-\rho\right) g k_{1} D^{3}$

Several concepts can be used for initiation of movement. The stability criteria for the phenomena referred to as lifting and sliding can respectively be expressed by:

$F_{L} \leq W_{s} \cos \phi$

$\left|F_{D}+F_{I}-W_{s} \sin \phi\right| \leq \tan \mu\left(W_{s} \cos \phi-F_{L}\right)$ 
where $\mu$ denotes the angle of internal friction and $\phi$ the local slope angle. Here, the phenomenon referred to as rolling is assumed to occur if both stability conditions are not satisfied.

An additional force is implemented at the intersection of the free surface with the slope (wave front). The first particle near the wave front is assumed not to be submerged $\left(W=\rho_{s} g k_{l} D^{3}\right)$. If velocities are in the direction of the particle, the pressure at the wet side of the particle is expressed by the pressure thrust approximated by $0.5 \cdot \rho g h^{2} D+\rho u^{2} h D$. If this force, acting parallel to the slope, exceeds the counteracting component of the weight of the particle, the particle is regarded as unstable. For unstable particles, the direction in which they will possibly move, has to be determined.

\subsubsection{Modelling of stone displacements}

In this section a method to simulate stone displacements on the seaward slope of structures and gravel beaches is discussed. Initiation of movement is calculated as described in the previous section.

Usually the flow pattern around particles is very complex. Consequently, the forces resulting from the pressure gradients around the particles are not easy to determine. The drag, inertial and lift forces implemented in the model for the initiation of movement, are the result of these pressure gradients. For particles moving along the slope other forces may be of importance. It is assumed that for particles moving along the slope the pressure gradient directly depending on the slope of the free surface (hydrostatic pressures) is of more importance than it is for stable stones in the cover layer. Therefore, such a force (Froude-Krylov force) is taken into account when determining the direction in which the unstable particles will move. This force is assumed to act parallel to the slope and is related to the volume of the particle. Calibration, however, will show that this force is of minor importance compared to the magnitude of the other forces.

$$
F_{P}=\rho c_{P} g k_{1} D^{3} \frac{\partial \eta}{\partial x}
$$


where $\eta$ is the free surface elevation and $c_{P}$ is a coefficient to be determined through calibration. This force, as well as the drag and inertial forces and the weight of the stone, determine in which direction an unstable particle will move after one of the stability criteria is (Eq.7.5 and/or Eq.7.6) not satisfied:

$$
\begin{aligned}
& \left|F_{D}+F_{I}-F_{P}-W_{s} \sin \phi\right|>0 \Rightarrow \text { UPWARD } \\
& \left|F_{D}+F_{I}-F_{P}-W_{s} \sin \phi\right|<0 \Rightarrow \text { DOWNWARD }
\end{aligned}
$$

The inertial force and the drag force act differently on non-moving stones in the cover layer than on stones moving along the slope. However, as a first approximation the same formulations and the same values for the drag and inertia coefficients are used for initiation of movement and for moving stones, even though for determining the direction of the stone the additional force shown in Equation 7.7 may also affect the values of these coefficients; the formulations for the drag and inertial forces and the coefficients $c_{D}$ and $c_{M}$ in Equations 7.1 and 7.2 are also used in Equations 7.8 and 7.9.

After determining the direction in which an unstable particle may move, the local hydrodynamic properties at a position one space-increment $(\Delta x)$ away from the original position, will be considered. Whether the particle would be stable or unstable in that neighbouring position is verified. If the particle is stable at that position, the particle will stay in its original position. If the particle is also unstable at the neighbouring position the particle will be moved to this position. This is done without any time-delay which means that the particle is moved over a spaceincrement $\Delta x$ within a period of $\Delta t$. The choice of $\Delta t$ depends on the spaceincrement $\Delta x$ and the wave celerity which means that the velocity of the stones is in fact related to the (average) wave celerity.

The phenomenon of particles moving while they stay at the same position is called rocking. In the present simulation model, unstable particles that are not displaced because they would be stable at their neighbouring position, are regarded as rocking.

The response/morphological model for cross-structure transport is interactive with the hydraulic model. At each time-step $(\Delta t)$ the hydraulic properties are determined at all positions. Whether the particles are stable at their present position and whether 
they need to be displaced or not is verified for each position and each time-step. The profile changes due to the movement of the particles while the new profile is immediately incorporated in the hydraulic model.

Some numerical problems remain. Particles are moved over one space increment within one time-step. The space-increment $\Delta z$ by which the profile is adapted in the vertical direction must still be determined. The space-increment $\Delta x$ is usually not equal to the size of the particles. For instance for small material several particles are positioned within one space-increment $\Delta x$. For the space-increment $\Delta z$ a value is taken such that an area in the cross-section equal to $D \cdot \Delta x$ is replaced within a period $\Delta x / u_{r}$. For the velocity $u_{r}$ a representative velocity of $\sqrt{ }\left(g \cdot H_{r m s}\right)$ is used although in principle a time and space dependent velocity of the particles can be applied here.

Another numerical problem occurs when the concept is used in combination with a one-dimensional hydraulic model. For particles that are relatively large compared to the wave height and compared to the numerical space-increment $\Delta x$, the variation in the vertical direction $\Delta z$ may disturb the hydraulic model to an unacceptable degree. The numerical model applied is a one-dimensional hydrostatic model which does not solve a non-hydrostatic momentum-equation in the vertical direction and is therefore relatively sensitive (causing inaccuracies) to abrupt changes of the profile. This means that for relatively large particles, the space-increment $\Delta z$ must be decreased. This leads to a slower response of the numerical structure to the wave climate. This can be partially overcome by increasing the total simulation-time, but if the relation between a smaller space-increment $\Delta z$ and the profile adjustment-time is not linear the development in time is not correct and therefore less suitable for studying the development in time of structures with relatively large particles. Several comparisons indicated that this relation was close to linear and therefore this does not seriously affect the accuracy of the results.

\subsection{Calibration and validation of the wave load-response model}

\section{Calibration}

In the first instance dynamically stable profiles can be classified by using the parameter $H_{s} / \Delta D_{n j 0}$. For dynamically stable profiles this value varies roughly 
between 3 and 500. This parameter varies between 4 and 6 for berm breakwaters. For gravel beaches this value is higher. Since in principle the procedure described in the previous sections can be applied to processes where suspension transport can be neglected, gravel beaches can also be dealt with. For calibration of the model a gravel beach was taken instead of a berm breakwater slope, since for gravel beaches many more displacements occur and material is often transported both upward and downward.

Tests performed by Van der Meer (1988) are used for calibration and validation of the morphological model described. The coefficients that need to be determined through calibration are the coefficients $c_{D}, c_{L}, c_{M}$ and $c_{P}$. The combination of the coefficients derived from the calibration test is used in other computations where several parameters vary. Van der Meer (1988) derived expressions for the prediction of reshaped profiles from his test-results. Conditions that these expressions have been derived from are used for comparison. Since for these tests the differences between the measured profiles and the profiles prescribed by the expressions are relatively small, the expressions have been used for convenience.

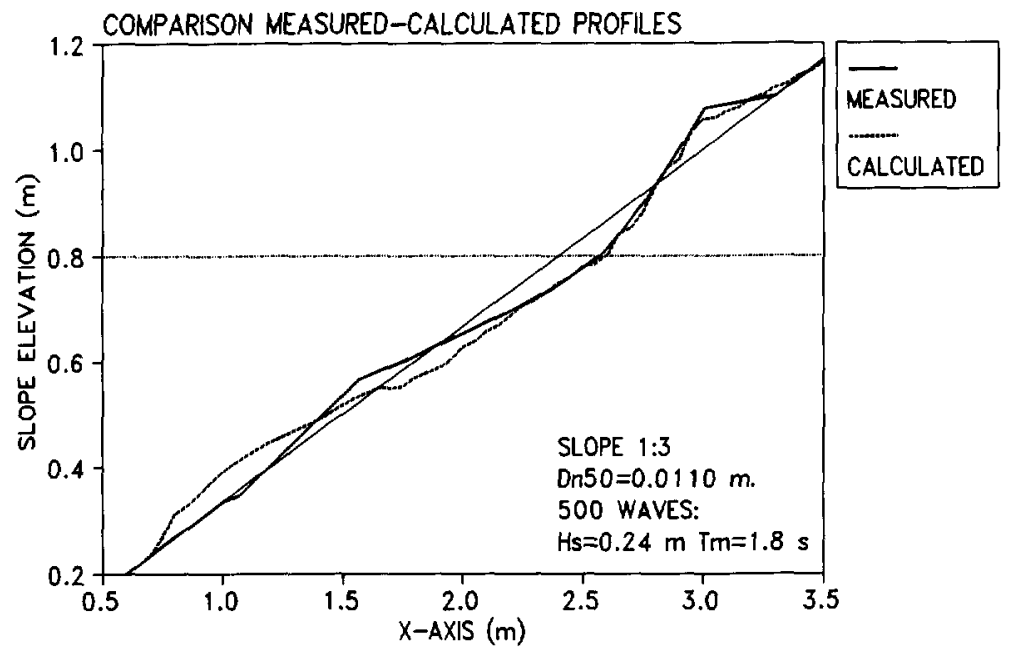

Fig.7.2 Comparison of profiles.

The computations for both calibration and validation have been done with a TMAspectrum (Section 4.3.2) although physical-model tests have been performed with 
different spectra. However, neither Van der Meer (1988) nor Kao and Hall (1990) observed a clear influence of the spectral shape. Therefore, it is assumed that these dissimilar spectra do not to contribute to possible deviations between the data from the measurements and computational results. The spectra are represented by the significant wave height $H_{s}$ and the mean wave period $T_{m}$. The material is characterised by the $D_{n 50}$. The computations have been performed for approximately 500 waves. For the friction coefficients in the porous medium and for the added mass coefficient, the expressions given by Equation 3.16 have been used (incorporated as described in Section 4.2.2).

In the test used for calibration, in the dynamically stable situation accretion occurs both above the still-water level and below the still-water level. The test concerns a uniform $1: 3$ slope with material with a diameter of $0.0110 m\left(D_{n 50}\right)$. The wave height $H_{s}$, the wave period $T_{m}$ and the still-water level were $0.24 \mathrm{~m}, 1.8 \mathrm{~s}$ and 0.80 $m$ respectively $\left(H_{s} / \Delta D_{n 50}=13.2\right)$. The friction factor $f$ was set at 0.10 (Eq.4.3 with $R=1.5 \cdot H_{s}$ ). Figure 7.2 shows the reshaped profile after 500 waves. The following values were found for the coefficients: $c_{D}=0.018, c_{L}=0.075, c_{M}=0.08$ and $c_{P}=0.01$ (with an angle of internal friction of $\mu=50^{\circ}$ ). A comparison with measured values will be discussed later in this section.

\section{Validation}

In Van Gent (1993-c), 20 comparisons between the profiles derived from the expressions and the simulated profiles were presented. Tests with stones of $D_{n 50}=0.0041 \mathrm{~m}, 0.0062 \mathrm{~m}, 0.0110 \mathrm{~m}$ and $0.0257 \mathrm{~m}$ were used. The initial slopes were $1: 5,1: 3$ and $1: 1.5$. Wave spectra represented by 500 waves with combinations of $H_{s}=0.14 \mathrm{~m}, 0.18 \mathrm{~m}, 0.24 \mathrm{~m}$ and $T_{m}=1.3 \mathrm{~s}, 1.8 \mathrm{~s}, 2.5 \mathrm{~s}$ and $3.0 \mathrm{~s}$ were simulated. For all computations the friction coefficient $f$ was set at 0.10 .

The above mentioned combination of the four coefficients was used in 16 of the 20 simulations. For the simulations with the larger material, $D_{n 50}=0.0257 \mathrm{~m}$, the lifting process appeared to be underestimated. The calibrated lift coefficient was therefore adapted; for material larger than $D_{n 50}=0.0110 \mathrm{~m}$, a linear relation is used as a first approximation: $c_{L}=7.85 \cdot D_{n s 0}$ with a maximum value for $c_{L}$ of 0.38 . This relation appeared to give rather good results, but in fact it is a procedure for which no physical explanation was found. 
As expected, differences occurred between the measured and calculated profiles. However, in most cases the trends were the same; in most cases accretion and erosion took place in roughly the same sections as observed in the measurements. For the computations with 1:5 slopes, often both the accretion and the erosion were underestimated; for the computations with the 1:3 slopes, the section above the stillwater level was rather good but the accretion below the still-water level was positioned too much downward; the computations with the $1: 1.5$ slopes showed both above and below the still-water level a rather good comparison. In general, it seemed as if accretion was underestimated in cases where it occurred above the stillwater level whereas it was overestimated where accretion occurred further down the slope. This conclusion was, however, not valid for all simulations.

For the calculation of forces, the model uses depth-averaged velocities rather than velocities near the surface of the slope. During up-rush, it is expected that a depthaveraged velocity is a rather good characteristic velocity in the run-up area. Lower down the slope, the layer of water above the slope is thicker. Here, the depthaveraged velocity may differ much more from the velocity near the surface of the slope. This may be an explanation for the relatively weaker correspondence with the measurements for the section below the still-water level compared to the slightly better results above the still-water level.

\section{Sensitivity analysis}

Several computations have been done to study the dependency of the reshaped profile on a number of model parameters. For this purpose a $1: 5$ slope with material with a diameter of $D_{n 50}=0.0041 \mathrm{~m}$ was used while the same wave train of 500 waves, characterised by $H_{s}=0.18 \mathrm{~m}$ and $T_{m}=2.5 \mathrm{~s}$, was used in all cases. Other parameters were the same as those used earlier in this section.

In Figure 7.3 the influence of variations of some of the model parameters is shown. The calibrated values were used, while in each graph one of the parameters was varied. Figure 7.3 shows that the values for the drag coefficient $c_{D}$, the lift coefficient $c_{L}$ and the friction factor $f$ affect the reshaped profile considerably. To obtain a significant influence of a variation of the inertia coefficient $c_{M}$ and the porosity $n$, these parameters must be varied over a rather large range. The sensitivity to the coefficients $c_{P}$, the angle of internal friction, the implementation of added 

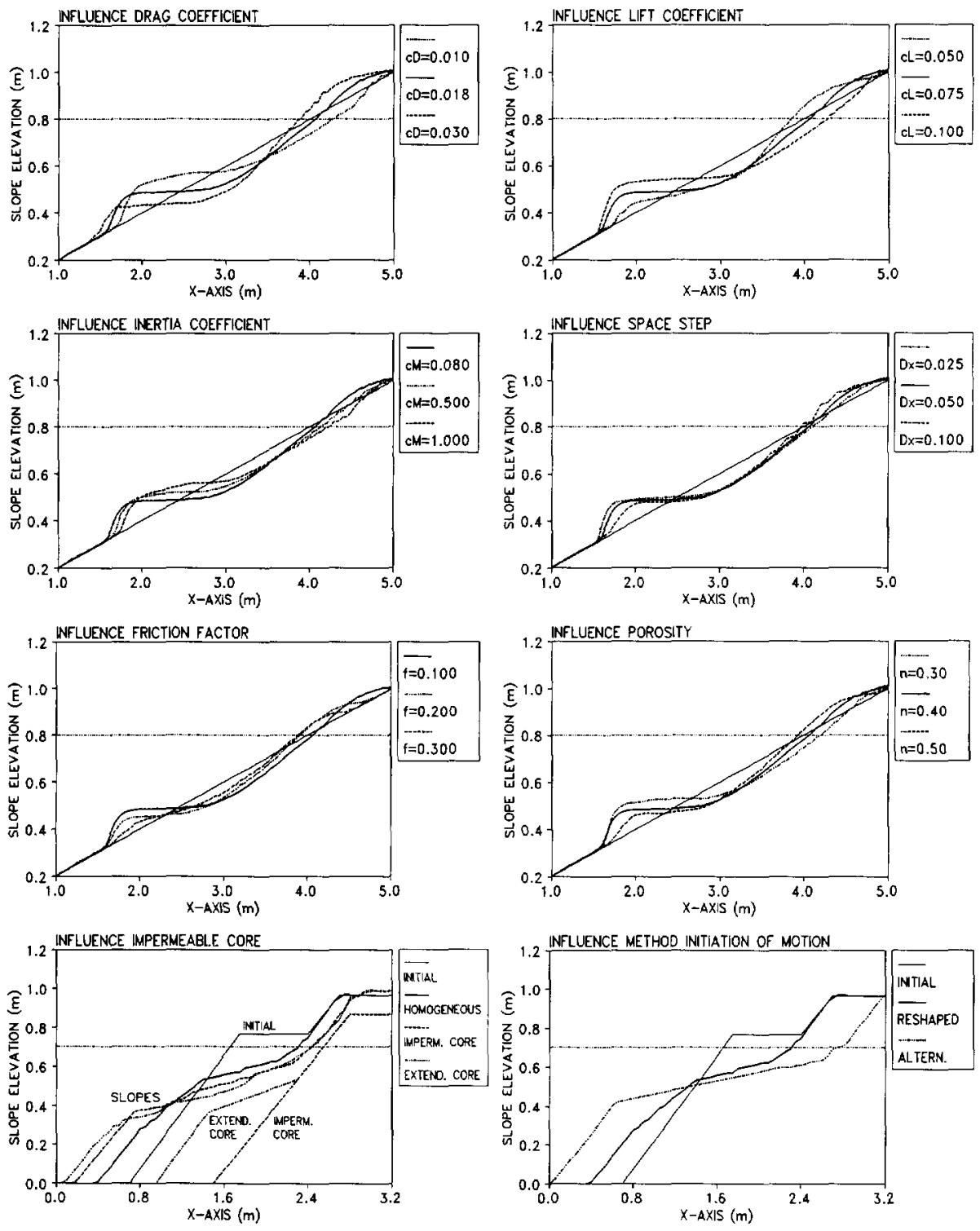

Fig. 7.3 Sensitivity of parameters to calculated reshaped profiles;

upper six: Gravel beach: $\quad D_{n s 0}=0.0041 \mathrm{~m} \mathrm{H}_{\mathrm{s}}=0.18 \mathrm{~m} T_{m}=2.5 \mathrm{~s}$. lower two: Berm breakwater: $D_{n 50}=0.034 \mathrm{~m} \quad H_{s}=0.20 \mathrm{~m} \quad T_{m}=2.4 \mathrm{~s}$. 
mass and the implementation of the flow-dependency of the porous-flow friction coefficients appeared to be very small for this case. For steeper initial slopes the effect of variations in the angle of internal friction increases.

To study the effect of the space-step $\Delta x$, three computations were performed but the time-step was also varied such that the CFL-number (see Section 4.3.2) is the same for all three computations $(\mu=0.56)$. The effect of this variation is small; Figure 7.3 shows that in particular the differences between the two computations with the two smallest space-steps are small.

The influence of the lay-out of the core of a berm breakwater on the reshaped profile is shown in the bottom-left graph of Figure 7.3. The same wave train was used in the three computations; 500 waves with a wave height of $H_{s}=0.20 \mathrm{~m}$, a wave period of $T_{m}=2.4 \mathrm{~s}$ and a still-water level of $0.70 \mathrm{~m}$. The first structure was modelled as homogeneous, the second structure had an impermeable core while for the third computation the impermeable core was extended below the berm. For all computations the friction factor was $f=0.30$, the porosity $n=0.40$, the stone diameter $D_{n 50}=0.034 \mathrm{~m}$, the angle of internal friction $39^{\circ}$ and the initial slope as shown in the bottom-left graph of Figure 7.3. Figure 4.15 shows the effect of an impermeable core on the maximum velocities for a very similar berm breakwater. It appeared that the maximum velocities in the direction away from the structure are much higher for the structure with an impermeable core. Comparison of the reshaped profiles shows that more erosion takes place for the structures with an impermeable core leading to more transport towards the toe of the structure. These results are therefore consistent. The effect of an extension of the core below the initial berm has less influence, although the part of profile that is affected is slightly wider. The effect of core material seems to be of some importance for the reshaped seaward slopes of berm breakwaters although the shape of the core has a relatively small influence.

\section{Alternative approach}

The calibration and validation described here shows that the model gives reasonable results regarding the rather simple formulations for the wave motion, the forces and the stone displacements. The same values for the coefficients $c_{D}, c_{L}$ and $c_{M}$ have been taken for stones in the cover layer as for stones moving along the slope. More accurate results might be obtained by using different values for these two situations 
of the stones. However, that would require a much more difficult calibration procedure. Measurements on a stone in the cover layer would be useful to determine the values for the coefficients $c_{D}, c_{L}$ and $c_{M}$ for stones in the cover layer. Hardly any data concerning these values are available although Tørum (1992) performed force measurements on a non-moving stone in a cover layer of a berm breakwater. These measurements resulted in values of $c_{D}$ in the range of 0.14 and 0.42 and in values for $c_{M}$ in the range of -0.22 and 0.36 , while no separate coefficient for sheltering was taken into account. However, Tørum (1992) proposed the values 0.35 and 0.20 for $c_{D}$ and $c_{M}$ respectively. Values of $c_{L}$ could not be determined accurately.

A comparison was made between computed reshaped profiles for the berm breakwater used in the experiments by Torum (1992). The first computation was performed with the coefficients obtained from the described calibration $\left(c_{D}=0.018\right.$, $\left.c_{L}=0.267, c_{M}=0.08\right)$. A second computation was performed by an alternative method. The coefficients obtained by Tørum (1992) were applied to the method of initiation of movement ( $c_{D}=0.35$ and $c_{M}=0.20$ for non-moving stones). For the lift coefficient $c_{L}$, which could not be obtained from the measurements, the calibrated value $\left(c_{L}=0.267\right)$ was used. For the procedure to prescribe in which direction unstable stones are moved, the values from the calibration were used although one might expect that the values for a moving stone would be higher than for a non-moving stone ( $c_{D}=0.018$ and $c_{M}=0.08$ for moving stones). Like in the computations concerning the effect of the core described in the previous sub-section, the initial profile of the berm breakwater was the same as the one on which the measurements were performed. Other parameters concerning the structure and the wave train are also the same as in those preceding computations. The bottom-right graph in Figure 7.3 shows that the alternative method with much higher values for the coefficients for initiation of movement produces a profile that is much more affected. It is concluded that the measured values cannot be used without serious adaptations to the method of reshaping.

\section{Failure mechanisms}

The numerical model deals with stability criteria against the failure mechanisms sliding and lifting. If neither of the criteria is satisfied, this failure mechanism is regarded as rolling. For the 20 computations mentioned in the sub-section on 
validation, the relative importance of each failure mechanism was studied. A more detailed discussion is given in Van Gent (1993-c). In nearly all cases rolling is the dominant failure mechanism. Den Breeker and Vries (1985) derived the same conclusion based on examination of high-speed film images, taken in physical-model tests. For the less dynamic slopes, with lower values of the parameter $H / \Delta D_{n 50}$, the percentages of stones displaced as rolling stones are in most cases lower. For these less dynamic slopes, the total number of displacements is also much lower. The initial profile also influences the percentages of the failure mechanisms; for berm breakwaters, lifting is more important than sliding while for reef-type structures with the same values for the parameter $H / \Delta D_{n 50}$, displacements due to sliding occur significantly more often than due to lifting, even exceeding the percentages of rolling stones.

\subsection{Applications with the wave load-response model}

\subsubsection{Profile development of gravel beaches}

Most of the computations for model calibration and validation described in the previous section concern gravel beaches. In addition to those comparisons and the sensitivity analysis, a qualitative verification is given in this section. Whether the influence of variation of parameters corresponds to those observed in physical-model tests is verified. The parameters wave height, wave period, stone diameter and the initial slope were varied, while the other parameters were kept constant.

In Van Gent (1993-c, 1995-b) several figures based on the results of this parametric study are given. Figure 7.4 shows an example of the influence of variations in the wave height. It is clearly shown that an increased wave height leads to longer reshaped profiles. This was also observed in physical-model tests described by Van der Meer (1988). The same trend occurs for longer wave periods. This trend also occurs in the numerical simulations. Figure 7.5 shows an example of reshaped profiles with variations of the wave periods.

The stone diameter was also varied. Figure 7.6 shows reshaped profiles after 500 waves with $H_{s}=0.24 \mathrm{~m}$ and $T_{m}=1.8 \mathrm{~s}$ and an initial slope of $1: 3$. The figure shows that with smaller material the effects on the slope are greater. This was also 


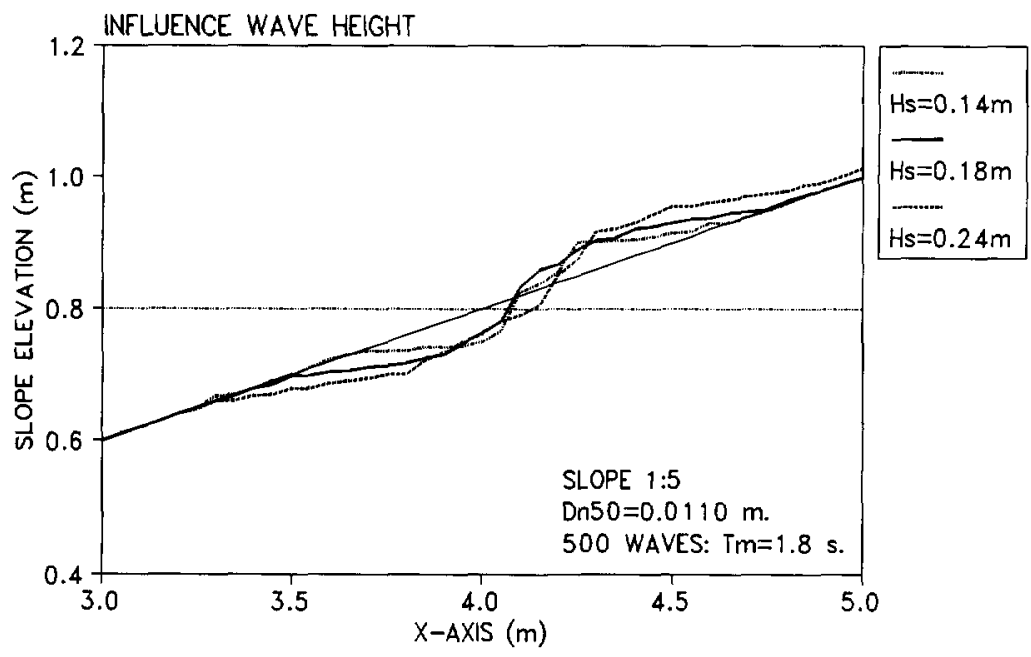

Fig.7.4 Influence of the wave height on calculated profiles.

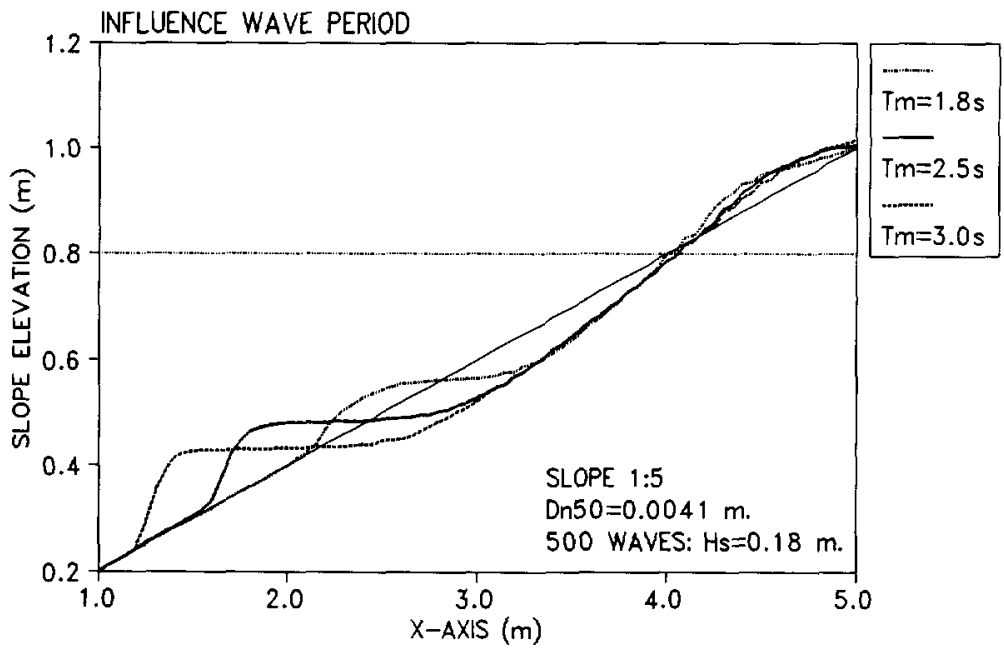

Fig.7.5 Influence of the wave period on calculated profiles.

observed in the physical-model tests. The simulations show that smaller material leads to more accretion below the still-water level. For two stone sizes, the initial slope has been varied as well. Initial slopes of $1: 5,1: 3$ and $1: 1.5$ were used. Figure 7.7 shows an example of such a comparison. The figure shows that reshaped profile 


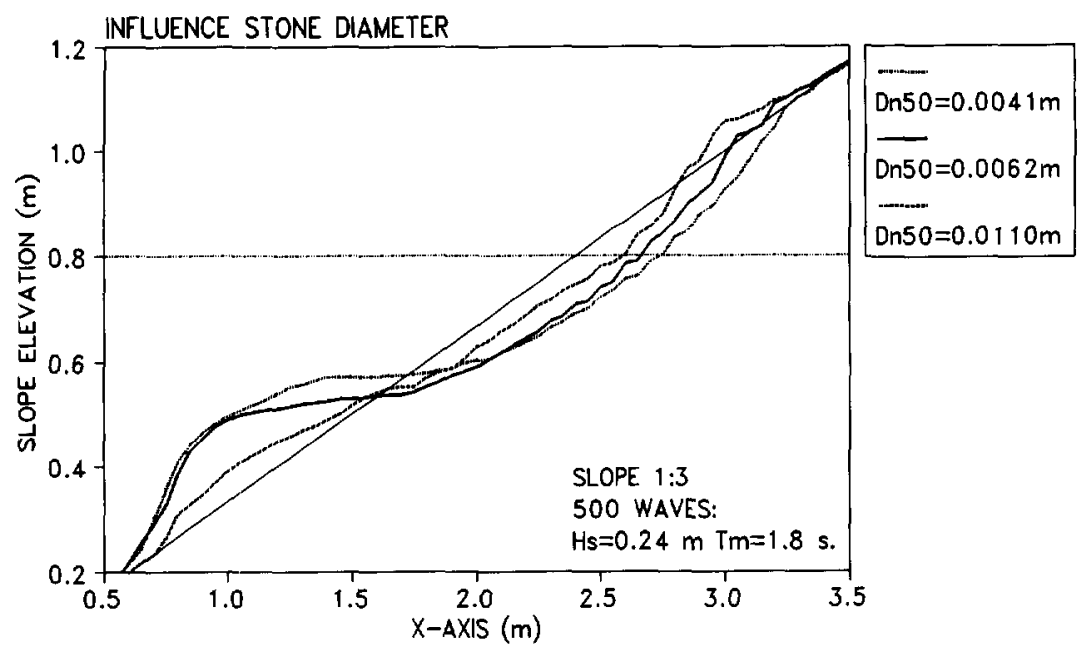

Fig.7.6 Influence of stone diameter on calculated profiles.

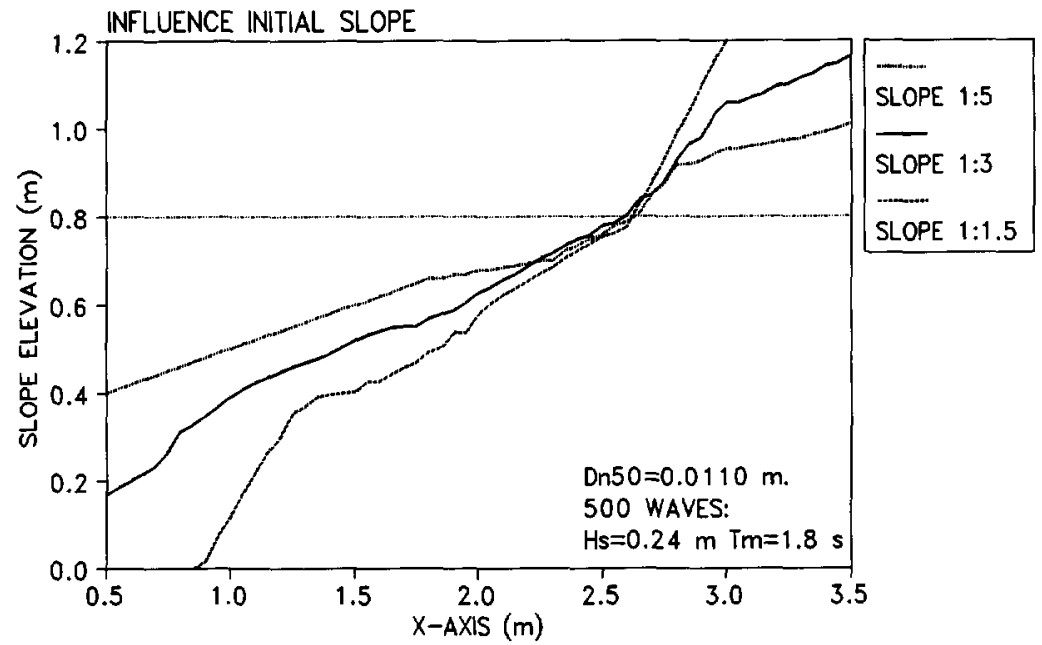

Fig.7.7 Influence of initial slope on calculated profiles.

near the still-water 'shoreline' is hardly influenced by the initial slope. This was also observed in physical-model tests. Further upward or downward, the reshaped profiles evolve more towards the initial slope. 
It can be concluded that the simulations described in this section show that the variation of the parameters wave height, wave period, stone diameter and initial slope show the same trends as observed in physical-model tests with gravel beaches.

\subsubsection{Profile development of berm breakwaters}

Most of the computations described in the previous section were performed with relatively high values of $H / \Delta D_{n 50}$ which represent gravel beaches. Although some reshaped profiles from calculations are similar to those of berm breakwaters, no validation was described for berm breakwaters where the initial slope contained a horizontal berm. Two additional verifications with berm breakwaters will be discussed, one for the small-scale model and one for a prototype breakwater.

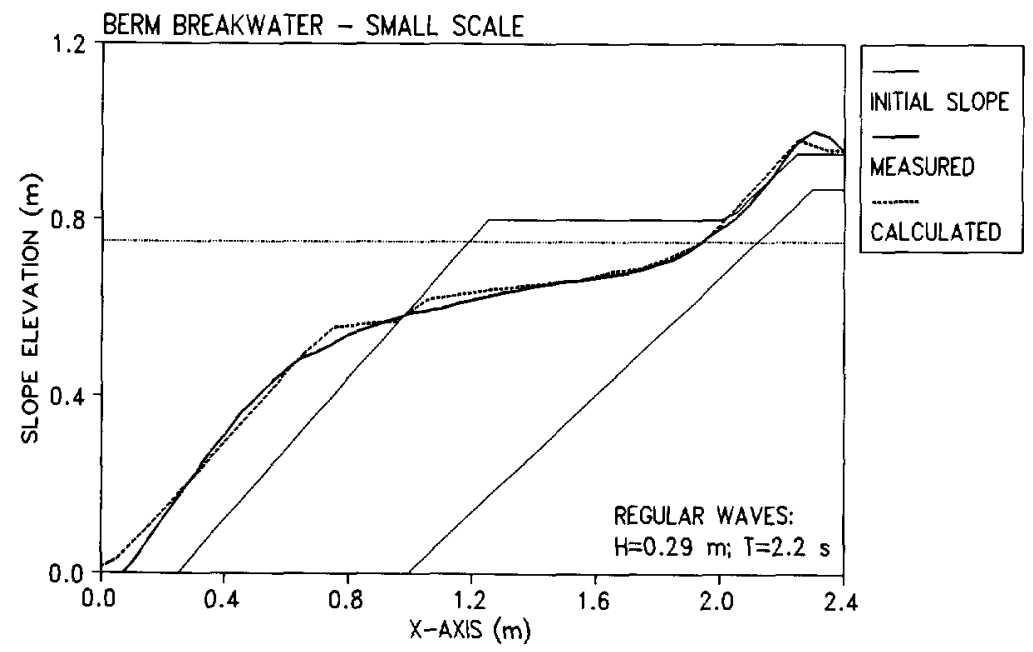

Fig.7.8 Comparison of measured and calculated profiles.

First, the berm breakwater from the physical-model tests described in Chapter 6 is treated. In these computations, unlike all others, regular waves rather than irregular waves were generated. In the physical-model tests, the reshaped profile was formed after four series of regular waves where the effect on the reshaped seaward slope increased for each subsequent series. In the computation, the last wave series which determined the final reshaped profile, has been used; $H=0.29 \mathrm{~m}$ and $T=2.2 \mathrm{~s}$. The 
numerical model cannot deal with two layers with different properties of the porous media. Therefore, the structure must be regarded as homogeneous or as a structure with an impermeable core. Here, the berm breakwater was modelled as homogeneous since the permeability of the core material is close to the permeability of the material in the cover layer.

In the physical-model tests, as well as in the computation, the reshaped profile became dynamically stable after a limited number of waves. In the computations this was after approximately 70 waves. Figure 7.8 shows the comparison of the measured profile and the simulated profile where for the friction coefficient $f$ the value 0.3 was taken above SWL and 0.1 below SWL. The increase in crest height as observed in the measurements is underestimated. This increase is larger if for the friction coefficient $f=0.1$ (Eq.4.3 with $\tan \theta_{s}=0.2$ and $R=0.25 \mathrm{~m}$ ) is used also above SWL, but then the computational results show a slightly less accurate fit in the region of the berm. Although the value of the friction coefficient affects the numerically reshaped profile, the reshaping process is represented rather well; the comparison shows good agreement.

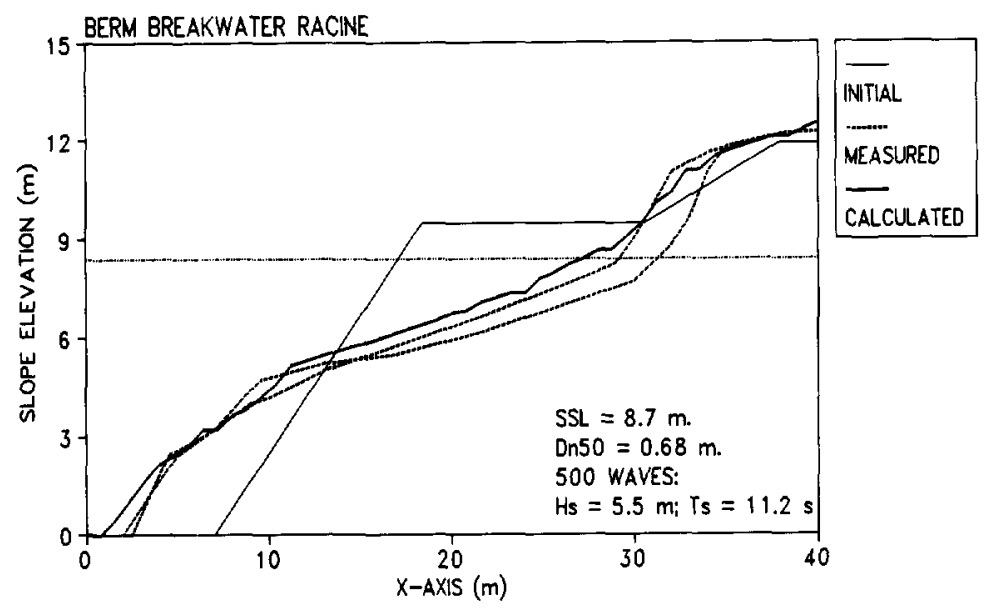

Fig.7.9 Comparison of measured and calculated reshaped seaward slopes for the berm breakwater at Racine.

For the second computation, the prototype berm breakwater in Racine (USA) was used. Montgomery et al. (1988) presented two measured reshaped profiles (dashed 
lines in Fig. 7.9) after a storm characterised by $H_{s}=5.5 \mathrm{~m} ; T_{\mathrm{s}}=11.2 \mathrm{~s}$ and SSL $=8.7$ $m$. These parameters were determined with a hindcast method using measured storm wind data. The structure, with stones with a $D_{n 50}$ of $0.68 \mathrm{~m}$, was modelled as homogeneous. For the friction coefficient $f$, the value 0.4 was used. Figure 7.9 shows the two measured profiles and the calculated profile. The figure shows fair agreement.

\subsubsection{Profile development of reef-type structures}

Reef-type structures can be described as piles of stones which undergo reshaping due to wave action. The initial crest is above the still-water level but severe wave action causes reshaping of the structure, which usually leads to lowering of the crest height to a level which is permanently below the still-water level.

Wave transmission over such low-crested or submerged structures has been studied by means of the one-dimensional hydraulic model (Fig.4.12) while the reshaping of this type of structure can also be modelled numerically by applying the approach described in this chapter. For this type of structure some experiments with smallscale models by Ahrens (1987) have been used to validate the model. Irregular waves were generated on a depth of about $0.50 \mathrm{~m}$, travelling over a 1:15 slope before reaching the structure positioned on a horizontal bottom in a depth of about $0.25 \mathrm{~m}$. Under these normally incident waves the structures reshaped to form a new dynamically stable profile of which the new crest height was measured as well as the damaged area of the structure. The wave transmission coefficients were also determined.

Four experiments with a relatively large deformation of the structure have been used for comparison with numerical model results. Figure 7.10 shows the initial crosssection of the structures and the numerically reshaped cross-section after reaching a dynamically stable profile. Based on measured wave parameters, irregular wave trains were generated representing a TMA-spectrum. In the computation these waves were generated about $1.0 \mathrm{~m}$ in front of the structure while an open boundary was used $0.5 \mathrm{~m}$ behind the structure. In the physical-model tests the structure was positioned about $30 \mathrm{~m}$ from the wave generator. As a result of this difference in model set-up, differences occurred between the wave fields in the physical-model tests and numerical model tests, e.g., the wave set-up. 
Computations with two types of rubble mound material were performed. The two upper graphs in Figure 7.10 had material with a $D_{n 50}$ of $0.018 \mathrm{~m}$ and a porosity of $n=0.45$. In the computations a friction factor of $f=0.20$ was used in these two computations ( $E q .4 .3$ with $\tan \theta_{s}=1: 1.5$ and $R=H_{s}$ ). The wave trains were characterised by $H_{s}=0.153 \mathrm{~m}$ and $T_{p}=3.0 \mathrm{~s}$ on a depth of $\mathrm{SWL}=0.25 \mathrm{~m}$. Two computations were performed with slightly larger material, $D_{n 50}=0.030 \mathrm{~m}$, and a porosity of $n=0.44$. The friction factor was set at $f=0.25$ for these two computations. The results are shown in the two lower graphs of Figure 7.10. The bottom left computation had waves with $H_{s}=0.158 \mathrm{~m}$ and $T_{p}=3.6 \mathrm{~s}$ on a depth of $\mathrm{SWL}=0.25 \mathrm{~m}$; the bottom right computation had a wave train with $H_{s}=0.176 \mathrm{~m}$ and $T_{p}=3.3 \mathrm{~s}$ on a depth of swL $=0.30 \mathrm{~m}$. For all four computations the angle of internal friction was $\mu=50^{\circ}$, the grid size was $\Delta x=0.02 \mathrm{~m}$ and the time-step $\Delta t=0.005 \mathrm{~s}$ while approximately 300 waves were computed.
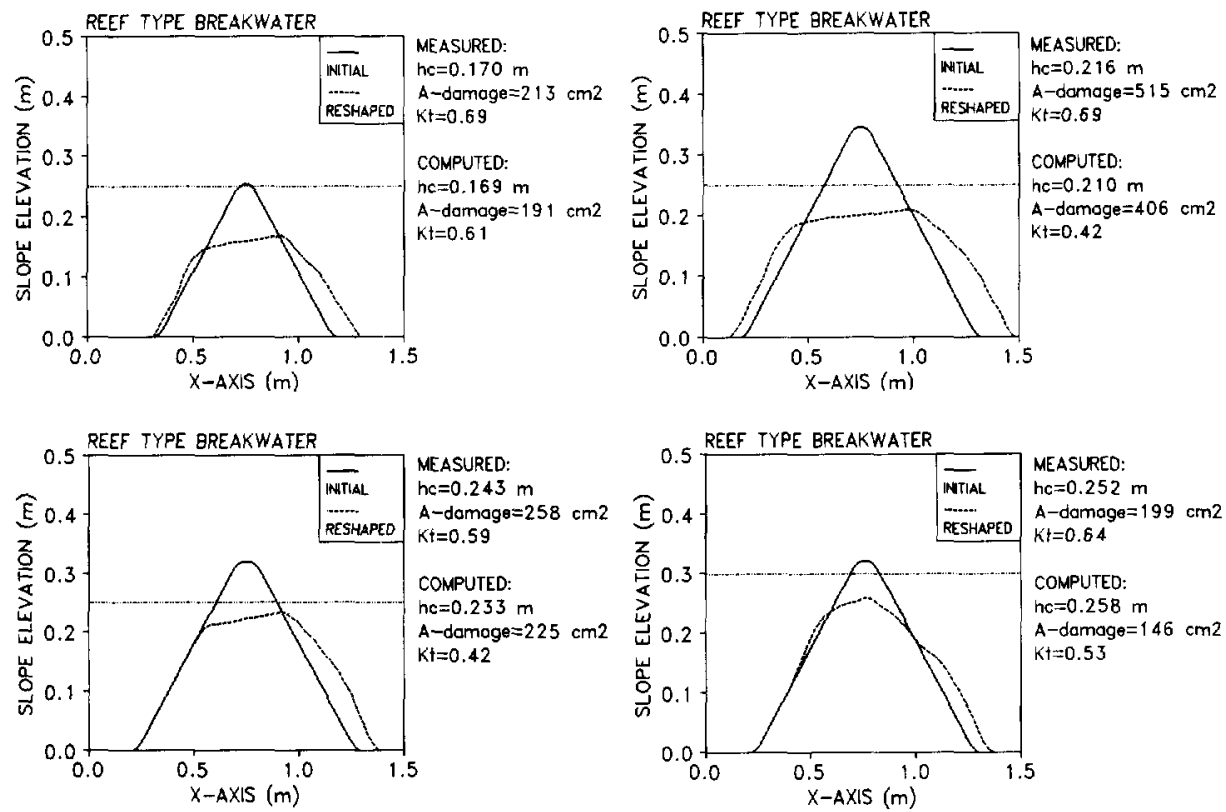

Fig. 7.10 Computations with reef-type structures, initial profiles and reshaped profiles (stable) after approximately 300 waves. 
Figure 7.10 shows that in all four computations a relatively large lowering of the crest occurred (from $h_{c}^{\prime}=0.257 m$ to $h_{c}=0.169 \mathrm{~m}$; from $h_{c}^{\prime}=0.350 \mathrm{~m}$ to $h_{c}=0.210$ $m$; from $h_{c}^{\prime}=0.314 m$ to $h_{c}=0.233 \mathrm{~m}$ and from $h_{c}^{\prime}=0.316 \mathrm{~m}$ to $h_{c}=0.258 \mathrm{~m}$ respectively). The difference between measured and computed crest heights after reshaping is smaller than $5 \%$. In all computations the damage to the initial crosssection was lower than those in the measurements (in average about $20 \%$ too low). The wave transmission in all four computations was significantly lower than that obtained from the measurements (on average about $25 \%$ too low). Although the wave transmission is underestimated, the reshaping of the structures seems to be represented accurately.

\subsection{Conclusions}

A numerical model for simulating both individual waves and the time-dependent response of dynamic structures has been developed. Although the formulations for simulating waves and wave loads and the formulations for simulating the response of the structure are rather simple, the computations indicate that these simplifications do not make such an approach unrealistic. A qualitative validation of the integrated model showed that the influence of variations of physical parameters are reproduced properly. A quantitative validation showed that for highly dynamic slopes such as gravel beaches (large $H / \Delta D$ ), differences that might be expected for such a relatively simple model occur. Comparisons with measured properties of less dynamic slopes like those of berm breakwaters and reef-type structures show fair agreement.

The model can be improved by implementing more physical processes and by making a clear distinction between initiation of stone movement in the cover layer and stones moving along the slope. This, however, also requires more coefficients through calibration or through physical-model testing, both of which might appear to be rather difficult. A few phenomena that have not been implemented but that may play an important role are three-dimensional effects, segregation, grading, settling of the porous medium, the inertia of moving stones and the interlocking of stones. It is possible that improvements to the model could also be achieved through a more accurate modelling of the wave motion. For instance, in the present model a more appropriate expression for the friction factor $f$ might improve the simulation of the wave motion. The concept of the response model can also be used in 
combination with other wave models, including the model described in Chapter 5. To make optimal use of a wave model with more information on the flow field, such a model must also be more accurate and require a manageable computational time. Reducing computing time of the model described in Chapter 5 is necessary, especially if again a concept is used where both the wave motion and the response of the structure are simulated in the time-domain by simulating individual waves and displacements of individual stones.

Although some improvements to the model presented might be envisaged, it can already be used as a complementary design tool, especially for conditions for which no empirical relations for describing the reshaping process exist. This is, for instance, the case for reef-type structures or for dynamic structures with large immovable components such as seawalls or crown-walls. A two-dimensional model (2DH), also based on shallow-water wave equations and the same concept for reshaping of the structure, might also be quite useful as a complementary design tool for studying effects of oblique wave attack such as longshore transport of material along dynamic structure. 


\section{Chapter 8}

\section{Conclusions and recommendations}

In this thesis essential aspects of the performance and analysis of laboratory experiments, and the development and validation of predictive numerical models for wave interaction with permeable coastal structures are described. Here, specific conclusions concerning these investigations are highlighted and recommendations for further research are given.

In order to describe the hydraulic and structural response of permeable coastal structures under wave attack, phenomena associated with porous media flow were studied. Theoretical investigations indicated that friction coefficients which describe the resistance by porous media to wave motion could depend on the flow field. To verify this and to determine the importance of possible dependencies on the flow field, characterised by parameters like the Reynolds-number $(R e)$ and the KeuleganCarpenter number $(K C)$, laboratory measurements were performed. By studying the differences between stationary and oscillatory porous media flow it was concluded that the friction coefficients in a conventional description of the resistance are higher for an oscillatory wave motion than for a stationary flow. As expected, this increased friction depends on the flow field; the friction due to turbulence, proportional to the velocity squared, appears to depend on the $K C$-number. Based on these experiments, new formulations for porous media flow, which could be implemented in two predictive numerical models, were derived. It is, nevertheless, recommended that the dependency of friction coefficients on parameters like grading, shape, aspect ratio and orientation of stones with respect to the mean flow direction, should be studied to obtain a more accurate description of porous media flow. 
Predictive numerical models are developed to simulate wave interaction with permeable structures in the time-domain. These models include the simulation and effects of porous media flow. A numerical model based on the shallow-water wave equations for normally incident waves on various types of structures was made. The wave motion outside structures and the flow inside the permeable regions are modelled simultaneously. In contrast with other existing models, the method used to connect the external wave motion and the internal wave motion allows the free surface and the phreatic surface to move independently, i.e., in the one-dimensional model the free surface can be disconnected from the phreatic surface. This permitted the implementation of phenomena like infiltration and seepage. Although many phenomena have been implemented in a rather simple way, validation against analytical solutions and results from physical-model tests showed that the present model provides accurate results. It is concluded that the coupling of a hydraulic wave model to a porous media flow model was successful. For instance accurate results were obtained by using the model for the parameter run-up. For parameters which do not show sufficient correspondence with values obtained from physicalmodel tests, variations resulting from changes in hydraulic and structural properties show the same trends as those observed in physical-model tests; the model can be used in a qualitative way to estimate the influence of variations of hydraulic and structural parameters on required output parameters. It can be concluded that the model can be used as an engineering and research tool for a rather wide range of types of structures and a wide range of hydraulic conditions.

The numerical model provides accurate results although many phenomena have been modelled in a rather simple way. To improve the numerical model results, for some of these phenomena more sophisticated modelling can be implemented. Physicalmodel tests showed that the internal pressures can deviate considerably from hydrostatic pressures. In the numerical model, however, pressures are assumed to be hydrostatic. Therefore, it is recommended to study whether an alternative modelling of the pressure gradients leads to a higher accuracy of the model. To obtain better results it is also recommended to improve the modelling of phenomena related to infiltration and seepage. The empirical relation for estimating the bottom friction coefficient is also rather simple; more sophisticated estimates lead to a better applicability and to more accurate results.

The above mentioned hydraulic model is combined with a procedure to compute the time-dependent response of dynamic structures such as gravel beaches, berm 
breakwaters and reef-type structures (wave load - response model). A qualitative validation of this integrated model showed that although both the waves and stone displacements are modelled in a rather simple way, the influence of variations of physical parameters, e.g., wave height, wave period or stone diameter, are reproduced properly. A quantitative validation showed that for highly dynamic slopes such as gravel beaches (large $H / \Delta D$ ), differences occur that might be expected for such a relatively simple model. Comparisons with measured properties of less dynamic slopes as for instance those of berm breakwaters and reef-type structures show fair agreement. The concept allows also computations with dynamic structures with large immovable components such as rubble slopes fronting seawalls. Based on validation of the integrated model it can be concluded that the present model could be improved, but it can already be used as a complementary design tool. This is especially the case when studying the qualitative influence of variations of hydraulic and structural parameters and for conditions for which no empirical relations to describe the reshaping process exist.

It is likely that the wave load-response model can be improved by implementing more physical processes. A clear distinction between processes concerning initiation of motion of stones in the cover layer and processes concerning stones moving along the slope might lead to better results. Other phenomena that have not been implemented, but that may be of importance are three-dimensional effects, segregation, grading, settling of the porous medium, the inertia of moving stones and the interlocking of stones. Although it can be concluded that the model already gives valuable results, study of the importance of such phenomena that have not yet been incorporated is recommended to improve the numerical wave load-response model. Improvements to the model might also be obtained by more accurate modelling of the wave motion. For instance, in the present model a more appropriate relation for the friction factor $f$ might improve the simulation of the wave motion. By developing a two-dimensional model $(2 \mathrm{DH})$ which can also be based on shallow-water wave equations and on the same concept for reshaping of the structure, effects of oblique wave attack such as longshore transport of material along dynamic structures can be studied. It is recommended that such a model should be developed since this might contribute to greater insight into the processes and to optimize physical modelling of dynamic structures for specific design-studies. Furthermore, eventually more accurate modelling of the response of structures can only be achieved if the wave loads are predicted more accurately. To achieve this, a two-dimensional model (2DV) is required and, therefore, a response model such 
as the one presented must be combined with such a hydraulic model which is able to provide better simulations of, for instance, breaking waves.

The above mentioned model solves one-dimensional equations which implies that wave motions in which the motion in the vertical direction is significant cannot be modelled accurately. Although the model is easy to apply in many practical situations, a more sophisticated description of the flow field including breaking waves is required for many other application. Such a two-dimensional model (2DV) has been developed, although the present version cannot yet be seen as a fully operational and sufficiently accurate model for the intended field of application. The model can simulate normally incident waves breaking on coastal structures, including permeable structures. Validations with analytical solutions, a validation with breaking waves on a submerged bar and the realistic impressions of the flow field for many other flow conditions indicate that the research model is accurate for specific conditions and widely applicable. However, more sophisticated modelling of turbulence and the free surface can improve the accuracy of the model. Present disadvantages, such as the restriction to regular waves can be overcome without seriously affecting the model descriptions; a treatment to reduce computing-time to enable computations with irregular waves has been proposed. The wide range of applicability, however, also requires validations for a wide range of flow conditions. It can be concluded that the sophisticated research model provides realistic impressions of the flow field for many applications and for some parameters provides sufficiently accurate results, but improvements and validations are required if it is also to serve as a valuable operational model.

Comparisons between the measured and simulated surface elevations above a berm breakwater slope indicated that both numerical models provide a good impression of the wave action until breaking. The resemblance is much weaker in the area where air is captured. Unlike the two-dimensional model, the one-dimensional model provides accurate estimates of the run-up levels. The reduction in wave height during breaking in the two-dimensional model is overestimated which produces run-up levels that are too low. The present version of the two-dimensional model is therefore not suitable to predict accurate run-up levels. Pore-pressures as well as velocities in the area just before breaking were accurately predicted by the two-dimensional numerical model. 
The effect of the lay-out of the core of a berm breakwater was studied. Numerical analysis of both the hydrodynamics and the reshaping process indicated that the permeability of the core influences the processes; in particular the differences between a berm breakwater with an impermeable core and a homogeneous berm breakwater are significant. The lay-out of the core, however, is less significant; its extension into the berm has relatively little effect on the hydrodynamics and the reshaping process. Since core material, for which in practise quarry-run is used, is relatively cheap compared to material in the cover layer, such an extension of the core reduces construction costs.

In general, it can be concluded that two valuable predictive numerical models have been developed. The two-dimensional (2DV) model was set up in close cooperation with Delft Hydraulics. Both models have already been used for engineering and research purposes. Basic research results in the field of porous media flow has been directly applied in these two models. Furthermore, a combined wave load-response model has been developed to serve as a complementary design tool to predict the response of dynamic coastal structures. 


\section{Acknowledgements}

The research described in this thesis could only be completed through the involvement of many mentioned and unmentioned friends and colleagues. Their contribution in stimulating, critical and professional concern was deeply appreciated. Both the Delft University of Technology and Delft Hydraulics, as represented by Kees d'Angremond and Jentsje van der Meer, are gratefully acknowledged for their essential involvement in providing the productive work-climate.

The financial support by the Commission of the European Communities through the MAST I and MAST II Coastal Structures projects, the Lely-stichting and the Ministry of Transport, Public Works and Water Management (Rijkswaterstaat-DWw) via the Technical Advisory Committee on Water Defenses (TAW) is appreciated. I wish to thank L. van Dam (Central dredging association) for her help to improve the English language in this thesis.

Throughout the entire period of research my colleagues at the Delft University of Technology have been of great help and have shown their sincere interest. For his support and professional participation I would especially like to thank Mark Voorendt. I greatly appreciate sharing everyday experiences in the University with my colleagues, in particular with Marien Boers.

The assistance of my colleagues at Delft Hydraulics, especially during my stays at the Laboratory 'de Voorst', was essential. The valuable comments and stimulating guidance of Jentsje van der Meer were highly appreciated. Special thanks are due to Peter van den Bosch, Gert Klopman, Henri Petit and Greg Smith. Gert Klopman provided many valuable suggestions for improvements of a draft-version of this thesis. The fruitful discussions and pleasant cooperation were proof of their expertise and fellowship.

Thanks are also due to some of the partners participating in the MAST research projects. I am grateful for the valuable comments by Henk den Adel of Delft Geotechnics on the analysis of the porous media flow experiments. Among the most appreciated contacts within the MAST program was that with Prof. Tørum from N.H.L.-Trondheim.

Finally, I would like to express my gratitude to those in private life whose attention and support was essential to the pleasure with which this research project was completed. 


\section{References}

Abbott, M.B., J. Larsen, P. Madsen and J. Tao (1983), Simulation of wave breaking and run-up, Proc. Seminar on hydrodynamics of waves in coastal areas, Sept.' 83 , Moscow.

Adel, H. den (1987), Re-analysis of permeability measurements using Forchheimer's equation, Report C0-272550/56, Delft Geotechnics (in Dutch).

Airy, G.B. (1845), Tides and waves, Encyclopaedia metropolitana, London.

Ahrens, J.P. (1987), Characteristics of reef breakwaters, Technical Report CERC-87-17, CERC, Vicksburg.

Allsop, N.W.H. and J.P. Latham (1987), Rock armouring to unconventional breakwaters; the design implications for rock durability, Berm breakwaters; unconventional Rubble mound breakwaters, Workshop Ottawa.

Ashgriz, N. and J.Y. Poo (1991), FLAIR: Flux Line-Segment Model for Advection and Interface Reconstruction, J. of Comp. Physics. Vol.93, pp.449-468.

Batchelor, G.K. (1967), An introduction to fluid dynamics, Cambridge University Press, Cambridge.

Battjes, J.A. (1974), Surf similarity, Proc. ICCE'74, Vol.1, pp.466-479, Copenhagen.

Bear, J. (1972), Dynamics of fluids in porous media, American Elsevier, New York.

Boussinesq, M.J. (1872), Théorie des ondes et des remous qui se propagent le long d'un canal rectangulaire horizontal, en communiquant au liquide contenu dans ce canal des vitesses sensiblement pareilles de la surface au fond, J. de Mathématiques Pures et Appliquées deuxième série, Vol.17, pp.55-108.

Bouws, E., H. Günther, W, Rosenthal and C.L. Vincent (1985), Similarity of the wind wave spectrum in finite depth water, I spectral form, Journal of Geophysical Research, Vol.90, no.C1, pp.975-986.

Bradbury, A.P., N.W.H. Allsop, J.P. Latham, M. Mannion and A.B. Poole (1988), Rock armour for rubble mound breakwaters, sea walls and revetments: Recent progress, H.R.Wallingford, Report SR 150.

Brandtzaeg, A, and A. Torum (1966), A simple mathematical model of wave motion on a rubble mound breakwater front, Proc. ICCE'66, Vol.2, pp.977-989, Tokyo.

Breeker, R.C. den and M. Vries (1985), Stability of top-layer elements; Research concerning failure mechanisms and damage-causing forces for breakwaters under monochromatic wave attack, In Dutch: Stabiliteit van afdekelementen; onderzoek naar schademechanismen en 
schade-veroorzakende krachten bij golfbrekers onder regelmatige golfaanval, M.Sc.-thesis, Delft University of Technology.

Broekens, R.D. and H.A.H. Petit (1991), sKYLLA: Wave Motion in and on Coastal Structures; Feasibility study on the applications of SAVOF, MAST-G6S report, Delft Hydraulics.

Broeze, J. (1993), Numerical modelling of nonlinear free surface waves with a $3 D$ panel method, Ph.D.-thesis, Twente University, Enschede.

Burcharth, H.F and P. Frigaard (1988), On 3-dimensional stability of reshaping berm breakwaters, Proc. ICCE'88, Vol.3, pp.2284-2298, Malaga.

Burger, A. and J.W. van der Meer (1983), Slope-protection of placed block-revetment, large-scale research in the Delta flume of placed block-revetment on sand, Report M1795/M1 881, part XII (In Dutch), Delft Hydraulics.

Cohen de Lara, M. (1955), Coefficient de perte de charge en milieu poreux base sur l'équilibre hydrodynamique d'um massif, La Houille Blanche, no.2.

Cornett, A.M. and E. Mansard (1994), Wave stresses on rubble-mound armour, Proc.ICCE'94, Vol.1, pp.986-1000, Kobe.

Darcy, H. (1856), Les fontaines publiques de la ville de Dijon, Dalmont, Paris.

Daemen, I.F.R. (1991), Wave transmission at low-crested structures, M.Sc.-thesis, Delft University of Technology, also Delft Hydraulics Report H462.

Dingemans, M.W. (1994), Water wave propagation over uneven bottoms, Ph.D.-thesis, Delft University of Technology, To be published also by World Scientific, Singapore.

Dold, J.W. and D.H. Peregrine (1986), Water-wave modulation, Proc.ICCE'86, Vol.1, pp.163-175, Taipei.

Engelund, F. (1953), On the laminar and turbulent flow of ground water through homogeneous sand, Trans. Danish academy of Technical sciences, Vol. 3.

Engering, F.P.H, S.E.J. Spierenburg and H. Yamazaki (1993), MBREAK, Computer model for the water motion on and inside a rubble mound breakwater, MAST-G6S-report, Delft Geotechnics.

Ergun, S. (1952), Fluid flow through packed columns, Chem. Engrg. Progress, Vol. 48, No. 2, pp.89-94.

Forchheimer, P. (1901), Wasserbewegung durch bodem, Z. Ver. Deutsch.Ing., Vol.45, pp.17821788.

Gent, M.R.A. van (1991), Formulae to describe porous flow, Communications on Hydraulic and Geotechnical Engineering, ISSN 0169-6548 No.92-2, Delft University of Technology and MAST-G6S-report.

Gent, M.R.A. van (1992), Numerical model for wave action on and in coastal structures, Communications on Hydraulic and Geotechnical Engineering, ISSN 0169-6548 No.92-6, Delft University of Technology. 
Gent, M.R.A. van (1993-a), Stationary and oscillatory flow through coarse porous media, Communications on Hydraulic and Geotechnical Engineering, ISSN 0169-6548 No.93-9, Delft University of Technology.

Gent, M.R.A. van (1993-b), Manual of ODIFLOCS (version 2.0), Delft University of Technology. Gent, M.R.A. van (1993-c), Berm breakwaters; Hydrodynamics, forces and profile development, Communications on Hydraulic and Geotechnical Engineering, ISSN 0169-6548 No.93-11, Delft University of Technology.

Gent, M.R.A. van (1994-a), The modelling of wave action on and in coastal structures, Coastal Engineering, Vol.22 (3-4), pp.311-339, Elsevier, Amsterdam.

Gent, M.R.A. van (1994-b), Wave motion and hydraulic stability, Proc. MAST-Rubble-Mound Breakwater Failure Modes, Workshop January`94, Bressanone.

Gent, M.R.A. van (1994-c), Permeability measurements for the modelling of wave action on and in porous structures, Proc. Coastal Dynamics'94, pp.671-685, Barcelona.

Gent, M.R.A. van (1994-d), Wave interaction with reshaping structures, Proc. Symp. on Waves Physical and numerical modelling, Vol.3., pp.1441-1450, Vancouver.

Gent, M.R.A. van (1994-e), Vegetative wave damping as bank protection, September'94, Report Delft University.

Gent, M.R.A. van (1995-a), Porous flow through rubble mound material, J. of Waterway, Port, Coastal and Ocean Engineering, ASCE, Vol.121, no.3, pp.176-181.

Gent, M.R.A. van (1995-b), Wave interaction with berm breakwaters, J. of Waterway, Port, Coastal and Ocean Engineering, ASCE, Vol.121, no.5, pp.229-238.

Gent, M.R.A. van, and F.C. Vis (1994), Simulations of wave action on coastal structures, Proc. Indian Nat. Conf. on Harbour and Ocean Engineering (INCHOE), Vol.1, pp.B191-196, Pune.

Gent, M.R.A. van, and H.A.H. Petit (1994), Simulations of wave interaction with coastal structures, Proc. Hydroinformatics'94, Vol.1, pp.141-146, IHE, Delft.

Gent, M.R.A. van, and H.A.H. Petit (1995), Numerical simulation of breaking waves, Proc. COPEDEC-IV, Vol.3, pp.2323-2333, Rio de Janeiro.

Gent, M.R.A. van, J.P. de Waal, H.A.H. Petit and P. van den Bosch (1994-a), SKYLLA: Wave motion in and on coastal structures; Verification of wave kinematics of waves breaking on an offshore bar, Delft Hydraulics Report H1780.

Gent, M.R.A. van, H.A.H. Petit and P. van den Bosch (1994-b), SKYLLA: Wave motion in and on coastal structures; Implementation and verification of flow on and in permeable structures, Delft Hydraulics Report H1780.

Gent, M.R.A. van, P. Tönjes, H.A.H. Petit and P. van den Bosch (1994-c), Wave action on and in permeable structures, Proc. ICCE'94, Vol.2, pp.1739-1753, Kobe.

Green, W.H. and G.A. Ampt (1911), Studies on soil physics, 1, The flow of air and water through soils, Agric. Sci., Vol.4, pp.1-24. 
Groot, M.B. de, H. Yamazaki, M.R.A. van Gent and Z. Kheyruri (1994), Pore pressures in rubble mound breakwaters, Proc. ICCE'94, Vol.2, pp.1727-1738, Kobe.

Gu, Z. and H. Wang (1991), Gravity waves over porous bottoms, Coastal Engineering. Vol.15, pp.695-524, Elsevier, Amsterdam.

Hannoura, A.A. (1978), Numerical and experimental modelling of unsteady flow in rockfill embankments, Ph.D.-thesis, Windsor, Canada.

Hamilton, D.G. and K.R. Hall (1994), Physical and numerical modelling of the interaction of waves with rubblemound breakwater crown walls, Proc. Symp. on Waves - Physical and numerical modelling, Vol.3, pp.1431-1440, Vancouver.

Hibberd, S. (1977), Surf and run-up, Ph.D.-thesis, University of Bristol.

Hibberd, S. and D.H. Peregrine (1979), Surf and run-up on a beach: a uniform bore, J. of Fluid Mechanics, Vol.95, part 2, pp.323-345.

Hirt, C.W. and B.D. Nichols (1981), Volume of fluid method for the dynamics of free boundaries, J. of Comp. Physics, Vol.39, pp.201-225.

Hölscher, P., M.B. de Groot and J.W. van der Meer (1988), Simulation of internal water movement in breakwaters, Modelling Soil-Water-Structure Interactions, Kolkman et al., Balkema, Rotterdam, ISBN 9061918154.

Hudson, R.Y. (1953), Wave forces on breakwaters, Transactions of the ASCE, Vol.11B, pp.653674.

Irmay, S. (1958), On the theoretical derivation of Darcy and Forchheimer formulas, Trans. Amer. Geophys. Union, No.4, Vol.39, pp.702-707.

Iribarren Cavanilles, R. (1938), A formula for the calculation of rock fill dikes, Revista de Obras Públicas, 1938 (in Spanish: Una formula para el cálculo de los diques de escollera), Madrid, M. Berjillo-Pasajes.

Julien, L. (1993-a), Evaluation of wave run-up prediction formulas for slopes with berms, Rijkswaterstaat-DWW Report, Delft.

Julien, L. (1993-b), Investigation of the effect of friction location on wave run-up and energy dissipation, Rijkswaterstaat-DWW Report, Delft.

Juhl, J and O.J. Jensen (1992), Practical experience with berm breakwaters, Proc. MAST-G6S Overall Workshop November'92, Lisbon.

Kamphuis, J.W. (1987), Friction factor under oscillatory waves, J. of Waterways and Harbour Division, Proc. of ASCE, Vol.101, pp.135-144, WW2.

Kao, J.S. and K.R. Hall (1990), Trends in stability of dynamically stable breakwaters, Proc. ICCE'90, Vol.2, pp.1730-1741, Delft.

Keulegan, G.H. and L.H. Carpenter (1958), Forces on cylinders and plates in an oscillating fluid, J. of Research of the National Bureau of standards, Vol.60, No.5, pp.423-440. 
Klopman, G. (1987), Numerical simulation of breaking waves on steep slopes, Proc. of Special Conf. on Coastal Hydrodynamics, ASCE, pp.317-327, New York.

Klopman, G. (1989), Program for the computation of periodic gravity waves on a horizontal bottom using the Fourier approximation method of Rienecker and Fenton, P.C.-program RFWAVE (with documentation), version 1.4, Delft Hydraulics.

Klopman, G. and M. Klein Breteler (1994), Overtopping and wave forces on vertical protective structures, In Dutch: Overslag en golfkrachten op verticale waterkeringsconstructies, Delft Hydraulics Report H2014.

Kobayashi, N. and A.K. Otta (1987), Hydraulic stability analysis of armour units, J. of Waterway, Port, Coastal and Ocean Engineering, ASCE, Vol.113, No.2, pp.171-185.

Kobayashi, N., A.K. Otta and I. Roy (1987), Wave reflection and run-up on rough slopes, J. of Waterway, Port, Coastal and Ocean Engineering, ASCE, Vol.113, No.3, pp.282-298.

Koenders, M.A. (1985), Hydraulic criteria for filters, Estuary physics, Kew.

Koutitas, C. (1982), A numerical model for rubble mound breakwaters stability, Proc. Symp. on Engineering in Marine Environmental, Brugge, pp.2.1-2.6.

Kozeny, J. (1927), Über kapillare Leitung des Wassers im Boden, Sitzungber. Akad. Wiss. Wien, Vol. 136, pp.271-306.

Kwik, M. (1994), Wave overtopping by incident waves with various shapes of wave spectra, In Dutch: Golfoverslag bij verschillende spectrumvormen van de inkomende golven, M.Sc.thesis, Delft University of Technology.

Lamb, H. (1932), Hydrodynamics, 6th Ed., Cambridge University Press.

Latham, J.P., M.B. Mannion, A.B. Poole, A.P. Bradbury and N.W.H. Allsop (1988), The influence of armourstone shape and rounding on the stability of breakwater armour layers, Queen Mary College, September'88.

Lax, P. and B. Wendroff (1960), System of conservation laws, Communications Pure Applied Mathematics, Vol.13, pp.217-237.

Lemos, C.M. (1992), A simple numerical technique for turbulent flows with free surfaces, Int. J. for Numerical Methods in Fluids, Vol.15, pp.127-146.

Lisev, N. (1993), Influence of the core configuration on the stability of berm breakwaters; experimental model investigations, R-6-93, Department of Structural Engineering, University of Trondheim.

Longuet-Higgins, M.S. and E.D. Cokelet (1976), The deformation of steep surface waves on water. I. A numerical method of computation, Proc. R. Soc. Lond. A, Vol.350, pp.1-26.

Luth, H.R., G. Klopman and N. Kitou (1994), Project 13G: Kinematics of waves breaking partially on an offshore bar, Delft Hydraulics Report H1573. 
Madsen, D.S. and S.M. White (1975), Reflection and transition characteristics of porous rubble mound breakwaters, Report no. 207, R.M. Parsons Lab, Dept. of Civil Engrg., Massachusetts Institute of Technology, Cambridge, Mass.

Meer, J.W. van der, (1988), Rock slopes and gravel beaches under wave attack, Ph.D.-thesis, Delft University of Technology. Also Delft Hydraulics publication No.396.

Meer, J.W. van der (1990), Static and dynamic stability of loose materials, Coastal Protection, Balkema, Rotterdam (ed. K.W. Pilarczyk).

Meer, J.W. van der, and K. d'Angremond (1992), Wave transmission at low-crested structures, In: Coastal structures and breakwaters, pp.25-41, Thomas Telford, London.

Meer, J.W. van der, and J.J. Veldman (1992), Singular points at berm breakwaters: scale effects, rear, round head and longshore transport, Coastal Engineering, Vol. 17, pp.153-171, Elsevier, Amsterdam.

Meer, J.W. van der, H.A.H. Petit, P. van den Bosch, G. Klopman and R.D. Broekens (1992), Numerical simulation of wave motion on and in coastal structures, Proc. ICCE'92, Vol. 2, pp.1772-1784, Venice.

Méhauté, B. Le $(1957,1958)$, Perméabilité des diques en enrochments aux ondes de gravité périodiques, La Houille Blanche, no.6 (1957), no.2 (1958), no.3 (1958).

Meyer, R.E. and A.D. Taylor (1972), Run-up on beaches, In: Waves on beaches and resulting sediment transport (ed. R.E. Meyer), pp.357-411, Academic Press, New York.

Montgomery, R.J., G.J. Hofmeister and W.F. Baird (1988), Implementation and performance of berm breakwater design at Racine, WI, Berm breakwaters; unconventional Rubble mound breakwaters, (ed. D.H. Willis et al.), derived from workshop at the Hydraulics Laboratory, National Research Council of Canada, Ottawa, September 1987, pp.230-249.

Morison, J.R., M.P. O'Brien, J.W. Johnsen and S.A. Schaff (1950), The forces exerted by surface waves on piles, Petrol. Trans. AIME, Vol.189, pp.149-154.

Norton, P.A. and P. Holmes (1992), Armour displacement on reshaping breakwaters, Proc. ICCE'92, Vol.2, pp.1448-1460, Venice.

Ouméraci, H. (1991), Wave-induced pore pressure in rubble mound breakwaters, Franzius Institute, MAST-G6S report.

Peregrine, D.H. (1967), Long waves on a beach, J. of Fluid Mechanics, Vol.27, pp.815-827.

Peregrine, D.H. (1972), Equations for water waves and the approximation behind them, In: Waves on beaches and resulting sediment transport (ed. R.E. Meyer), pp.95-121, Academic Press New York.

Petit, H.A.H. (1994), Note on dissipation and dispersion of numerical schemes for hyperbolic problems, Personal communications, May'94.

Petit, H.A.H. and P. van den Bosch (1992), SKYLLA: Wave motion in and on coastal structures; Numerical analysis of program modifications, Delft Hydraulics Report H1351, Draft. 
Petit, H.A.H., P. van den Bosch and M.R.A. van Gent (1994-a), SKYLLA: Wave motion in and on coastal structures; Implementation and verification of modified boundaries, Delft Hydraulics Report HI780.

Petit, H.A.H., P. Tönjes, M.R.A. van Gent and P. van den Bosch (1994-b), Numerical simulation and validation of plunging breakers using a $2 D$ Navier-Stokes model, Proc. ICCE'94, Vol.1, pp.511-524, Kobe.

Petit, H.A.H., P. van den Bosch and M.R.A. van Gent (1994-c), SKYLLA: Wave motion in and on coastal structures; Implementation of impermeable slopes and overtopping-boundary conditions, Delft Hydraulics Report H1780.

PIANC (1972), Classification of soils to be dredged, Permanent International Association of Navigation Congresses - Bulletin No.11, Vol.1.

Polubarinova-Kochina, P. Ya. (1952), Theory of groundwater movement, University Press, Princeton.

Reeder, J.W., D.L. Freyberg, J.B. Franzini and I. Remson (1980), Infiltration under rapidly varying surface water depths, Water Resources Research, Vol.16, no.1, pp.97-104.

Ribberink, J.S. (1989), The large oscillating water tunnel, Delft Hydraulics Report H840.

Richards, L.A. (1931), Capillary conduction of liquids through porous mediums, Physics, Vol.1, pp.318-333.

Richtmyer, R.D. and K.W. Morton (1967), Difference method for initial value problems, (2 ${ }^{\text {nd }}$ edition), Wiley-Intersience.

Rienecker, M.M. and J.D. Fenton (1981), A Fourier method for steady water waves, J. of Fluid Mechanics, Vol.104, pp.119-137.

Roy, I. (1983), Numerical simulation of wave runup on steep rough slopes, M.Sc.-thesis, Univ. of Delaware.

Sakai, T., T. Muzutani, H. Tanaka and Y. Tada (1986), Vortex formation in plunging breaker, Proc. ICCE'86, Vol.1, pp.711-723, Taipei.

Sandstrøm, $\AA$ (1974), Wave forces on blocks of rubble mound breakwaters, Bulletin no.83, Dept. of Civil Engrg, Royal Institute of Technology, Stockholm.

Schäffer, H.A., P.A. Madsen and R. Deigaard (1993), A Boussinesq model for waves breaking in shallow water, Coastal Engineering, Vol.20, pp.185-202, Elsevier, Amsterdam.

Sigurdsson, G. (1962), Wave forces on breakwater cap-stones, J. of Waterways and Harbour Division, Proc. of ASCE, Vol.88 (3), pp.27-60.

Smith, G. (1991), Comparison of stationary and oscillatory flow through porous media, M.Sc.thesis, Queen's University, Canada.

Stokes, G.G. (1847), On the theory of oscillatory waves, formula and tables, Inst. Hydrodynamic and Hydraulic Engineering, Techn. University of Denmark. 
Tørum, A (1992), Wave induced water particle velocities and forces on an armour unit on a berm breakwater, MAST-G6S report and Report STF60-A92104, Norwegian Hydrotechnical Laboratory-Trondheim, Norway.

Tørum, A and M.R.A. van Gent (1992), Water particle velocities on a berm breakwater, Proc. ICCE'92, Vol.2, pp.1651-1665, Venice.

Ursell, F. (1953), The long-wave paradox in the theory of gravity waves, Proc. Cambridge Phil. Soc., Vol.49, part 4, pp.685-694.

Vinje, T. and P. Brevig (1981), Numerical simulation of breaking waves, Advances in Water Resources, Vol.4, pp.77-82.

Welch, J.E., F.H. Harlow, J.P. Shannon and B.J. Daly (1966), The MAC method: a computing technique for solving viscous incompressible, transient fluid flow problems involving free surface, Report LA-3425, Los Alamos Scientific Laboratory.

Wu, N.T. (1994), Numerical simulation of wave impacts by breaking waves on vertical structures, In German: Numerische Simulation der Druckschlagbelastung durch brechende Wellen auf senkrechte Bauwerke, Ph.D.-thesis, University of Hannover.

Wurjanto, A. and N. Kobayashi (1993), Irregular wave reflection and runup on permeable slopes, J. of Waterway, Port, Coastal and Ocean Engineering, ASCE, Vol.119, No.5, pp.537-557. 


\title{
Notation
}

\author{
Roman letters:
}

a : dimensional porous friction coefficient $(s / m)$.

$a_{\delta} \quad$ : wave orbital amplitude outside boundary layer $(m)$.

$A_{s} \quad$ : vertical amplitude at the shoreline $(m)$.

$A c$ : non-dimensional number for acceleration, for a porous medium: $A c=\hat{U} /(n T g)(-)$.

$b \quad: \quad$ dimensional porous friction coefficient $\left(s^{2} / m^{2}\right)$.

c : dimensional coefficient in the extended Forchheimer equation $\left(s^{2} / m\right)$.

c : wave celerity $(\mathrm{m} / \mathrm{s})$.

$c_{A} \quad: \quad$ coefficient for added mass (-).

$c_{D} \quad: \quad$ drag coefficient $(-)$.

$c_{L} \quad: \quad$ lift coefficient $(-)$.

$c_{M} \quad: \quad$ inertia coefficient $(-)$.

$c_{P} \quad: \quad$ pressure coefficient $(-)$.

$D \quad$ : particle size $(m)$.

$D_{E Q} \quad$ : equivalent sphere diameter defined as the $D_{I Q}=\left(6 M_{50} / \pi \rho_{a}\right)^{1 / 3}(\mathrm{~m})$.

$D_{n / 5}$ : diameter (based on weight) of a sample, exceeded by $85 \%$ of the material $(\mathrm{m})$.

$D_{n s o}$ : diameter (based on weight) of a sample, exceeded by $50 \%$ of the material $(\mathrm{m})$.

$D_{n \delta 5}$ : diameter (based on weight) of a sample, exceeded by $15 \%$ of the material $(\mathrm{m})$.

$D_{90} \quad$ : sieve diameter, $90 \%$ of the material is smaller $(\mathrm{m})$.

$D_{\Delta t} \quad$ : $\quad$ growth-rate of wave component per time-step by discretisation (-).

$e_{1} \quad$ : coefficient in numerical damping term $(-)$.

$e_{2} \quad: \quad$ coefficient in numerical damping term (-).

$f \quad: \quad$ friction coefficient for the external wave motion (-).

$f_{1} \quad$ : code for resistance caused by inertia (-).

$f_{L} \quad$ : $\quad$ code for resistance caused by the laminar contribution (-).

$f_{T} \quad: \quad$ code for resistance caused by the turbulence contribution (-).

$F \quad$ : fluid fraction in a computational cell (-).

$F \quad$ : freeboard, crest height above still-water level $(m)$.

$F^{\prime} \quad$ : $\quad$ relative freeboard $\left(F^{\prime}=F /\left(H_{s}^{2} g T_{p}^{2} / 2 \pi\right)^{1 / 3}\right)(-)$.

$F_{D} \quad: \quad$ drag force $(N)$. 
$F_{l} \quad: \quad$ inertia force $(N)$.

$F_{L} \quad$ : lift force $(N)$.

$F_{p} \quad$ : force caused by a pressure gradient $(N)$.

$g \quad: \quad$ gravitational acceleration $\left(\mathrm{m} / \mathrm{s}^{2}\right)$.

$g_{x} \quad: \quad$ gravitational acceleration in $x$-direction $\left(\mathrm{m} / \mathrm{s}^{2}\right)$.

$g_{z} \quad: \quad$ gravitational acceleration in $z$-direction $\left(\mathrm{m} / \mathrm{s}^{2}\right)$.

$h \quad: \quad$ water-depth $(m)$.

$h_{c}^{\prime} \quad: \quad$ crest level relative to seabed before exposure to waves $(m)$.

$h_{c}:$ : crest level relative to seabed after exposure to waves $(m)$.

$h_{0} \quad$ : depth at the toe of a structure at still water $(m)$.

$H \quad$ : wave height $(m)$.

$H_{i} \quad$ : wave height of incident waves $(m)$.

$H_{r} \quad$ : $\quad$ wave height of reflected waves $(m)$.

$H_{s} \quad$ : $\quad$ significant wave height $(m)$.

$H_{\imath} \quad$ : $\quad$ wave height of transmitted waves $(m)$.

$H_{r m s}$ : root-mean-square wave height $(m)$.

$I \quad: \quad$ non-dimensional hydraulic gradient (-).

$\boldsymbol{k}$ : $\quad$ source term in momentum equation $\left(\mathrm{m} / \mathrm{s}^{2}\right)$.

$k \quad$ : wave number $\left(m^{-1}\right)$.

$k_{s} \quad$ : Nikuradse's sand grain roughness $(m)$.

$k_{i} \quad: \quad$ volume shape factor $(-)$.

$k_{2} \quad: \quad$ area shape factor (-).

$K \quad: \quad$ permeability coefficient $(K=1 / a)(\mathrm{m} / \mathrm{s})$.

$K_{r} \quad$ : $\quad$ wave reflection coefficient, $K_{r}=H_{r} / H_{i}(-)$.

$K_{r} \quad$ : $\quad$ wave transmission coefficient, $K_{t}=H_{t} / H_{i}(-)$.

$K C \quad$ : Keulegan-Carpenter number, for a porous medium: $K C=\hat{U} T /(n D)(-)$.

$l \quad: \quad$ length of the longest axis of a particle $(m)$.

$l / t \quad: \quad$ aspect ratio (-).

$L \quad$ : wavelength $(m)$.

$M_{50} \quad$ : average mass of a rock grading, determined by the $50 \%$ value on the mass distribution curve $(\mathrm{kg})$.

$n \quad: \quad$ porosity (-).

$n_{\Delta x}:$ number of computational points per wavelength (-).

$p \quad: \quad$ pressure $\left(\mathrm{kg} / \mathrm{ms}^{2}\right)$.

$P \quad: \quad$ pressure, $P=p / \rho\left(\mathrm{m}^{2} / \mathrm{s}^{2}\right)$.

$q \quad: \quad$ flow from permeable part to free surface region $(\mathrm{m} / \mathrm{s})$.

$q_{x} \quad: \quad x$-component of the velocity of $q(\mathrm{~m} / \mathrm{s})$. 
$Q \quad$ : $\quad$ overtopping discharge $(l / s / m)$

$r_{u} \quad$ : parameter for describing an average value of $u$ at open boundary (-).

$r_{\eta} \quad$ : parameter for describing an average value of $\eta$ at open boundary (-).

$R \quad: \quad$ run-up level above still-water level, in vertical direction $(m)$.

$R_{c} \quad$ : level of the crest above the still-water level $(m)$.

Re : Reynolds-number, for a porous medium: $\hat{U} D /(n v)(-)$.

$s \quad$ : $\quad$ slope, $s=\tan \theta_{s}$.

$s_{o p} \quad: \quad$ wave steepness (-).

$S S L \quad$ : $\quad$ storm surge level $(m)$.

$S W L \quad: \quad$ still-water level $(m)$.

$t \quad: \quad$ time $(s)$.

$t \quad: \quad$ length of the smallest axis perpendicular to the longest axis of a particle $(\mathrm{m})$;

$T \quad$ : oscillation/wave period $(s)$.

$T_{m} \quad$ : mean wave period $(s)$.

$T_{p} \quad$ : peak period $(s)$.

$u$ : velocity vector.

$\boldsymbol{u}^{\prime} \quad$ : turbulence components of velocities (deviations from ensemble-averaged values).

$u_{i} \quad$ : velocity of incident wave $(\mathrm{m} / \mathrm{s})$.

$u_{r}: \quad$ velocity of reflected wave $(\mathrm{m} / \mathrm{s})$.

$u$ : horizontal velocity; for a porous medium the filter velocity $(\mathrm{m} / \mathrm{s})$.

$u_{p} \quad$ : pore velocity $(\mathrm{m} / \mathrm{s})$.

$U \quad$ : Ursell-number, $U=H L^{2} / S W L^{3}(-)$.

$\hat{U} \quad$ : amplitude of the velocity $(\mathrm{m} / \mathrm{s})$

$w \quad$ : vertical velocity; for a porous medium the filter velocity $(\mathrm{m} / \mathrm{s})$.

$W_{s} \quad$ : submerged weight of a particle $(N)$.

$x \quad$ : coordinate, mostly in the horizontal direction $(m)$.

$z \quad: \quad$ coordinate, mostly in the vertical direction $(m)$.

$z_{0} \quad: \quad$ slope elevation with respect to the horizontal axis $(m)$.

$z_{c} \quad$ : elevation of impermeable layer with respect to the horizontal axis $(m)$. 
Greek letters:

$\alpha \quad$ : coefficient in the expression for $a(-)$.

$\alpha-D_{E Q}: \quad \alpha$ calculated with $D_{E Q}$ as the representative stone diameter in the expression for $a(-)$.

$\alpha-D_{n l 5} ; \quad \alpha$ calculated with $D_{n l 5}$ as the representative stone diameter in the expression for $a(-)$.

$\alpha-D_{n 50}: \quad \alpha$ calculated with $D_{n 50}$ as the representative stone diameter in the expression for $a(-)$.

$\alpha_{R} \quad: \quad$ Riemann-invariant $(\mathrm{m} / \mathrm{s})$.

$\beta \quad$ : coefficient in the expression for $b(-)$.

$\beta_{c}: \quad$ coefficient in the expression for $b$, derived from stationary flow tests (-).

$\beta_{0}$ : coefficient in the expression for $b$ for the implementation of the orientation of stones, derived from stationary flow tests (-).

$\beta^{\prime}$ : coefficient taking the extra resistance, caused by non-stationary motion, into account (-).

$\beta-D_{E Q}: \quad \beta$ calculated with $D_{E Q}$ as the representative stone diameter in the expression for $b(-)$.

$\beta-D_{n j s}: \quad \beta$ calculated with $D_{n i s}$ as the representative stone diameter in the expression for $b(-)$.

$\beta-D_{n s 0}: \quad \beta$ calculated with $D_{n s 0}$ as the representative stone diameter in the expression for $b(-)$.

$\beta_{R} \quad: \quad$ Riemann-invariant $(\mathrm{m} / \mathrm{s})$.

$\beta_{u p}:$ upwind fraction in partial upwind discretisation (-).

$\gamma \quad$ : coefficient in the expression for $c(-)$.

$\Delta \quad: \quad \rho_{s} /(\rho-1)(-)$.

$\Delta \quad: \quad$ minimum water depth at the shoreline $(m)$.

$\Delta t \quad: \quad$ time-step $(s)$.

$\Delta x \quad: \quad$ grid size in $x$-direction $(m)$.

$\Delta z \quad: \quad$ grid size in $z$-direction $(m)$.

$\epsilon_{1}:$ coefficient in numerical damping term (-).

$\epsilon_{2} \quad: \quad$ coefficient in numerical damping term (-).

$\eta \quad$ : $\quad$ free surface elevation, $\eta=0$ at still-water level $(m)$.

$\eta_{i} \quad$ : $\quad$ surface elevation by incident wave $(m)$.

$\eta_{r} \quad$ : $\quad$ surface elevation by reflected wave $(m)$.

$\theta_{c} \quad: \quad$ angle of the slope of the core.

$\theta_{s}$ : angle of the slope of the structure. 


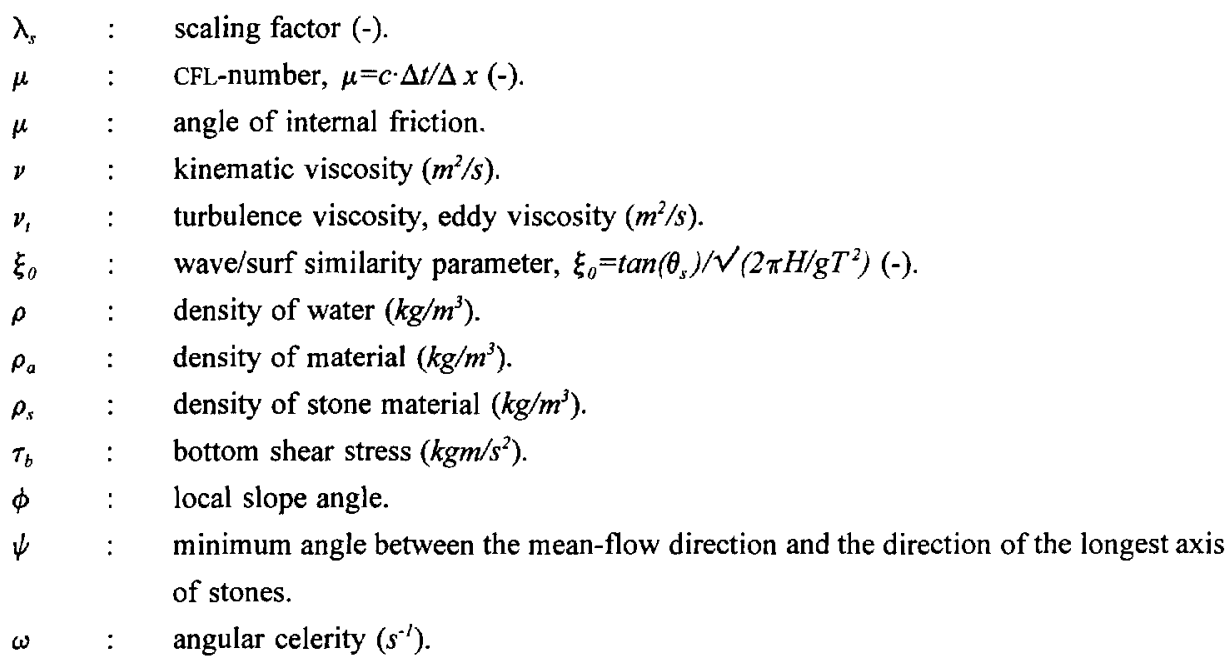




\section{Curriculum vitae}

7-8-1968

1980-1986

1986-1991

$1989-1990$

1991

1991

1990-1995

1991-1995

1991-1995

1992-1995
Marcel Roland Alexander van Gent, geboren te Ermelo.

Atheneum, Christelijk College Groevebeek, Ermelo.

Technische Universiteit Delft, Ingenieursopleiding Civiele Techniek.

Bestuur studievereniging 'Waterbouwdispuut'.

Diploma Civiele Techniek, Vakgroep Waterbouwkunde

Afgestudeerd bij de Sectie Vloeistof Mechanica (cum laude).

Aanvullend examen in tien vakken.

Deelname in Europese onderzoeksprojecten (MAST-Coastal Structures).

Onderwijswerkzaamheden, o.a. tentamineren van het vak Kustwaterbouwkunde en begeleiding van afstudeerders.

Toegevoegd onderzoeker / promovendus bij de Vakgroep Waterbouwkunde.

Werkzaamheden bij het Waterloopkundig Laboratorium 'de Voorst'. 